\title{
DEVELOPMENT OF VIETNAMESE PRE-SERVICE EFL TEACHERS' ASSESSMENT LITERACY
}

\author{
BY
}

NGUYẼ̃N TH!̣ HUỲNH LộC

\begin{abstract}
A thesis submitted to the Victoria University of
Wellington in fulfilment of the requirements for the degree of Doctor of Philosophy in Applied Linguistics
\end{abstract}

Victoria University of Wellington (2016) 

The importance of teachers' assessment literacy has been increasingly emphasised in the literature. However, very little research has paid attention to pre-service EFL teachers' assessment literacy and how they develop this area during teacher training programmes. Moreover, there is a paucity of research on Vietnamese pre-service EFL teachers' assessment literacy. This study was conducted in three phases to address these gaps: (1) Phase 1 provided a description of current assessment training at four Vietnamese teacher training universities, (2) Phase 2 attempted to map out preservice EFL teachers' confidence levels in assessment literacy, and (3) Phase 3 mainly focused on the development of four pre-service EFL teachers' assessment literacy during their nine-week practicum at Bach Dang University (pseudonym).

Phase 1 relied on individual semi-structured interviews with four Vietnamese teacher-trainers to describe the current status of assessment training for pre-service EFL teachers at four key teacher training universities in terms of: (1) teacher-trainers' background, (2) course content, (3) method of instruction, (4) support for assessment training, and (5) constraints of assessment training. The teacher-trainers noted their lack of professional development in testing and assessment. The method of instruction varied for different teacher training universities. The results showed a greater emphasis on training in summative rather than formative assessment. Also, teacher-trainers identified two main constraints in the current training programmes including: (i) the lack of systematic innovation in language testing and assessment and (ii) the lack of labour, facilities and time for language testing and assessment training.
\end{abstract}

In Phase 2, a questionnaire of pre-service EFL teachers' confidence levels in assessment literacy was developed and validated. It was then administered to 365 preservice EFL teachers. The results indicated pre-service EFL teachers' high confidence levels in assessment literacy. Moreover, gender and career choice did not influence their confidence levels in assessment literacy while teaching experience and training in language testing and assessment did. However, those who had had more training scored lower confidence levels in assessment literacy. 
Phase 3 was conducted in two parts to focus on assessment literacy development of four pre-service EFL teachers. Part 1 had two stages. Stage 1 administered the same questionnaire as in Phase 2 to thirty-one pre-service EFL teachers to investigate their confidence levels in assessment literacy over three time periods: before their language testing and assessment course, before their practicum, and after their practicum. The findings showed a significant statistical increase in their assessment literacy confidence levels. In Stage 2, eighteen pre-service EFL teachers in Stage 1 participated in two semi-structured focus group interviews to check if their confidence levels reflected their assessment literacy. The results indicated a need for data triangulation to claim their assessment literacy based on confidence levels.

Part 2 employed different research instruments including interviews, observation, stimulated recalls, and questionnaires to examine assessment literacy development of four pre-service EFL teachers over a nine-week practicum. The data indicated three main themes in pre-service EFL teachers' development in assessment literacy: (1) pre-service EFL teachers' development in: (i) giving feedback, (ii) designing test items, (iii) administering tests, (iv) observing students' learning, (v) giving instructions, and (vi) improving their content knowledge, (2) pre-service EFL teachers' individual differences in their assessment literacy development, and (3) incident-based learning of assessment literacy.

Overall, this study offered insights into the dynamic, situated and developmental nature of pre-service EFL teachers' assessment literacy, which has useful implications for theory, research methodology and assessment training for preservice EFL teachers. Moreover, the findings are very practical for different levels of administration, and for my role as a teacher-trainer in Vietnam. 


\section{ACKNOWLEDGEMENT}

"As we express our gratitude, we must never forget that the highest appreciation is not to utter words, but to live by them"

\section{John F. Kennedy}

This PhD journey is a great chapter of my life and I was blessed to receive tremendous support from many people whom I would like to take this opportunity to thank from the bottom of my heart.

I owe a deep depth of gratitude to my primary supervisor Associate Professor Peter $\mathrm{Gu}$ for his expertise in scholarly supervision, valuable guidance, and continuous support. His constant encouragement and critical and timely comments have helped me improve my research skills and academic writing skills. Moreover, his kindness, passion for knowledge and academic expertise have had a significant impact on my personal and professional development.

My heartfelt appreciation also goes to my secondary supervisor, Dr. Jean Parkinson for her kindness, academic expertise, and continuous support during my $\mathrm{PhD}$. I also wish to thank Dr. Jean Parkinson for being a caring, and supportive coordinator of $\mathrm{PhD}$ programmes at the School of Linguistics and Applied Language Studies.

I am especially indebted to the New Zealand Ministry of Foreign Affairs and Trade for granting me a doctoral scholarship to pursue this study. Without this scholarship, I could not have made my dream of pursuing higher education come true. My sincere thanks also go to the wonderful scholarship coordinators at Victoria University of Wellington who worked hard to support me in many ways.

I owe a special thank you to the participants in this study who cannot be named due to ethical reasons. I highly appreciate all their hard work, valuable information, enthusiasm and generous time to participate in my research. I also thank my friends and colleagues who helped me with data collection.

I am grateful to the School of Linguistics and Applied Language Studies, Student Learning Support Service and the thesis group for creating a supportive and friendly 
academic environment. I also thank the Faculty of Humanities and Social Sciences for providing me with grants for field trips and conference presentations. I would like to thank the Association of Language Testing and Assessment of Australia and New Zealand for the Travel Award which enabled me to present my work at the ALTANZ conference, 2014.

My gratitude also goes to Dr. Dalice Sim, and Dr. Lisa Woods for the expert responses to all my statistical questions, Associate Professor Chris Shepphard for his statistical discussions and expertise, Dr. Stuart Webb for his Research Method classes, Tony Quinn for assistance with library resources, Kirsten Reid for her advice with my conference presentations, Helen Bernard for her advice with my writing, Laila Faisal for useful tips for thesis formatting, and Dr. Patrick Coelho for proofreading my thesis.

Last but not least, I would like to thank and dedicate this thesis to my family for their unconditional love and continuous support during my $\mathrm{PhD}$ journey and my life in general. 


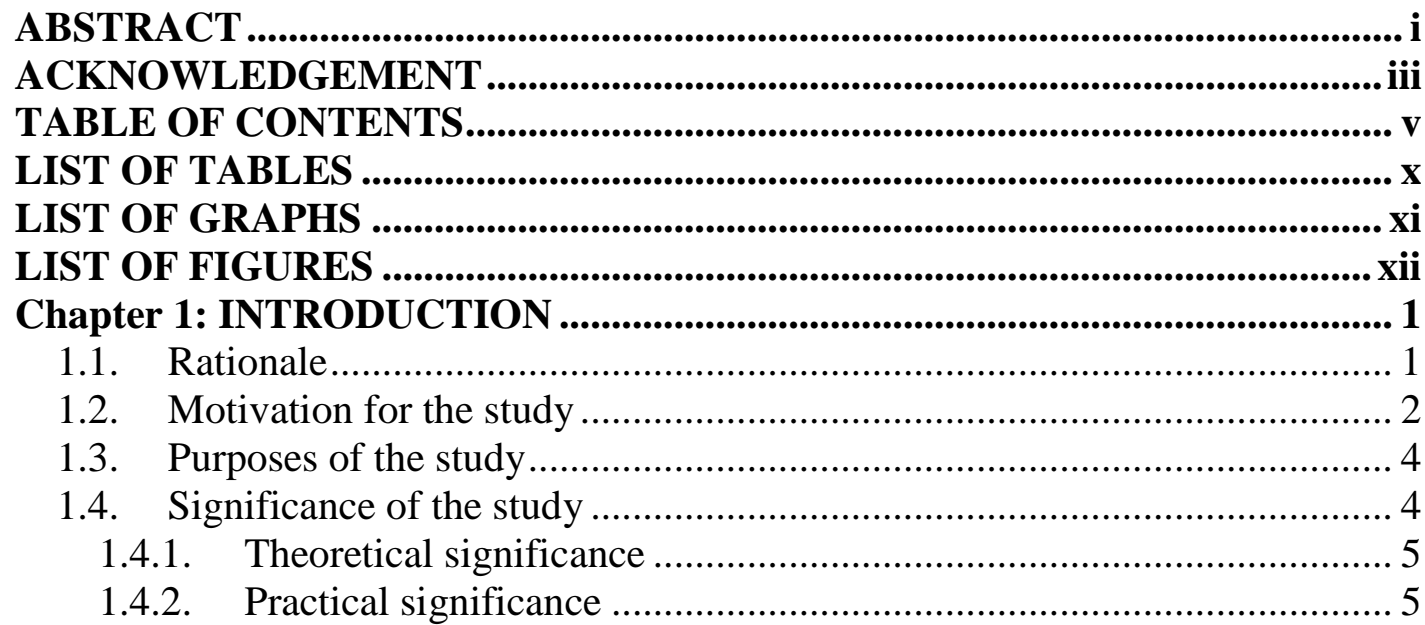

1.5. Third generation Activity theory as theoretical framework ……………..... 5

1.6. Definitions of terms used in this study ................................................... 6

1.7. Organisation of the thesis .................................................................. 7

Chapter 2: BACKGROUND OF THE STUDY ....................................................... 10

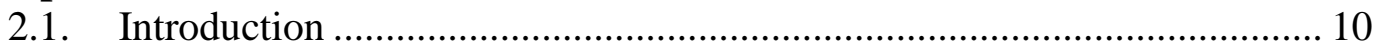

2.2. Exam-oriented education system in Vietnam............................................ 10

2.3. English testing and assessment in Vietnam.............................................. 13

2.4. Pre-service teacher education in Vietnam ................................................ 14

2.4.1. Pre-service EFL teacher education..................................................... 14

2.4.2. TESOL practicum in Vietnam ……………………....................... 15

2.5. Problems encountered ...................................................................... 15

Chapter 3: LITERATURE REVIEW ..................................................................... 17

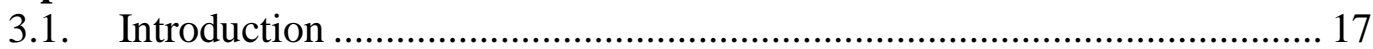

3.2. Fundamental understandings of assessment ............................................ 17

3.2.1. Assessment .............................................................................. 18

3.2.2. Different kinds of assessment ........................................................ 20

3.2.3. Assessment quality ..................................................................... 26

3.3. Assessment literacy …………………………………………….... 30

3.3.1. An overview of assessment literacy ............................................... 30

3.3.2. Assessment literacy competences for assessment literate teachers.... 32

3.3.3. Pedagogical content knowledge (PCK) and teachers' assessment practices........................................................................................... 41

3.3.4. Ethical issues in testing and assessment........................................... 44

3.3.5. Previous studies on assessment literacy .............................................. 45

3.3.6. Previous studies on language testing and assessment courses ............ 48

3.4. Teacher cognition ................................................................................ 54

3.4.1. Defining teacher cognition ................................................................ 54

3.4.2. Teachers' beliefs and teachers' knowledge..........................................56

3.4.3. Teacher cognition and teachers' classroom practices ..........................58

3.4.4. Previous studies on pre-service teacher cognition ..............................58 58

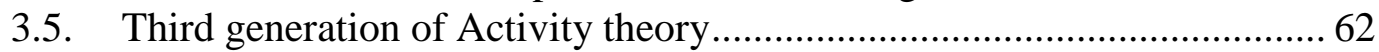

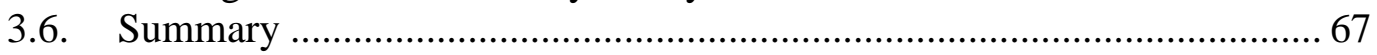




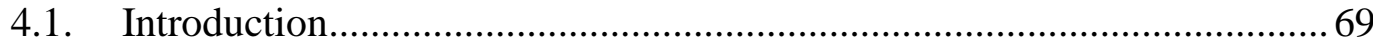

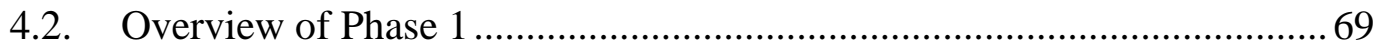

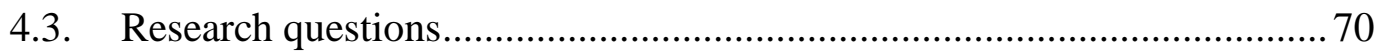

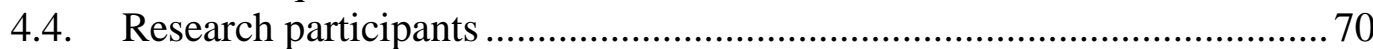

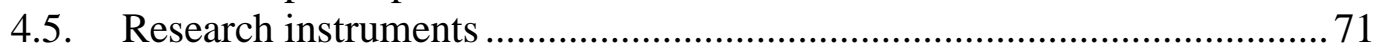

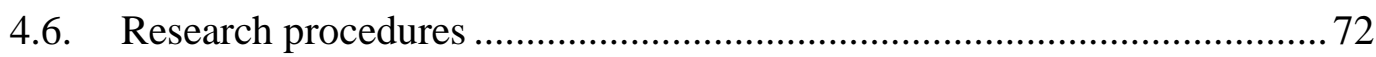

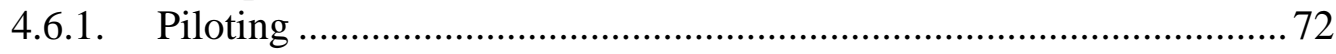

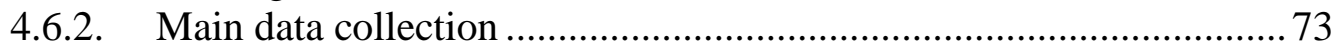

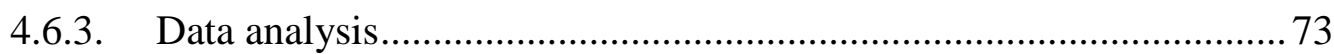

4.7. Problems with data analysis and interpretation ....................................... 76

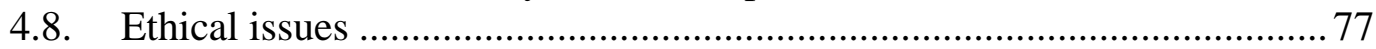

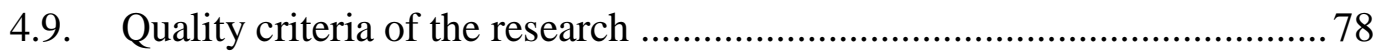

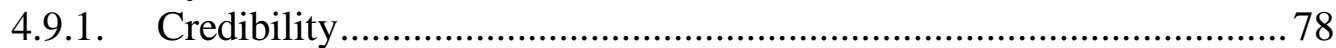

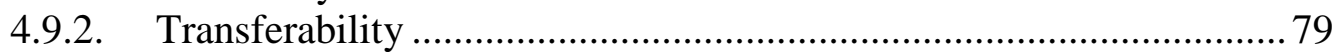

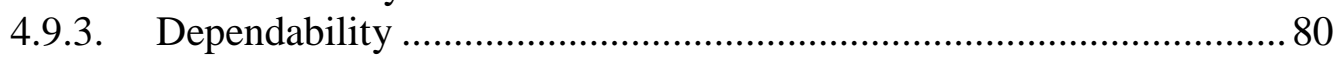

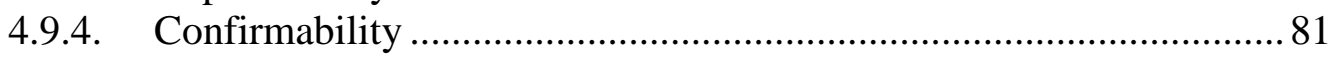

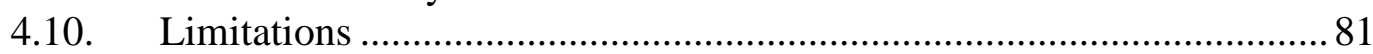

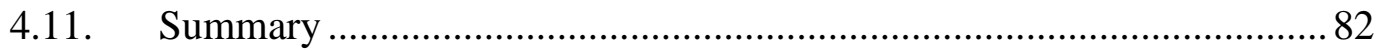

Chapter 5: PHASE 1 - LANGUAGE TESTING AND ASSESSMENT

COURSES Results and Discussion ...............................................................83

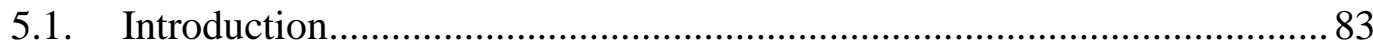

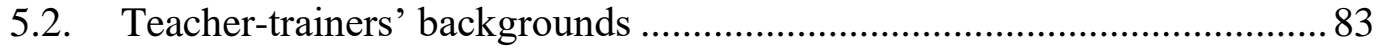

5.2.1. The teacher-trainers' dissatisfaction with their knowledge and skills in language testing and assessment ................................................................. 83

5.2.2. Teacher-trainers' need for more formal language testing and

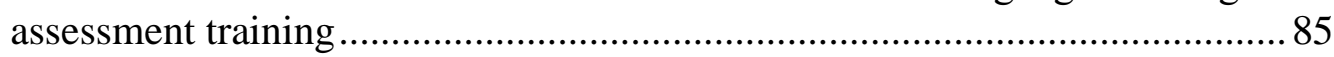

5.3. The current status of language testing and assessment courses.................86 86

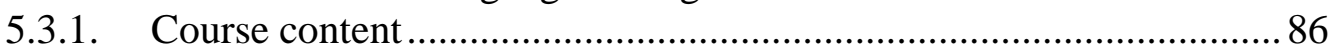

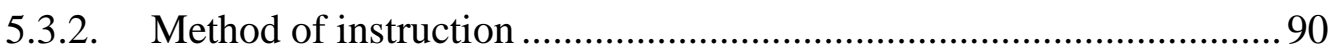

5.3.3. Support for testing and assessment training .................................. 92

5.3.4. Testing and assessment training in the practicum .......................... 93

5.4. Pre-service EFL teachers' perception and attitudes toward language testing and assessment courses or module of language testing and assessment ..............94

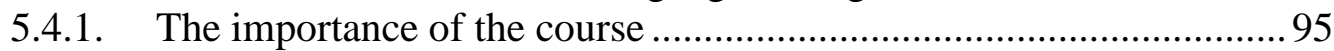

5.4.2. Pre-service EFL teachers' interest in the course ............................... 95

5.5. The constraints of language testing and assessment training ................... 96

5.5.1. The lack of systematic innovation in language testing and assessment

5.5.2. The lack of labour, facilities and time for language testing and

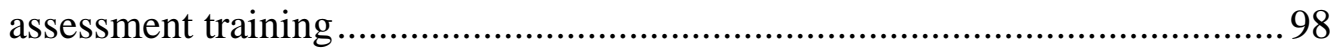

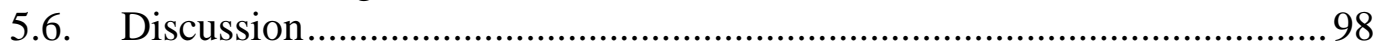

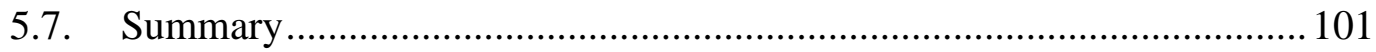

Chapter 6: PHASE 2 - PRE-SERVICE EFL TEACHERS' ASSESSMENT

LITERACY CONFIDENCE LEVELS Research Methodology ....................... 104

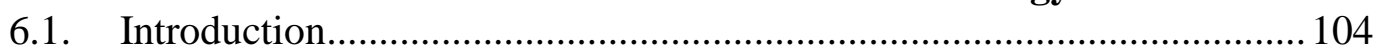

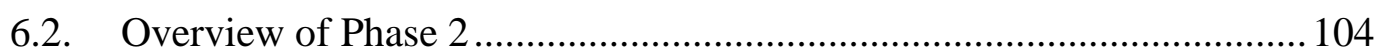




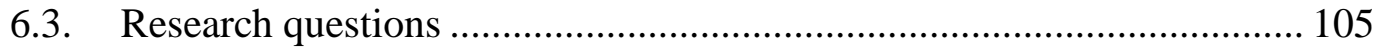

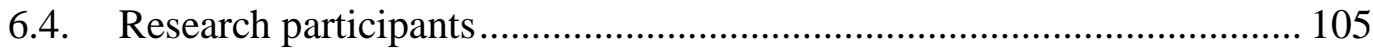

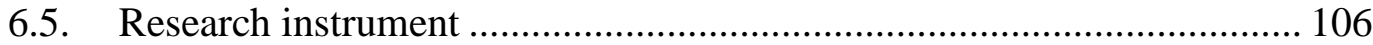

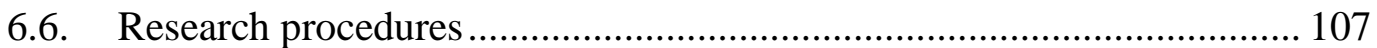

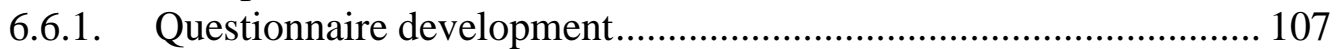

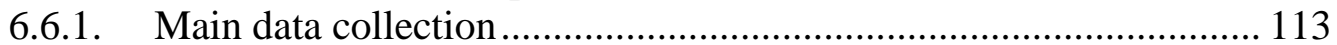

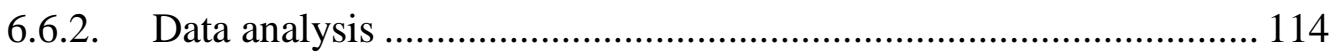

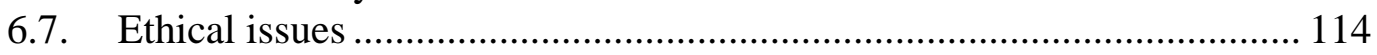

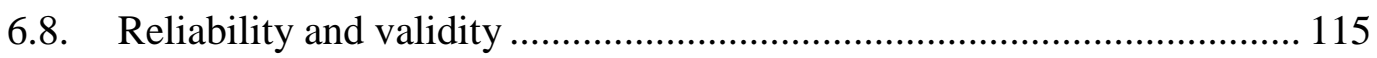

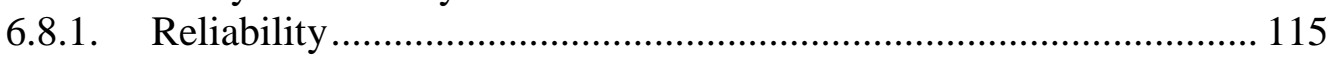

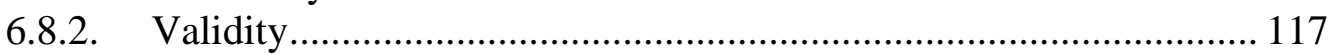

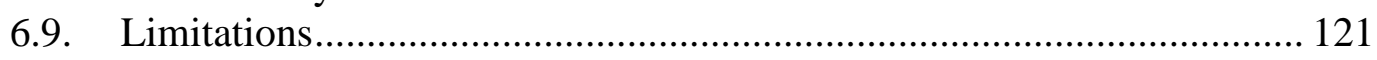

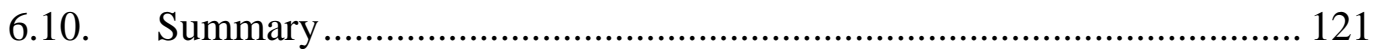

Chapter 7: PHASE 2 - PRE-SERVICE EFL TEACHERS' ASSESSMENT

LITERACY CONFIDENCE LEVELS Results and Discussion .................... 123

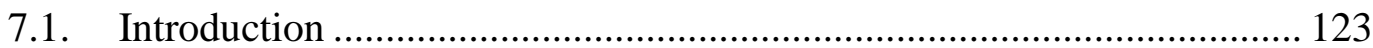

7.2. Pre-service teachers' assessment literacy confidence levels .................. 123

7.3. Gender and pre-service teachers' assessment literacy confidence levels 126

7.4. Career choice and pre-service EFL teachers' assessment literacy confidence

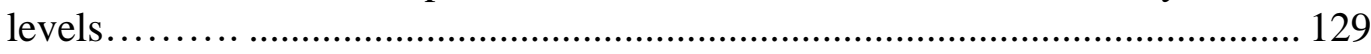

7.5. Teaching experience and pre-service EFL teachers' assessment literacy

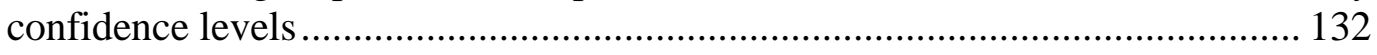

7.6. Language testing and assessment training and pre-service teachers' assessment literacy confidence levels ........................................................... 135

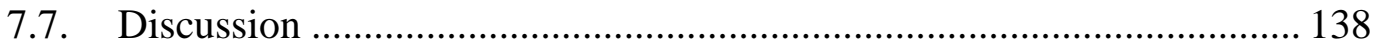

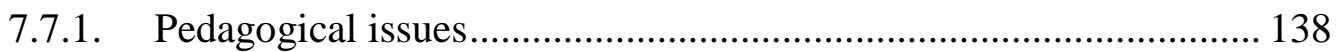

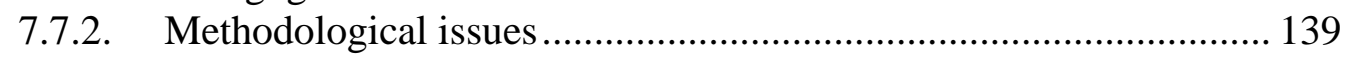

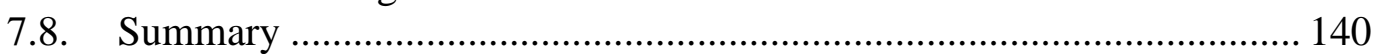

Chapter 8: PHASE 3 - DEVELOPMENT OF PRE-SERVICE EFL TEACHERS' ASSESSMENT LITERACY DURING PRACTICUM Research

Methodology ................................................................................................ 142

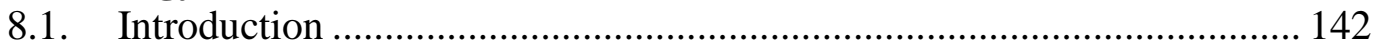

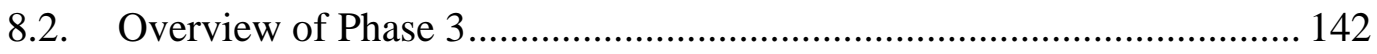

8.3. PART 1: Development of pre-service EFL teachers' confidence levels in assessment literacy during practicum............................................................ 143

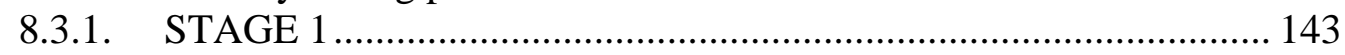

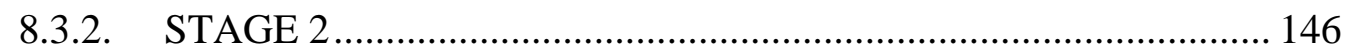

8.4. PART 2: Development of pre-service EFL teachers' assessment literacy

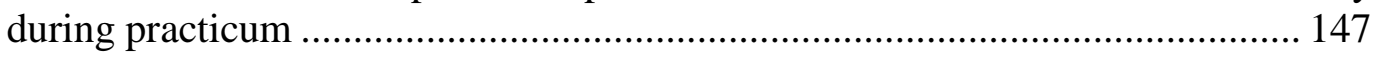

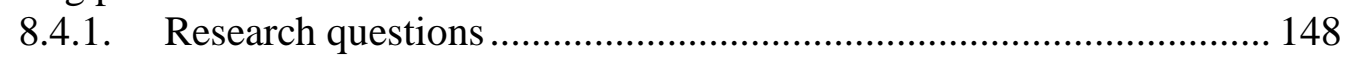

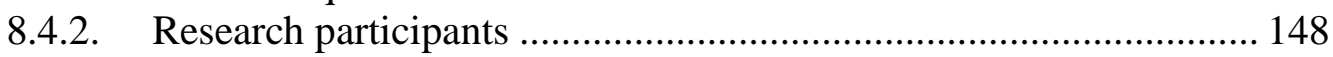

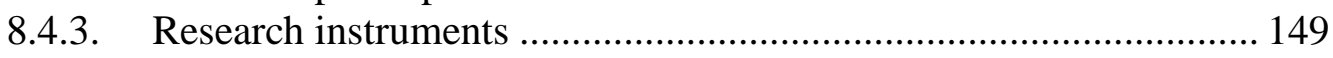

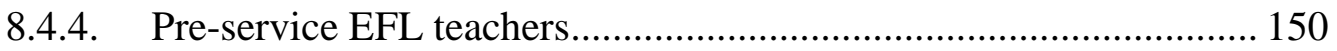

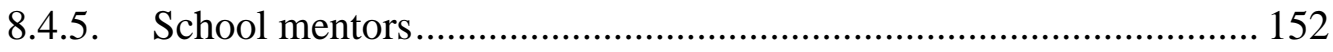

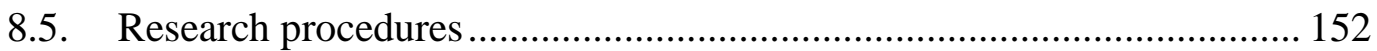

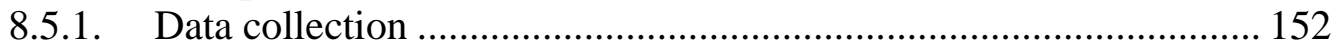

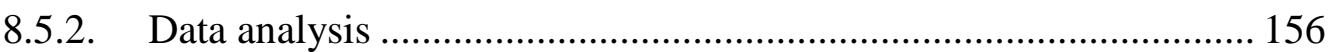

8.6. Problems with data analysis and interpretation ................................... 158 


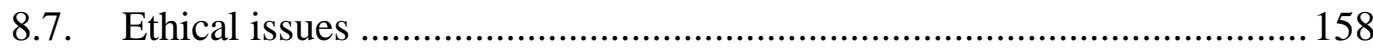

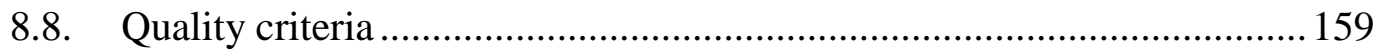

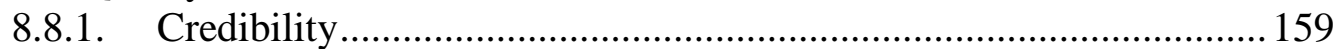

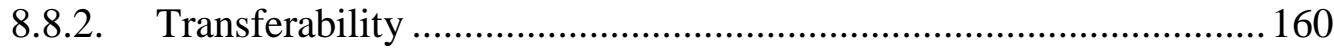

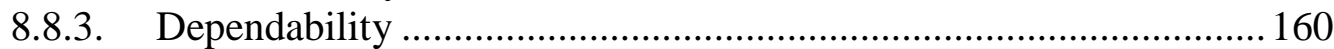

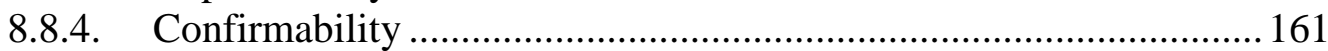

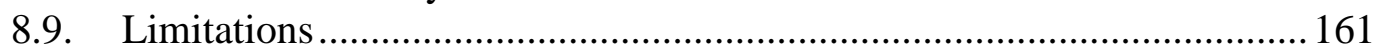

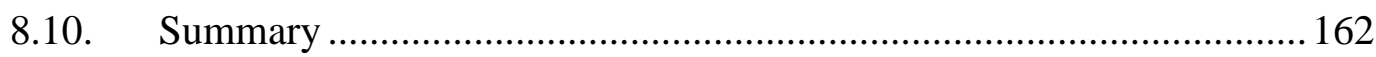

Chapter 9: PHASE 3 - DEVELOPMENT OF PRE-SERVICE EFL TEACHERS' ASSESSMENT LITERACY DURING PRACTICUM Results and Discussion.............................................................................................................163

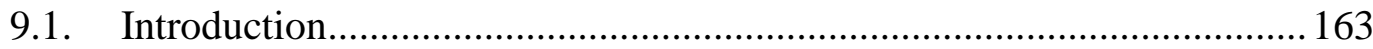

9.2. PART 1 - Development of pre-service EFL teachers' confidence levels in

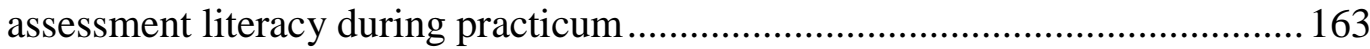

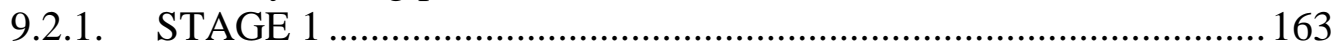

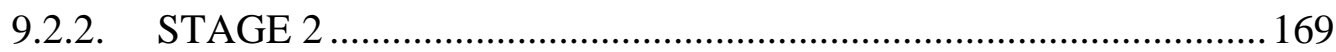

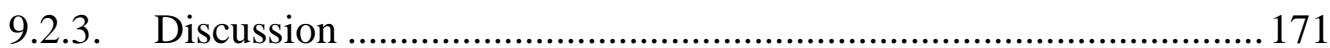

9.3. PART 2 - Development of pre-service EFL teachers' assessment literacy

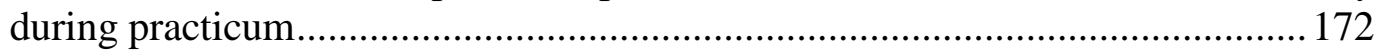

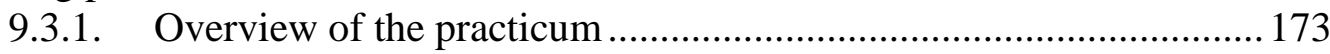

9.3.2. Development of four EFL pre-service teachers' assessment literacy

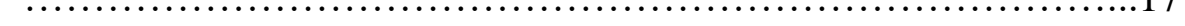

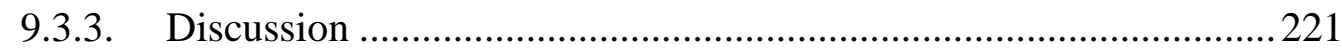

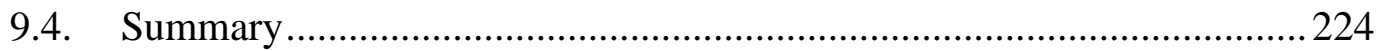

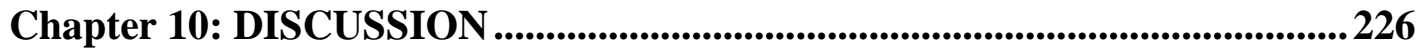

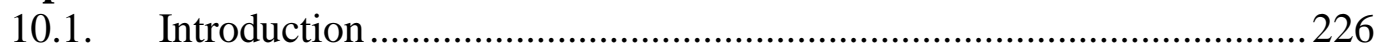

10.2. Language testing and assessment courses.......................................226

10.3. Pre-service teachers' confidence levels in assessment literacy ...........234

10.4. Development of pre-service EFL teachers in assessment literacy during

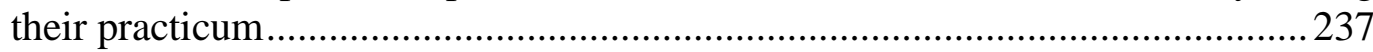

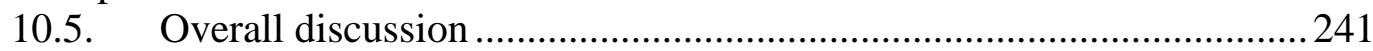

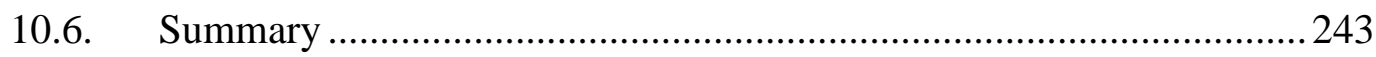

Chapter 11: SUMMARY, IMPLICATIONS AND CONCLUSIONS .............245

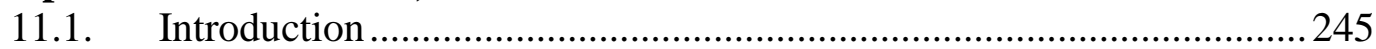

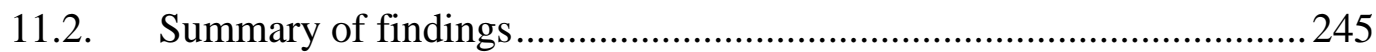

11.2.1. Phase 1 - Language testing and assessment courses...................... 245

11.2.2. Phase 2 - Pre-service EFL teachers' assessment literacy confidence

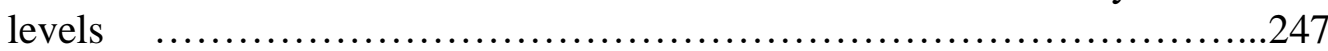

11.2.3. Phase 3 - Development of pre-service EFL teachers in assessment

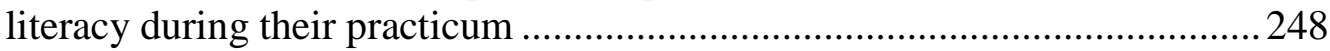

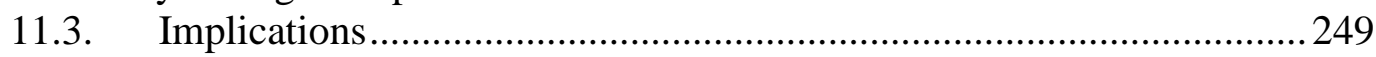

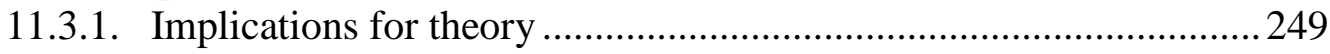

11.3.2. Implications for assessment training in teacher education ..............250

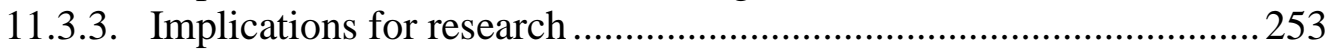

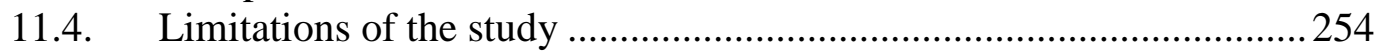

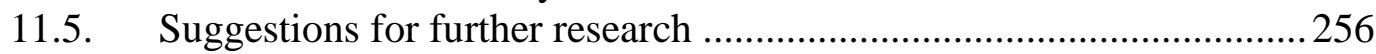

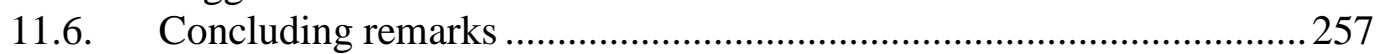

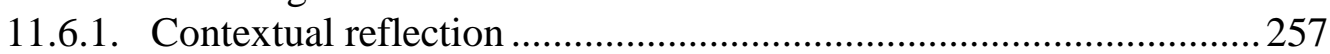

viii 
11.6.2. Personal reflection.

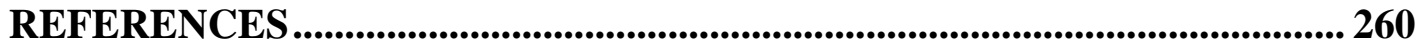

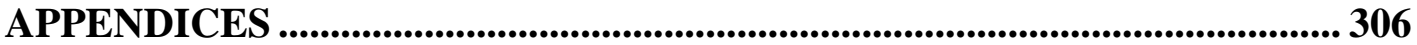




\section{LIST OF TABLES}

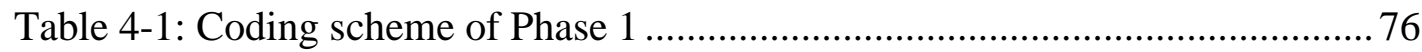

Table 5-1: Current status of language testing and assessment training ................ 103

Table 6-1: Summary of the pilot studies in Phase 2 ............................................ 108

Table 6-2: Overview of the draft questionnaire .................................................. 111

Table 6-3: Overview of the revised questionnaire ............................................. 113

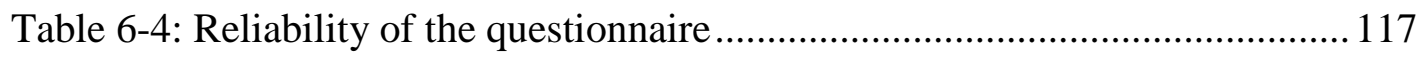

Table 6-5: Correlations among the sub-sections of PCK …................................... 120

Table 6-6: Correlations among the items of UAQ ............................................. 120

Table 6-7: Correlations among the sub-sections of AFL ...................................... 120

Table 6-8: Correlations among the items of EI ............................................... 120

Table 6-9: Correlations among the sub-sections of AOL...................................... 120

Table 6-10: Correlations among the sub-constructs ............................................ 121

Table 7-1: Overall pre-service EFL teachers' assessment literacy ........................ 125

Table 7-2: Gender and pre-service EFL teachers' assessment literacy confidence

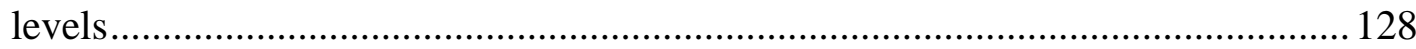

Table 7-3: Career choice and pre-service EFL teachers' assessment literacy ........ 131

Table 7-4: Teaching experience and pre-service EFL teachers' assessment literacy confidence levels ....

Table 7-5: Language testing and assessment training and pre-service EFL teachers'

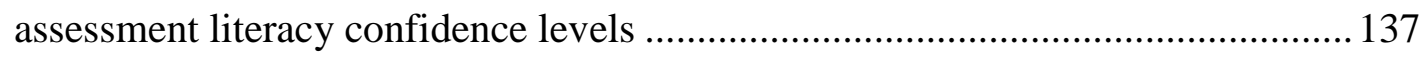

Table 8-1: Summary of research instruments in Part 2 of Phase 3 ........................ 150

Table 9-1: Pre-service EFL teachers' assessment literacy confidence levels between

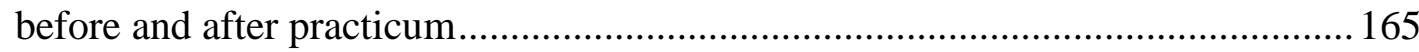

Table 9-2: Pre-service EFL teachers' assessment literacy confidence levels over prelanguage testing and assessment course, pre-practicum and post-practicum........ 168 Table 9-3: Four pre-service EFL teachers' assessment literacy before and after the

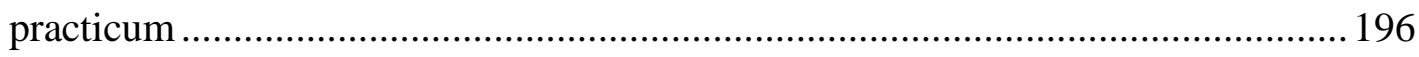

Table 9-4: Overview of pre-service teachers' assessment literacy development during

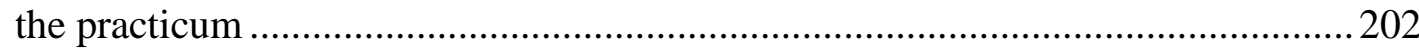

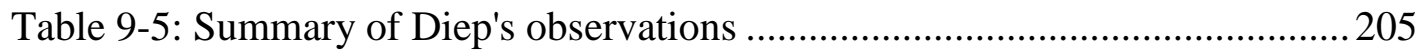




\section{LIST OF GRAPHS}

Graph 7-1: Overall pre-service EFL teachers' confidence levels in assessment

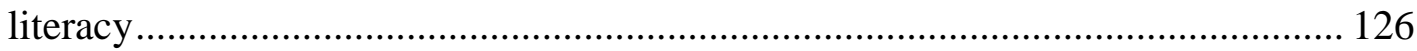

Graph 7-2: Gender and pre-service EFL teachers' assessment literacy confidence levels 127

Graph 7-3: Career choice and pre-service EFL teachers' assessment literacy confidence levels

Graph 7-4: Teaching experience and pre-service EFL teachers' assessment literacy confidence levels 133

Graph 7-5: Language testing and assessment training and pre-service EFL teachers' assessment literacy confidence levels 136

Graph 9-1: Pre-service EFL teachers' confidence levels in assessment literacy before and after practicum.

Graph 9-2: Pre-service EFL teachers' assessment literacy confidence levels over prelanguage testing and assessment course, pre-practicum and post-practicum 167

Graph 9-3: Four pre-service EFL teachers' assessment literacy confidence levels before the practicum. 194

Graph 9-4: Four pre-service EFL teachers' assessment literacy confidence levels after the practicum 195

Graph 9-5: Nhien's assessment literacy confidence levels before and after practicum 198

Graph 9-6: Diep's assessment literacy confidence levels before and after the practicum.... 199

Graph 9-7: Thuyen's assessment literacy confidence levels before and after the practicum. 200

Graph 9-8: Van's assessment literacy confidence levels before and after the practicum. 201 


\section{LIST OF FIGURES}

Figure 3-1: H. D. Brown and Abeywickrama's (2010) framework ......................... 19

Figure 3-2: Fulcher's (2012) assessment literacy framework ............................... 39

Figure 3-3: Assessment literacy framework..................................................... 41

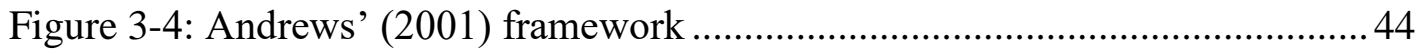

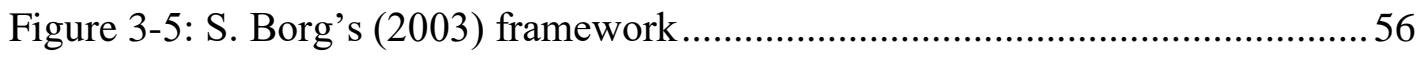

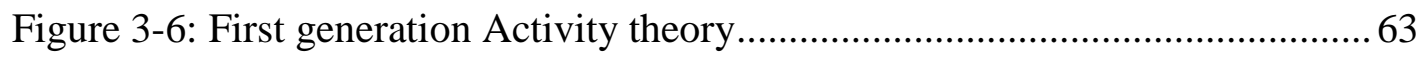

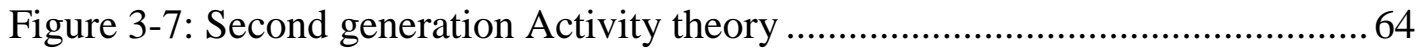

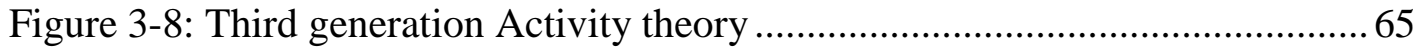

Figure 3-9: Joint activity system of pre-service EFL teachers and teacher trainers. 66

Figure 3-10: Joint activity system of pre-service EFL teachers and school mentors

66

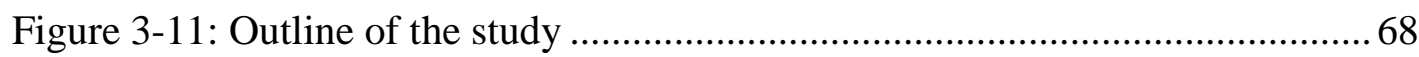

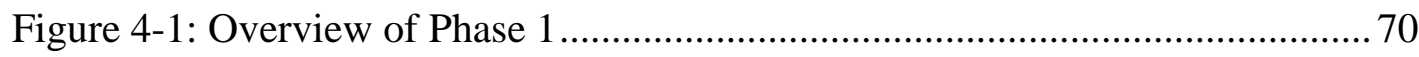

Figure 4-2: Phase 1's research procedures......................................................... 72

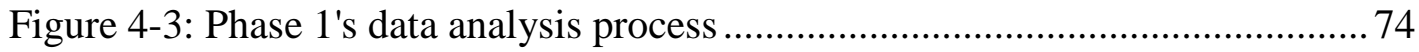

Figure 6-1: Questionnaire development ........................................................... 107

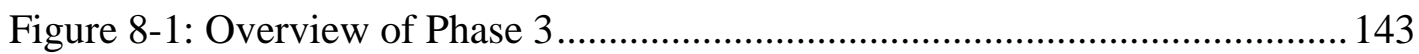

Figure 8-2: Overview of Part 2's data collection................................................ 153

Figure 8-3: Data collection from school mentors ................................................ 154

Figure 8-4: Data collection from pre-service EFL teachers .................................. 156 


\section{Chapter 1: \\ INTRODUCTION}

\subsection{Rationale}

Teachers' assessment literacy, or their knowledge and skills in testing and assessment, has gained in importance over the past two decades. Illiteracy in assessment is also considered as "professional suicide" for teachers (Popham, 2004, p. 82); even Popham (2011), a leading assessment expert and teacher trainer, made a "confession about a serious curricular sin" (p. 265), of overlooking assessment literacy during his early years as a teacher educator. In addition, previous research has shown notable benefits of teachers' assessment literacy for students' learning and teaching improvements (Wilson, Floden, \& Ferrini-Mundy, 2001). Teachers' assessment literacy also enables teachers to avoid misdirected and inappropriate educational decisions (DeLuca \& Klinger, 2010) which can be harmful to their students' development (Schafer, 1993; Stiggins \& Chappuis, 2005).

However, it is obvious that teachers are not "born testers" (Jin, 2010). As they can spend as much as half of their professional time on testing and assessment-related activities (Stiggins, 1999a), they definitely need training in testing and assessment (Noll, 1955; Scales, 1993). Sadly enough, despite the widespread demand for assessment education, research so far has revealed a dearth of this training in teacher professional development (Arce-Ferrer, Cab, \& Cisneros-Cohernour, 2001; Davison, 2012; Huai, Braden, White, \& Elliott, 2006; Impara, Plake, \& Fager, 1993; Kubiszyn \& Borich, 1996; C. S. White, Sturtevant, \& Dunlap, 2002). Teachers have been reported to be under-prepared to assess their students (Davison, 2012; Impara et al., 1993; Popham, 2011; Volante \& Fazio, 2007). Also, they often claim that their inadequate preparation in assessment is largely due to the lack of training in teacher preparation programs (Plake, 1993).

Despite the importance of teacher's assessment literacy, little has been done to inform knowledge about EFL (English as a Foreign Language) teachers' assessment literacy, let alone pre-service EFL teachers' assessment literacy. Also, in terms of teacher cognition, in spite of a large body of research investigating various aspects of this 
area (S. Borg, 2003), how pre-service EFL teachers learn to test and assess during their practicums still remains underexplored. As initial teaching experiences are critical to teachers' professional development (Johnson, 1996), research to inform how pre-service EFL teachers learn to assess their students in a practicum is unquestionably important. Due to the importance of assessment literacy for language teachers (Coombe, Davidson, O’Sullivan, \& Stoynoff, 2012), there has been a pressing need for more research into pre-service EFL teachers' assessment literacy. Moreover, in an exam-oriented culture where exam success has been central to English language teaching and learning (Carless, 2011; Carless \& Lam, 2014), it is essential that pre-service EFL teachers be provided with assessment literacy training.

In general, there are two main rationales behind undertaking this study. First, this study attempts to fill a gap in the literature of assessment literacy and teacher cognition for pre-service EFL teachers. Second, it is motivated by the context of English language teaching and learning and my role as a teacher-trainer in Vietnam. The details of my motivation for this present study are presented in Section 1.2 below.

\subsection{Motivation for the study}

"Students who have studied English for seven years beginning in grade six are often not able to use English beyond simple greetings and questions such as 'hello,' 'goodbye,' and 'what's your name?" ("English teaching in Vietnam: Teacher 'reeducation," 2007). This quotation comes from a highlighted comment of a senior consultant working for the Vietnamese Ministry of Education and Training (MOET) on Tuoitre, the most popular online newspaper in Vietnam. It reflects a persistent problem of English language teaching and learning in Vietnam. Although English is a compulsory subject accounting for at least 700 periods in the curriculum from secondary to high school, Vietnamese students have been reported to lack English proficiency ("Sinh viên Việt Nam sử dụng tiếng Anh rất kém," 2008). Moreover, despite huge efforts towards curriculum reform, textbook design and teaching method innovation, English language teaching and learning in Vietnam have been severely criticised for their poor quality ("Sinh viên Việt Nam sử dụng tiếng Anh rất kém," 2008). The significant factors influencing this situation have been reported to include unqualified teachers and an outdated testing model which only focuses on students' 
grammar and vocabulary ("Vì sao dạy và học tiếng Anh mãi 'giậm chân tại chỗ'?," 2014)

In response to an increasing demand for Vietnamese students to have greater English proficiency, the government has shown a strong desire to improve English teaching and learning quality. It is also acknowledged that English proficiency will reduce the gap between the Vietnamese workforce and the international labour market. In other words, English has become more important than ever before, especially when Vietnam wants to strengthen its diplomatic, economic, social and educational relations with other countries (Tsuboi, 2007).

Therefore, in 2008, the Vietnamese Prime Minister issued Decision 1400/QD-TTg ("Decision on the approval of the project entitled 'Teaching and Learning Foreign Languages in the National Education System, Period 2008-2020,"” 2008). The intent of this Decision was to approve the National Foreign Language Education Plan for the period from 2008 to 2020. The foci of this plan include: i) beginning English instruction in grade 3 , ii) setting proficiency benchmarks for teachers and students, iii) drafting English teacher competencies, and iv) appointing regional foreign language centers (RFLCs) throughout the country ("Vietnam's inservice English teacher competency framework: Guidelines for professional practice", 2014). In order to accomplish these goals, five teacher training universities were appointed to be in charge of improving teachers' capacity in terms of English proficiency and teaching methodology.

As a teacher-trainer at one of these training hubs, I can see the urgency for providing a new generation of EFL teachers with assessment literacy. This is because testing and assessment training for future teachers is unquestionably important in Vietnam where testing and assessment can significantly influence the way English is taught and learned. Moreover, future teachers' assessment literacy can help them introduce an assessment reform in their classrooms and this will gradually improve English teaching and learning quality in Vietnam.

In order to improve future EFL teachers' assessment literacy in Vietnam, it is crucial to be well-informed about testing and assessment training for pre-service EFL 
teachers, their assessment literacy confidence levels as well as how they develop their assessment literacy during teacher preparation programmes. Thus, my increasing interest in these above issues has enlightened my research into Vietnamese preservice EFL teachers' assessment literacy. This $\mathrm{PhD}$ research not only addresses the gaps in the literature but also is very practical and useful in the context of Vietnam. Moreover, it is particularly relevant for my role as a teacher trainer who wants to contribute to the development of the current language testing and assessment training for Vietnamese pre-service EFL teachers.

\subsection{Purposes of the study}

The study consists of three phases which investigate Vietnamese pre-service EFL teachers' assessment literacy from three different angles including: (i) language testing and assessment courses for pre-service EFL teachers, (ii) pre-service EFL teachers' assessment literacy confidence levels, and (iii) pre-service EFL teachers' development in assessment literacy during the practicum. The study strives to answer the following main research questions:

1. Phase one: What is the current status of language testing and training for preservice EFL teachers in Vietnam?

2. Phase two: What are Vietnamese pre-service EFL teachers' assessment literacy confidence levels?

3. Phase three: Is Vietnamese pre-service EFL teachers' assessment literacy developed during the practicum? What aspects of assessment literacy are developed? In what way are they developed?

\subsection{Significance of the study}

This study responds to a recent call for increasing research in the area of teachers' assessment literacy and teacher cognition of assessment literacy. The research is necessary for both theoretical and practical reasons. The possible contributions of this study are presented in Section 1.4.1 and Section 1.4.2 below. 


\subsubsection{Theoretical significance}

Firstly, this study contributes to the current limited research on pre-service EFL teachers' assessment literacy. Some studies have investigated pre-service teachers' assessment literacy in general education but very little research has paid attention to pre-service EFL teachers. Secondly, this thesis is among the very first studies which trace the development of assessment literacy among a group of pre-service EFL teachers during a practicum, and therefore offers insights into the dynamic, situated, and developmental nature of assessment literacy. Thirdly, the questionnaire developed in this study is likely to be useful for further research and professional activities of pre-service EFL teachers' assessment literacy. Fourthly, as the study was carried out in Vietnam, the findings add to a better understanding of a little explored context (Creswell, 2013).

\subsubsection{Practical significance}

The research is very practical for different levels of educational administration in Vietnam. At a higher level, the findings can assist the Ministry of Education and Training (MOET) to make more informed decisions related to teacher recruitment, their professional development, and other language teacher education policies. The findings can also give teacher training universities a contextualized view of their assessment training programmes for their graduates. Lastly, the results of this study are practical for my role as a teacher-trainer who desires to improve the current testing and assessment training programmes at my university.

\subsection{Third generation Activity theory as theoretical framework}

To investigate pre-service EFL teachers' development in assessment literacy, this study employs third generation Activity theory as the theoretical framework. This is because the field of second language teacher education has witnessed a shift towards a sociocultural perspective in looking at teacher learning and teaching (Freeman \& Johnson, 1998). According to this view, learning to teach is not an isolated process but is embedded in teachers' sociocultural interactions and contexts (Freeman \& Johnson, 1998; Johnson, 2009; Johnson \& Golombek, 2011). Furthermore, Johnson (2009) argues that "learning to teach is based on the assumption that knowing, 
thinking and understanding come from participating in the social practices of learning and teaching in specific classrooms and social situations" (p. 13).

In addition, this study acknowledges the importance of the social dimensions in helping pre-service EFL teachers shape and develop the way they test and assess their students. The development of pre-service EFL teachers' assessment literacy cannot be examined separately from their social and professional background and contexts. With a sociocultural perspective, this study adopts third generation Activity theory (Engeström, 1987) as the theoretical framework to analyse the development of preservice EFL teachers' assessment literacy.

The lens of third generation Activity theory (Engeström, 1987, 2001) is chosen in this study for three main reasons. Firstly, this framework guides the unit analysis of this study when it views the process of developing pre-service EFL teachers' assessment literacy as a joint activity system in which pre-service EFL teachers interacted with other stakeholders such as school mentors, teacher-trainers and other pre-service teachers to develop their assessment literacy. Secondly, this lens helps to zoom into the supportive and contradictory relationships among the components of this joint activity system. Lastly, identifying these contradictions will assist the understanding of the motive force for change/development within each componential system and the whole system (Engeström, 1987, 1999, 2001).

\subsection{Definitions of terms used in this study}

For the purpose of this study, the working definitions for some key terms are used as follows:

$\checkmark$ Pre-service EFL teachers: also known as mentees, or student teachers, or trainee teachers are the final year students of an undergraduate EFL teacher training programme.

$\checkmark$ Peer student teachers: refer to those who are assigned in the same teaching group under the supervision of a school mentor or in the same school during the practicum.

School mentors: also known as supervising teachers or supervisors in this study, are experienced teachers at a local school who are assigned to 
supervise, guide, support and train pre-service teachers in terms of teaching skills during a practicum. They are also required to provide reports of their pre-service teachers' development during the practicum.

$\checkmark$ Teacher trainers: are university lecturers who work with pre-service teachers in teacher preparation programmes at teacher training universities.

$\checkmark$ Practicum: is designed for the final year students of teacher training programmes who have finished most of their coursework. This period of time allows pre-service teachers to observe experienced teachers' teaching, practise their teaching skills and learn about how to become a professional teacher in a real-life context at a local school.

\subsection{Organisation of the thesis}

This thesis is organised into eleven chapters as follows:

$\checkmark$ Chapter 1: Introduction

This chapter presents the rationale for the study, the purposes, and the significance of the study. It also briefly mentions the theoretical framework and provides some definitions of key terms used in this study.

$\checkmark$ Chapter 2: Background of the study

This chapter briefly describes the current language testing and assessment system in Vietnam and its influences on language testing and assessment. It also provides an overview of pre-service EFL teachers' training and the role of the practicum in language teacher preparation programmes. The chapter ends with a discussion of some problems in the current education system and teacher training in Vietnam.

$\checkmark$ Chapter 3: Literature review

This chapter reviews the literature on teachers' assessment literacy, teacher cognition and language teacher education. It also presents the development of third generation Activity theory as the theoretical framework of the study. 
Chapter 4: Phase 1 - Language testing and assessment courses: Research methodology

This chapter details the research methodology used in Phase 1 which investigates the language testing and assessment courses at four teachertraining universities in Vietnam.

$\checkmark$ Chapter 5: Phase 1- Language testing and assessment courses: Results and discussion

This chapter presents and discusses the results of Phase 1.

$\checkmark$ Chapter 6: Phase 2 - Pre-service EFL teachers' assessment literacy confidence levels: Research methodology

This chapter presents the research methodology for Phase 2 which investigates Vietnamese pre-service EFL teachers' assessment literacy confidence levels.

$\checkmark$ Chapter 7: Phase 2 - Pre-service EFL teachers' assessment literacy confidence levels: Results and Discussion

This chapter presents and discusses the findings of Phase 2.

$\checkmark$ Chapter 8: Phase 3 - Development of pre-service EFL teacher's assessment literacy during practicum: Research methodology

This chapter details the research methodology for Phase 3 which traces the development of pre-service EFL teachers' assessment literacy during their practicum.

$\checkmark$ Chapter 9: Phase 3 - Development of pre-service EFL teacher's assessment literacy during practicum: Results and discussions

This chapter presents and discusses the findings of Phase 3.

$\checkmark$ Chapter 10: Discussions

This chapter discusses the main findings of this study in the light of contradictions of third generation Activity theory. Moreover, it provides an overall discussion of the findings.

$\checkmark$ Chapter 11: Summary, implications and conclusions

This chapter summarises the key findings of this study. It also discusses the theoretical, research and pedagogical implications of this study. Moreover, it 
presents the limitations and proposes future research directions. It ends with concluding remarks with my reflection on assessment literacy in my context.

The next chapter (Chapter 2) provides the background of the study. 


\section{Chapter 2:}

\section{BACKGROUND OF THE STUDY}

\subsection{Introduction}

Adopting a sociocultural perspective, this study acknowledges that in order to understand Vietnamese pre-service EFL teachers' assessment literacy development, it is crucial to be informed about the current testing and assessment system as well as language teacher education in Vietnam. This knowledge can inform the development of this research and help to explain possible problems of assessment literacy development for pre-service EFL teachers in the Vietnamese context. This chapter provides an insight into the background of this study by briefly describing the examoriented education system in Vietnam and its influences on English testing and assessment. After that, it presents the key issues of pre-service EFL teacher education in Vietnam. Finally, it discusses the problems that the current educational system encounters.

\subsection{Exam-oriented education system in Vietnam}

During the 4000 years of the country's establishment and development, Vietnam was invaded and ruled by the Chinese for 1000 years (218 BC-1858). Then it warred with France for about 100 years (1858-1954), and also fought against Japan, and the United States and its allies for thirty years (1945-1975) before it gained its independence in 1975. Due to a long history of wars and invasion, the education system in Vietnam was considerably influenced by the above countries.

The most significant influence was the blending of Confucianism, a social philosophy developed from the teachings of Confucius (551-479 BC), a Chinese philosopher, into the society of Vietnam during the 1000 years of the Chinese's dominance from 111 B.C and 939 A.D (Bich, 1998; Jamieson, 1995; K. W. Taylor, 1998). At the heart of this philosophy, the role of education in cultivating a moral man is strongly emphasized. In the past, the Vietnamese official mandarins had to undertake competitive examinations in order to have a social status. Therefore, testing functioned as the gatekeeper for those who wanted to be promoted and respected. 
Nowadays, the influence of Confucianism still remains strong in Vietnam (Ho, 2011; Truong, 2013). In education, this ideology is reflected in the way Vietnamese parents, regardless of their family and financial status, invest their time and finance into their children's education. Moreover, Vietnamese parents insist that their children should pursue education as much as possible because education is believed to be the key to success in life. In order to pursue higher education, Vietnamese students have to pass exams. As a result, students are always under considerable pressure to achieve good examination results. In order to prepare for examinations, most of them have to take after-school classes. According to a recent survey, $46 \%$ of Vietnamese students take after-school classes (“Sướng và khổ của sinh viên Việt Nam,” 2014).

Even though these after-school classes have been criticized for their negative impacts on students' physical health and learning, most parents continue to pay for these classes (“Tìm đến cội nguồn vấn nạn 'dạy thêm - học thêm' tràn lan,” 2014). This is because they have a fear that their children will fail the exams if they do not study for extra hours after school. A recent report shows that $69 \%$ of Vietnamese students are mentally and physically affected by the pressure of testing and assessment and $67 \%$ of them need to do at least 10 homework exercises every day ("Sướng và khổ của sinh viên Việt Nam,” 2014).

Moreover, most Vietnamese parents want their children to get a university degree because it is considered to be a passport to success. Regardless of their family's financial status, parents invest heavily in their children's university entrance examinations. This is particularly evident in the rural areas where many poor families are willing to spend their life savings on their children's preparation for university entrance examinations. Hence, for these families, their children's failure in these examinations is considered to be a tragedy, while their success leads to great joy.

It is not easy to get into university in Vietnam. This is illustrated in the latest report from the MOET which showed that more than $50 \%$ of the university entrance examination takers in Vietnam were unsuccessful in 2013 (“Tổng số thí sinh rớt đại học năm nay," 2013). For those who fail university entrance exams, instead of going to vocational schools or finding a job, a large number of them spend the following years re-taking the exams with the hope of getting a place at university ("Thừa thầy, 
thiếu thợ, vì đâu?,”2013). After the university entrance exam results every year, there are many sad stories of unsuccessful students committing suicide or suffering from depression.

To make matters worse, testing and assessment place a heavy burden not only on students and their parents but also on the teachers whose teaching quality is evaluated by their students' examination success rate (Le, 2000). Thus, Vietnamese teachers, who are under pressure for their students to pass examinations, teach to the test. Moreover, as teaching quality is evaluated by students' grades, teachers tend to please their students' parents and the society by giving their students higher marks than their students’ actual performance (“Điểm số ‘bóp méo’ học trò,” 2014). This causes a socalled phenomenon "bệnh thành tích" in Vietnam which means that teachers employ different strategies to help their students get higher exam results but do not check to see whether students really understand what they are learning. Despite the teachers' awareness of the negative effects of this phenomenon, they are unable to change the situation due to their fear of lowering their school's reputation and losing their teaching positions.

Further, such an examination-oriented education system negatively affects teaching and learning quality in Vietnam, especially since it encourages rote learning and memorisation. To cope with testing requirements, Vietnamese students are usually required to learn all the lessons by heart. As a result, many Vietnamese experts (Le, 2000; T. C. L. Nguyen, 2009; Truong, 2013) have criticized the passive learning styles of Vietnamese students who consider teachers as a source of knowledge and learn what teachers teach without critical thinking.

In summary, testing and assessment have been widely used as a powerful tool to select and differentiate the levels of success among the Vietnamese. This examoriented education system significantly affects teaching and learning quality in Vietnam. Similarly, English teaching and learning in Vietnam cannot avoid the influence of this system as described in Section 2.3. 


\subsection{English testing and assessment in Vietnam}

Testing and assessment have a huge impact on English teaching and learning in Vietnam. The mismatch between teaching and testing requirements is reported to be one of the main reasons for Vietnamese students' poor English communication skills (“Chất lượng dạy và học Anh văn trong trường phổ thông," 2005). Although communicative language teaching is encouraged in language classrooms, English tests and examinations mainly focus on English grammar and vocabulary. It appears that those who write the tests are not in touch with the realities of the classroom and the communicative needs of the students.

Moreover, due to the pressure of helping their students pass the examinations, teachers teach directly to exam requirements. In addition, students only learn what they need to know for the sake of testing and assessment ("Chất lượng dạy và học Anh văn trong trường phổ thông,” 2005). This explains why, despite enormous efforts in textbook and curriculum design, teaching method innovation, English teaching and learning in Vietnam still remains unchanged and Vietnamese students are described as passive and lacking English communicative competence ("Chất lượng dạy và học Anh văn trong trường phổ thông,” 2005).

Further, although English is considered important in the curriculum, its importance is not emphasized in final examinations in Vietnam. This is clearly evident as English examinations are only optional in the final examinations at secondary and high school levels. Students only choose to sit for English examinations if they want to get some extra marks for their final results. Consequently, it is common that those who do not need English examinations will neglect studying this subject. According to a recent report, English and History have the lowest number of students sitting for their final examinations (“Thí sinh ít chọn môn sử, ngoại ngữ," 2014). For example, in 2014, in Hau Giang province, among 6000 high school students, fewer than $6 \%$ of them chose English for their final examination (“Thí sinh ít chọn môn sử, ngoại ngữ,” 2014).

In short, in order to improve the quality of English teaching and learning in Vietnam, a reform in English testing and assessment is urgent. To do that, teachers definitely need to be assessment-literate because there is no assessment reform that can be translated into the classroom without teachers' assessment literacy (Popham, 2009). 
Thus, because pre-service EFL teachers will start their teaching career after graduation, their testing and assessment training at university is undeniably important.

\subsection{Pre-service teacher education in Vietnam}

As this study investigates pre-service EFL teachers who study in four-year teacher training programmes, only issues related to this level are described in this section.

\subsubsection{Pre-service EFL teacher education}

In order to encourage excellent high school students to pursue a teaching career, the Vietnamese government exempts those who pass entrance examinations to teacher training universities from paying tuition fees. For those who want to become English teachers at high school, they are required to obtain a four-year-teacher-traininguniversity degree. , Those who have a university degree in English translating and interpreting studies can become English language teachers at secondary or high schools if they obtain a certificate in teaching methodology.

The Ministry of Education and Training (MOET) has basic guidelines for the knowledge required to qualify as language teachers in Vietnam. During the training programme, compulsory subjects include 1) foundation knowledge, 2) subject-matter knowledge (English linguistics, i.e. phonology, grammar, semantics, and discourse analysis, and the four macro-skills of speaking, listening, reading and writing); 3) professional knowledge (teaching methodology and a practicum for six to ten weeks). According to the MOET's basic curriculum, students at teacher training universities have to take about 137 credits (one credit is equal to fifteen hours of instruction) in their training programme. Of these, only 20-23 credits (14-17\%) go towards professional knowledge, while 30-33 credits (21-23\%) are for foundation knowledge such as Hochiminhism, Marxism, and Vietnamese culture. Therefore, pre-service teacher EFL training programmes in Vietnam have been criticized for their inadequacy and irrelevance for the context of teaching in Vietnam (Le, 2011; M. H. Nguyen, 2013). 


\subsubsection{TESOL practicum in Vietnam}

In the final year of their teacher preparation programmes, Vietnamese pre-service EFL teachers need to complete a compulsory six to ten-week practicum. This practicum aims to provide pre-service EFL teachers with opportunities to practise teaching skills in real-life teaching contexts. During a practicum, they are usually divided into different groups working under the supervision of school mentors at local schools. One school mentor is usually assigned to a group of two to three pre-service EFL teachers. During the practicum, pre-service EFL teachers are supposed to observe their school mentors and practise teaching. At the end of a practicum, school mentors provide a full report of the pre-service teachers' performance and development during the practicum.

Due to limited teaching practice in their courses at university (Pham, 2001), the practicum is a good opportunity for Vietnamese pre-service teachers to apply their knowledge and skills in real language classrooms. However, the practicum has been criticized for its lack of guidance and support for pre-service teachers (Le, 2002). This leads to a lack of confidence and teaching skills after graduation (M. H. Nguyen, 2013). Therefore, there has been an urgent call for changes in how the practicum should be organized and evaluated (Le, 2002; H. T. M. Nguyen, 2010, 2013; Pham, 2001). Some empirical studies have been conducted to respond to this urgent need. These studies address the pre-service teachers' need for more support in order to face challenges during the practicum (H. T. M. Nguyen, 2010; T. M. H. Nguyen \& Hudson, 2010). H. T. M. Nguyen (2010) recommended peer mentoring as an effective way to help the pre-service teachers improve their teaching skills during a practicum. Even though the TESOL practicum is critical to the quality of teacher training programmes, very little has been done about the role of the practicum in teacher education in Vietnam (Le, 2002; M. H. Nguyen, 2013, 2014). This study, therefore, will add more knowledge to the limited literature on how the Vietnamese pre-service teachers develop their assessment literacy during the practicum.

\subsection{Problems encountered}

The above overview has identified some unsolved tensions in the current situation. Firstly, the strong influence of exam-oriented culture, which advocates the role of 
testing and assessment, has been unchanged for years. Thus, testing and assessment continue to drive English language teaching and learning. Secondly, there is a mismatch between English language testing and teaching requirements. Even though communicative language teaching is encouraged in EFL classrooms, test formats still focus on receptive skills and vocabulary. Last but not least, the lack of teachers' assessment literacy is also a great concern.

In order to solve these problems, different strategies need to be implemented. As Stiggins (1999b) and Volante and Fazio (2007) stated, teacher training institutions should be responsible for the enhancement of language assessment literacy. Therefore, a priority for these institutions is to have more professional and effective teacher education programmes to help pre-service teachers become more assessmentliterate. In short, to improve the situation of language teacher assessment literacy training in Vietnam, it is necessary to be well-informed about: 1) the current situation of language testing and assessment courses at some popular teacher training universities, 2) the pre-service teachers' assessment literacy confidence levels, and 3) their assessment literacy development during a practicum. These are also the main issues that this $\mathrm{PhD}$ study addresses.

The following chapter, Chapter 3, will discuss the previous literature about assessment literacy, teacher cognition and third generation Activity theory. 


\section{Chapter 3:}

\section{LITERATURE REVIEW}

\subsection{Introduction}

This chapter reviews the previous literature about assessment, assessment literacy, teacher cognition, and third generation Activity theory to inform and develop this study. Section 3.1 gives an overview of the chapter. Section 3.2 provides fundamental understandings of what assessment involves. Section 3.3 focuses on defining assessment literacy and teachers' assessment competence to identify the subconstructs of assessment literacy. This section also discusses the previous work on assessment literacy and assessment training in teacher preparation programmes. Section 3.4 presents the issues of teacher cognition and how pre-service teachers learn to teach during the practicum. Section 3.5 gives a brief description of the development of third generation Activity theory which serves as the theoretical framework of this study.

\subsection{Fundamental understandings of assessment}

“Assessment is unquestionably one of the teachers' most complex and important tasks" (Moss, 2013). Research shows that teachers can spend as much as a third to one half of their professional time on assessment-related activities (Plake, 1993; Stiggins \& Conklin, 1992). However, these activities are considered to be the least pleasant ones in a teacher's job (Jacobs \& Chase, 1992). Moreover, teachers have been reported to be under-prepared in this area (Brookhart, 2001b; Mertler \& Campbell, 2005; Plake, 1993; Stiggins, 1991b; Stiggins \& Conklin, 1988; K. Vogt \& Tsagari, 2014; Walters, 2010). Therefore, assessment training in teacher preparation programmes is important. In order to help pre-service EFL teachers develop their assessment knowledge and skills, it is crucial to understand what assessment involves. This section, therefore, presents the fundamental understandings of assessment as the guidelines for examining pre-service EFL teachers' assessment literacy in this study. 


\subsubsection{Assessment}

Hall and Burke (2004) pointed out that assessment is still traditionally associated with measurement in the form of paper and pencil tests. Wiliam (2011) noted that for many years, the word "assessment" was used to indicate the evaluation of "the effectiveness of sequences of instructional activities when the sequence was completed. The actions that guided learning processes before the end of the sequence were generally not regarded as kinds of assessments" (p. 3). However, Inbar-Lourie (2008) stressed a significant change of the term assessment both semantically and conceptually in the last few years. Assessment has been widely perceived as "an overarching term" (Inbar-Lourie, 2008, p. 385) to refer to "all methods and approaches to testing and evaluation whether in research or educational contexts" (Kunnan, 2004a, p. 1)

Bachman (2004b) argued that the usage of the term assessment in the fields of language testing and educational measurement has been so diverse that "there seems to be no consensus on what precisely it means" (p. 6). He defined assessment as "the process of collecting information about a given object of interest according to procedures that are systematic and substantively grounded" (p. 39). With this view, he emphasized the importance of the reliability and validity of an assessment.

Elsewhere, Bachman (2004a) described the interrelationship between assessment, evaluation, measurement, and test. He presented examples to argue that evaluation does not need to employ measurement and tests as shown in teachers' use of qualitative descriptions when evaluating students. He further explained that test and measurement can be used for non-evaluative purposes. However, he did not discuss the interrelationship between assessment and teaching in this work.

Similar to Bachman (2004a), H. D. Brown and Abeywickrama (2010) also illustrated the interrelationship between testing, assessment and measurement in their framework as shown in Figure 3-1. The difference is that they included assessment as an integral part of the teaching process. This view is in line with an ongoing shift in the learning culture when the primary purpose of an assessment should be to enhance teaching and learning quality (Black et al., 2003; Broadfoot, 2007; Carless, 2011; Gardner, 2006; Gipps, 1994; Heritage, 2010; Shepard, 2000; Timperley \& Parr, 2010). 


\section{Figure 3-1: H. D. Brown and Abeywickrama's (2010) framework}

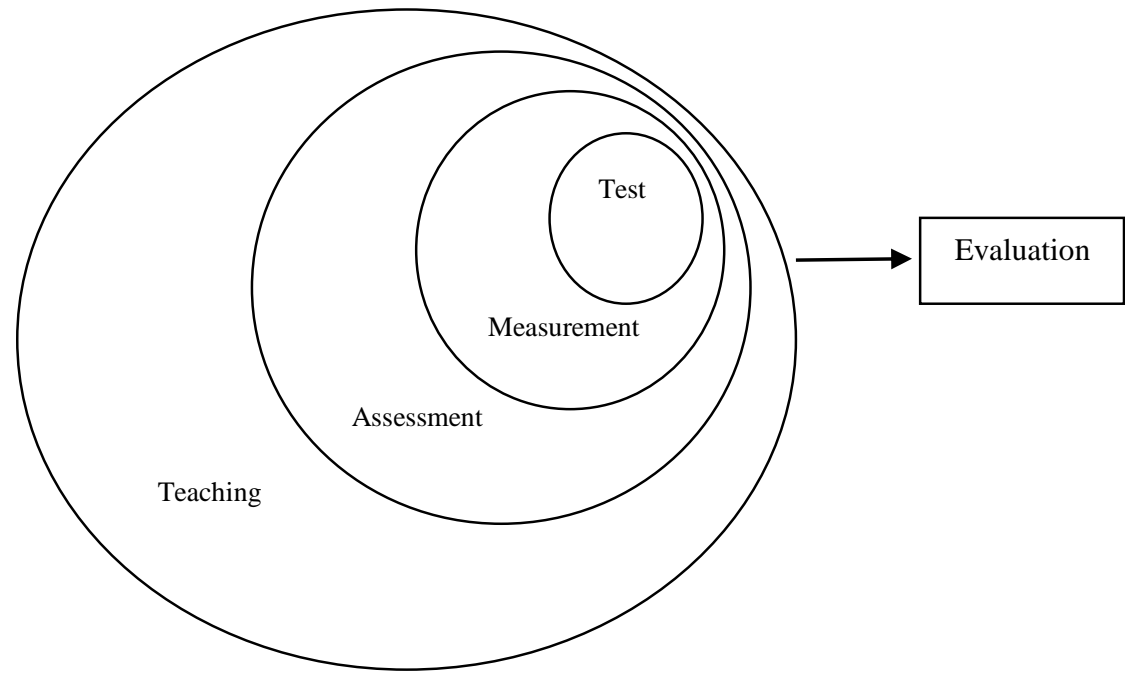

H. D. Brown and Abeywickrama (2010) also differentiated between tests and assessment in language classrooms. They argued that although the terms testing and assessment have been widely used together, they are not synonyms. Assessment can employ different techniques including tests, for example, a quiz, a portfolio, a question that teachers ask students, feedback teachers give students, and teachers' observations of students' learning, whereas, testing is just "a subset of assessment, a genre of assessment techniques" (H. D. Brown \& Abeywickrama, 2010, p. 3) and is organised at a specific time to measure and evaluate what students have learned in specific areas, for example, a reading test that teachers give their students at the end of a lesson to measure their students' reading skills.

In this framework, between assessment and test, similar to Bachman (2004b), H. D. Brown and Abeywickrama (2010) also added measurement which involves the quantification of "the observed performance of classroom learners" (p. 4) This quantification can be presented as a score or a percentile which teachers can use as evidence for evaluation. For example, students who score over $85 \%$ in a listening test can be evaluated as excellent in listening skills. In addition, Bachman (2004a, 2004b), and H. D. Brown and Abeywickrama (2010) claimed that evaluation can be done without measurement; as in, for example, teachers can use verbal or written feedback such as "correct" or "excellent" as a way to evaluate students" performance. Davies and Hill (2009) believed that "an important first step for making classroom 
assessment work is to understand the difference between assessment and evaluation" (p. 1). They also advocated that assessment should be used for enhancing teaching and learning quality, rather than only for evaluation.

In this study, assessment is used as an umbrella term which includes test, evaluation and measurement. Therefore, it argues that teachers' assessment literacy should also include knowledge and skills of these assessment-related issues (i.e., testing, evaluation and measurement). Moreover, due to a shift from a testing and examination culture to an assessment culture (Gipps, 1994; Shepard, 2000), this study considers assessment as an integral part of the teaching and learning process, rather than only as the end-point of instruction (Shepard, 2000). It is also important to note that "assessment in education must, first and foremost, serve the purpose of supporting learning" (Black \& Wiliam, 2006) and the understandings of assessment should be examined with regard to the cultural and context issues (Carless, 2011; Carless \& Lam, 2014).

To promote pre-service teachers' assessment literacy, it is necessary to identify different kinds of assessment they have to deal with. This is because their grasp of different kinds of assessment can help them select the most appropriate and effective assessment to meet their purposes (Andrade, 2010; Siegel \& Wissehr, 2011). The following section, Section 3.2.2, briefly presents different kinds of assessment.

\subsubsection{Different kinds of assessment}

Popham (2009) suggested a framework which consists of two kinds of assessment: classroom assessment and accountability assessment. In his framework, classroom assessment includes both informal and formal assessment teachers use to diagnose what their students know and can do in class to collect evidence for enhancing teaching and learning quality. By contrast, accountability assessment involves "those measurement devices, almost always standardized, used by government entities such as states, provinces, or school districts to ascertain the effectiveness of educational endeavors" (Popham, 2009, p. 6).

However, recent years have seen a major distinction between assessment of learning (also known as summative assessment) and assessment for learning (also known as 
formative assessment) (Broadfoot, 2007; Brookhart, 2001a, 2007; Ewing, 2010; Hall \& Burke, 2004; Harlen, 2008; Looney, 2011; Newton, 2007; Stiggins, 2007b). Earl (2003, 2012) added the concept of assessment as learning in which the active role of students in assessment and learning is the central focus. In this study, the terms assessment of learning and summative assessment, and assessment for learning and formative assessment are used interchangeably.

Many experts have worked on the differences between formative and summative assessment (Black \& Wiliam, 1998; Bloom, Hastings, \& Madaus, 1971; Gipps, 1994; Harlen \& James, 1997; Newton, 2007; Sadler, 1989, 1998). Bloom, Hastings, and Madaus (1971) proposed that assessment can be classified into summative or formative according to its purposes, timing, and level of generalization. They pointed out that the central purpose of formative assessment is to assist students' learning while summative assessment mainly focuses on accountability purposes such as grading, certification and admission. Moreover, summative assessment usually occurs at the end of an instructional unit while formative assessment happens along the process of teaching and learning to provide evidence for adjusting teaching and learning. Due to this feature, summative assessment usually covers more knowledge and skills than formative assessment.

Gipps (1994) argued however that "the key difference between formative and summative assessment is not timing but purpose and effect" (p. 125). This is because she noted that some assessments during a course or a session are used for summative purposes, rather than supporting learning. Torrance and Pryor (1998) also included the importance of both function and timing in the differences between formative and summative assessment. Harlen (2006) differentiated between formative assessment and summative assessment using different criteria such as judgement, purposes, and focus. Further, she suggested that this distinction should be used to help understand different assessment practices.

Although the distinction between formative and summative assessment is important, the central issue of this classification is not to certify if one kind of assessment is more advanced than the other. Gipps and Cumming (2005) recommended that this classification should not be used to evaluate whether one assessment approach is 
good or bad but to determine which approach is best suited for a specific purpose. Many other experts (e.g., G. T. L. Brown, Irving, \& Keegan, 2008; Dudley \& Swaffield, 2002; Harlen, 2006; Wiliam \& Thompson, 2008) shared the same view that the distinction between assessment of learning and assessment for learning does not mean that assessment for learning is good and assessment of learning is bad. Newton (2007) warned that "we give the wrong message when we try to simplify assessment purposes by allocating them to a small number of categories (such as formative, summative and evaluative" (p. 161). See Newton (2007) for his categorization of assessment purposes into eighteen purposes.

Earl (2012) also noted that assessment purposes can sometimes conflict with each other or require teachers different skills. Harlen (2005) suggested that the synergy of formative and summative assessment comes from the fact that the same evidence from assessment can be used for the two purposes. Therefore, pre-service teachers should understand different purposes of assessment to use assessment appropriately for various purposes (Andrade, 2010). Moreover, the tension between formative assessment and summative assessment can be resolved if educators could understand how the purposes and practices of these assessments can be mutually supported (Black, 2013; Harlen, 2005; Wiliam \& Thompson, 2008).

\subsubsection{Assessment of learning}

Assessment of learning (also known as summative assessment) is usually formal assessment that occurs at the end of a learning cycle (for example, the end of a course, or the end of a learning unit) to measure what students have learned. Shepard (2006) defined summative assessment as "the assessments carried out at the end of an instructional unit or course of study for the purpose of giving grades or otherwise certifying student proficiency" (p. 627).

Moreover, an assessment is considered summative when it is used for evaluating learning goals, for tracking progress, for certification of achievement and for publicly reporting achievement information (Harlen, 2008; Harlen \& James, 1997). According to many experts (e.g., Broadfoot, 2007; Brookhart, 2008; G. T. L. Brown et al., 2008), there are three types of assessment: 
$\checkmark$ Norm-referenced assessment: comparing students' performances with each other (norm-referenced).

$\checkmark$ Criterion referenced assessment: comparing students' performance against established criteria or standards.

$\checkmark$ Self-referenced/ ipsative assessment: comparing students' performance to their previous performance.

Summative assessment is necessary for all educational contexts because it provides evidence for accountability purposes such as student ranking, student admission and teaching programme evaluation. Due to its accountability purposes, assessment of learning can have a great impact on students' lives and future (H. D. Brown \& Abeywickrama, 2010; Carless, 2011; P. White, 2009). These formal assessments can also provide teachers with evidence to help them enhance the validity and reliability of their professional judgement (Davies \& Hill, 2009).

Although teachers may not be directly involved in the design and validation process of summative assessment, it is important that they understand how to ensure an effective summative assessment (Earl, Manitoba, \& School Programs Division, 2006; P. White, 2009). Therefore, most of the previous work on teachers' assessment literacy competencies (e.g., American Federation of Teachers, National Council on Measurement in Education \& National Education Association, 1990; Brookhart, 2011) required teachers to understand how to use assessment of learning properly and how to ensure the validity and reliability of these assessments.

\subsubsection{Assessment for learning}

Although the terms formative assessment and assessment for learning have been widely used interchangeably, the difference between the two has been debated over the last two decades (Gardner, 2006; Harlen \& James, 1997; Heritage, 2010; Stiggins, 2005; Swaffield, 2011). Both Gardner (2006) and Heritage (2010) emphasized the importance of understanding the purposes of formative assessment when it is used as equivalent to assessment for learning. Gardner (2006) analysed the origin of the term formative assessment, which was rooted in programme evaluation, to conclude that "assessment for learning is arguably less likely to be used to describe the summative use of multiple assessments of learning" (p. 2). However, he advocated for the use of 
both terms assessment for learning and formative assessment interchangeably when "there is no ambiguity in the type of assessment process being described" (Gardner, 2006, p. 2).

For the purpose of this study, both the terms assessment for learning and formative assessment are used interchangeably. It views "formative assessment, in particular, as something teachers do with and for students. Teachers involve students in the assessment, thus students and teachers are partners, both sharing responsibility for learning. Formative assessment provides evidence for improving student learning" (Heritage, 2010, p. 7). Research has shown that formative assessment is essential and it does improve learning (Black \& Wiliam, 1998).

One of the significant differences between assessment of learning and assessment for learning is that both teachers and students are involved in the process of assessment for learning. Therefore, assessment for learning requires teachers' change of their classroom roles and their behaviours (James \& Pedder, 2006). Also, teachers are supposed to use the evidence from this type of assessment to improve their teaching and their students' learning. Assessment for learning, thus, can be used to promote learner autonomy when it shows learners how well-prepared they are, and how to improve their learning to achieve the success criteria (Willis, 2011).

The Assessment Reform Group (2002) outlined ten principles of assessment for learning which stated that assessment for learning:

\footnotetext{
$\checkmark$ is part of effect planning,

$\checkmark$ focuses on how students learn,

$\checkmark$ is central to classroom practice,

$\checkmark$ is a key professional skill,

$\checkmark$ is sensitive and constructive,

$\checkmark$ fosters motivation,

$\checkmark$ promotes understanding of goals and criteria,

$\checkmark$ helps learners how to improve,

$\checkmark$ develops the capacity for self-assessment,

$\checkmark$ recognizes all educational achievement.
} 
Black \& Wiliam (2006) also advocated that the main purpose of assessment in education is to support learning. Therefore, effective feedback, effective questioning, successful learning goals, communication of success criteria, and effective use of peer and self-assessment are considered to be the key issues in assessment for learning (Black et al., 2003; Black \& Wiliam, 1998; Clarke, 2005; Heritage, 2010; Looney, 2011).

Two significant classroom-based studies looking at formative assessment inside the classroom are worth mentioning. First, Torrance and Pryor (1998) examined formative assessment in class for four to seven year-old students to identify two different kinds of formative assessment: convergent and divergent assessment. Convergent assessment aims at finding out whether a student knows, or understands a pre-determined thing or not while divergent assessment focuses on what a student knows, understands and can do. Torrance and Pryor (1998) also proposed that the choice of assessment should depend on teachers' understanding of students' learning and assessment. They added that "understanding the possibilities of both convergent and divergent assessment and developing the ability consciously to manipulate them would seem to be the prerequisite for teachers to make the most of formative assessment" (Torrance \& Pryor, 1998, p. 155).

Second, Bell and Cowie (2001a, 2001b) and Cowie and Bell (1999) identified two forms of formative assessment in science education: planned formative assessment and interactive formative assessment. In their research, Bell and Cowie (2001a, 2001b) found that planned formative assessment was what teachers had planned before while interactive formative assessment arose during teacher-student interactions. Teachers used planned formative assessment at the beginning or at the end of a unit with the whole class to inform them if their teaching met the curriculum requirements. For this type of assessment, teachers focused on eliciting, interpreting and acting on assessment information. In contrast, for interactive formative assessment, the focus was on individual students or a small group of students and it involved "teachers noticing, recognizing and responding to student thinking during these interactions" (Bell \& Cowie, 2001a, p. 86). 
In language testing and assessment, Hill and McNamara (2011) conducted an empirical study of two language classrooms at a school in Australia to propose a comprehensive framework for researching classroom-based assessment processes. For classroom-based assessment processes, teachers are supposed to plan, frame, conduct assessment, and use assessment data for different purposes such as teaching, learning, reporting, management and socialization. See Hill and McNamara (2011) for a detailed framework for research on classroom-based assessment processes. ReaDickins (2001) also developed a framework for identifying teachers' formative, classroom-based assessment practices.

Although assessment for learning has gained more popularity in Western countries, there has been a lack of research on how to use assessment for learning effectively in language classrooms in Confucian heritage countries. Davison $(2004,2007)$ were among a few research on school-based assessment in Hong Kong. Therefore, there has been a need for more research to provide a more contextual view of how to use assessment for learning in exam-oriented countries.

In summary, assessment is a complex yet sometimes unpleasant task for teachers. It is important that teachers choose an appropriate assessment for their specific purposes. In other words, the quality of the assessment is the central issue that teachers should pay attention to. Therefore, the next section, Section 3.2.3, presents issues of assessment quality.

\subsubsection{Assessment quality}

Assessment quality is an important issue in teachers' assessment literacy because the main purpose of assessment literacy should be to enhance the quality of assessment and ensure that an assessment is used properly for a specific purpose. Stiggins (2007a) noted that "high quality assessments encourage further learning; low quality assessments hinder learning" (p. 26). Harlen $(2005,2006)$ argued that it is important to understand for what purposes the evidence from an assessment was gathered and for what purposes it is used to evaluate whether an assessment is 'good' or 'bad'. She further explained that this is because: 
One can conduct the same assessment and use it for different purposes just as one can travel between two places for different purposes. As the purpose is the basis for evaluating the success of the journey, so the purpose of assessment enables us to evaluate whether the purpose has been achieved.

(Harlen, 2006, p. 116)

In assessment for learning, the main purpose is to assist students' learning. Therefore, effective assessment for learning should help students identify "where they need to get to in their learning" (Assessment Reform Group, 2002). Effective feedback is the key to the quality of assessment for learning because the previous meta-analyses confirmed that effective feedback can have a significant impact on students' learning (Black \& Wiliam, 1998; Hattie, Biggs, \& Purdie, 1996). Popham (2004), Wiliam (2011) and Willis (2011) also acknowledged the role of feedback in assessment for learning.

According to Black and Wiliam (1998), there are two main functions of feedback: directive and facilitative. Directive feedback can tell students what needs to be corrected or revised, whereas, facilitative feedback aims at guiding students towards their own revision and conceptualization. Hattie and Timperley (2007) proposed three main questions that effective feedback must be able to answer:

$\checkmark$ Where am I going? (What are the goals?) - Feed up

$\checkmark$ How am I going? (What progress is being made toward the goal?) - Feed back

$\checkmark$ Where to next? (What activities need to be undertaken to make better progress?) Feed forward

Hattie and Timperley (2007) also identified four levels of feedback: feedback about the task, feedback about the processing of the task, feedback about self-regulation, feedback about the self as a person. Among these different levels of feedback, they argued that feedback about the self as a person is the least effective and emphasized the role of feedback about the processing of the task and feedback about selfregulation in deep processing and mastery of the task.

Sadler (1998) identified that highly-competent teachers use six intellectual and experiential resources in their judgement and feedback act: 
Superior knowledge about the content or substance of what is to be learnt.

$\checkmark$ A set of attitudes or dispositions towards teaching as an activity, and towards learners, including their own ability to emphasise with students who are learning, their desire to help students develop, improve and do better, their personal concern with the validity of feedback and the veracity of their own judgements, and their patterns in offering help.

$\checkmark$ Skill in constructing or compiling tests, in devising tasks, and generally working out ways to elicit revealing and pertinent responses from students

$\checkmark$ A deep knowledge of criteria and standards appropriate to the assessment task

$\checkmark$ Evaluative skill or expertise in having made judgments about student efforts on similar tasks in the past

$\checkmark$ Expertise in framing feedback statements for students

Sadler (1998) also proposed that students should be trained how to make use of the feedback they receive to improve their learning. The previous studies showed different factors that affect the quality of the feedback. For example, Shute (2008) reviewed formative feedback and presented evidence of the different factors affecting the quality of feedback such as timing, feedback complexity and length.

Different from assessment for learning, assessment of learning focuses on measuring students' learning and serving accountability purposes such as grading, certification, and the public report of students' achievements. Due to its purposes, assessment of learning can have a great impact on society and students' life. Therefore, many experts, for example, Bachman (2004a, 2004b) and Gipps (1994), stressed the importance of the reliability and validity of a test. Bachman and Palmer (1996) introduced the concept of test usefulness as "the essential basis for quality control throughout the entire test development process" (p. 17). They proposed the six test qualities that need to be taken into consideration when designing a test including: reliability, construct validity, authenticity, interactiveness, impact and practicality. They also suggested applying three principles in test design and development:

$\checkmark$ Principle 1: It is the overall usefulness of the test that is to be maximized, rather than the individual qualities that affect usefulness. 
$\checkmark$ Principle 2: The individual test qualities cannot be evaluated independently, but must be evaluated in terms of their combined effect on overall usefulness of the test.

$\checkmark$ Principle 3: Test usefulness and the appropriate balance among the different qualities cannot be prescribed in general, but must be determined for each specific testing situation.

(Bachman \& Palmer, 1996, p. 18)

Moreover, one important factor of effective classroom summative assessment is grading. However, Brookhart (2013) reviewed previous studies to show that teachers still include non-achievement factors such as behaviour and effort into their grading and this grading practice is hard to change, even with professional development. She called for more research into the best ways to help teachers focus on grading students' achievement.

Moss (2013) carried out a review of research on classroom summative assessment practices from 1999 to 2011 and reported a gap between teachers' perceived and actual competence in designing, using and interpreting assessments for summative purposes. She also showed research evidence of the significant impact of summative assessment on students' motivation and learning. Moss (2013) addressed the lack of assessment training in teacher education and how this could affect teaching and learning quality. There was evidence that teachers who collaborated with each other and had coaching from those with expertise in summative assessment practices were more likely to realize their problems with assessment competencies and their need for more assessment training. To improve the practice of summative assessment, Moss (2013) called for more research into the impact of interested stakeholders such as principals and administrators on teachers' summative assessment practices, and more assessment training in university teacher preparation programmes.

In short, assessment quality is a critical issue that pre-service teachers must understand to become assessment-literate. Moreover, it is important for them to note that "even the most valid and reliable assessment cannot be regarded as high quality if it causes a student to give up" (Stiggins, 2007a, p. 25). Crooks (1988) reviewed extensive literature on the impact of classroom assessment practices on students to note that "too much emphasis has been placed on the grading function of evaluation, and too little on its role in assisting students to learn" (p. 468). He recommended that 
assessment should be done more frequently to help students enhance their learning, rather than only to serve summative purposes. This is because frequent high-stake testing can have a negative effect on students' motivation for learning (Harlen, 2005).

\subsection{Assessment literacy}

Due to the interrelationship between teaching and assessment, in order to improve teaching quality, pre-service teachers need to develop foundation knowledge in assessment. Many researchers (for example, Boyles, 2005; Campbell, 1998; Mertler, 2003; Mertler \& Campbell, 2005; Plake, 1993; Stiggins, 1995) advocated that preservice teachers should be well-prepared in testing and assessment in their teacher training programmes. This is because teachers were reported to lack assessment literacy due to their inadequate assessment training in teacher preparation programmes (Impara, Plake, \& Fager, 1993; Mertler \& Campbell, 2005; Stiggins, 1999b; Stiggins \& Conklin, 1988).

Although teachers' assessment literacy has received attention in general education, Brindley (2001), Davison (2012), and Fulcher (2012) pointed out a paucity of research on language teachers' assessment practices, levels of training, and professional training needs. Therefore, this study responds to an urgent need for more research into how pre-service EFL teachers are trained in testing and assessment and how they develop their assessment literacy in a practicum.

\subsubsection{An overview of assessment literacy}

"Good teaching is impossible in the absence of good assessment" (Eckhout, Davis, Michkelson, and Goodburn, 2005, cited in Khadijeh \& Amir, 2015, p. 140). Moreover, Koh (2011) considers assessment as “a key lever for driving teachers' instructional practice" (p. 256). Thus, teachers need to improve their knowledge and abilities in assessment in order to enhance their teaching quality.

Although the ideas of teachers' competences in testing and assessment were initiated in the Standards for Teacher Competence in Educational Assessment of Students (American Federation of Teachers, National Council on Measurement in Education \& National Education Association, 1990), the term assessment literacy first appeared in the work of Stiggins (1991a). In his paper, Stiggins (1991a) promoted the 
importance of assessment literacy to teaching and learning quality and called for research in this area. He defined assessment literate teachers as those who "have a basic understanding of the meaning of high- and low-quality assessment and are able to apply that knowledge to various measures of student achievement" (p. 535). In addition, he emphasised the importance of classifying the levels of assessment literacy for different groups of assessment users. According to him, the first level includes students, and parents who use assessment data generated by others. The second level involves more practically literate users including teachers, teachertrainers, school counselors, principals, school psychologists, and trainers of administrators who can generate and use assessment data. The last group involves specialists in measurement and evaluation who are able to generate assessment data for use by others. Stiggins required teachers to reach the second level of assessment literacy. This means that teachers are not only the users of assessment data but need more sophisticated skills and knowledge in order to distinguish the high-quality assessment practices from the low-quality ones. Later, Stiggins (1995) proposed four key questions that assessment-literate teachers should be able to answer including (i) what to assess, (ii) why to assess, (iii) how to assess and (iv) how to prevent the possible negative problems of their assessment.

Since then, for the past two decades, assessment literacy has received increasing attention in general education (Brookhart, 2011; DeLuca \& Klinger, 2010; Mertler \& Campbell, 2005; Plake, 1993; Popham, 2009; Stiggins, 1991a, 1995; K. Vogt \& Tsagari, 2014). L. Taylor $(2009,2013)$ advocated that assessment literacy, like computer literacy, is one of the neccessary literacies that teachers need to acquire. A number of experts have worked on what is involved in promoting teachers' assessment literacy (Boyles, 2005; Brookhart, 2011; Inbar-Lourie, 2008; McMillan, 2000; Mertler \& Campbell, 2005; Popham, 2009; Schafer, 1993; Stiggins, 1991a, 1995). Although there have been different definitions of assessment literacy, it is generally agreed that assessment literacy requires teachers to have the ability to connect testing and assessment theory with the practice of testing and assessment. In other words, teachers' assessment literacy includes two aspects: their understanding and knowledge of the theoretical issues of assessment, and their appropriate use of assessment practices. Teachers who are assessment literate not only understand the 
theoretical issues of testing and assessment but also know how to apply them in practice.

Despite the importance of teachers' assessment literacy, language testing and assessment have witnessed a lack of attention in this area (Brindley, 2001; Coombe, Troudi, \& Al-Hamly, 2012; Inbar-Lourie, 2008). Not much has been done to explore language teachers' assessment literacy. Coombe et al. (2012) pointed out a lack of focus on assessment literacy in the ALTE's Multilingual Glossary of Language Testing Terms by Association of Language Testers in Europe (1998) and Alan Davies et al. (1999). They also expressed concern for this lack of attention in language teaching and put more emphasis on helping language teachers to choose appropriate assessment for specific purposes and use assessment to improve their instruction. Inbar-Lourie (2008) advocated that "the time is ripe for revisiting the notion of drafting or adapting a set of standards for language assessment competencies... Such core competencies would be intended for language assessment professionals in educational contexts, and may also detail particular skills for specific capacities" (p. 397-398). There is a pressing need for more work in language teachers' as well as pre-service language teachers' assessment literacy.

In order to develop pre-service EFL teachers' assessment knowledge and skills, it is crucial to clarify what assessment knowledge and skills they need for their future job. The following section, Section 3.3.1, reviews assessment literacy competences for assessment literate teachers.

\subsubsection{Assessment literacy competences for assessment literate teachers}

A number of frameworks have been proposed regarding the basic components of assessment literacy. The most popular framework is the Standards for Teacher Competence in Educational Assessment of Students developed by American Federation of Teachers, National Council on Measurement in Education and National Education Association (1990). This framework has provided the guidelines for most research into teachers' assessment literacy so far. Examples include the studies of Impara et al. (1993), McGee \& Colby (2014), Mertler (2003), Mertler \& Campbell (2005), Plake (1993). According to this framework (American Federation of 
Teachers, National Council on Measurement in Education \& National Education Association, 1990), assessment literate teachers should be skilled in:

$\checkmark$ choosing assessment methods appropriate for instructional decisions;

$\checkmark$ developing appropriate assessment methods;

$\checkmark$ administering, scoring, and interpreting the results of both externally-produced and teacher-produced assessment methods;

$\checkmark$ using assessment results when making decisions about individual students, planning teaching, developing curriculum and involving students;

$\checkmark$ developing valid grading procedures which use assessment;

$\checkmark$ communicating assessment results to students, parents, and other stakeholders;

$\checkmark$ recognizing unethical, illegal, and inappropriate assessment methods and uses of assessment information.

However, as it was developed more than two decades ago, the Standards for Teacher Competence in Educational Assessment of Students (American Federation of Teachers, National Council on Measurement in Education \& National Education Association, 1990) have been criticized for being out of date and for their lack of emphasis on classroom assessment. Oosterhof (1995) observed fifteen classroom teachers and found that teachers spent more time on informal assessment than formal assessment. Black and Wiliam (1998) analysed the previous research to conclude that formative assessment was an important part of teaching and learning. Therefore, it is argued that the Standards for Teacher Competence in Educational Assessment of Students (American Federation of Teachers, National Council on Measurement in Education \& National Education Association, 1990) do not adequately recognise the importance of formative assessment in the classroom and focus more attention on summative assessment (Brookhart, 2011; Oosterhof, 1995).

Other experts have also proposed standards and guidelines for teachers' assessment literacy (see Lian, Yew, \& Meng, 2014; McMillan, 2000; Sadler, 1998; Stiggins, 1991, 1995, 1999a, 2002; Webb, 2002). Similar to many points listed in the Standards for Teacher Competence in Educational Assessment of Students (American Federation of Teachers, National Council on Measurement in Education \& National 
Education Association, 1990), Stiggins (1991a) proposed the five key issues that an assessment-literate teacher needs including:

$\checkmark$ starting with clear purposes of assessment;

$\checkmark$ understanding the importance of assessing different kinds of interrelated achievement targets (i.e., mastering of content knowledge, developing reasoning proficiencies, attaining performance skills, and developing high-quality products);

$\checkmark$ selecting proper assessment methods for the different kinds of achievement targets;

$\checkmark$ sampling and collecting student achievement based on representative performance tasks;

$\checkmark$ avoiding assessment bias and distortion that arise from technical and practical problems.

Stiggins $(1995,1999 b, 2002)$ focused on the four questions that teachers have to answer to become assessment-literate: (i) what to assess, (ii) why to assess, (iii) how to assess and (iv) how to prevent negative problems of assessment. In order to answer these questions, teachers need different knowledge and skills in testing and assessment. However, he did not detail what specific knowledge and skills teachers need.

Both Sadler (1998) and McMillan (2000) mentioned the importance of teachers' skills in giving effective feedback and enhancing assessment quality. Sadler (1998) also recognised the role of teachers' content knowledge and pedagogy in assessment literacy.

P. White (2009) summarised what Sadler (1998) required for an assessment-literate teacher:

Superior knowledge about content and substance of what is to be learned.

$\checkmark$ Knowledge about learners and learning and a desire to help students develop, improve and do better.

$\checkmark$ Skills in selecting and creating assessment tasks.

$\checkmark$ Knowledge of criteria and standards appropriate to assessment tasks.

$\checkmark$ Evaluative skills and expertise in the analysis and use of assessment information.

$\checkmark$ Expertise in giving appropriate and targeted feedback.

(P. White, 2009, p. 8) 
McMillan (2000) outlined eleven fundamental principles for teachers to become assessment-literate:

$\checkmark$ Assessment is inherently a process of professional judgment.

$\checkmark$ Assessment is based on separate but related principles of measurement evidence and evaluation.

$\checkmark$ Assessment decision-making is influenced by a series of tensions

$\checkmark$ Assessment influences student motivation and learning.

$\checkmark$ Assessment contains error.

$\checkmark$ Good assessment enhances instruction.

$\checkmark$ Good assessment is valid.

$\checkmark$ Good assessment is fair and ethical.

$\checkmark$ Good assessments use multiple methods.

$\checkmark$ Good assessment is efficient and feasible.

$\checkmark$ Good assessment appropriately incorporates technology.

Lian et al. (2014) focused on the Malaysian context and suggested five necessary knowledge and skills of assessment for Malaysian teachers including: "(1) validity of assessment, (2) reliability of assessment, (3) transparency of assessment, (4) fairness of assessment and (5) using of assessment information" (p. 74).

In general, it has been agreed that according to these above guidelines, an assessmentliterate teacher needs to understand different types of assessment, how to ensure assessment quality, and ethical issues in testing and assessment. However, like the Standards for Teacher Competence in Educational Assessment of Students (American Federation of Teachers, National Council on Measurement in Education \& National Education Association, 1990), these lists did not pay enough attention to teachers' assessment knowledge and skills in formative assessment. Brookhart (2011) recognised this lack of focus on formative assessment in the previous work; therefore, she worked on a list of eleven assessment skills which emphasized the importance of formative assessment According to her, in order to become assessment literate,

i. Teachers should understand learning in the content area they teach. 
ii. Teachers should be able to articulate clear learning intentions that are congruent with both the content and depth of thinking implied by standards and curriculum goals, in such a way that they are attainable and assessable.

iii. Teachers should have a repertoire of strategies for communicating to students what achievement of a learning intention looks like.

iv. Teachers should understand the purposes and uses of the range of available assessment options and be skilled in using them.

v. Teachers should have the skills to analyze classroom questions, test items and performance assessment tasks to ascertain the specific knowledge and thinking skills required for students to do them.

vi. Teachers should have the skills to provide effective, useful feedback on student work.

vii. Teachers should be able to construct scoring schemes that quantify student performance on classroom assessments into useful information for decisions about students, classrooms, schools, and districts. These decisions should lead to improved student learning, growth, or development.

viii. Teachers should be able to administer external assessments and interpret their results for decisions about students, classrooms, schools, and districts.

ix. Teachers should be able to articulate their interpretations of assessment results and their reasoning about the educational decisions based on assessment results to the educational populations they serve (student and his/her family, class, school, community).

x. Teachers should be able to help students use assessment information to make sound educational decisions.

xi. Teachers should understand and carry out their legal and ethical responsibilities in assessment as they conduct their work.

(Brookhart, 2011, p. 8)

Brookhart's (2011) list, so far, has been among the very few works that cover most aspects of teachers' assessment knowledge and skills. In addition, it overcomes a lack of focus on formative assessment and standard-based assessment in the Standards for Teacher Competence in Educational Assessment of Students (American Federation of Teachers, National Council on Measurement in Education \& National Education Association, 1990) as well as the previous frameworks (e.g., McMillan, 2000; Sadler, 1998; Stiggins, 1995). It also highlighted the importance of teachers' feedback, success criteria communication in assessment literacy. More importantly, in her 
paper, Brookhart (2011) also presented a clear and detailed description of what teachers need to become assessment-literate. Further, she recognized the role of pedagogical content knowledge in teachers' assessment literacy as shown in the first and second points of her list. Basically, her list requires assessment literate teachers to have pedagogical content knowledge, knowledge and skills in assessment for learning and assessment of learning, as well as ethical issues in testing and assessment.

Although teachers' assessment literacy has been advocated since 1991, language testing and assessment rather lagged behind in this area (Brindley, 2001; InbarLourie, 2008). Bailey and Brown (1996) were the pioneers in investigating language assessment education for teachers. However, they only used a survey to look at what was offered in language testing and assessment courses and did not clarify what knowledge and skills are important to become assessment literate. A decade later, Brown and Bailey (2008) replicated their study but still did not propose any framework of assessment literacy competences for teachers. However, it can be seen from their studies that assessment training for language teachers mainly focused on the importance of psychometrics and summative assessment.

Recognising the lack of attention to assessment literacy in language teaching and learning, Inbar-Lourie (2008), from a social constructivist perspective, introduced the concept of language assessment literacy into the literature. She also highlighted the need for discussing the issue of language teachers' assessment literacy in the light of current assessment developments. Moreover, she recognised the role of assessment for learning as advocated around the world (Assessment Reform Group, 2002; Davison, 2007; Leung, 2004) and called for "a reformulation of the competencies needed for conducting assessment in the educational contexts" (Inbar-Lourie, 2008, p. 228). Later, Inbar-Lourie (2012) continued her work on the knowledge base of language teachers' assessment literacy. She pointed out the shift from 'testing culture' to 'assessment culture' to acknowledge the importance of assessment for learning in language teachers' assessment literacy. Also, Inbar-Lourie (2012) indicated that language assessment literacy should include teachers' "familiarity with current approaches in language education and applied linguistics, and with research 
findings and controversies as they arise in contemporary glocalized societies, for such knowledge is directly related to assessment concerns and practices" (p. 5).

Alan Davies (2008) was among the first scholars who attempted to define what language assessment literacy involves. In his review of the textbook trends in testing and assessment, Alan Davies (2008) argued that language teacher assessment literacy includes three parts: knowledge, skills and principles. He linked skills to the teachers' abilities in "item writing, statistics, test analysis and increasingly software programmes for test delivery, analysis and reportage" (Alan Davies, 2008, p. 328), knowledge to the "relevant background in measurement and language description" (p. 328), and principles to "the proper use of language tests, their fairness and impact, including questions of ethics and professionalism" (p. 328). Alan Davies (2008) also argued that language testing and assessment professionals should not only acquire skills and knowledge but also the principles of language testing and assessment. Alan Davies' (2008) model was widely adopted in many countries around the world (Fulcher, 2012). However, like the previous frameworks in general education (e.g., McMillan, 2000; Sadler, 1998; Stiggins, 1995), Alan Davies' (2008) framework also pays more attention to measurement theory such as test validation and test analysis, and does not adequately emphasize the importance of feedback, as well as the important role of assessment for enhancing teaching and learning.

Expanding the model of Alan Davies (2008), Fulcher (2012) added the "historical context" because he argued that "young disciplines like language testing are constantly reinventing the wheel" (p. 115). He developed a three component model of assessment literacy including practices, principles and contexts as shown in Figure 3-2. 


\section{Figure 3-2: Fulcher's (2012) assessment literacy framework}

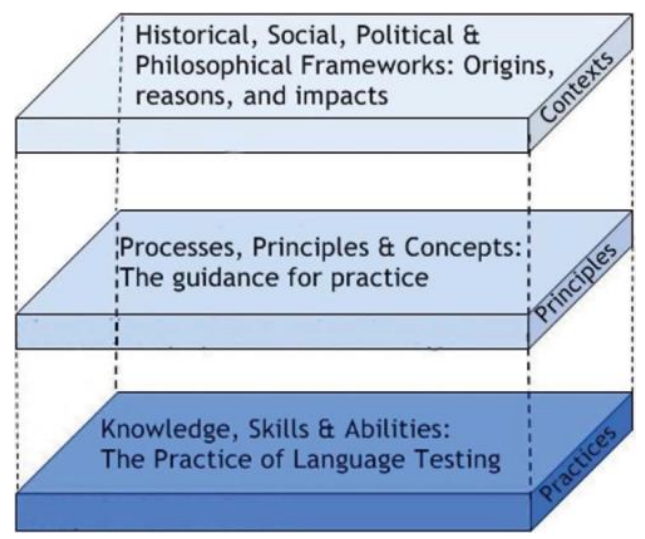

Fulcher (2012) then re-defined teachers' assessment literacy as:

The knowledge, skills and abilities required to design, develop, maintain or evaluate large-scale standardized and/or classroom based tests, familiarity with test processes, and awareness of principles and concepts that guide and underpin practice, including ethics and codes of practice. The ability to place knowledge, skills, processes, principles and concepts within wider historical, social, political and philosophical frameworks in order to understand why practices have arisen as they have, and to evaluate the role and impact of testing on society, institutions, and individuals.

In his model, Fulcher (2012) took into account the importance of the historical background, washback as well as the impact of testing and assessment. His view is aligned with the current trends of testing and assessment and of socio-cultural theory in education. Thus, he emphasized that training in testing and assessment for language teachers should consider the historical background of the testing and assessment system. In addition, similar to previous experts, for example, Stiggins (1995), L. Taylor (2009) and Fulcher (2012) argued that not all the components of his model are essential for every stakeholder in testing and assessment. There are different requirements of assessment literacy for different groups. However, he did not clarify clearly what language teachers need to become assessment literate in his paper.

$\mathrm{Gu}$ (2012) identified six key components assessment-literate teachers should pay attention to: (i) assessment purposes, (ii) pedagogical content knowledge, (iii) elicitation techniques, (iv) interpretation and feedback, (v) follow-up activities and 
(vi) ethical assessment. Gu (2012), similar to some other experts (e.g., Brookhart, 2011; Heritage, 2010; Inbar-Lourie, 2012), highlighted the importance of teachers' pedgogical content knowledge and the role of assessment to move learning forward by giving students appropriate feedback and follow-up activities. More importantly, $\mathrm{Gu}$ (2012) added the artistry of testing and assessment as an ideal feature of assessment-literate teachers. However, it is obvious that it is difficult to train teachers about the artistry of testing and assessment.

Because assessment is an indispensable part of the teaching process, pedagogical content knowledge, as suggested by many researchers (for example, Brookhart, 2011; $\mathrm{Gu}, 2012$; Heritage, 2010; Inbar-Lourie, 2012), is one of the prerequisite requirements for pre-service teachers to become assessment-literate. Moreover, due to the complexity and different purposes of assessment (Boud, 2000; Newton, 2007), pre-service teachers need to "keep the purposes of each type of assessment in mind as this is fundamental to helping them learn to judge the appropriateness of one over the other" (Andrade, 2010).

In addition, as noted in previous work, for example, Standards for Teacher Development in Assessment (American Federation of Teachers, National Council on Measurement in Education \& National Education Association, 1990), Brookhart (2011), Alan Davies (2008) and Fulcher (2012), the understanding of the principles, i.e., the impact and ethical issues in testing and assessment is important for teachers to become assessment-literate. This is in line with what McNamara and Roever (2006) acknowledged when they said: "in terms of academic training, we stress the importance of a well-rounded training for language testers that goes beyond applied psychometrics ... a training that includes a critical view of testing and social consequences" (p. 255). Further, pre-service teachers need to hold a belief in the role of assessment for enhancing teaching and learning quality because there exists a close link between teachers' beliefs and classroom assessment practices (e.g., G. T. L. Brown, 2004; Feiman-Nemser, 2008; Levin \& He, 2008; Tatoo \& Coupland, 2003).

The synthesis of the previous work identifies five sub-constructs of assessment literacy that guide the development of the questionnaire of pre-service EFL teachers' assessment literacy confidence levels in Phase 2 of this study including pedagogical 
content knowledge, different types of assessment (assessment for learning, assessment of learning), understanding of assessment qualities, beliefs of testing and assessment and the ethical issues in testing and assessment. These components interact with each other to help teachers make decisions about their assessment choice and how to use assessment for teaching and learning quality improvement. Figure 3-3 illustrates the assessment literacy framework used in this study.

The different types of assessment and assessment quality are discussed in Section 3.2.2 and Section 3.2.3 respectively above. The following sections, Section 3.3.3 and Section 3.3.4 focuses on pedagogical content knowledge and ethical issues in testing and assessment respectively.

Figure 3-3: Assessment literacy framework

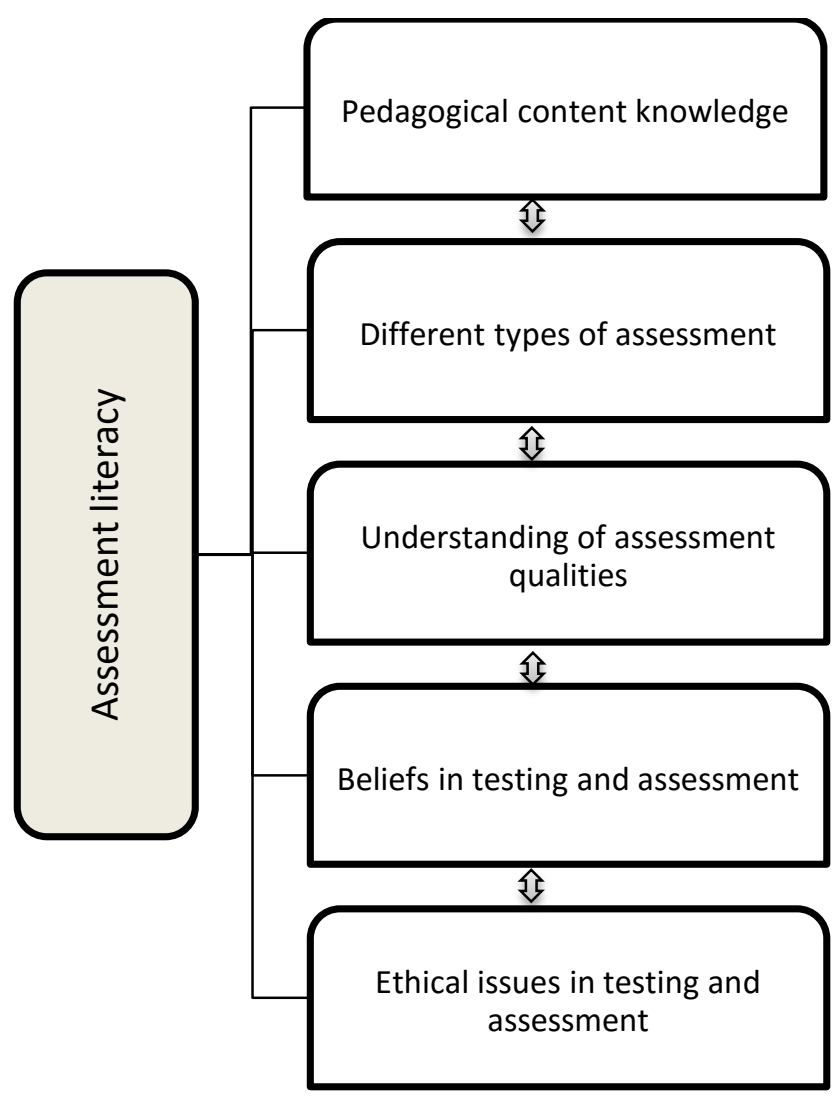

\subsubsection{Pedagogical content knowledge (PCK) and teachers' assessment practices}

As stated earlier, because assessment is an integral part of teaching and should serve learning purposes (Shepard, 2000), many experts, for example, Brookhart (2011), Gu 
(2012), Heritage (2010) and Inbar-Lourie (2012), highlighted the important role of pedagogical content knowledge (PCK) in teachers' assessment practice. They argued that PCK is the foundation for teachers to know how to assess their students as well as to use the assessment results to refine teaching and learning. Heritage (2010) also included PCK as a key knowledge that teachers need to make formative assessment happen in the classroom. Therefore, when I designed the questionnaire of pre-service teachers' confidence levels in assessment literacy, I included one section on PCK.

Shulman (1986) was the first to introduce the concept of PCK into the literature. According to Shulman (1986, 1987), PCK is one of the seven knowledge bases that teachers need to become the best possible teacher. Shulman (1986) argued that teachers' subject knowledge and pedagogy should not be separated but combined. He also believed that "those who understand, teach" (Shulman, 1986, p. 14). Moreover, he stressed that general pedagogical knowledge and skills were insufficient for teachers to teach content knowledge.

Thus, Shulman (1987) introduced the notion of PCK which he defined as a specific teacher knowledge that combines content and pedagogical knowledge. PCK "represents the blending of content and pedagogy into an understanding of how particular topics, problems, or issues is organised, represented, and adapted to the diverse interests and abilities of learners and presented for instructions" (Shulman, 1987, p. 8). This feature of PCK helps to distinguish between expert knowledge and teacher knowledge (Shulman, 1987). Shulman (1987) further explained that PCK helps to form an understanding of how the lessons, and the related issues are organised, delivered, and used in teaching to suit various students' interests and abilities. In other words, PCK is teachers' understanding of how to help students understand specific subject matter.

Later, many other experts and scholars expanded his notion (Appleton, 2003; GessNewsome \& Lederman, 1999; Gudmundsdottir, 1990; Loughran, Mulhall, \& Berry, 2004; Zeidler, 2002) and advocated the role of PCK in teaching (Halim, Meerah, Zakaria, \& Abdullah, 2012; van Driel \& Berry, 2012). Moreover, researchers have worked on the role of PCK in different subjects; for example, English , mathematics (Lee, Brown, Luft, \& Roehrig, 2007), science (Halim et al., 2012; Kind, 2009; 
Magnusson, Krajcik, \& Borko, 1999) and physical education (Jenkins \& Veal, 2002). These works also drew attention to the importance of understanding PCK from the perspective of each content area. Further, there have been various works on the components of PCK (see Andrews, 2001; Cochran, DeRuiter, \& King, 1993; Grossman, 1990; Magnusson et al., 1999; Tamir, 1988). Among these works, Tamir (1988) and Magnusson et al. (1999) considered teachers' understanding of evaluation and assessment as one of the components of PCK. Based on this view, Abell and Siegel (2011) developed a model of assessment literacy for science teachers which requires teachers to have knowledge of what to assess, knowledge of assessment purposes, knowledge of assessment strategies and knowledge of assessment interpretation and action-taking.

In language teaching, PCK, according to Hlas and Hildebrandt (2010), "is central to teaching since the content is typically the medium of instruction" (p. 3). In foreign language teacher education, Lafayette (1993) considered content knowledge as the "special component" which "consists of proficiency in and knowledge about the language and culture to be taught" (p. 124). Andrews (2001, 2003b) also acknowledged the uniqueness of language teachers' PCK because the content and the medium of instruction are closely related. Andrews (2001, 2003b) stressed the importance of EFL teachers' proficiency in English language and its culture to assess their students properly. Previous research has shown that PCK in language teaching can be acquired by teachers' previous experience with language teaching and learning as a learner, with L2 teacher preparation, and their observation during their teaching career (S. Borg, 1994, 2003; Calderhead \& Robson, 1991). Moreover, PCK is considered to be specific in different subject areas (see Andrews, 2001; Cochran, DeRuiter, \& King, 1993; Grossman, 1990; Magnusson et al., 1999; Tamir, 1988).

In this study, I adopted Andrews' (2001) framework (as shown in Figure 3-4) and identified five areas of PCK to develop my questionnaire of pre-service EFL teachers' assessment literacy confidence levels. These are (i) knowledge of teaching objectives and curriculum, (ii) knowledge of contextual issues, (iii) knowledge of instructional strategies, (iv) knowledge of students' learning and (v) knowledge of subject matter. 


\section{Figure 3-4: Andrews' (2001) framework}

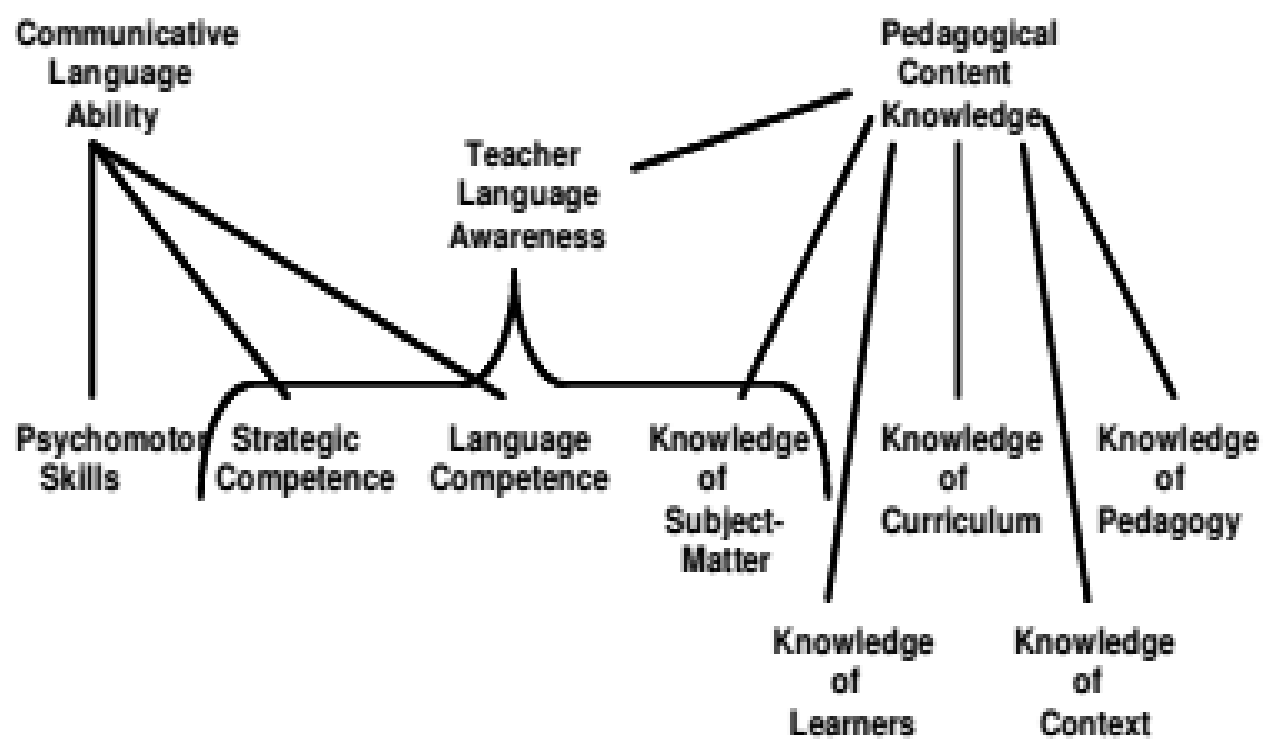

\subsubsection{Ethical issues in testing and assessment}

Assessment is a powerful tool: it can shape curriculum, teaching and learning; it can affect how pupils come to see themselves both as learners and in a more general sense as competent or not; through labelling and sorting pupils (certificating and selecting) it affects how pupils are viewed by others; it controls access to further education and high status career... Assessment has become increasingly widespread and significant in our education system and shows no sign of going away or losing its power (Gipps, 1994, p. 144).

Due to the impact of testing and assessment, those who are assessment-literate must understand how to minimize the negative effects of testing and assessment (A. Brown, 2012). Previous work on teachers' assessment literacy competence included ethical issues as a crucial component of assessment literacy (American Federation of Teachers, National Council on Measurement in Education \& National Education Association, 1990; Brookhart, 2011; Gu, 2012; McMillan, 2000).

Gipps (1994) included equity issues and ethical test preparation as key ethical issues that need to be addressed. According to her, testing and assessment should ensure fairness and equality among students and test-takers. Moreover, she stressed that 
teaching directly to the tests is unethical because this will jeopardise the role of testing and assessment to improve teaching and learning.

The importance of fairness in testing and assessment was emphasised by many experts (Bachman, 2000; Davies et al., 1999; Fulcher \& Davidson, 2007; HampLyons, 2001; Kunnan, 2000, 2004b, 2006). Fairness traditionally refers to non-biased tests and a fair chance for all test-takers to demonstrate their abilities. Later, this construct was expanded to include validity, access (e.g., financially and educationally) and justice (in terms of social equity and legal challenges) (Kunnan, 2000). As ethical issues in testing and assessment are important, pre-service EFL teachers should be provided with this knowledge to help them minimize the biases of their assessment and avoid teaching to the tests.

\subsubsection{Previous studies on assessment literacy}

Previous research has shown a relationship between teachers' assessment literacy and notable benefits in students' learning and teaching improvement (Wilson et al., 2001). Teachers' assessment literacy also enables them to avoid misdirected and inappropriate educational decisions (DeLuca \& Klinger, 2010) which can be harmful to their students' development (Schafer, 1993; Stiggins \& Chappuis, 2005). Due to the importance of assessment literacy, there has been a call for more research into this area. A review of the previous research identifies six main issues that need to be addressed in empirical research about teachers' assessment literacy.

First, most of the previous work on assessment literacy targeted teachers in general education (e.g., G. T. L. Brown, 2008; Coombe et al., 2012; Fulcher, 2012; Impara et al., 1993; Mertler, 2003; Mertler \& Campbell, 2005; Siegel \& Wissehr, 2011; Volante $\&$ Fazio, 2007). Very few studies have been done to look at language teachers' assessment literacy (e.g., Coombe et al., 2012; Fulcher, 2012; Newfields, 2006; Scarino, 2013; K. Vogt \& Tsagari, 2014), let alone pre-service EFL teachers. As each discipline has its own features and this can affect the way teachers of each discipline assess their students, it is important that more research should be done to understand how assessment literacy is viewed and developed in EFL settings. 
Second, most of these studies have been done in Western contexts such as in the United States and Canada; only a few studies have looked at teachers' assessment literacy in the Asian context. In Taiwan, the study of Fan, Wang, and Wang (2011) and Wang, Wang, and Huang (2008) examined how to use a web-based program to improve pre-service science teachers' assessment literacy. Koh and Velayutham, (2009) and Koh (2011) investigated the impact of professional training on assessment literacy development of primary Year 4 - Year 5 teachers of English, Mathematics and Science in Singapore. Jin (2010) and Lam (2014) investigated assessment courses and assessment training in China and Hong Kong respectively. Recently, Lian, Yew, and Meng (2014) discussed the role of assessment literacy and some key components of teachers' assessment knowledge and skills in Malaysia. Due to the limited research in the Asian context, it will be useful to investigate assessment literacy in examination-oriented countries like Vietnam

Third, most of the instruments used in most of the previous studies (e.g., Coombe et al., 2012; Fulcher, 2012; Impara et al., 1993; Mertler, 2003, 2005; Mertler \& Campbell, 2005; Plake, 1993; Volante \& Fazio, 2007) were developed based on the Standards for Teacher Competence in Educational Assessment of Students (American Federation of Teachers, National Council on Measurement in Education \& National Education Association, 1990). As this framework was developed more than two decades ago, it lacks focus on formative assessment in the classroom (Brookhart, 2011). This limited the coverage of teachers' assessment literacy in the previous research. With an ongoing shift from testing and examination culture to assessment culture in which assessment should serve the purpose of improving teaching and learning (Shepard, 2000), the construct assessment literacy needs to be expanded to include assessment for learning, rather than only focusing on assessment of learning.

Fourth, the majority of the previous studies employed a quantitative approach using a test of teachers' assessment literacy (e.g., Impara et al., 1993; Mertler, 2003, 2005; Mertler \& Campbell, 2005; Plake, 1993), or a survey of teachers' assessment practices (e.g., DeLuca \& Klinger, 2010; K. Vogt \& Tsagari, 2014; Volante \& Fazio, 2007; Zhang \& Burry-Stock, 1997). See Gotch and French (2014) for a systematic 
review of the previous tools to measure assessment literacy in the literature. Gotch and French (2014) criticized the validity and reliability of the previous instruments and called for more research about the relationship between teacher assessment literacy and student outcomes. To the best of my knowledge, very little research has employed a qualitative approach or mixed methods approach to look at the complex nature of teachers' assessment literacy. Therefore, there is a pressing need for more in-depth research which looks closely into teachers' assessment literacy in practice.

Fifth, the review of the key studies in teachers' assessment literacy has shown two main findings. Firstly, training and experience play an important role in teachers' assessment literacy. For example, Mertler and Campbell (2005) asked secondary teachers to complete a test of assessment literacy and found that those with experience and training in assessment literacy scored higher on this test than those without experience and training. Similar findings were found in the other studies; for example, Chen (2005) found that graduate teacher candidates scored higher results in the test of assessment literacy developed by Impara et al. (1993) than undergraduate teacher candidates and the same findings were found among those with prior teaching experience. Koh and Velayutham (2009) did a longitudinal study with two groups of primary Year 4 - Year 5 teachers of English, science and concluded that the group with extensive training in testing and assessment were better at their assessment practices. Secondly, teachers and pre-service teachers have been reported to be underprepared in testing and assessment for their job. The studies of Chen (2005), Impara et al. (1993), Mertler and Campbell (2005) and Plake (1993) showed that teachers did not achieve high scores in the test of assessment literacy. For example, Plake (1993) conducted a national survey with 555 teachers in the United States which showed that teachers only completed 23 out of 35 items correctly in the test of assessment literacy. Therefore, the previous studies suggested further training to improve teachers' assessment knowledge and skills.

Lastly, assessment literacy should be promoted among other stake-holders, apart from teachers, such as students, parents, principals and policy-makers. Many experts (e.g., Arter, Stiggins, Duke, \& Sagor, 1993; Popham, 2006; Price, Rust, O’Donovan, Handley, \& Bryant, 2012; Schafer \& Lissitz, 1987; Stiggins, 2010) raised their voice 
in support of assessment literacy for principals and school administrators. Moreover, the test-takers should be assessment-literate, as seen in the study of O'Loughlin (2009) about assessment literacy for IELTS test-users. Engelsen and Smith (2014) argued that "the three main actors need to develop assessment literacy: the principal as a knowledge broker and facilitator, teachers as conductors of AfL [assessment for learning], and the students as consumers and conductors of AfL in relation to their own learning” (p. 106).

As assessment training is an important part of assessment literacy development, the following section, Section 3.3.6 reviews previous studies on language testing and assessment courses for teachers.

\subsubsection{Previous studies on language testing and assessment courses}

In a summary of published research findings on assessment knowledge and skills for teachers, Marso and Pigge (1992) identified three main problems with assessment training: (1) a huge lack of assessment courses in teacher training programmes, (2) a lack of attention to measurement courses if they are not required, and (3) no training in testing and assessment for in-service teachers. Other researchers showed that the situation has not changed a lot and that teachers and pre-service teachers continue to be reported to be under-prepared in testing and assessment (Dudley \& Swaffield, 2002; Impara et al., 1993; Mendoza \& Arandia, 2009; Mertler, 2005; K. Vogt \& Tsagari, 2014; Volante \& Fazio, 2007). Moreover, research has shown the impact of this training on teachers and pre-service teachers' assessment literacy; for example, the study of Koh and Velayutham (2009) stated that those with extensive training in assessment had better assessment practices.

Brown and Bailey (2008) suggested that more research should be done to find out what is happening in language testing courses worldwide. An understanding of this would be beneficial for better professional development in the field of applied linguistics. To date there have been three significant studies looking at language testing courses. These studies looked at these courses from the viewpoints of language testing educators. The first study by Bailey and Brown (1996) investigated language testing courses in terms of the topics, course materials and the perspectives 
of students. Later, Brown and Bailey (2008) replicated their study and added more topics in testing and assessment in their survey. Jin (2010) carried out a similar study in China. The common themes arising from these three studies were that (1) the role of language testing and assessment training was emphasized, (2) the topics of the courses focused more on psychometrics and summative assessment than classroom assessment and assessment for learning, (3) a survey was the only research instrument in these studies, and (4) only the voices from the course instructors were heard and none of them examined the training from students' perspective.

Recently, Lam (2014) overcame some limitations of the previous studies on language testing and assessment courses when he employed various research instruments: a survey, interviews, government documents, student tasks and listened to the voice of the students who took the courses to depict the landscape of assessment training in Hong Kong. The study identified five themes: (1) inadequate support for language assessment literacy training, (2) lack of focus on classroom-based and large-scale assessment, (3) perceptions of language assessment literacy in an examinationoriented culture, (4) experience of course-based language assessment training and (5) restricted application of language assessment literacy in authentic school contexts. It is noteworthy in this study that instructors and students in an examination-oriented culture often viewed assessment literacy as knowledge of testing and grading than formative assessment. Moreover, students of these courses were not given adequate opportunities to apply what they learned in practice, i.e. in the practicum.

With regard to research on assessment training, previous studies showed an impact of this training on teachers' assessment literacy, for example, the study of Koh (2011), Lomax (1996), Montee, Bach, Donovan, and Thompson ( 2013), and McGee and Colby (2014). McGee and Colby (2014) used the Assessment Literacy Inventory developed by Mertler and Campbell (2005) to examine teacher candidates' assessment literacy before and after a course. The findings indicated that teacher candidates scored higher in this assessment literacy test after the course. Moreover, they had highest scores in ethical assessment, scoring and choosing assessment methods and lowest scores in sound design of assessment and communicating assessment results. In Physics education, Ogan-Bekiroglu and Suzuk (2014) 
employed both quantitative and qualitative approaches to look at twenty eight preservice physics teachers' assessment literacy and how they implemented it in practice. The results from both the quantitative and qualitative study indicated a high level of assessment literacy among these teacher candidates. However, the most significant finding of this study was the gap in teacher candidates' assessment literacy between theory and practice. Ogan-Bekiroglu and Suzuk (2014) recommended that assessment training for pre-service teachers should offer them opportunities to practise and reflect on their assessment knowledge and skills. Further, OganBekiroglu and Suzuk (2014) believed that teacher preparation programmes should pay attention to teacher candidates' content knowledge and how best to help them overcome challenges and adjust their attitudes toward assessment.

Another important issue in assessment training is role of the training materials and textbooks in testing and assessment. Alan Davies (2008) examined the textbook trends in language testing and assessment. He identified two trends of language testing and assessment textbooks in which assessment training for teachers should be expanded to include skills, knowledge and principles. He referred skills to "item writing, statistics, test analysis and increasingly software programmes for test delivery, analysis and reportage" (p. 328); he proposed knowledge as "relevant background in measurement and language description, as well as context setting ... [it] may involve an examination of different models of language learning, of language teaching, and of language testing such as communicative language testing, performance testing, and nowadays, a socio-cultural theory" (p. 328); he defined principles as "the proper use of language tests, their fairness and impact, including the questions of ethics and professionalism ...a consideration of the growing professionalism of language testing, of the responsibilities of language tests and of the impact of their work on a range of stakeholders and of the ethical choices they must take" (p. 328). L. Taylor (2009) criticised current textbooks for training language testing and assessment as "highly technical or too specialized for language educators seeking to understand basic principles and practice in assessment" (p. 23).

Malone (2013) investigated the feedback of two groups: language instructors $(\mathrm{N}=$ $44)$ and language teachers $(\mathrm{N}=30)$ in the United States about the content of an online 
tutorial on language testing and assessment. The results showed that there were different needs and levels of interest in issues in testing and assessment. Malone advocated that course material development in assessment should take this difference into account because "while language assessment literacy is an important goal, for such efforts to succeed, they must meet the needs and expectations of the target audience, language instructors" (p. 343).

K. Vogt and Tsagari (2014) conducted a needs analysis of assessment literacy training for foreign language teachers in seven European countries: Cyprus, Former Yugoslavian Republic of Macedonia, Germany, Greece, Italy, Poland and Turkey. The questionnaire was conducted using 853 participants and after that, 22 Greek, 25 German, and 16 Cypriot participants were involved in the follow-up interviews. The findings showed different priorities for different areas of testing and assessment training. Moreover, the extent of training needs depended on the assessment requirements of different educational contexts. Thus, K. Vogt and Tsagari (2014) advocated that professional development in testing and assessment for teachers should be based on the needs analysis of teachers in testing and assessment.

Moss (2013) reviewed previous studies on summative assessment to highlight the current problem of the university programs where there are graduate teachers "who are over confident and under-competent when it comes to summarizing achievement and using assessment information to improve student learning" (p. 252). She recommended that assessment training goes "beyond counting the number of assessment courses in particular curricula to examining what actually happens in those courses to develop assessment literacy and follow the graduates into the field to see if those courses impact actual assessment practices" (Moss, 2013, p. 252). Inbar-Lourie (2012) proposed that training courses for assessment literacy should examine "the weight of literacy components" (p. 3) and whether everyone working with assessment is offered "an identical or differential assessment literacy menu" (p. 3) and "whether teachers, for example, should be familiar with the theoretical underpinnings of assessment practices or just with the hard core of hands-on assessment know-how" (p. 3). 
Volante and Fazio (2007) called for more research into how to help future teachers improve their assessment literacy and stated that "this type of research should logically begin in faculties of education because they provide future teachers with their first introduction to assessment and evaluation" (p. 751). This is because research has shown that pre-service teacher education can improve future teachers' knowledge and practice in assessment. For example, Graham (2005) tracked 38 secondary English teacher candidates' growth in knowledge about classroom-based assessment and assessment-driven planning across time. The findings showed that these pre-service teachers' assessment practices were influenced by their previous experience in both university courses and mentored practicum. Also, Graham (2005) suggested that the role of school mentors was very critical as pre-service teachers observed and learned from modelling assessment practices of their mentors.

Thus, it is important to find an effective way to offer pre-service teachers opportunities to improve their assessment literacy. The study of Wang et al. (2008) focused on an experiment of how to use a web-based model called "Practising, Reflecting and Revising with WATA system (P2R-WATA) Assessment Literacy Development Model" to improve pre-service biology teachers' assessment literacy. The WATA system can allow personalised learning resources and opportunities for pre-service teachers to create tests and administer them to students on-line. This system enables pre-service teachers to view the test analysis and item analysis of the test to revise their test items. Sixty pre-service teachers were involved in the experiment and the results showed that this model could help these teachers improve their assessment knowledge and perspectives. Walters (2010) investigated how to use standards reverse engineering (SRE) to language test specifications as a way to improve assessment literacy. Three small workshop groups about how to use SRE to review the test items were organised for the participants in this study. The results indicated a positive effect of SRE on assessment literacy development. Therefore, Walters (2010) called for more research into how to use SRE to develop teachers' assessment literacy and its impact on teachers' classroom testing and assessment practices. 
Kleinsasser (2005) described how his students and he cooperated to transform an assessment course for second language teachers at postgraduate level at an Australian university. Instead of telling his students what to do, he involved them in the process of learning and encouraged them to share their enthusiasm of learning with each other. The students of this course were required to develop a portfolio to help them design, negotiate and document their individual learning. By doing this, the students could change their assessment practices and their attitudes towards professional training in testing and assessment. Therefore, Kleinsasser (2005) advocated that professional development in testing and assessment should challenge a teacher to become a "practical and theoretical assessment materials developer within a developing, supportive, professional community" (p. 97).

In summary, assessment literacy is an important requirement for pre-service teachers to cope with the quality of teaching and learning in their future job. Although it has received increasing attention in the literature recently, there is still a pressing need for research to understand how to promote assessment literacy in language testing and assessment and how assessment literacy can affect teaching and learning quality. Moreover, assessment training in language testing and assessment courses is only the initial input that may lead to teachers' assessment competence. Likewise, the assessment literacy frameworks discussed above cannot effectively cover the practical and contingent deployment and manipulation of assessment literacy inside the classroom.

Research into teacher professional development has embraced a widely accepted distinction between theory and practice, or between professional knowledge and practitioner knowledge (Schön, 1987). More recently, some researchers are beginning to see beyond the two-way distinction and have begun proposing an "artistry" or an aesthetics of teaching performance beyond "episteme" (true and certain knowledge) and "phronesis" (decision-making based on the dynamics of practical situations) (Eisner, 2002). While these efforts help understand the ideal teacher's performance, what this study is interested in is the basic or minimal level of preparedness in terms of assessment competence of the trainee teachers (see Mitchell, Robinson, Plake, and Knowles', 2001, argument for the licensure of the 
beginning teacher). For pre-service teachers, the lack of classroom experience has always remained a critical issue (Brandt, 2006). Novice teachers either have been thrown in at the deep end, or receive very little systematic help (Farrell, 2008) in the practical deployment of their pedagogical and pedagogical content knowledge (Shulman, 1986). Understandably, the current consensus points to the closer collaboration among university supervisors, school mentors, and the trainee teachers during the practicum (Farrell, 2008). This study zooms into the practicum of a group of Vietnamese pre-service EFL teachers and sees how assessment literacy in action was deployed and developed on-site during the practicum experience. In order to inform and develop this study, a review of the literature on teacher cognition is unquestionably important.

\subsection{Teacher cognition}

According to S. Borg (2003), "teachers are active, thinking decision-makers who make instructional choices by drawing on complex, practically-oriented, personalised, and context-sensitive networks of knowledge, thoughts, and beliefs" ( $p$. 81). In fact, teachers are considered as one of the most important factors which influence student learning (Darling-Hammond, 2000; Harris \& Sass, 2011; Stronge, Ward, Tucker, \& Hindman, 2007). Research has shown that what teachers think, know and believe can influence their teaching (S. Borg, 2003, 2006). As assessment practices are an indispensable part of teachers' jobs, it is crucial to understand their cognition about this area. However, there has been a lack of research about how teachers learn to assess their students as well as develop their language assessment practices. This section focuses on the key issues in teacher cognition which help to position this study in the landscape of research on teacher cognition and assessment practices.

\subsubsection{Defining teacher cognition}

What teachers know, believe, think and do and how these are developed have been referred to as 'teacher cognition' in the language teaching field (S. Borg, 2003). Teacher cognition is considered to be "the unobservable cognitive dimension of teaching" (S. Borg, 2003, p. 81). In addition, the term 'teacher cognition' has been widely used as an overarching term to refer to different sub-areas such as attitudes, 
beliefs, and conceptions (S. Borg, 2003, 2006). Teacher cognition is also characterized by a diversity of different terms such as BAK (beliefs, assumptions and knowledge) (Woods, 1996), beliefs (Basturkmen, Loewen, \& Ellis, 2004), maxims (Richards, 1996), pedagogic principles (Breen, Hird, Milton, Thwaite, \& Oliver, 2001), pedagogical knowledge (Gatbonton, 2000; Mullock, 2006), practical knowledge (Meijer, Verloop, \& Beijaard, 1999), and personal practical knowledge (Golombek, 1998). S. Borg (2003) identified sixteen different terms for teacher cognition that have been used in the literature so far. However, he suggested that: "Arguably, one or more of cognition, knowledge (and its subtypes), beliefs, attitudes, conceptions, theories, assumptions, principles, thinking and decision-making should be adequate for most purposes" (S. Borg, 2006, p. 272; original emphasis).

This study adopts what S. Borg $(2003,2006)$ claims about teacher cognition i.e. that it guides teachers' behavior and practices. As Borg notes, teacher cognition is situated within the context of a set of interrelated factors including the teachers' own schooling background, their professional coursework, their classroom practice (such as practicum), and contextual factors (S. Borg, 2003). S. Borg (2003) developed a framework of teacher cognition as shown in Figure 3-5.

Teacher cognition has become a vibrant field of study in recent years, together with the larger field of second language teacher education (Wright, 2010). There has been a large body of research on teacher cognition in different areas of language teaching (see S. Borg (n.d.) for an updated bibliography about research on language teacher cognition). However, there is little research to date looking at how second language teachers learn and develop their assessment literacy during teacher preparation programmes. This study, thus, addresses this gap in the literature.

As assessment literacy not only involves teachers' knowledge of testing and assessment but also how they view testing and assessment and put them into practice. Thus, the following section, Section 3.4.2, discusses teachers' beliefs and teachers' knowledge. Section 3.4.3 reviews the relationship between teacher cognition and teachers' classroom practices. Section 3.4.4 provides an overview of previous studies on teacher cognition and classroom practices. 
Figure 3-5: S. Borg's (2003) framework

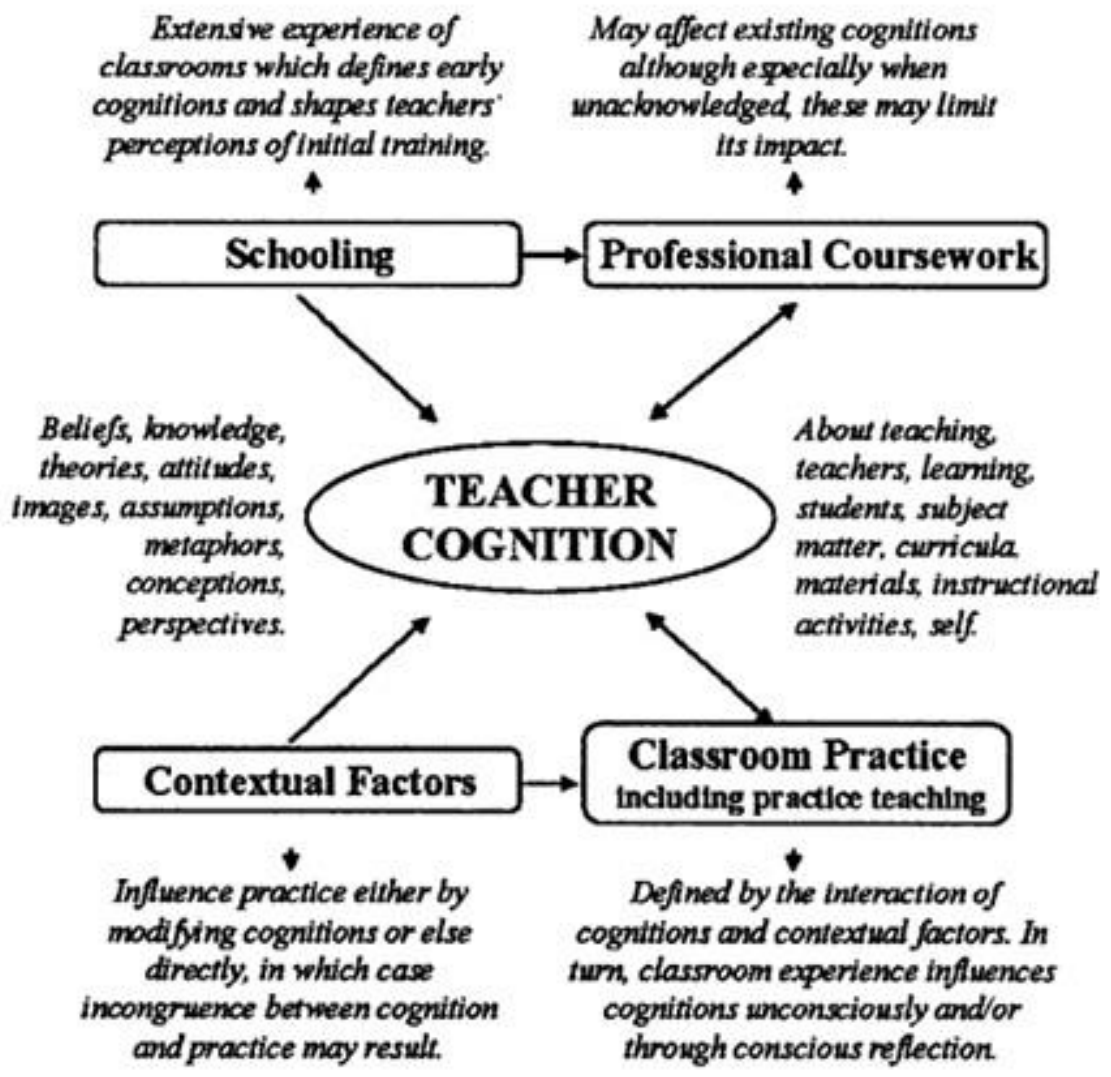

\subsubsection{Teachers' beliefs and teachers' knowledge}

The distinction between teachers' beliefs and teachers' knowledge has been debated over the last two decades. Although the literature has shown that that teachers' beliefs have a greater impact on instructional practices than their knowledge (Nespor, 1987; Pajares, 1992), it has been argued that teachers' beliefs and knowledge are interwoven (Verloop, Van Driel, \& Meijer, 2001; Woods, 1996) and thus it is difficult to separate teachers' beliefs from their knowledge (Pajares, 1992). In addition, research has shown that beliefs are more powerful than knowledge in determining how individuals organise and define tasks and problems (Kagan, 1992; Nespor, 1987; Pajares, 1992).

For teachers' beliefs, Haney and McArthur (2002) and Phipps and S. Borg (2009) identified the difference between core and peripheral beliefs. According to them, core beliefs are more influential and less likely to change than peripheral beliefs. Thus, core beliefs are more consistent in both teachers' expression and their classroom 
practices whereas peripheral beliefs are stated but may not be observed in their behaviours and practices.

With regard to teachers' knowledge, Wallace (1991) noted the difference between received knowledge and experiential knowledge. The first comes from teachers' academic training while teachers get the second from their reflection on their teaching experience. Wallace (1991) argued that teachers' knowledge is a mixture of these two types of knowledge and critical reflection is central to teachers' knowledge construction. Moreover, teachers' knowledge guides their instructional practices and reflection helping them to connect received knowledge and experiential knowledge (Wallace, 1991).

In assessment literacy development, language testing and assessment courses at university can provide pre-service teachers with received knowledge in testing and assessment. However, in order to help them develop their experiential knowledge, the role of practicum and field work are unquestionably important. In addition, preservice teachers have to be given opportunities to reflect on their teaching experience because reflection is important to their knowledge formation.

Moreover, as their experiential knowledge is critical to their instructional practices, teacher preparation programmes should provide their teacher candidates with more opportunities to link theory to practice. In other words, it is very important to help pre-service teachers gain experience of testing and assessment practices during their training. Further, to understand pre-service teacher cognition in testing and assessment, their teaching practices and behaviours need to be traced over a long period of time. This helps to check whether their beliefs in testing and assessment are reflected in their teaching practices and whether they can apply what they learned in their teaching practices. This study, therefore, looks at the development of pre-service teachers by tracking their assessment literacy over a prolonged period of the practicum which assists the understanding of pre-service teachers' beliefs and knowledge in testing and assessment. 


\subsubsection{Teacher cognition and teachers' classroom practices}

Previous research has shown that teacher cognition influences teachers' classroom practices (L. Q. Allen, 2002; Andrews, 2003a; S. Borg, 2003; Elbaz, 1983; Woods, 1996). However, the relationship between the two is considered to be highly complex, and neither linear nor causal (Fang, 1996), but rather dialectic (Clark \& Peterson, 1986), symbiotic (Foss \& Kleinsasser, 2001) and interactive (Richardson, 1996). Moreover, it is important to note that teachers' teaching practices do not always reflect their stated beliefs. This is because teaching practices can be influenced by other factors such as context and particular situations and constraints (S. Borg, 2003).

In the context of this present study, during a practicum, pre-service teachers are supposed to follow their mentors' advice and instructions. Thus, when tracing their assessment practices to illustrate pre-service teachers' development in assessment literacy, this study employed different research techniques such as interviews, observations, and stimulated recalls to triangulate whether the pre-service teachers' assessment practices truly reflected their beliefs and knowledge in testing and assessment.

\subsubsection{Previous studies on pre-service teacher cognition}

S. Borg $(2006,2012)$ observed that language teacher cognition research has burgeoned recently and has covered different themes. Moreover, S. Borg (2003) identified a set of interrelated factors that can affect teacher cognition such as prior learning experience, professional coursework, classroom practices, and contexts. Also, it can be seen in his review that previous studies put more weight on teacher cognition in grammar teaching than other areas. Also, the influence of contextual factors on teacher cognition has not been much investigated. See S. Borg (2003) for a review of previous research on the impacts of these factors on teacher cognition.

As this study looks at pre-service teachers' assessment literacy development, only studies related to pre-service teacher cognition are reviewed in this section. This section groups the previous studies on pre-service teacher cognition into themes that are relevant to this study including: (1) prior language learning experience and preservice teacher cognition, (2) teacher education programmes and pre-service teacher 
cognition, (3) practicum and pre-service teacher cognition, and (4) pre-service teacher cognition and assessment practices.

\subsubsection{Prior language learning experience and pre-service teacher cognition}

Research has shown that pre-service teachers come into teacher training programmes with a set of beliefs and knowledge in teaching and learning that they developed through the apprenticeship of observation during their school time (Lortie, 1975). It is also noted that these initial beliefs can continue to influence their teaching practice (Cheng, Cheng, \& Tang, 2010). In fact, pre-service teachers' beliefs are reported to be hard to change (e.g., Kagan, 1992; Korthagen \& Kessels, 1999; Pajares, 1992; Peacock, 2001). There have been a number of research studies on the relationship between prior language learning experience and pre-service teacher cognition (Bailey et al., 1996; Farrell, 1999; Johnson, 1994; Macalister, 2012; Numrich, 1996; Urmston, 2003; Warford \& Reeves, 2003).

The review of Zheng ( 2009) and S. Borg (2003) mentioned two studies: Johnson (1994) and Numrich (1996). The first study showed that pre-service teachers' decisions during a practicum were influenced by their images of teachers, materials, activities and classroom organization from their own L2 learning experience. The second study found that novice teachers' positive and negative experiences as learners can influence their choice of specific instructional practices.

Moreover, both reviews Zheng (2009), and S. Borg (2003) shared the same evidence that pre-service teachers' prior beliefs can influence their instructional practices during teacher education as well as throughout their professional lives. This current study also looks at whether pre-service teachers' previous experience with testing and assessment during school time affects their assessment practices.

\subsubsection{Teacher-education programmes and pre-service teacher cognition}

As stated above, pre-service teachers enter teacher education programmes with a set of beliefs about teaching and learning that they got from their observation during school time (Lortie, 1975). However, at the beginning of their teacher education 
programmes, pre-service teachers may not have appropriate, and realistic understandings of teaching and learning (Brookhart \& Freeman, 1992). A rich body of research has been undertaken about the influence of teacher-education programmes on pre-service teacher cognition (e.g., Bodur, 2012; M. Borg, 2005; Busch, 2010; Curtiss \& Nistler, 1998; Peacock, 2001; Richards, Ho, \& Giblin, 1996)

There is controversy about whether teacher education can significantly influence teacher cognition or not. A review by Kagan (1992) suggested that the relationship is not significant. However, S. Borg (2003) presented evidence to show that teacher education influenced teacher candidates' cognition and this influence varied across studies and even among the trainees in the same study.

This information is important to the current study because it is interesting to know whether training in testing and assessment courses can help pre-service EFL teachers improve their assessment literacy and whether the participating pre-service EFL teachers would differ in the way they learn about testing and assessment.

\subsubsection{Practicum and pre-service teacher cognition}

In order to link theory to practice, the role of the practicum in teacher education is very important and it can be considered to be central to education reform (Beck \& Kosnik, 2002; Ewell, 2004; Schulz, 2005). The practicum provides pre-service teachers with opportunities to apply what they learned from training courses into the reality of the classroom and develop their experiential knowledge as this can only be achieved through reflection upon teaching experience (Wallace, 1991).

However, research has shown a number of challenges that pre-service teachers have to deal with during a practicum. First, power struggles are a common issue in a practicum (Doppen, 2007; Graham, 1997; Weaver \& Stanulis, 1996). For example, pre-service teachers have to learn how to negotiate the relationship with their supervisors and university supervisors. Second, school mentors' lack of efficacy has been reported to be a difficulty for pre-service teachers (Hudson, 2005). Third, a practicum can offer limited opportunities for pre-service teachers to apply what they learned (Ajayi \& Lee, 2005; Dunn, Ehrich, Mylonas, \& Hansford, 2000). Last, they 
can have lack of support during their practicum (Farrell, 2001, 2008). These challenges can have a great impact on the quality of a practicum.

Several studies have been done to track pre-service teacher cognition development during a practicum (e.g., Farrell, 2007; Gao \& Benson, 2012; Johnson, 1994; Macalister, 2012; Nguyen \& Hudson, 2010; Numrich, 1996). Two main findings of these studies can be grouped into two themes: (1) pre-service teachers' previous experience with language teaching and learning can influence their instructional practices during their practicum, and (2) the practicum has a significant impact on pre-service teacher cognition.

Geographically these studies were done in different countries and various settings. In Vietnam, most of the previous studies on teacher cognition targeted in-service teachers (for example, Le, 2011; G. V. Nguyen, 2013; T. S. Nguyen, 2013). To date, there is still limited knowledge about Vietnamese pre-service teacher cognition. The study of Nguyen and Hudson (2010) was among the very first studies to look at Vietnamese pre-service teachers' beliefs and their writing practices during a practicum. There is a need for more research into the Vietnamese context as contextual issues are important to pre-service teacher cognition (S. Borg, 2003). This current study fills the gap in the literature about Vietnamese pre-service teacher cognition in testing and assessment. It looks at how pre-service EFL teachers develop their assessment literacy during teacher preparation programmes.

\subsubsection{Pre-service teacher cognition and assessment practices}

Although there is a body of research looking at teacher cognition and classroom practices, Yin (2010) pointed out a lack of research on teacher cognition and their assessment practices. He argued that if teachers' cognition can influence their classroom practices, then the same thing can happen to their assessment practices. In his study, Yin (2010) found that teachers' cognition in assessment practices can be grouped into: strategic cognitions and interactive cognitions. He listed several factors influencing the two participating teachers' cognition in assessment practices including: their beliefs about language learning, class parameters (class size and class 
timing), course syllabus, summative assessment, and their understanding of assessment principles.

Some previous studies have examined language teachers' assessment practices (e.g., Daniel \& King, 1998; Davison, 2004; Hill \& McNamara, 2011; Rea-Dickins, 2001; Yin, 2010). In her study, Davison (2004) examined assessment practices of English teachers in Australia and Hong Kong and found that contextual differences between teachers in the two countries led to differences in their interpretation of criteria for a written test and in using these criteria for their scoring decisions. Moreover, she observed that a lack of professional development in assessment might have led to the greater individual variation between teachers in Hong Kong.

There have been several studies that have looked into the area of pre-service teachers' cognition and their assessment practices in general education (e.g., Eyers, 2014; Ogan-Bekiroglu, 2009; C. S. White, Sturtevant, \& Dunlap, 2002). However, there has been little research in this area in the language testing and assessment field. This current study addresses this gap by looking into Vietnamese pre-service EFL teachers' cognition and their assessment practices.

\subsection{Third generation Activity theory}

As stated in Chapter 1, this study employs third generation Activity theory as the theoretical framework to account for the development of Vietnamese pre-service EFL teachers' assessment literacy. This part first provides an overview of the development of third generation Activity theory. Moreover, it presents the reasons for choosing this theory as the theoretical framework to examine pre-service EFL teachers' assessment literacy in this study.

Activity theory has its origins in Kant, Hegel, Marx and Engels, and the Soviet Russian socio-cultural psychology of Vygotsky, Leont'ev, Luria and Ilyenkow. It explains how sociocultural historical contexts influence and shape human activity. In educational research, Activity theory has received increasing attention and has been widely used to examine the way sociocultural, and historical factors can influence students' learning and teachers' teaching. In this study, third generation Activity 
theory is employed to examine the contradictions within activity systems of developing pre-service EFL teachers' assessment literacy in Vietnam.

Third generation Activity theory was developed from its earlier generations. First generation Activity theory was based largely on Vygotsky's concept of meditation. According to Vygotsky and Cole (1978), human cognition and activity are driven by mediational tools and are object-oriented. The triangle in Figure 3-6 represents Vygotsky's concept of mediation which includes subject, mediational means and object in first generation Activity theory. In this triangle, the subject is the person or the group who carries out the activity, the object refers to the target of the activity, and the mediational tools are the instruments the subject uses to achieve the outcomes.

\section{Figure 3-6: First generation Activity theory}

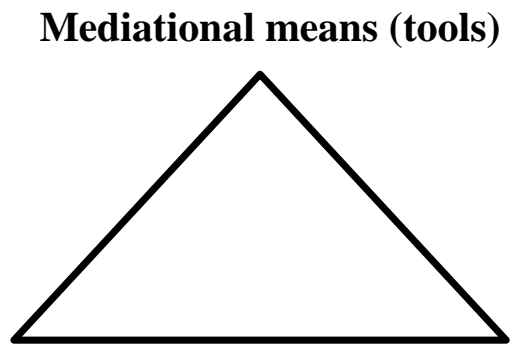

Subjects

Object/ Motive Outcomes

However, Engeström (1987) and Wells (1999) argued that first generation Activity theory mainly focuses on individuals and cannot take into account the dynamic and collective nature of the activities. According to Engeström (1999), human activity is more complex and involves more than the interactions among subject, object and mediational tools as in first generation Activity theory. To address this problem, Engeström (1987), inspired by Leontiev and others, expanded first generation Activity theory by adding the interaction among rules, community and division of labour to represent the social/ collective elements of the activity system. This triangle, represented by Figure 3-7, is called second generation Activity theory. 


\section{Figure 3-7: Second generation Activity theory}

\section{MEDIATIONAL TOOL(S)/ARTIFACT(S)}

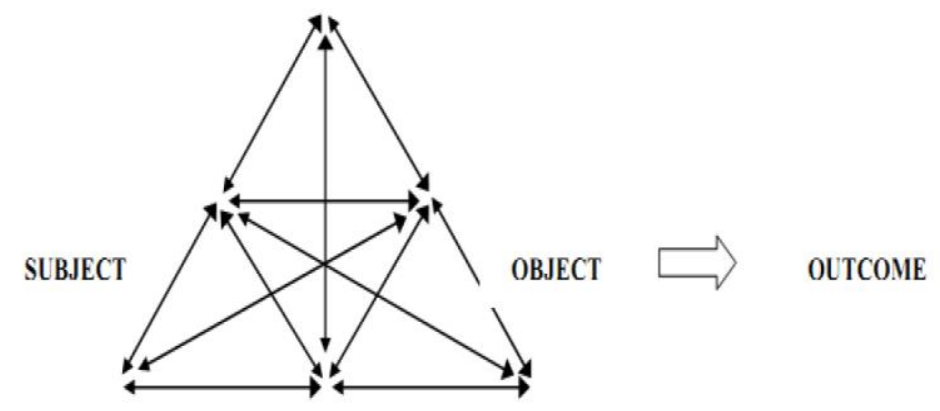

COMMUNITY

RULES

DIVISION OF LABOR

Engeström (1999) shifts the focus from the individual in first generation Activity theory to the joint activity and practice as the unit of analysis in second generation Activity theory. Moreover, as he views the importance of social transformations and the complexity of human activity in which instability, and contradiction are the "motive force of change and development" (Engeström, 1999, p.9), he continues to develop third generation Activity theory as a conceptual tool "to understand dialogue, multiple perspectives, and networks of interacting activity systems" (Engeström, 2005, p. 62).

According to Engeström (1999), there are five principles of Activity theory including 1) the unit of analysis, 2) the 'multi-voiceness' of the activity systems, 3) the historicity, 4) the central role of contradictions as sources of change and development, 5) the possibility of expansive transformations in activity systems. Third generation Activity theory uses a joint activity system, which includes at least two interacting activity systems as the unit of analysis as shown in Figure 3-8. Each componential activity system includes subject, tools/ artifacts, object, rules, division of labour and community. Moreover, an activity system always involves multiple points of view, tradition and interest. The division of labour creates different positions for the participants in the activity systems. Also, third generation Activity theory views contradictions as fundamental to understanding both what motivates certain action in activity system and the general evolution of the activity system. When a new element 
is adopted in the activity systems, it can create contradictions as the new element can collide with an old element in the systems. In other words, contradictions are considered as the drivers of change/development in the activity system.

In this study, pre-service EFL teachers, teacher trainers, and school mentors are the subjects in the joint activity systems. In order to improve their assessment literacy, pre-service EFL teachers have to interact with teacher trainers, school mentors, and their peers to learn how to conduct testing and assessment. To introduce new knowledge and skills of testing and assessment to the subjects in the joint activity systems, there will be contradictions that emerge in this process. This study uses third generation Activity theory to look at the contradictions between and within the activity systems to understand the motive for changes of pre-service EFL teachers' assessment literacy and how to improve their assessment literacy in the context of Vietnam. This framework also guides the analysis of pre-service EFL teachers' activities when they learn to develop their assessment literacy.

\section{Figure 3-8: Third generation Activity theory}

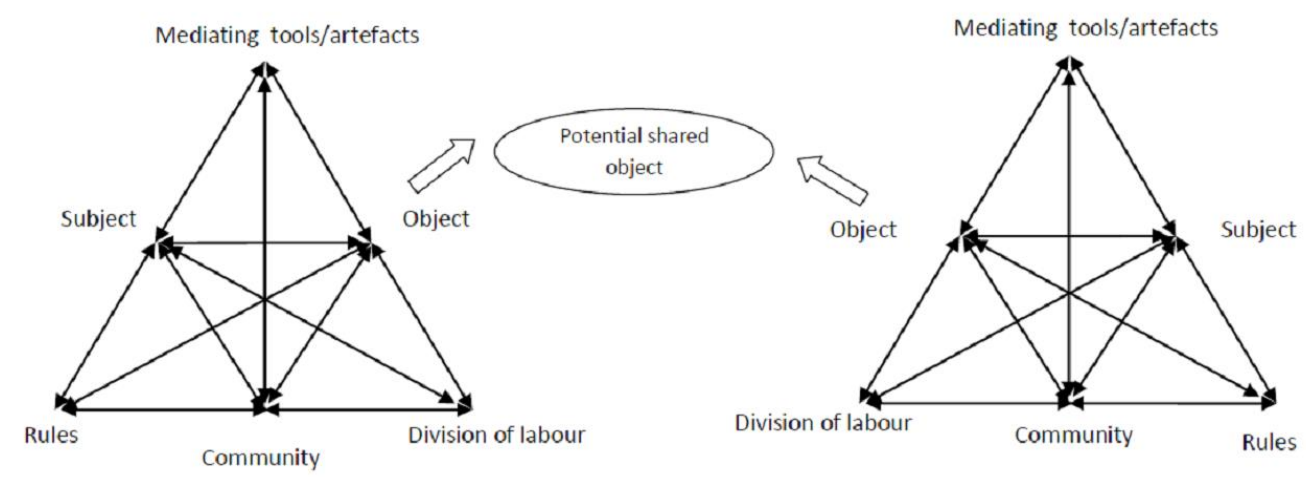

In this study, Figure 3-9 and Figure 3-10 illustrate the activity systems of the interactions among the subjects involved in pre-service EFL teachers' development of assessment literacy. 


\section{Figure 3-9: Joint activity system of pre-service EFL teachers and teacher trainers}

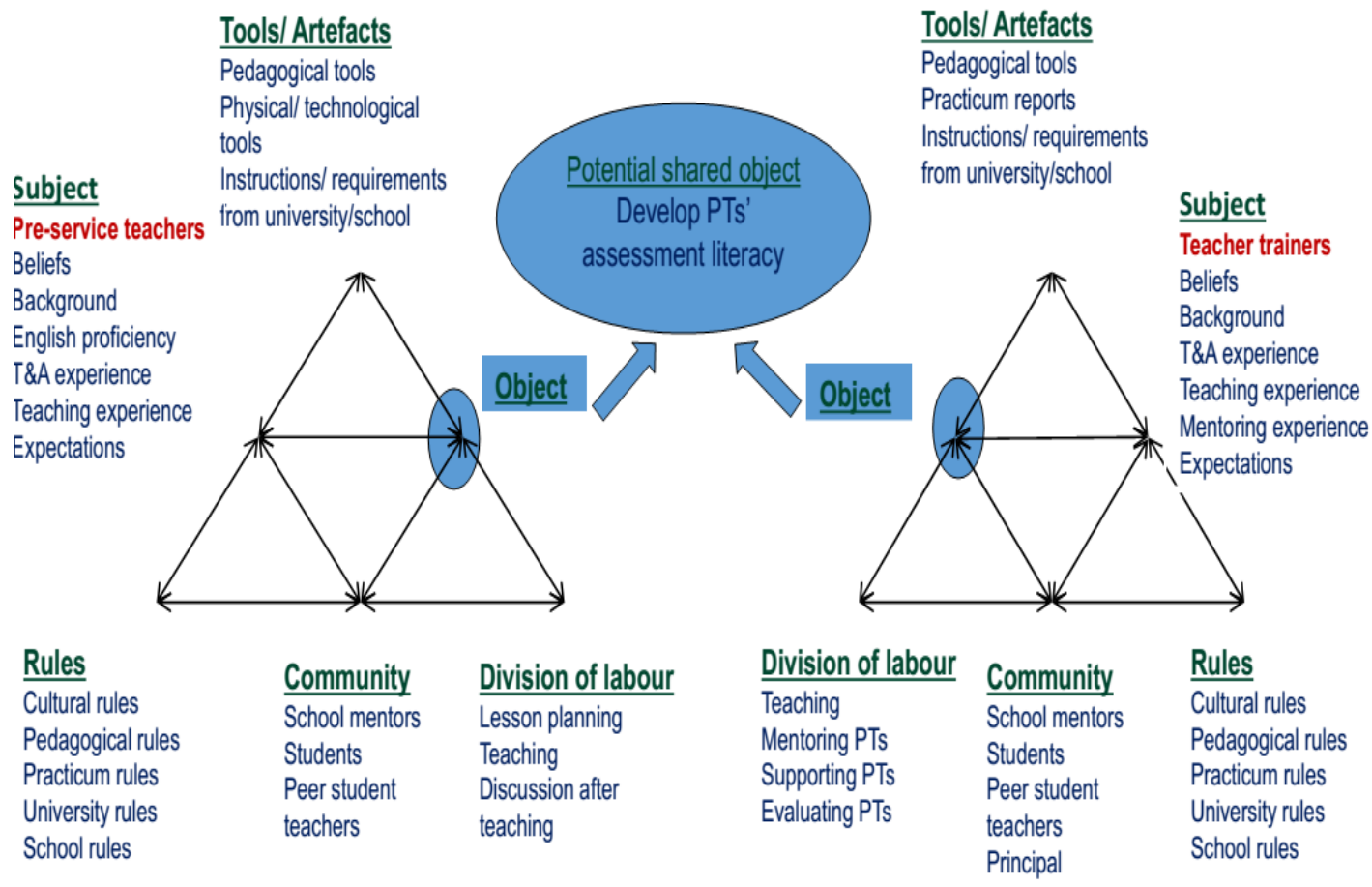

Figure 3-10: Joint activity system of pre-service EFL teachers and school mentors

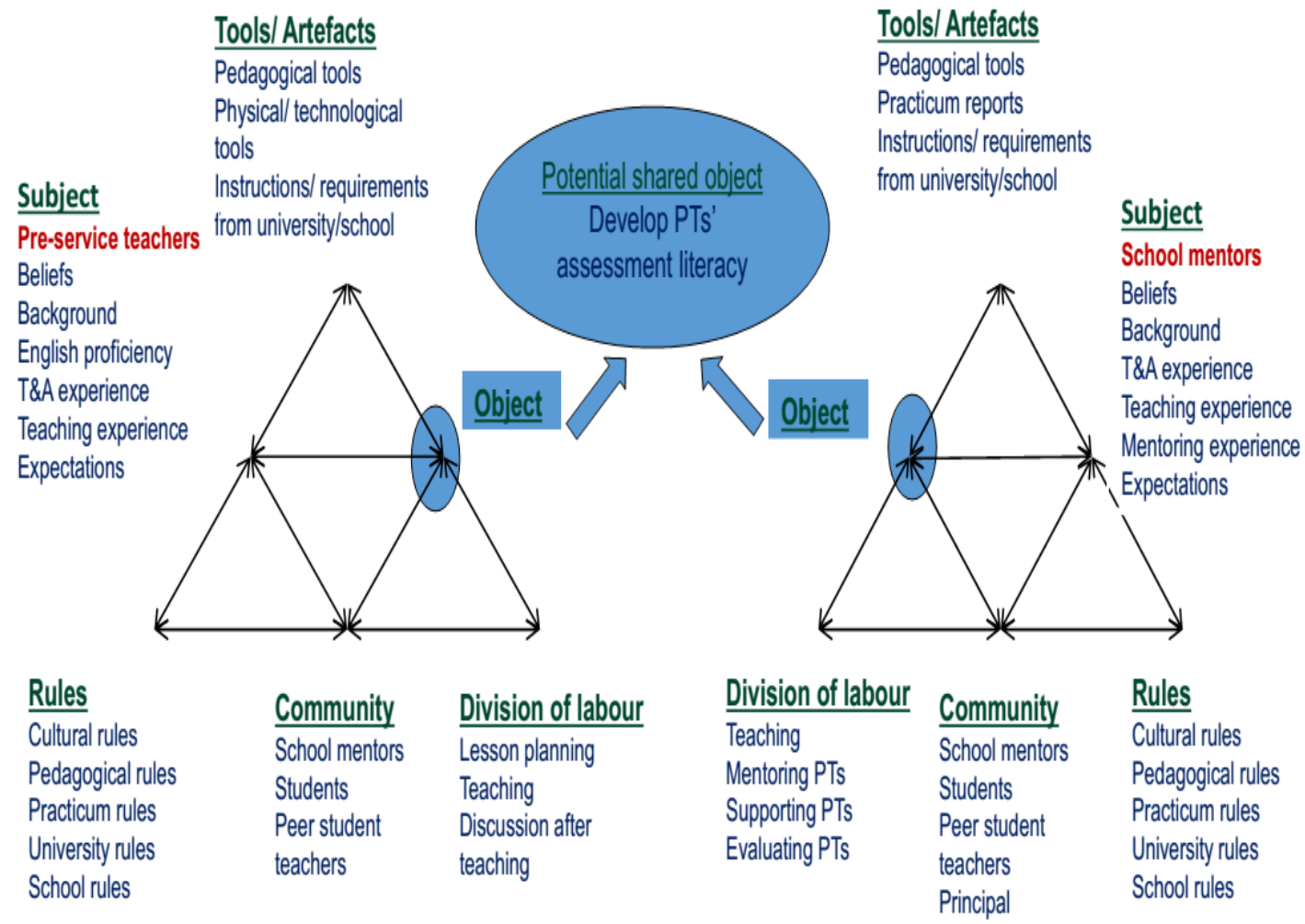




\subsection{Summary}

This chapter has reviewed a range of relevant literature on assessment, assessment literacy, and teacher cognition to inform and develop this current study. The review has shown five main points that motivate this current study.

$\checkmark$ First, despite the importance of assessment literacy, language testing and assessment witnesses a lack of research into this area. There has been little research to examine how pre-service teachers develop their assessment literacy.

$\checkmark$ Second, there is a pressing need for more research into assessment training for pre-service EFL teachers. Only a few studies to date look into language testing and assessment courses in teacher preparation programmes. Research into how language testing and assessment are taught in different settings and contexts should be recommended.

$\checkmark$ Third, methodologically, previous research has relied on the survey approach and a test of assessment literacy to measure assessment literacy. There has been a lack of research looking at the complexity of assessment literacy using different tools such as observation, stimulated recalls and interviews.

$\checkmark$ Fourth, the instruments developed in most previous studies did not pay adequate attention to classroom assessment, particularly assessment for learning.

$\checkmark$ Fifth, little knowledge has been gained about how pre-service EFL teachers learn about assessment and how they improve their assessment literacy. Moreover, in the area of teacher cognition, not much research has been conducted on the relationship between teacher cognition and their assessment practices.

To address the gaps in the literature, this study is conducted in three phases: 1) Phase 1 investigates language testing and assessment courses for pre-service EFL teachers, 2) Phase 2 examines their assessment literacy confidence levels, and 3) Phase 3 traces the development of a group of pre-service teachers' assessment literacy during a practicum. The outline of the study is summarized in Figure 3-11. 
Figure 3-11: Outline of the study

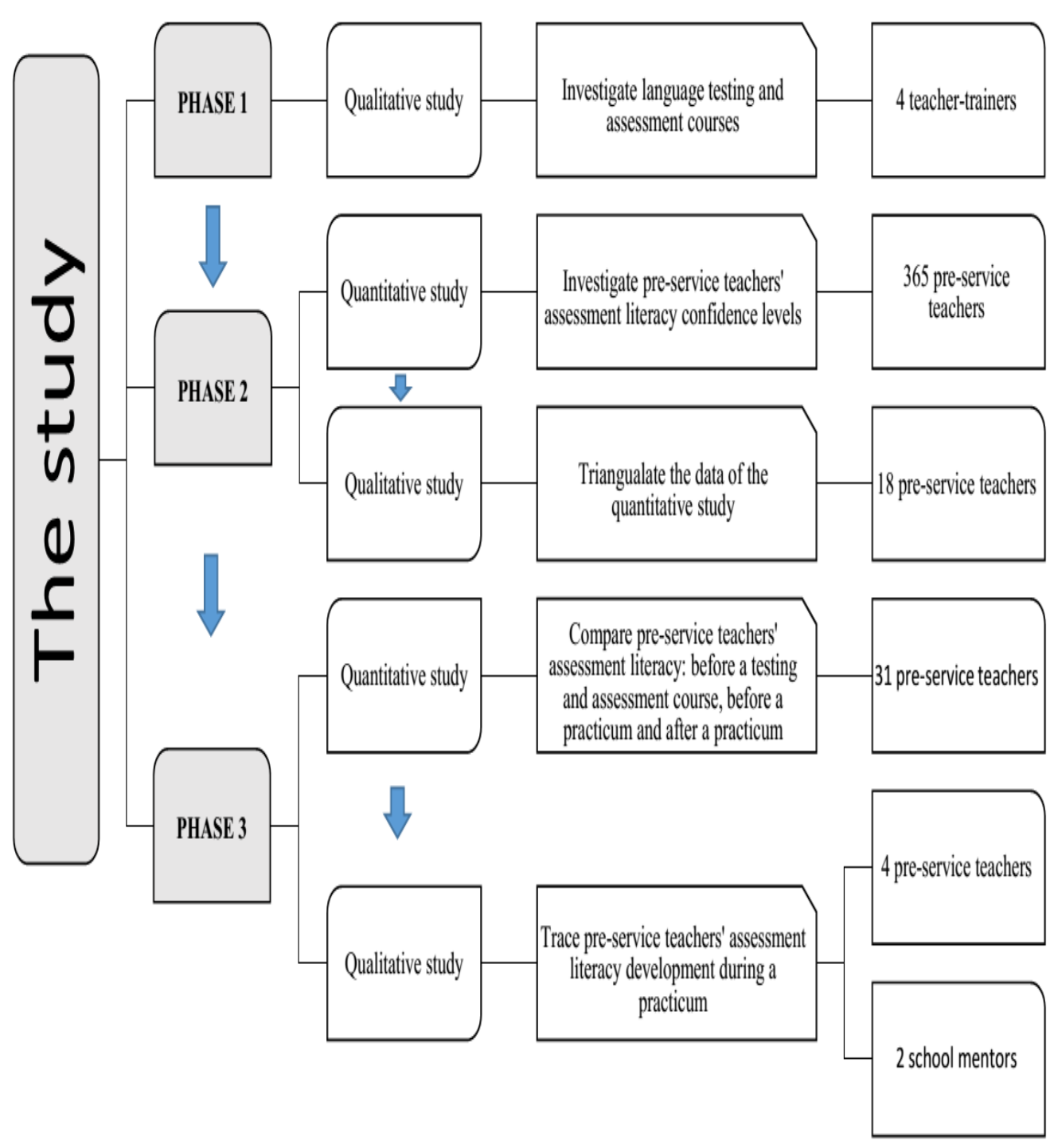

The next chapter (Chapter 4) details the research methodology used in Phase 1 of this PhD study. 


\section{Chapter 4:}

PHASE 1 - LANGUAGE TESTING AND ASSESSMENT COURSES

Research Methodology

\subsection{Introduction}

Language testing and assessment training is important for the development of preservice EFL teachers' assessment literacy. In order to help Vietnamese pre-service EFL teachers improve their assessment literacy, it is necessary to be informed about the current language testing and assessment training for them. Therefore, Phase 1 investigates language testing and assessment courses at four key teacher-training universities in Vietnam including Bach Dang University, Chi Lang University, Do Cong University and En Bac University. The universities' names are pseudonyms for ethical reasons

This chapter describes the research methodology for Phase 1. It starts with an overview of Phase 1 and the research questions. Then it gives a description of the research participants and the research instruments. Next, it presents the research procedures which are followed by a discussion of the research quality criteria, the limitations and the ethical issues. Finally, the key points of the chapter are summarised.

\subsection{Overview of Phase 1}

Phase 1 looks at language testing and assessment training at four Vietnamese teachertraining universities including Bach Dang University, Chi Lang University, Do Cong University and En Bac University. Figure 4-1 below gives an overview of Phase 1. The details of the research methodology are presented below. 


\section{Figure 4-1: Overview of Phase 1}

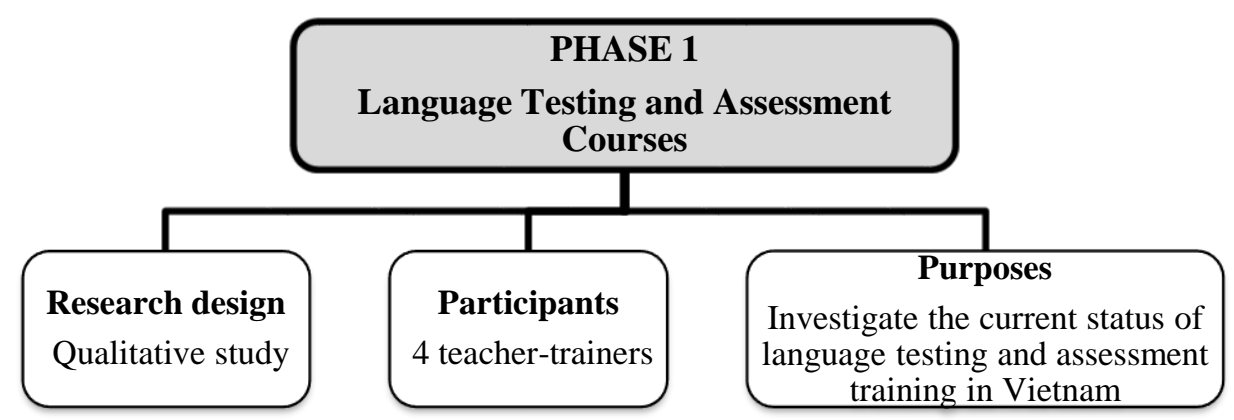

\section{3. $\quad$ Research questions}

In order to understand the current status of language testing and assessment training in Vietnam, Phase 1 asked the following research questions:

1. What are the teacher-trainers' backgrounds in language testing and assessment?

2. What are the topics covered in language testing and assessment courses? Why are these topics chosen? Are the teacher-trainers satisfied with the course materials/content?

3. What are the methods of instruction in language assessment courses? Why are these methods chosen? Are the teacher-trainers satisfied with the methods of instruction?

4. What is the level of support that the teacher-trainers have received for testing and assessment training?

5. Is testing and assessment a part of the practicum requirements?

6. According to the teacher trainers, what are the students' attitudes and perceptions about language testing and assessment training at their university?

7. What are the constraints of language testing and assessment training in their context?

\subsection{Research participants}

Bach Dang University, Chi Lang University, Do Cong University, and En Bac University were selected for this study because of their significant influence on language teacher education in Vietnam. At each university, one teacher-trainer was 
chosen based on their experience in language testing and assessment training and their willingness to participate in the study. Ms Quy and Mr Vinh were the teachertrainers at the two teacher training universities without a separate course in language testing and assessment while Ms Hang and Ms Yen were from the two universities with a separate course of language testing and assessment.

Among the four teacher-trainers, two gained their Master's degrees overseas while the others had finished their degrees in Vietnam. At the time of the study, they all had many years of teaching experience $(M=13.25, S D=5.25)$ and were involved in administrative work and course design at their universities.

\subsection{Research instruments}

In order to select an appropriate research instrument for Phase 1, I began with a review of the tools used in the previous studies which examined language testing and assessment courses. The review shows that surveys have been widely employed to investigate language testing and assessment courses (e.g. Bailey \& Brown, 1996; Brown \& Bailey, 2008; Jin, 2010). Although using a survey is practical in obtaining a large amount of information, it can limit the depth of the participants' answers (Dörnyei, 2010). Therefore, this tool was not chosen for Phase 1 because the main purpose of this phase was to capture the insightful thoughts of the four teachertrainers about language testing and assessment training at their universities.

Instead of employing a survey like in the previous studies, a semi-structured interview was selected as a more appropriate tool for two main reasons. Firstly, a semistructured interview can allow flexibility of interview questions (Patton, 2002). This feature helped to make the interviews between the teacher-trainers and me natural and allowed room for discussion. Secondly, a semi-structured interview can enhance the depth of the participants' answers (Patton, 2002). Due to the flexibility of refining and asking follow-up questions in the semi-structured interviews, I was able to gain insights into language testing and assessment courses.

Apart from the semi-structured interviews, the course outlines were examined so that I could be more informed about the courses. However, only two of the participants 
were able to provide me with the course outlines while the others were not because of the regulations of their universities.

\subsection{Research procedures}

Before the data collection began, I obtained ethics approval from the Human Ethics Committee, Victoria University of Wellington (See Appendix A). After that, I contacted the teacher-trainers to seek their consent to participate in my study. The research procedures are outlined in Figure 4-2 and the details are described as follows.

\section{Figure 4-2: Phase 1's research procedures}

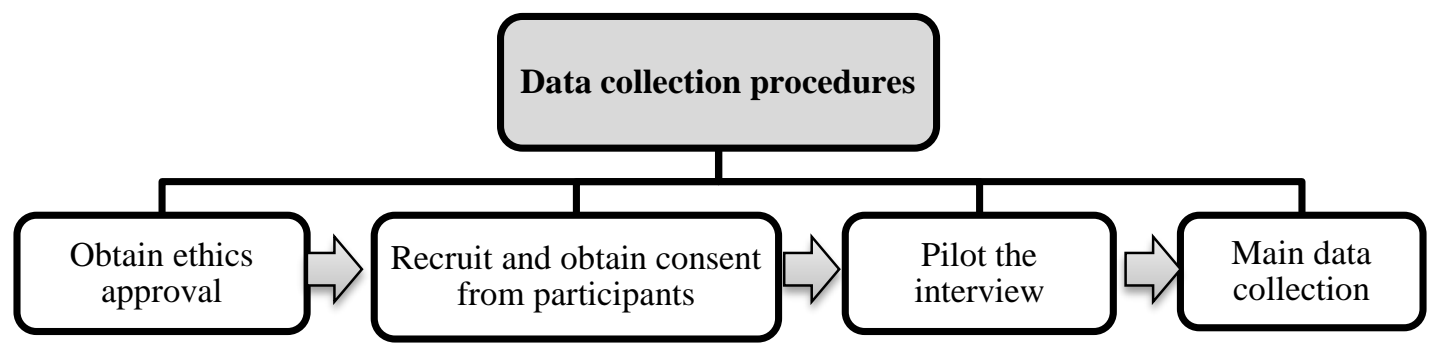

\subsubsection{Piloting}

Before the main data collection, I piloted the interview questions with two Vietnamese teacher-trainers who were familiar with the context of teacher education in Vietnam. I asked them to check if any interview questions were problematic. In general, they found most interview questions clear and meaningful. However, they suggested that some terms, for example, summative assessment and formative assessment, for which equivalent Vietnamese terms would be difficult to find, should be retained in English to avoid potential misunderstandings of the interview questions.

Realizing the language issues in the interview, I then asked for the participants' advice about whether to use Vietnamese or English in the interviews. Despite their English fluency, they advised me to use Vietnamese because they believed that using their mother-tongue in the interviews could help them express their ideas more meaningfully and comfortably. I used their comments for a further revision of the interview questions. 


\subsubsection{Main data collection}

I contacted the teacher-trainers to ask for their voluntary participation in this study. After receiving their consent, I scheduled the interviews at a convenient time and venue for them because each teacher-trainer was from a different university.

I conducted the interviews face-to-face and individually. At the interviews, I gave each participant an information sheet and a consent form. I then described the research purposes clearly to them, and responded to their questions and concerns. The interviews only began when the participants had agreed to sign the consent forms. Each interview lasted about forty-five minutes and was conducted in Vietnamese. All the interviews were audio-recorded for data transcription and data analysis.

\subsubsection{Data analysis}

"Qualitative analysis transforms data into findings. No formula exists for that transformation. Guidance, yes. But no recipe" (Patton, 2002, p. 432). Even though there is no exact formula for data analysis (Patton, 2002), most researchers agree that the data analysis process is an ongoing and iterative process which starts right from the early stages of data collection (Creswell, 2013; Mauthner \& Doucet, 2003; Miles \& Huberman, 1994). In addition, during the data analysis process, Green and Thorogood (2004) noted that different approaches can be used to find answers to the research questions. W. P. Vogt (2014) suggested two main questions that should be considered during this process including what methods of analysis should be used and what kinds of data interpretation problems might be encountered.

Taking the above issues into consideration, both inductive and deductive content analysis and Creswell's (2013) procedures were adapted in my data analysis. Although this analysis process is presented as a linear hierarchical approach, it is an interactive process in practice with various interrelated stages (Creswell, 2013). The outline and the details of this process are described below. 


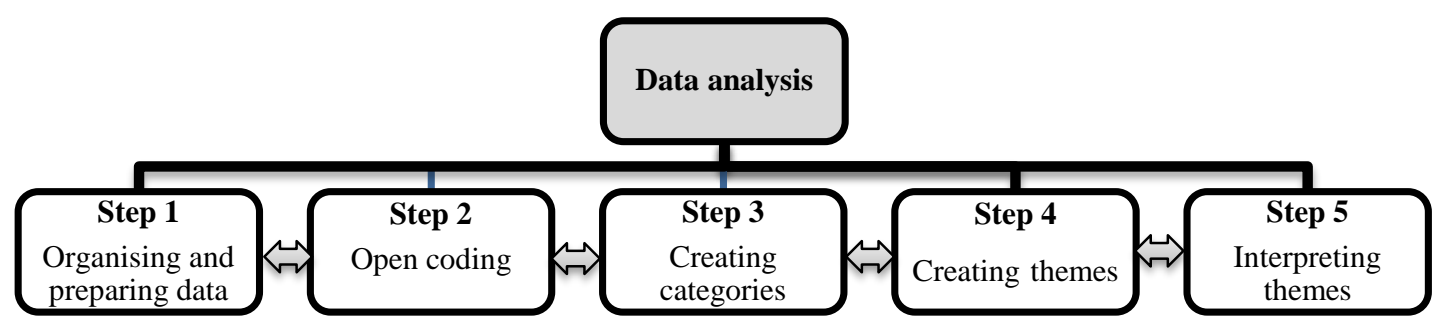

\section{- Step 1: Organising and preparing the data}

The data analysis process usually starts with a step which is called "data organization and preparation" (Creswell, 2013; Flick, 2009), or "data familiarization” (Braun \& Clarke, 2006), or "data overview" (Bradley, Curry, \& Devers, 2007). This step allowed me to work intensively with the interviews while repeatedly examining the interviews, transcribing them and reading their transcripts to get initial data codes. In this step, I first transcribed all the recorded interviews carefully using Microsoft Word. While I repeatedly listened to the interviews to be familiar with the data, I thoroughly checked the transcripts' accuracy. In addition, to ensure their trustworthiness and authenticity, I conducted member check (also known as respondent validation or informant feedback) (W.P. Vogt, 2014) when I emailed the interviewees the transcripts and asked them to check if they needed to adjust their answers. Among the four participants, only one required changes to the language used in her answers. This was because she wanted to use more formal language, rather than the conversational style in the interview. However, this language change did not affect the content of the answers. The transcripts were kept in Vietnamese for analysis with the assistance of NVivo 9 software (Bazeley \& Jackson, 2013).

\section{- Step 2: Open coding}

I then imported all the transcripts in NVivo 9 for coding. I decided to use computer assistance because it has been widely perceived as an effective tool to ensure the rigour of the analysis process (Bazeley \& Jackson, 2013). Using NVivo 9, I did open coding by reading the transcripts line by line and assigning codes to particular segments of words, sentences and paragraphs that represented a meaning. 
- Step 3: Creating categories

After the open coding, I carefully read the codes again and grouped them into meaningful categories. For example, the codes: an inadequate policy in testing and assessment, mismatch between teaching methodologies and testing and assessment can be grouped into a parent category - the lack of systematic innovation in language testing and assessment. This step can be related to axial coding when I identified the relationships among the open codes. The process of creating categories was sometimes done concurrently with the open coding. During this process, I also referred to the main focus of the interviews including: teacher trainer background, the current status of language testing and assessment courses, students' perceptions/attitudes of the courses, the constraints of language testing and assessment training. With the assistance of NVivo 9, I classified all the codes into tree nodes.

\section{- Step 4: Creating themes}

Holliday (2007) pointed out that "the themes themselves, although emergent, are also influenced by questions or issues that the researcher brought to research" (p. 97). This is true in this study when I referred to the research questions and the focus of this study to identify the categories and group them into major themes to answer the research questions. Table 4-1 below summarises the coding scheme.

\section{- Step 5: Interpreting the themes}

Once the previous steps had been concluded, all the themes were identified. Then I tried to make sense of the themes in order to find the answers to the research questions. The main themes and categories are summarised in Table 4-1 below. 
Table 4-1: Coding scheme of Phase 1

\begin{tabular}{|c|c|}
\hline Themes & Categories \\
\hline $\begin{array}{l}\text { Teacher-trainer } \\
\text { background }\end{array}$ & $\begin{array}{ll}\text { - } & \text { Qualifications } \\
\text { - } & \text { Teaching experience } \\
\text { - } & \text { Dissatisfaction with their knowledge and skills in language testing and } \\
\text { assessment } \\
\text { - } & \text { Need for more formal training in testing and assessment } \\
\end{array}$ \\
\hline $\begin{array}{l}\text { Current status of } \\
\text { language testing and } \\
\text { assessment courses }\end{array}$ & $\begin{array}{l}\text { - Course content } \\
\checkmark \text { Summative assessment as the main focus } \\
\checkmark \text { Reasons for determining course materials } \\
\checkmark \text { Teacher-trainers' dissatisfaction with the current content of } \\
\text { teaching } \\
\text { - Methods of instruction } \\
\checkmark \quad \text { Reasons for choosing method of instruction } \\
\checkmark \quad \text { Teacher-trainers' satisfaction with their methods of instruction } \\
\text { - Support for testing and assessment training } \\
\text { Testing and assessment in practicum } \\
\checkmark \text { Lack of testing and assessment training in practicum } \\
\checkmark \text { The role of school mentors in testing and assessment training in } \\
\end{array}$ \\
\hline $\begin{array}{l}\text { Students' perception } \\
\text { and attitudes toward } \\
\text { testing and } \\
\text { assessment training }\end{array}$ & $\begin{array}{l}\text { - The importance of the course } \\
\text { - } \quad \text { Students' interest in the course }\end{array}$ \\
\hline $\begin{array}{l}\text { Constraints of } \\
\text { language testing and } \\
\text { assessment training }\end{array}$ & $\begin{array}{l}\text { - Lack of systematic innovation in language testing and assessment } \\
\text { training } \\
\text { - Lack of labour, facilities and time frames for language testing and } \\
\text { assessment training }\end{array}$ \\
\hline
\end{tabular}

\subsection{Problems with data analysis and interpretation}

As a teacher-trainer in Vietnam, it was not difficult for me to gain access to the research sites and to build trust with the participants. This helped the interviews between the participants and me become more natural and informative. However, my in-depth knowledge of the context, and my familiarity with the participants could bring about biases and inaccuracies during the process of data analysis and interpretation despite my attempt to take an 'outsider's' perspective during this whole process.

In order to limit the possible biases and my influences during data collection and data analysis, I followed the following strategies suggested by Patton (2002):

I tried to enhance trust with the participants to maximise the honesty of their answers. Before the interview, I carefully explained to them the importance of their answers to the research findings. 
I consulted closely with my supervisors to avoid the influences of my feelings on my data analysis and interpretation.

$\checkmark \quad$ I discussed the summary of the findings with the participants after I finished the data collection.

$\checkmark$ I thoroughly checked the accuracy of my translation of the transcripts. Moreover, I asked for help from one of my colleagues, who was fluent in English, to review my translation.

$\checkmark$ In order to control the quality of the coding process, I also performed intercoder reliability which is recommended as a common methodological requirement in content analysis and qualitative research (Krippendorff, 2011). According to Patton (2002), kappa and percentage agreement are two common criteria for checking inter-rater reliability. With the assistance of NVivo 9 software, I first coded one interview and then trained another coder to use NVivo 9 to code the same data with the given coding scheme. Next, I used NVivo 9 to run an inter-coder reliability check. After that, I calculated the average of Kappa and percentage agreement. The results of Kappa is $(\kappa=.77)$ and percentage agreement 97\%. According to Landis \& Koch (1977), Kappa ranging from .61 to .80 indicates substantial agreement.

\subsection{Ethical issues}

Before I conducted Phase 1, I obtained the approval of the Human Ethics Committee (HEC) of Victoria University of Wellington (Appendix A). Traditionally, ethical concerns involve three main issues including informed consent, right to privacy, and protection from harm (Fontana \& Frey, 2005, p. 715). Different strategies were employed to strictly follow the regulations of the HEC:

The participants were given information sheets and consent forms which described clearly the purposes of the study and their rights. They were also given the right to withdraw from the study at any time during data collection.

$\checkmark$ In order to ensure that all the participants understood the purposes of my study and their rights, they were given a sufficient amount of time to read the information sheets and consent forms. Moreover, any questions about the study as well as their participation in the study were clearly explained. The 
main data collection only took place when the participants agreed to sign the consent forms.

$\checkmark$ To avoid any potential risks that the research may cause to the participants, the confidentiality of their identity was maximized by using pseudonyms during data analysis and reporting. Their data was kept in a safe place and no one was able to gain access to the data except for my supervisors and me.

\subsection{Quality criteria of the research}

As stated earlier in this chapter, unlike most previous studies which used a survey to investigate language testing and assessment courses, Phase 1 used semi-structured interviews. Although this qualitative approach could give me a deeper insight into the language testing and assessment courses, it might be criticized for its lack of objectivity and transparency in data collection and analysis (Bryman, 2008; R. B. Burns, 2000). Moreover, due to "the subjective nature of qualitative data and its origin in single contexts" (R. B. Burns, 2000, p. 13), it is difficult to apply the same conventional standards of reliability and validity of quantitative research to qualitative research.

However, this does not mean that qualitative studies do not attempt to ensure their quality. There are a number of criteria to enhance the trustworthiness of a qualitative study (Patton, 2002). This study relies on the social construction and constructivist criteria proposed by Lincoln and Guba (1986). This taxonomy views "credibility as an analogue to internal validity, transferability as an analogue to external validity, dependability as an analogue to reliability, and confirmability as an analogue to objectivity" (Patton, 2002, p. 546).

\subsubsection{Credibility}

Credibility in qualitative research can be associated with the internal validity in quantitative research (Davis, 1992; Lincoln \& Guba, 1986). While internal validity in quantitative research is usually evaluated by its ability to measure what it is supposed to measure, credibility can be enhanced by ensuring that "findings and interpretations are credible to those being researched" (Davis, 1992, pp. 605-606). Moreover, Davis (1992) emphasized the importance of the participants' trust for the 
researcher, the honesty of their answers, the researcher's grasp of the study's context and culture, and the use of time and methods to triangulate the data in ensuring this quality. In other words, according to Lincoln and Guba (1986), credibility can be enhanced by prolonged engagement, persistent observation, peer debriefing, negative case analysis, member checks and triangulation.

This study used the following strategies suggested by Lincoln and Guba (1986) to enhance its credibility:

\section{$\checkmark$ Member checking}

I sent all the transcripts and the summary of findings to the participants to ensure that they agreed with what they provided in the interviews.

\section{$\checkmark$ Data triangulation}

I examined both the data from the semi-structured interviews and course outlines to be more informed about the testing and assessment training at the four universities.

\section{$\checkmark$ Peer debriefing}

Before the main data collection, I consulted with the two teacher trainers in the pilot study to review the interview questions. Moreover, I sought advice from my supervisors throughout the process of data collection and data analysis.

\section{$\checkmark$ Prolonged engagement}

As a teacher-trainer at tertiary level in Vietnam for eight years before I conducted this study, I have had a long exposure to the context of study which gives me a deep insight into its background. My familiarity with the participants could facilitate the research procedures and help me be more informative about the participants' answers.

\subsubsection{Transferability}

Transferability in qualitative research is related to external validity in quantitative research. In quantitative research, this construct can be achieved when "the findings can be generalised to other contexts or subjects" (Davis, 1992, p. 606). However, qualitative research differs from quantitative research as the nature of qualitative 
research is usually described as context specific and subjective. Therefore, it is difficult to enhance the replicability or generalizability as in qualitative research. Instead, qualitative research attempts to claim its transferability (Lincoln \& Guba, 1986) or relatability (Bassey, 1981).

In order to enhance the transferability of a qualitative study, Lincoln and Guba (1986) suggested researchers provide a rich, and detailed description of the research so that the reader can determine the extent of transferability into their own context and their study. Following this suggestion, I described the context, the participants' profiles, and the data collection and analysis procedure carefully. This detailed description will assist readers to determine which part of my study is relevant for their context and their research.

\subsubsection{Dependability}

Dependability in qualitative studies can be related to reliability in quantitative research which is assured by the use of testing instruments to ensure the results are stable, consistent, and predictable. However, R. B. Burns (2000) argued that "it is impossible to establish reliability in the traditional sense" (p. 475) in qualitative studies. Instead, R. B. Burns (2000) and Davis (1992) recommended that qualitative researchers focus on dependability, the extent to which "the results make sense and are agreed on by all concerned" (R. B., Burns, 2000, p. 475). In order to enhance dependability, different strategies should be followed including triangulation (R. B. Burns, 2000; Davis, 1992), external audit (Lincoln \& Guba, 1986) and the report of any possible biases during data collection and analysis (R. B. Burns, 2000). This study, therefore, took the following steps to enhance its dependability:

$\checkmark$ During data analysis, peer-debriefing was done when I closely consulted with my supervisors, the teacher-trainers and other $\mathrm{PhD}$ fellows. In this study, my supervisors were considered as professionals to help me shape my study and provide continuous feedback about the findings and conclusions of the study. This helped me probe my biases, emotions and feelings that may have emerged in the study (Lincoln \& Guba, 1986). In addition, the possible biases 
during the process of data analysis and interpretation were also carefully reported in Section 4.7 above.

$\checkmark$ Triangulation was done when the course outlines, together with the interviews, served as the data sources to investigate the course.

$\checkmark$ External audit was done when I kept track of my data analysis' procedures and also performed an inter-coder reliability check of my coding. Moreover, the translation of the data was also checked by one of my colleagues who is fluent in English and understands the context of the study.

\subsubsection{Confirmability}

Confirmability in qualitative research can be considered as objectivity in quantitative research (Lincoln \& Guba, 1986; Patton, 2002). However, Patton (2002) argued that it is difficult to enhance real objectivity. He further explained that even in quantitative research, human biases are unavoidable because the research instruments are designed and validated by researchers. Therefore, in qualitative research, he suggested that in order to enhance confirmability, a detailed description of the research method and procedures as well as the potential biases of data collection and data interpretation need to be provided. Following this suggestion, I carefully discussed all the potential biases in Section 4.7 above as well as described the research participants' profiles, context and research procedures.

\subsection{Limitations}

This study has the following limitations:

Due to the limited sample size, the findings cannot be generalised but can only describe the current situation of language testing and assessment training for the pre-service EFL teachers at the four key teacher training universities in Vietnam

$\checkmark$ Moreover, within the time and financial limits, I could not recruit more participants and involve more teacher training universities. Only four teacher training universities took part in this study and only the interviews with the teacher-trainers served as the main data source for investigating the assessment education in teacher preparation programmes. Therefore, this 
study is unable to provide a well-rounded picture of language testing and assessment training in teacher education in Vietnam.

$\checkmark$ In addition, data triangulation was not done properly because I was unable to observe any training classes or interview students about the courses. I only relied on the interviews with the teacher-trainers and the course outlines to be informed about the language testing and assessment courses.

\subsection{Summary}

In summary, this chapter outlines the key issues in the research methodology of Phase 1. It presents the research questions, the research participants and the research instrument. In addition, it details the procedures of Phase 1 in terms of piloting, data collection and data analysis. It also describes the problems of data collection and data analysis. Furthermore, it addresses the ethical issues and concludes with a detailed discussion of the quality criteria pertaining to the study.

The next chapter (Chapter 5) will present the findings and discussion of Phase 1. 


\section{Chapter 5:}

\section{PHASE 1 - LANGUAGE TESTING AND ASSESSMENT COURSES}

\section{Results and Discussion}

\subsection{Introduction}

This chapter presents the findings and the discussion of Phase 1 which looks at the current language testing and assessment courses at the four key teacher training universities in Vietnam. In this chapter, the answers to the research questions are presented respectively. The universities' and the teacher-trainers' names are pseudonyms because of ethical reasons.

\subsection{Teacher-trainers' backgrounds}

At the time of the study, the teacher-trainers involved in this study had at least ten years' experience in training pre-service EFL teachers and had taught testing and assessment for at least three years. Therefore, it can be said that they had an adequate understanding of the current language testing and assessment training environment and practices at their universities.

The semi-structured interviews with each individual teacher-trainer show two main issues regarding their backgrounds in testing and assessment including: the teachertrainers' dissatisfaction with their own knowledge and skills in language testing and assessment, and the teacher-trainers' need for more formal training in testing and assessment. The details of each issue are presented as follows.

\subsubsection{The teacher-trainers' dissatisfaction with their knowledge and skills in language testing and assessment}

The data analysis shows that three teacher-trainers received some training in testing and assessment in their postgraduate study as well as in some professional development workshops while only one teacher-trainer had no formal training in testing and assessment. Ms. Quy shared information about testing and assessment training for the teaching staff of language testing and assessment courses at her university: “The teaching staff obtained Master's Degree at least. Therefore, they all have had training in testing and assessment in their postgraduate programmes". 
Similar to Ms. Quy, Ms. Yen also mentioned that the teacher-trainers at her university had received assessment training in their postgraduate programmes and professional development workshops. She said: "There are only two teacher-trainers, including me, who are in charge of the language testing and assessment course at the moment. We have had some training in our postgraduate programmes and some workshops".

However, for those who had training, they commented that they had only learned very basic testing and assessment theory and skills. This is evident in Ms. Yen's summary about what she had learned:

When I studied about testing and assessment in a programme of SEAMEO, I was introduced to test qualities including validity, reliability, practicality and then a checklist for test validation. Then they taught me how to write test items. All I studied from this programme is very practical. But that is all I have learned about testing and assessment.

From Ms. Yen's comment above, it can be seen that assessment for learning had received inadequate attention in her professional development. Instead, the focus had been placed on test validation and how to write test items. Due to the inadequate formal training, none of the participants felt well-prepared for the demands of their teaching. This led to their dissatisfaction with their current knowledge and skills of testing and assessment. Ms. Hang, who did not have any training in this area, expressed her difficulties:

I do not have any formal training in language testing and assessment. I have to selfstudy from books, online resources and experiences, and from the other lecturers. Although I can self-study, I find it is sometimes very difficult to understand some theories in testing and assessment without formal training.

It is obvious that testing and assessment knowledge and skills are complex and difficult to self-study. It is important that teacher-trainers are given opportunities to keep updated with new trends in testing and assessment in professional development programmes. Without adequate training, teacher-trainers can hardly meet the demand of their training. This is evident in Ms. Yen's concern about her lack of confidence in supervising her students' research in language testing and assessment as well as 
explaining the advanced theories of testing and assessment to her students. Ms. Yen said:

With our current knowledge of testing and assessment, we can only help pre-service EFL teachers with the basic knowledge and needs in language testing and assessment. If we want to explain language testing and assessment theories further to pre-service EFL teachers or help them do research in language testing and assessment, we really need further training in language testing and assessment.

In summary, all the four teacher-trainers were unsatisfied with their current knowledge and skills of testing and assessment. This dissatisfaction mainly resulted from their inadequate formal training in testing and assessment. Therefore, they expressed their need for more formal training in testing and assessment.

\subsubsection{Teacher-trainers' need for more formal language testing and assessment training}

Due to their dissatisfaction with their current assessment literacy, the teacher-trainers expressed their wish to improve their knowledge of this area. The four teachertrainers agreed that it would be difficult for them to improve the quality of their courses if they did not have adequate formal training in testing and assessment. This is evident in Ms. Hang's statement: "If we have a formal training in language testing and assessment, we can understand more deeply about the testing theories, terminology, and other issues. When we have to self-study, we meet some certain difficulties".

Ms. Quy also shared her concern: "To improve the quality of the course, it is necessary that teacher-trainers are updated with the current knowledge in testing and assessment. More formal training should be offered to those who teach the course".

All the teacher-trainers were in need of more formal training in testing and assessment. They believed that this would help them improve the quality of their testing and assessment training for pre-service teachers at their universities. Teachertrainers' professional development in testing and assessment is also the concern of many experts (for example, Bachman, 2000; Brookhart, 2011; Stiggins, 1991b, 1995). This is because "the majority of practitioners who develop and use language 
tests, both in language classroom and as part of applied linguistics research, still do so with little or no professional training" (Bachman, 2000, pp. 19-20).

\subsection{The current status of language testing and assessment courses}

At the time of this study, according to the teacher-trainers, language testing and assessment training had recently been introduced into their programmes. Among the four universities, only two had a separate language testing and assessment course which accounted for about thirty or forty-five periods (each period lasts forty-five minutes). The other two universities took just five to ten periods of their teaching methodology courses for teaching language testing and assessment.

Due to the regulations of their universities, the teacher-trainers at two universities were not able to provide the course outlines. However, the interviews revealed the current status of language testing and assessment courses in terms of the course content, the course teaching methodology, students' perception and attitudes about the course and the constraints of this training as presented in the following sections.

\subsubsection{Course content}

\subsubsection{Summative assessment as the main focus in the training programmes}

At the time of the study, all the four teacher-trainers agreed that there was an imbalance between summative assessment and formative assessment training in their programmes. This is clearly illustrated in the description of the course content by Ms. Yen:

The curriculum has thirty periods for the language testing and assessment course. The first content in this course is the introduction of the key terms and definitions so that pre-service EFL teachers can have some basic knowledge about testing assessment, summative assessment, and formative assessment. Then they will learn about the qualities of a good test. I divide testing in one section and assessment in another section of the course but I focus more on testing including the qualities of a good test, test evaluation, then how to write a test. In test design, I provide them with different test items and teach them how to write test instructions. Finally, I teach them about test administration. 
As can be seen from Ms. Yen's comment, assessment training for pre-service EFL teachers gives more attention to the role of summative assessment. The teachertrainers explained that they focused more on teaching their students about summative assessment because it was more important for their students' future jobs. Ms. Quy commented:

There is some feedback from pre-service EFL teachers that summative assessment is more emphasised in real-life contexts. Even though teachers do not have a lot of power in designing the high-stake tests, they need to learn about summative assessment in order to choose the right test, design 15-minutes tests, one-hour tests.

This finding is similar to what many experts (Bailey \& Brown, 1996; Brown \& Bailey, 2008; Jin, 2010; Stiggins, 2002) were concerned about regarding the dominance of summative assessment over formative assessment in education systems. Although psychometrics and summative assessment are important to preservice EFL teachers, they should also be introduced to other new trends and methods of testing and assessment. When pre-service EFL teachers understand about different methods of testing and assessment, it is much easier for them to identify which assessment is more suitable for their teaching purposes.

\subsubsection{Reasons for determining the course materials}

Among the four universities, one university uses one main course textbook while the others combined their course materials from different sources. Two teacher-trainers were unable to provide me with the course materials due to the regulations of their universities. Therefore, I had insufficient evidence to compare the similarities and differences in the training materials among the four universities. However, in the interviews, the teacher trainers revealed three main reasons for choosing their course materials.

Firstly, three teacher-trainers indicated that the design of the course materials was determined by the future teaching requirements of pre-service EFL teachers. In other words, the teacher-trainers based their course content on the real-life testing and assessment tasks that pre-service EFL teachers would have in their classrooms. This is illustrated in the comments of the three teacher-trainers: 
In the future, in everyday classroom, pre-service EFL teachers have to design tests, and know these procedures... Therefore, they need to know the basic knowledge for designing tests and understand the importance of test design. These are the main reasons for choosing what to teach in our courses. (Ms. Hang)

I informally investigated the reality at the secondary and high schools to find out what knowledge of testing and assessment teachers lack and what they need to know before I designed the course. (Ms. Yen)

This module belongs to the language teaching methodology which also involves the practicum. During practicum, pre-service EFL teachers may be asked to design the tests. Therefore, the course content must prepare pre-service EFL teachers for this requirement. (Mr. Vinh)

Secondly, they considered other factors such as time allocation for the course when designing the course. Ms. Yen said: "Within only thirty periods, we cannot teach them everything about testing and assessment. We have to consider what content is more useful for them and whether we have enough time or not".

Thirdly, the teacher-trainers were also concerned about pre-service EFL teachers' current understanding levels. The teacher-trainers reported that they could only select the most pertinent content to provide pre-service EFL teachers with background knowledge. This is evident in the following comments from the three teacher-trainers:

The first and foremost thing I had to consider before designing the course was the basic knowledge of testing and assessment the pre-service EFL teachers need to know based on the language testing and assessment theories. (Ms. Yen)

We chose the content based on what we thought pre-service EFL teachers need to know in the course. Moreover, the content has to be suitable for pre-service EFL teachers' current levels of understanding. It should not be too difficult or too easy. (Mr. Vinh)

We believe that the basic knowledge we provide our pre-service EFL teachers will help them develop their knowledge in the future. With that basic understanding, they can read books, articles and refer to the online resources if they want to learn more about language testing and assessment. (Ms. Quy) 
Although the teacher-trainers reported their design of the language testing and assessment courses was based on the needs of pre-service EFL teachers, none of them conducted a formal survey to understand clearly what areas of language testing and assessment pre-service EFL teachers needed to improve. If teacher-trainers only rely on their assumptions, it will be difficult for them to design a course that is relevant for pre-service EFL teachers' needs. Therefore, it is necessary that needs analysis be done to provide teacher-trainers with more evidence about pre-service EFL teachers' assessment literacy. For example, K. Vogt and Tsagari (2014) carried out a survey in many European countries to understand the needs of language teachers in testing and assessment in order to assist curriculum development for assessment training.

\subsubsection{Teacher-trainers' dissatisfaction with the current content of teaching}

At this stage, none of the four teacher-trainers were completely satisfied with the content of their teaching partly due to the difficulty of testing and assessment knowledge, and partly due to time constraints of the course. Ms. Hang expressed her concern about the difficulty of the teaching content:

From my teaching experience, I feel that the content is rather difficult for my preservice EFL teachers. I will make some changes in the future. For example, I will reduce the amount of knowledge pre-service EFL teachers need to learn or give them specific tasks and instruct them how to design a test for each skill. I have to teach them to pay attention to the smallest things in testing and assessment such as test instruction and how to design test items so they can assess their students appropriately.

Mr. Vinh expressed his concern for time constraint: "Within the short period of time of the course, we can only pick up some very basic knowledge of testing and assessment. Although we know it is not enough, that is all we can offer our preservice EFL teachers". Moreover, the teacher-trainers reported their lack of reference resources in testing and assessment as a barrier to course material development.

Although the teacher-trainers realised some problems in the current system, they could not make any changes because it required support from different levels of 
administration. Ms. Quy criticised the current situation: "It is extremely difficult to change the course content in Vietnam. This is because we need to obtain permission and complete a lot of paperwork in order to change the course materials". However, one teacher-trainer planned to re-design some parts of the course materials which she thought were too difficult for pre-service EFL teachers. To improve the quality of assessment training for pre-service EFL teachers, it is important that teacher-trainers be provided with adequate reference resources and be aware of how to make use of them as most available textbooks in testing and assessment are "highly technical or too specialized for language educators seeking to understand basic principles and practice in assessment” (L. Taylor, 2009).

\subsubsection{Method of instruction}

The teacher-trainers reported two main methods of instruction for their courses. For the universities with a separate testing and assessment course, the teacher-trainers chose a task-based approach, whereas, at universities without a separate course, teacher-trainers used a lecture approach to teach testing and assessment.

\subsubsection{Reasons for choosing the method of instruction}

Practicality and the appropriateness are the two main considerations for choosing the method of instruction. At the universities which offered a separate language testing and assessment course, the teacher-trainers chose the task-based approach as the main teaching methodology. According to them, due to its ability to encourage pre-service EFL teachers to practise what they learned, this approach could maximise their understanding about different tasks in language testing and assessment. They argued that it is difficult for pre-service EFL teachers to absorb necessary knowledge if theories are taught separately from practice. Ms. Yen commented about the benefits of this approach:

Task-based teaching can encourage the interaction between teachers and students. Therefore, this approach can provide an interactive environment inside the classroom. Moreover, it requires students to work on their own; they themselves have to work out the principles and the definitions in language testing and assessment. This will help them remember and understand what they study more clearly. I did 
not choose the lecture approach because I do not think it is effective. If I use lectures only, students will not understand clearly.

Teacher-trainers illustrated how they applied task-based teaching by providing the following example. In their assignment, they asked pre-service EFL teachers to analyse a previous test which was relevant to the content of the lesson. Then they provided guideline questions and required pre-service EFL teachers to work in groups and discuss these questions. After that, each group would report their answers to the class. Teacher-trainers only played the role of facilitator and advisor who gave comments and advice about what pre-service EFL teachers did.

On the other hand, due to limited time at the other two universities where teachertrainers had only five to ten periods in their teaching methodology courses for testing and assessment training, the teacher-trainers could only use lectures to deliver language testing and assessment lessons. This is also because lecturing is the most convenient way to introduce the relevant basic knowledge to pre-service EFL teachers. Ms. Quy said: "We only had five to ten periods for testing and assessment. So we can only teach them through lectures". For these universities, pre-service EFL teachers hardly had any opportunities to practise doing testing and assessment due to the limited course length.

\subsubsection{Teacher-trainers' satisfaction with their methods of instruction}

All the teacher-trainers were satisfied with their teaching methods. Moreover, they believed that these methods were the most appropriate for the current situation at their universities. For example, Ms. Yen commented about her teaching method: "Taskbased approach is the main teaching methodology at my university. The pre-service EFL teachers' feedback about this approach is quite positive. I do not want to change this into lecture approach. I think task-based approach is better for them”. Moreover, the two lecturers at the universities which could not offer a separate course in testing and assessment believed that they were unable to choose other teaching methods except for the lecture approach because it helped them deliver their lessons effectively within the limited time of the course. 


\subsubsection{Support for testing and assessment training}

The four teacher-trainers did not complain about the support from their universities in terms of the time and facilities allocations for the courses. Within the current situation of teaching and learning in Vietnam, they agreed that they could hardly ask for more than what they were offered. Ms. Yen said:

At my university, the number of pre-service EFL teachers is small; we only have from two to three classes and the university designed a special room for training preservice EFL teachers. Whenever we have language testing and assessment classes, we will use this room because the teaching and learning facilities are quite good. The room has computers, projectors and stationery for pre-service EFL teachers to do group work. In general, the current condition of teaching is acceptable. We do not meet any difficulties.

However, they all showed their concerns about the length of their courses. They suggested the current training programme be extended for a longer period so that preservice EFL teachers will be more prepared in language testing and assessment. They believed that the more time they had, the better they could help pre-service EFL teachers. Moreover, according to them, if the course was longer, pre-service EFL teachers would be given more opportunities to apply the theories they learned. This is shown in the following comments from two teacher-trainers:

We do not think we have enough time for training our pre-service EFL teachers. We need more time for helping them understand more thoroughly. Thirty periods are inadequate. We definitely need more time or more effective organization of the course so that pre-service EFL teachers have time for practice. If pre-service EFL teachers have time to reflect on what they learn, it will be more effective than just receiving knowledge from teacher-trainers. At this moment, pre-service EFL teachers only learn from their teacher-trainers but do not have opportunities to try out what they learn. If they can practise their knowledge and have reflection on that, it will be more useful for them. (Ms. Yen)

To be honest, we do not have enough time to teach language testing and assessment thoroughly at our university. At present, we can only introduce the very basic knowledge of language testing. Other techniques, for example test evaluation, will need more teaching time. (Mr. Vinh) 
In this study, two universities did not offer a separate course in testing and assessment. Within five to ten periods in a language teaching methodology course, it is impossible for teacher-trainers at these universities to equip their pre-service EFL teachers with adequate knowledge and skills in testing and assessment. To help teacher-trainers improve their assessment training, it is important that language testing and assessment courses be made compulsory and lengthened. This finding is similar to what happened in China where Jin (2010) and Lam (2014) respectively emphasized the importance of the length and credits of language testing and assessment courses.

\subsubsection{Testing and assessment training in the practicum}

\subsubsection{Lack of testing and assessment training in the practicum}

The four teacher-trainers also reported the lack of opportunities for pre-service EFL teachers to apply what they learned about testing and assessment during the practicum. Only one teacher-trainer mentioned that pre-service EFL teachers were required to design a test during their practicum. While at the other universities, the teacher-trainers were dissatisfied that their pre-service EFL teachers were not instructed to practise their teaching skills during the practicum. For example, Ms. Hang said: "During the practicum, pre-service EFL teachers have no opportunities to do testing and assessment. They spend most of their time practising their teaching skills". Ms. Quy also expressed her concern for this: "During the practicum, they only learn how to teach vocabulary, grammar, reading, writing, pronunciation. School mentors do not spend time on instructing them to design tests or at least how to write a small test".

\subsubsection{The role of the school mentors in testing and assessment training during the practicum}

All the teacher-trainers emphasized the role of school mentors in testing and assessment training for pre-service EFL teachers during their practicum. According to them, school mentors were those who decided if training in testing and assessment would be provided during the practicum. 
However, according to the teacher-trainers, school mentors had different educational backgrounds, teaching methodologies and teaching beliefs. This might influence their mentoring approach. Moreover, their view of testing and assessment might vary. For example, Ms. Yen commented:

The school mentors who were educated in the 1980s usually support the grammartranslation method in language teaching; therefore, they only design tests to test vocabulary and grammar. They are not aware of how to use reading and speaking tasks to measure their students' communicative competence.

The teacher-trainers added that despite the difference in school mentors' mentoring approaches, pre-service EFL teachers had to follow their school mentors' instructions to avoid conflicts. According to the teacher-trainers, pre-service EFL teachers would be reluctant to apply what they learned about testing and assessment without their school mentors' support. Mr. Vinh was very frank about this issue:

As usual, pre-service EFL teachers have to follow the school mentors' instructions. Despite the fact that the environment varies at different schools, and school mentors have different teaching beliefs, pre-service EFL teachers have to follow their school mentors to avoid conflicts during a practicum.

Previous studies have highlighted the importance of a practicum to pre-service teachers' professional development (Beck \& Kosnik, 2002; Ewell, 2004; Schulz, 2005). Moreover, a practicum can provide pre-service teachers with opportunities to apply what they learned from their training into real-life classrooms and helping them develop their experiential knowledge (Wallace, 1991). It is important that testing and assessment should be included in practicums for pre-service EFL teachers so that they are able to improve their assessment literacy from their fieldwork experience.

\subsection{Pre-service EFL teachers' perception and attitudes toward language testing and assessment courses or module of language testing and assessment}

The teacher-trainers agreed that language testing and assessment training is important for pre-service EFL teachers. In addition, they all showed their strong support for this training in teacher education. Further, they believed that if pre-service EFL teachers 
are assessment-literate, they can minimize the negative impact of testing and assessment on students and this helps improve the current situation of language testing and assessment in Vietnam. This is illustrated in Ms. Yen's comment:

Language testing and assessment is very important for pre-service EFL teachers. When they become teachers at schools, they will know the right approach in testing and assessment, know how to plan their assessment as well as have better attitudes and beliefs about testing and assessment. This will influence teaching and learning at high schools. For example, if they are not aware of the impact of testing and assessment, they will design inappropriate tests which are not reliable and valid and this, for sure, will affect teaching and learning quality at high schools.

Through the interviews, the teacher-trainers revealed their evaluation of their students' perception and attitudes toward language testing and assessment training offered at their university as follows.

\subsubsection{The importance of the course}

The teacher-trainers observed that their pre-service EFL teachers could realise the importance of the language testing and assessment courses. For example, Ms. Hang commented: "I think pre-service EFL teachers find the course important. They know testing and assessment are a part of their daily job in the future".

Ms. Yen shared a moving story about the long-term effects of the course on preservice EFL teachers after their graduation. She said that some of her former students from different parts of Vietnam emailed her to express their gratitude for her language testing and assessment course. Her students found what they learnt from the course very useful for their teaching. According to them, the course not only helped them improve their test design but also influenced their beliefs and confidence to change the current language testing and assessment at their schools. Furthermore, these students expressed their wish to receive more language testing and assessment training at university.

\subsubsection{Pre-service EFL teachers' interest in the course}

Ms. Quy observed that pre-service teachers' learning styles and attitudes toward their future jobs determined their interest in the course and explained: "Only the pre- 
service EFL teachers who have positive attitudes towards their future jobs will be interested in this course while the others just attend this course because it is a compulsory course".

Two teacher-trainers believed that the course was interesting because the knowledge from this course was totally new and beneficial to pre-service EFL teachers:

According to my observation, pre-service EFL teachers do not know why they have to include different parts when they design tests. Therefore, when we provide them with testing knowledge, they find it very interesting and meaningful. (Ms. Hang)

I think pre-service EFL teachers are interested in the course because they have not learned about testing and assessment before. This knowledge is new and useful for their future jobs. (Mr. Vinh)

\subsection{The constraints of language testing and assessment training}

The interviews with the teacher-trainers identify two main constraints of language testing and assessment training including: (i) the lack of systematic innovation in language testing and assessment and (ii) the lack of labour, facilities and time frames for language testing and assessment training.

\subsubsection{The lack of systematic innovation in language testing and assessment}

The four teacher-trainers agreed that systematic innovation in language testing and assessment should be conducted from top-down. They shared a concern that teachers will not be able to apply what they learned if they do not get the appropriate support from school administrators and the Ministry of Education and Training (MOET). They also talked of their disquiet about the testing culture in Vietnam which puts more value on summative assessment. According to the teacher-trainers, school leaders, parents and teachers in Vietnam are seriously affected by exam results. Moreover, the teacher-trainers claimed that exam results drive teachers' teaching and students' learning. They further explained that teachers teach directly to test requirements only to help their students get the best exam results. This is shown in Ms. Quy's comment: 
In my opinion, language testing and assessment's problems are the alarming issues which need a long-term solution from not only teacher training universities but also the whole education system in our country. At all levels of the education system, summative assessment is regarded as the most important. This influences learners, parents, and especially teachers when they design their teaching lessons. Teachers can apply some innovations in language testing and assessment they have learnt but it will be much more effective if we have systematic change from the top-down.

One teacher-trainer expected the policy-makers to give teachers more power in testing and assessment. According to her, in the current system, teachers are not expected to be involved in designing high-stake tests and exams. All the teachertrainers concurred with this and thought that this demotivates pre-service EFL teachers from improving their knowledge and skills of testing and assessment. This is clearly evident in Ms. Quy's comment: "Because test design is supposed to be the duty of the head of the school or the head of the teaching groups, teachers do not feel the need to improve their knowledge of testing and assessment".

One teacher-trainer also pointed out the mismatch between the policies of the MOET and the tests they design. Even though the MOET encouraged the teachers to apply the communicative approach in language teaching and learning, the final tests they designed only focused on testing students' receptive skills and knowledge of vocabulary and grammar. Ms. Quy shared a critical story of how the mismatch between testing and teaching requirements could affect the way her friend, a high school English teacher, applied what she had learned in her postgraduate programme into practice:

My friend teaches at a popular gifted school and had learned about testing and assessment in her postgraduate programme. However, when she designs tests for her students, she keeps designing tests which focus on vocabulary, especially testing unpopular words that students rarely use in English communication. She explained that although she is aware of this problem, she has to teach her students to cope with the exams. Teaching to the tests is so popular and affects teaching quality. Moreover, testing does not go with the context, and does not have a clear rationale and objectives. 


\subsubsection{The lack of labour, facilities and time for language testing and assessment training}

Even though the teacher-trainers wanted the MOET to take further action to change the current situation, they shared their understanding of the difficulties that the MOET faces. They further explained that a change in language testing and assessment in Vietnam cannot be done in a short time due to the large class size and the lack of labour, facilities and time. Ms. Yen directly addressed this problem:

This is a big problem which needs support from policy makers. Firstly, we need to reduce the number of students in one class. If we can decrease the class size to allow a good environment for communicative language testing, from 60 students or 40 students in one class into 10 students in one class, teachers can do speaking tests. Secondly, the lack of labour and time is a concern. In order to test the communicative skills of students, teachers need to test speaking and listening skills. But in the current condition, teachers do not have enough time and can only test writing, reading and grammar.

\subsection{Discussion}

In order to become assessment-literate, pre-service EFL teachers definitely need training in testing and assessment during their teacher preparation programmes. Despite the important role of language testing and assessment courses in the development of pre-service EFL teachers' assessment literacy, not much has been done to investigate what and how language testing and assessment are taught in language teacher training programmes around the world as well as how to improve the quality of this training (Brown \& Bailey, 2008). Therefore, this research, together with the previous studies of Bailey and Brown (1996), Brown and Bailey (2008), Jin (2010) and Lam (2014), adds to the limited knowledge of language testing and assessment training for language teachers.

While a questionnaire approach has been widely used in the previous studies including Bailey and Brown (1996), Brown and Bailey (2008), and Jin (2010), this study conducted semi-structured interviews with teacher-trainers to get an in-depth understanding of assessment training at four teacher-training universities in Vietnam. Using semi-structured interviews helped to uncover many issues in assessment 
training at the four teacher training universities such as the attitudes of pre-service EFL teachers toward this training and the constraints of language testing and assessment courses.

Despite the difference in the research instrument, this study shares three main findings with previous studies. First, as many experts have noted inadequate assessment training in teacher preparation programs (Mertler, 2003; Plake, 1993; Volante \& Fazio, 2007), this study showed a lack of focus on assessment training in language teacher preparation programmes. Among the four universities involved in this study, two did not offer a separate course in testing and assessment. Moreover, all the four teacher-trainers reported a need for the extension of course length. Second, similar to the studies of Bailey and Brown (1996), Brown and Bailey (2008), Jin (2010) and Lam (2014), assessment training in Vietnam pays more attention to the role of summative assessment and psychometrics than the importance of assessment for learning. In Vietnam, this can be explained by the influence of language testing and assessment culture on the way pre-service EFL teachers are trained for testing and assessment practices. Third, this study, together with Jin (2010) and Lam (2014), identified the limited length of time, and the gap between theory and practice in language testing and assessment courses as the barriers to the quality of assessment training for pre-service teachers. The four teacher-trainers in this study were concerned that they had inadequate time for assessment training for pre-service EFL teachers. Moreover, they noted a lack of assessment training during the practicum, and a lack of opportunities for pre-service EFL teachers to apply what they had learned into practice.

In spite of the common findings with the previous studies as mentioned above, this study acknowledged four main contextual constraints that affected assessment training for pre-service EFL teachers in Vietnam. First, teacher-trainers at the four participating universities did not receive adequate formal training in testing and assessment. This, they claimed, limited their training quality. Second, the training resources and reference materials for assessment training in Vietnam were reported to be insufficient. Teacher-trainers were concerned that they were unable to adjust their course materials due to their limited exposure to training resources and reference 
materials in testing and assessment. Third, teacher-trainers were concerned that Vietnamese pre-service EFL teachers who were not interested in a teaching career were not motivated to develop their assessment literacy. They claimed that assessment literacy is not the central focus for pre-service EFL teachers who did not want to become teachers after graduation. Fourth, the influence of testing and assessment culture on English language teaching and learning has affected the content and the focus of language testing and assessment courses. Assessment training for pre-service EFL teachers in Vietnam puts more emphasis on psychometrics and the role of summative assessment over formative assessment. This is because the teachertrainers believed that these skills were more relevant for pre-service teachers' future jobs.

As language testing and assessment courses can improve pre-service teachers' assessment literacy as shown in the study by McGee andColby (2014), the quality of assessment training for pre-service EFL teachers should be taken into consideration. To improve the current situation of this training in Vietnam, both top-down and bottom-up actions need to be taken. First, it is recommended that policy-makers make assessment training compulsory and increase the length as well as the credits of this training in teacher preparation programmes. This highlights the importance of assessment literacy for pre-service EFL teachers in teacher preparation programmes. Second, more investment into training resources and reference materials are crucial to the improvement of assessment training quality. Without sufficient reference resources, it is difficult for teacher-trainers to keep updated with current trends in language testing and assessment. This also prevents them from adjusting their current teaching materials. Third, professional development in testing and assessment for teacher-trainers is indispensable. In order to help pre-service EFL teachers develop their knowledge and skills in testing and assessment, teacher-trainers themselves must be assessment-literate. This is also a concern of Lam (2014) and L. Taylor (2009) when they argued that the first step in improving pre-service teachers' assessment literacy is to offer professional development in testing and assessment for university-based instructors. Fourth, in a climate of limited resources and financial support in Vietnam, it is important to encourage teacher-trainers to make use of free sources to develop their assessment literacy and improve their training quality. 
Nowadays, with the growth of Internet, teacher-trainers can refer to free online resources to learn about testing and assessment and to avoid lagging behind the current trends of language testing and assessment. Last, needs analysis to identify the areas of assessment knowledge and skills pre-service EFL teachers need will be useful for curriculum and course material development. Language testing and assessment requires pre-service EFL teachers to have specialized knowledge and various skills that language testing and assessment courses within teacher preparation programmes can fully cover. It is essential to identify the priorities of knowledge and skills in testing and assessment that pre-service EFL teachers need for their future jobs to shape the content and the method of instruction in language testing and assessment courses.

In conclusion, assessment training for pre-service EFL teachers has received inadequate attention in teacher preparation programmes in Vietnam. Therefore, it is important that teacher training universities make this training compulsory and increase the length and credits of language testing and assessment courses. This is because assessment literacy is critical to pre-service EFL teachers' professional development and their future jobs.

\subsection{Summary}

This chapter outlines and discusses the key issues of language testing and assessment training at the four key teacher training universities in Vietnam. The findings show the lack of formal training in testing and assessment for teacher-trainers which prevented them from improving the quality of their testing and assessment education in the teacher preparation programmes. Due to time constraints, the teacher-trainers could not offer adequate training in testing and assessment for pre-service EFL teachers or provide them enough opportunities to practise what they had learned. Additionally, in practicum, school mentors' approaches and beliefs determined whether pre-service EFL teachers would be given the chance to practise testing and assessment knowledge and skills. Therefore, it can be seen that pre-service EFL teachers in Vietnam are not provided with enough knowledge and skills of testing and assessment for their future job when they graduate from teacher training universities. 
Moreover, there are some constraints of testing and assessment training that need solutions from the top-down. In order to solve these problems, improving assessment literacy of teacher-trainers who are in charge of these courses should be among the priorities. Without their adequate formal training in testing and assessment, teachertrainers may have difficulties acquiring new knowledge and skills in testing and assessment needed to improve assessment education at their universities.

Further, this phase shows the influence of contextual factors on the way pre-service EFL teachers were trained in testing and assessment. In an exam-oriented culture like Vietnam, assessment training is affected by the way language testing and assessment is viewed and used in language teaching and learning. The role of testing and assessment to enhance teaching and learning is not highly emphasised. Instead, the teacher-trainers in this study were more concerned about training their pre-service EFL teachers in summative assessment and psychometrics due to the importance of these in their future jobs.

In conclusion, Phase 1 shares some similar findings with previous studies. Moreover, it presents the contextual factors that might affect the quality of assessment training at the four teacher training universities in Vietnam. Despite some limitations, Phase 1 makes clear the lack of emphasis on assessment literacy for Vietnamese pre-service EFL teachers. Table 5-1 below summarizes the current status of language testing and training offered at the universities under study. 
Table 5-1: Current status of language testing and assessment training

\begin{tabular}{|c|c|c|c|c|c|}
\hline & $\begin{array}{l}\text { Course } \\
\text { availability }\end{array}$ & Course title & $\begin{array}{l}\text { Course } \\
\text { materials }\end{array}$ & $\begin{array}{l}\text { Course } \\
\text { teaching } \\
\text { methodology }\end{array}$ & $\begin{array}{l}\text { Course } \\
\text { length }\end{array}$ \\
\hline $\begin{array}{l}\text { Do Cong } \\
\text { University }\end{array}$ & Yes & $\begin{array}{l}\text { Language } \\
\text { testing and } \\
\text { assessment }\end{array}$ & $\begin{array}{l}\text { Language } \\
\text { testing }\end{array}$ & $\begin{array}{l}\text { Task-based } \\
\text { learning }\end{array}$ & $\begin{array}{l}30 \text { forty- } \\
\text { five- } \\
\text { minute } \\
\text { periods }\end{array}$ \\
\hline $\begin{array}{l}\text { Chi Lang } \\
\text { University }\end{array}$ & No & $\begin{array}{l}\text { Module of } \\
\text { Language } \\
\text { testing and } \\
\text { assessment } \\
\text { in the } \\
\text { teaching } \\
\text { methodology } \\
\text { course }\end{array}$ & $\begin{array}{l}\text { Combined } \\
\text { from } \\
\text { different } \\
\text { sources }\end{array}$ & $\begin{array}{l}\text { Lectures, } \\
\text { tutorials }\end{array}$ & $\begin{array}{l}5-10 \\
\text { forty- } \\
\text { five- } \\
\text { minute } \\
\text { periods }\end{array}$ \\
\hline $\begin{array}{l}\text { Bach Dang } \\
\text { University }\end{array}$ & Yes & $\begin{array}{l}\text { Language } \\
\text { testing and } \\
\text { assessment }\end{array}$ & $\begin{array}{l}\text { Combined } \\
\text { from } \\
\text { different } \\
\text { sources }\end{array}$ & $\begin{array}{l}\text { Task-based } \\
\text { learning }\end{array}$ & $\begin{array}{l}30 \text { forty- } \\
\text { five- } \\
\text { minute } \\
\text { periods }\end{array}$ \\
\hline $\begin{array}{l}\text { En Bac } \\
\text { University }\end{array}$ & No & $\begin{array}{l}\text { Module of } \\
\text { Language } \\
\text { testing and } \\
\text { assessment } \\
\text { in the } \\
\text { teaching } \\
\text { methodology } \\
\text { course }\end{array}$ & $\begin{array}{l}\text { Combined } \\
\text { from } \\
\text { different } \\
\text { sources }\end{array}$ & $\begin{array}{l}\text { Lectures, } \\
\text { tutorials }\end{array}$ & $\begin{array}{l}5 \text { forty- } \\
\text { five } \\
\text { minute } \\
\text { periods }\end{array}$ \\
\hline
\end{tabular}

The next chapter (Chapter 6) continues with the research methodology of Phase 2 which investigated pre-service EFL teachers' assessment literacy confidence levels at the four teacher training universities involved in Phase 1. 


\section{Chapter 6:}

\section{PHASE 2 - PRE-SERVICE EFL TEACHERS' ASSESSMENT LITERACY \\ CONFIDENCE LEVELS \\ Research Methodology}

\subsection{Introduction}

Phase 2 looks at assessment literacy confidence levels of the pre-service EFL teachers at the four teacher-training universities (Bach Dang University, En Bac University, Do Cong University, and Chi Lang University) which were involved in Phase 1. This chapter first presents an overview of Phase 2. It then addresses the research questions. Next, it describes the research participants, the research instruments and the research procedures. After that, it discusses ethical issues, and the reliability and validity of the study. The chapter ends with a summary.

\subsection{Overview of Phase 2}

Phase 2 aims to:

1. examine Vietnamese pre-service EFL teachers' assessment literacy confidence levels.

2. compare the mean scores of assessment literacy confidence levels between

$\checkmark$ the pre-service EFL teachers who had a separate language testing and assessment course and the ones who only studied language testing and assessment as a part of their teaching methodology courses. The relationship between assessment training and pre-service EFL teachers' confidence levels in assessment literacy was checked to investigate the role of assessment training in their development of assessment literacy.

$\checkmark$ the male and female pre-service EFL teachers. Due to the dominance of female pre-service teachers in teacher-training universities, it is important to examine whether gender influenced pre-service teachers' assessment literacy

$\checkmark$ the pre-service EFL teachers who chose to become teachers and the ones who did not. Because not all the pre-service teachers chose to study at teacher training universities wanted to become teachers after graduation, 
whether their career choice affected their confidence levels in assessment literacy needs to be explored.

$\checkmark$ the pre-service EFL teachers who had teaching experience and the ones who did not. The majority of the pre-service teachers in this study had a part-time job as teaching assistants at language centers, whether these teaching experiences influenced their assessment literacy is worth an investigation.

\subsection{Research questions}

This stage addressed the following research questions:

1. What are Vietnamese pre-service EFL teachers' assessment literacy confidence levels?

2. Is there any difference in Vietnamese pre-service EFL teachers' assessment literacy confidence levels between those who took a separate language testing and assessment course and those who only studied language testing and assessment as a part of teaching methodology courses?

3. Is there a significant difference in the mean of assessment literacy confidence levels between males and females?

4. Is there a significant difference in assessment literacy confidence levels between those who chose teaching as their career and those who did not?

5. Is there a significant difference in assessment literacy confidence levels between those who had teaching experience and those who had not?

\subsection{Research participants}

The research participants in this phase were final-year students at the four key teacher training universities (Bach Dang University, Chi Lang University, Do Cong University, En Bac University) that were involved in Phase 1. These universities were chosen due to their representativeness and their influence on teacher training in Vietnam. Moreover, because I had conducted Phase 1 at these universities, it was easy to gain access to the research sites.

In the main data collection process, I distributed 500 questionnaires to the pre-service EFL teachers at these universities. $381(76.2 \%)$ of the distributed questionnaires were 
returned which indicates a good return rate. After data screening, I discarded sixteen questionnaires due to consistent effortless answers; for example, incomplete questionnaires with the answers to only a few questionnaire items. Therefore, only 365 participants were involved in this phase. Among them, eighty-eight were from two universities that had a separate language testing and assessment course while 277 were from the other two universities which did not have a separate course in language testing and assessment. There were 11 times more female teachers $(\mathrm{N}=336)$ than male teachers $(\mathrm{N}=29)$. This indicates the dominance of female students at teacher training universities in Vietnam because teaching is considered to be a more suitable job for Vietnamese women than men. Nearly $78 \%$ of the participants $(\mathrm{N}=291)$ wanted to become English teachers after graduation. Before their practicum, 293 participants had teaching experience as English tutors or teaching assistants while 72 did not have any teaching experience.

\subsection{Research instrument}

Currently, in the literature, two methods have been widely used to investigate teachers' assessment practices and their levels of preparation to assess students: 1) surveys of attitudes, beliefs, and practices (O’Sullivan \& Johnson, 1993; Zhang \& Burry-Stock, 1997); and 2) tests of assessment knowledge (Impara et al., 1993; Mertler, 2003; Mertler \& Campbell, 2005; Volante \& Fazio, 2007). However, these methods were not selected for my study partly due to the nature of Vietnamese preservice EFL teachers and their lack of experience in testing and assessment, and partly due to the impracticality of the previous instruments.

The first method was ruled out because it was impossible to collect data about beliefs, attitudes and actual assessment practices of Vietnamese pre-service EFL teachers when they had not had any formal teaching experience at school. Moreover, the second method (a test of assessment literacy) in the previous studies (e.g., Impara et al., 1993; Mertler, 2003; Mertler \& Campbell, 2005; Volante \& Fazio, 2007) was inappropriate for this study because these tests are lengthy and are designed for teachers of general education, and therefore encompass various educational situations which are not specific enough for pre-service EFL teachers. In addition, I could 
foresee the reluctance of the Vietnamese pre-service EFL teachers to complete a test due to their fear of testing and assessment.

Instead of using the instruments in previous studies, I developed a questionnaire to measure pre-service EFL teachers' confidence levels in assessment literacy. This approach was chosen due to its practicality to get a large amount of data within a short period of time (Dörnyei, 2010). Moreover, in the context of Vietnam where students are afraid of testing and assessment, a questionnaire of pre-service EFL teachers' assessment literacy confidence levels helps to reduce the fear of participants to complete a test.

\subsection{Research procedures}

The first step in Phase 2 was to develop and validate a questionnaire of pre-service EFL teachers' assessment literacy. After that, the instrument was used in the main data collection. The details of the research procedures are described as follows.

\subsubsection{Questionnaire development}

The questionnaire development included three steps which are illustrated in Figure 6-1 and described in detail as below.

\section{Figure 6-1: Questionnaire development}

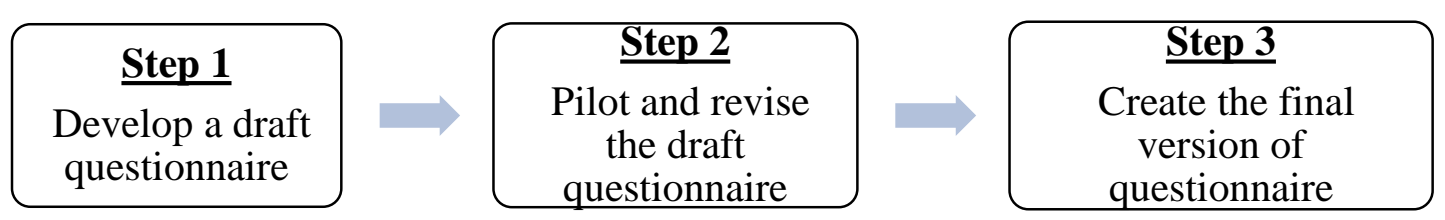

\subsubsection{Step 1: Develop a draft questionnaire of pre-service EFL teachers' confidence levels in assessment literacy}

I reviewed the literature and used a top-down approach to break up the assessment literacy construct into six sub-constructs including pedagogical content knowledge, beliefs about language testing and assessment, understanding of assessment qualities, assessment for learning, assessment of learning, and ethical issues in language testing and assessment practices. Then, from two main sources: (1) adaptation from the existing literature; and (2) self-design, I developed a draft 
questionnaire of 101 items covering the six sub-constructs as mentioned above. The draft questionnaire was carefully reviewed by my supervisors to ensure its content validity and construct validity.

In this draft questionnaire, a scale from $0 \%$ (the lowest level) to $100 \%$ (the highest level) was chosen for each questionnaire item for two main reasons. Firstly, this scale is familiar to the pre-service EFL teachers in this study because they used the same scale for rating their study results. Secondly, a scale from $0 \%$ to $100 \%$ was selected since it is recommended that a scale which offers a wide range of choices can allow more accuracy in the respondents' answers (R. B. Burns, 2000). Moreover, during this step, to ensure the quality of the questionnaire, its items' length, format and clarity were carefully checked. Also, double-barrelled questionnaire items were avoided.

\subsubsection{Step 2: Pilot the questionnaire of pre-service EFL teachers' confidence levels in assessment literacy}

After the draft questionnaire was developed, it was piloted three times with three different groups of participants. The purposes of these three pilots were to try-out and validate the questionnaire for the main data collection. Based on the results of the pilots, the draft questionnaire was revised and shortened. See Table 6-1 for the information about the participants involved in the pilots. The details of each pilot are described below.

\section{Table 6-1: Summary of the pilot studies in Phase 2}

\begin{tabular}{|l|rl|}
\hline Pilot 1 & $\checkmark$ & $\begin{array}{l}\text { One Vietnamese teacher-trainer who was doing her PhD degree in } \\
\text { Applied Linguistics at Victoria University of Wellington, New Zealand }\end{array}$ \\
& $\checkmark$ & $\begin{array}{l}\text { Two Vietnamese teacher-trainers who were doing their Master's degree } \\
\text { in Applied Linguistics at Victoria University of Wellington, New } \\
\text { Zealand }\end{array}$ \\
\hline Pilot 2 & $\checkmark$ & $\begin{array}{l}\text { Four pre-service EFL teachers at two teacher training universities (Anh } \\
\text { Duong University, and Bach Dang University) in Vietnam }\end{array}$ \\
\hline Pilot 3 & $\checkmark$ & $\begin{array}{l}\text { Forty-eight pre-service EFL teachers at Anh Duong University in } \\
\text { Vietnam }\end{array}$ \\
\hline
\end{tabular}




\section{$\underline{\text { Pilot } 1}$}

Three Vietnamese teacher-trainers who were doing their PhD and Master's degrees at Victoria University of Wellington were asked to think-aloud while answering the questionnaire. During this process, the questionnaire items' clarity was carefully checked. In this pilot, the teacher-trainers could identify some items that needed rephrasing and revising. For example, item "I can plan my teaching to meet what the curriculum requires me to teach my students" was rephrased as "I can plan my teaching to meet the curriculum requirements". Based on their comments, I carefully revised any items that were vague. This process took place in close consultation with my primary supervisor in order to ensure that the changes did not influence the content validity of the questionnaire. After the questionnaire was revised based on the results of Pilot 1, the second pilot of the revised questionnaire was carried out. The details of Pilot 2 are presented below.

\section{$\underline{\text { Pilot } 2}$}

In the second pilot, I tried out the revised version of the questionnaire with four Vietnamese pre-service EFL teachers from two teacher-training universities: Anh Duong University and Bach Dang University. These participants were chosen because they had similar backgrounds to the targeted participants in the main data collection. Due to my inability to return to Vietnam, I had to ask one of my colleagues to help me with one pilot with two pre-service EFL teachers at Anh Duong University while I worked with another two at Bach Dang University via a web chat. During this process, the participants were required to:

$\checkmark$ complete the questionnaire and track the amount of time required for completing the questionnaire.

$\checkmark$ answer the following guideline questions:

1. How long did it take you to complete the questionnaire?

2. Are the questionnaire's instructions clear enough?

3. Is the questionnaire's layout clear enough?

4. Do you understand all the questions?

5. Which questions do you find it difficult to understand?

6. Which questions do you find difficult to answer? 
7. Do you think the fourth-year students at your university can understand the language used in this questionnaire?

8. Do you have any further comments?

On average, it took the four pre-service EFL teachers about thirty minutes to complete the questionnaire. They found no difficulty with understanding the language used in the questionnaire. However, they suggested shortening the length of the questionnaire because it would be tiring to answer 101 questionnaire items.

After the two previous pilots, I discussed the results with my supervisors and revised any questionnaire items that were problematic. This revised version still consisted of 101 questionnaire items as summarised in Table 6-2. Moreover, the questionnaire included six sub-constructs: pedagogical content knowledge, beliefs of language testing and assessment, understanding of assessment qualities, assessment for learning, assessment of learning and ethical issues in testing and assessment. Some sub-constructs included sub-sections; for example, pedagogical content knowledge consisted of four sub-sections: knowledge of teaching objectives and curriculum, knowledge of contextual issues, knowledge of instructional strategies, knowledge of students' learning, and knowledge of subject-matter. 
Table 6-2: Overview of the draft questionnaire

\begin{tabular}{|c|c|c|c|}
\hline Sections & Subsections & Questions & $\begin{array}{l}\text { Number } \\
\text { of items }\end{array}$ \\
\hline Personal information & & Q1-Q4 & 04 \\
\hline \multirow{5}{*}{$\begin{array}{l}\text { Pedagogical content } \\
\text { knowledge }\end{array}$} & $\begin{array}{l}\text { Knowledge of teaching objectives and } \\
\text { curriculum }\end{array}$ & Q1-Q4 & 04 \\
\hline & Knowledge of contextual issues & Q5-Q11 & 07 \\
\hline & Knowledge of instructional strategies & Q12-Q17 & 06 \\
\hline & Knowledge of students' learning & Q18-Q27 & 10 \\
\hline & Knowledge of subject matter & Q28-Q38 & 11 \\
\hline \multirow{2}{*}{$\begin{array}{l}\text { Beliefs of language } \\
\text { testing and assessment }\end{array}$} & Assessment for learning & Q39-Q47 & 09 \\
\hline & Assessment of learning & Q48-Q55 & 08 \\
\hline $\begin{array}{l}\text { Understanding of } \\
\text { assessment qualities }\end{array}$ & & Q56-Q62 & 07 \\
\hline Assessment for & Planning assessment & Q63-Q67 & 05 \\
\hline \multirow[t]{2}{*}{ learning } & Conducting assessment & Q68-Q76 & 09 \\
\hline & Using assessment data & Q77-Q85 & 09 \\
\hline \multirow{2}{*}{$\begin{array}{l}\text { Assessment of } \\
\text { learning }\end{array}$} & Prepare for tests & Q86-Q89 & 04 \\
\hline & Interpret test results & Q90-Q94 & 05 \\
\hline \multirow[t]{2}{*}{ Ethical issues } & & & 07 \\
\hline & & TOTAL & 105 \\
\hline
\end{tabular}

\section{$\underline{\text { Pilot } 3}$}

After Pilot 2, I continued to pilot the revised version of the questionnaire with fortyeight pre-service EFL teachers at Anh Duong University. Due to my inability to return to Vietnam, I had to ask one teacher-trainer at Anh Duong University to collect data for me. In order to ensure that the data collection was conducted properly, I carefully described the process of data collection with that teacher-trainer via email and phone calls. I also emailed her the information sheet, the consent form and the questionnaire. She printed them out and distributed them to the participants. After she finished the data collection, she sent all the questionnaires to me.

\subsubsection{Step 3: Create the final version of the questionnaire}

On receipt of the questionnaires from Pilot 3, I coded and imported them into SPSS version 18. The data from Pilot 3 served as the evidence to enhance the questionnaire's validity and reliability by using factor analysis and Cronbach's alpha as described below. 
First, exploratory factor analysis was performed to check the construct validity of the questionnaire. Before performing factor analysis, as Pallant (2010) suggested, the suitability of the data for factor analysis was checked by examining the sample size and the strength of the relationships among the variables. Despite the controversy over the sample size for factor analysis, many experts suggested that the more participants involved, the more reliable the results of factor analysis are (Field, 2013; Pallant, 2010). However, due to the unavailability of Vietnamese pre-service EFL teachers, I was only able to recruit forty-eight participants for Pilot 3. Although it is not an ideal sample size, forty-eight participants is relatively close to the suggested sample size by (Jung, 2013) who recommended a minimum of fifty participants for factor analysis. Two statistical measures to help assess the suitability of the data for factor analysis including Barlett's test of sphericity, and the Kaiser-Meyer-Olkin (KMO) were used. The results for Barlett's test of sphericity were all significant $(\mathrm{p}<$ $.05)$ and KMO were above .6.

As Petrić and Czárl (2003) noted, while exploratory factor analysis provides insightful information for construct validation as to the underlying dimensions of a questionnaire, it also often results in uninterpretable factor loadings as well. After initial explorations with factor analysis, I decided to keep the conceptual categories and perform an internal consistency check for each sub-construct/sub-section. This process was done in close consultation with my primary supervisor and the statistical consultant at Victoria University of Wellington. During these discussions, any items that reduced the reliability of each sub-construct were deleted. This process was done to shorten the questionnaire. For example, the group of twelve items in the subsection knowledge of subject matter was checked to see if these variables clustered under one factor. The result shows that they loaded under one factor with a high value of Cronbach's alpha $(\alpha=.939)$. In order to shorten the questionnaire, I discussed the results with my primary supervisor and deleted two items (Numbers 29, 34) which affected the reliability of the group. Then a reliability check was done with this new group of items. The Cronbach's alpha of knowledge of subject matter after some items were excluded is $\alpha=.940$. This similar process was performed with other subconstructs of the questionnaire. Finally, the draft questionnaire was shortened from 101 items to 82 items. Although I tried to keep a minimum of four items per sub- 
construct as recommended by Creswell (2013), I was only able to attain two items for the sub-section prepare for tests.

In addition, another item-level revision was done to make the questionnaire clearer. For example, the item: "I consider how to help my students improve their English communication skills when planning my lesson" was revised as: "When planning my lessons, I consider how to help my students improve their communication skills". After this process, the questionnaire consisted of eighty-two items. The summary of the questionnaire and the reliability of each sub-construct/ sub-section after the problematic items were deleted are presented in Table 6-3 below. This revised questionnaire was then used for the main data collection.

Table 6-3: Overview of the revised questionnaire

\begin{tabular}{|c|c|c|c|c|}
\hline Sections & Subsections & Questions & $\begin{array}{l}\text { Number } \\
\text { of items }\end{array}$ & $\begin{array}{l}\text { Reliability } \\
(\alpha)\end{array}$ \\
\hline \multirow{5}{*}{$\begin{array}{l}\text { Pedagogical content } \\
\text { knowledge }\end{array}$} & $\begin{array}{l}\text { Knowledge of teaching objectives and } \\
\text { curriculum }\end{array}$ & Q1-Q4 & 04 & .854 \\
\hline & Knowledge of contextual issues & Q5-Q10 & 06 & .869 \\
\hline & Knowledge of instructional strategies & Q11-Q15 & 05 & .882 \\
\hline & Knowledge of students' learning & Q16-Q22 & 07 & .926 \\
\hline & Knowledge of subject matter & Q23-Q31 & 09 & .940 \\
\hline \multirow{2}{*}{$\begin{array}{l}\text { Beliefs of language } \\
\text { testing and } \\
\text { assessment }\end{array}$} & Assessment for learning & Q32-Q38 & 07 & .690 \\
\hline & Assessment of learning & Q39-Q43 & 05 & .705 \\
\hline $\begin{array}{l}\text { Understanding of } \\
\text { assessment qualities }\end{array}$ & & Q44-Q49 & 06 & .840 \\
\hline \multirow{3}{*}{$\begin{array}{l}\text { Assessment for } \\
\text { learning }\end{array}$} & Planning assessment & Q50-Q55 & 06 & .922 \\
\hline & Conducting assessment & Q56-Q62 & 07 & .915 \\
\hline & Using assessment data & Q63-Q69 & 07 & .936 \\
\hline \multirow{2}{*}{$\begin{array}{l}\text { Assessment of } \\
\text { learning }\end{array}$} & Prepare for tests & Q70-Q71 & 02 & .926 \\
\hline & Interpret test results & Q72-Q76 & 05 & .904 \\
\hline \multirow[t]{2}{*}{ Ethical issues } & & Q77-Q82 & 06 & .919 \\
\hline & & TOTAL & 82 & \\
\hline
\end{tabular}

\subsubsection{Main data collection}

For the main study, I returned to Vietnam and worked directly with the four participating universities (Bach Dang University, Chi Lang University, Do Cong University and En Bac University). Due to the time constraints, I could not get access to all the pre-service EFL teachers at these four training universities. Therefore, I had 
to ask some teacher-trainers at these universities to help me collect data. In some classes where I could not be present to administer the questionnaires directly to the participants, I explained to the teacher-trainers of these classes the purposes of my study and the data collection process. They then helped me to administer the questionnaires.

\subsubsection{Data analysis}

The data from the questionnaires were coded and entered item by item for each participant into SPSS version 18.0 for analysis. Any questionnaires which showed consistent effortless answers from the participants were not recorded in the data entry. After that, data screening on SPSS was done to ensure the data input was accurate. Then the questionnaire's reliability was checked.

For the first research question about pre-service EFL teachers' assessment literacy confidence levels, descriptive statistics was employed. For the research questions (from two to five), an independent samples t-test was conducted to identify the difference in the mean score of the six constructs of assessment literacy confidence levels:

$\checkmark$ between two groups: Group 1 was from two teacher training universities which offered a separate language testing and assessment course and Group 2 was from two teacher training universities which did not have a separate course for language testing and assessment.

$\checkmark$ between male and female pre-service EFL teachers.

$\checkmark$ between those who chose teaching career and those who did not choose teaching career.

$\checkmark$ between those who had teaching experience and those who did not have teaching experience.

\subsection{Ethical issues}

Before I conducted Phase 2, I obtained the ethics approval of the Human Ethics Committee (HEC) from Victoria University of Wellington (Appendix A). During the whole study, I strictly followed the regulations and conduct of the HEC as shown below: 
$\checkmark$ All the participants in this study were recruited based on their voluntary participation. They had the right to withdraw from the study.

$\checkmark$ The data collection only began when all the participants agreed to sign the consent forms.

$\checkmark$ Their identity was kept confidential and only my supervisors and I could access the data.

$\checkmark$ At some points in this phase, I could not be in Vietnam to work directly with the participants and had to ask for help from some teacher-trainers. However, I carefully explained to the teacher-trainers who helped me collect data all the details related to my research and the ethics of the study.

\subsection{Reliability and validity}

To ensure the research quality of Phase 2, the reliability and validity of the research instrument used in this phase were carefully checked. Two important criteria to judge the quality of a questionnaire includes: validity and reliability (Creswell, 2013). Many experts agree that validity is concerned with the extent to which an instrument is able to measure what it is intended to measure, whereas, reliability is the consistency of an instrument to measure a construct (Brown, 2000; R. B. Burns, 2000; Creswell, 2013; Mackey, 2005). Moreover, it should be noted that the reliability of an instrument is closely associated with its validity. In other words, an instrument cannot be valid unless it is reliable. However, the reliability of an instrument does not depend on its validity.

In this study, the reliability and validity of the questionnaire was established during lengthy processes of developing and validating the questionnaire in close consultation with my supervisors and a statistical consultant at Victoria University of Wellington. The details of these processes are provided in Section 6.6.1 above.

\subsubsection{Reliability}

There are different methods to check the reliability of a questionnaire/ survey such as the repeated-surveys methods (also known as test-retest reliability), the equivalentsurvey methods (also called equivalent forms reliability), and the internal-consistency method (Brown, 2000). Among these, the internal-consistency method using 
Cronbach's alpha is the most widely used method due to its practicality and its accuracy. This study also referred to Cronbach's alpha to check the reliability of the questionnaire.

In the process of questionnaire development, the reliability of the questionnaire was checked with the data from forty-eight participants in Pilot 3. The results as presented in Table 6-3 above show a good reliability rating for the questionnaire. Moreover, the reliability of the questionnaire was checked again with the data from the main data collection (with good sample size, $\mathrm{N}=365$ ). The results also indicate good reliability with Cronbach's alpha $(\alpha=.983)$. Besides, scholars recommend checking the reliability of individual subsections if survey instruments have distinct subsections (Brown, 2000; Creswell, 2013). The results of the reliability of each sub-section in the questionnaire are summarised in Table 6-4 below. Most of the sub-constructs and sub-sections show good reliability. Only two sub-sections, assessment of learning in beliefs of language testing and assessment $(\alpha=.667)$ and preparing for tests in assessment of learning $(\alpha=.573)$ show a relatively low reliability level. However, the reliability of these two sub-sections might be affected by their small number of items; for example, there are only two items in the preparing for tests sub-section. 
Table 6-4: Reliability of the questionnaire

\begin{tabular}{|c|c|c|c|c|}
\hline Sections & Subsections & Questions & $\begin{array}{l}\text { Number } \\
\text { of items }\end{array}$ & $\begin{array}{l}\text { Reliability } \\
\qquad(\boldsymbol{\alpha})\end{array}$ \\
\hline \multirow{5}{*}{$\begin{array}{l}\text { Pedagogical content } \\
\text { knowledge }\end{array}$} & $\begin{array}{l}\text { Knowledge of teaching } \\
\text { objectives and curriculum }\end{array}$ & Q1-Q4 & 4 & 0.874 \\
\hline & $\begin{array}{l}\text { Knowledge of contextual } \\
\text { issues }\end{array}$ & Q5-Q10 & 6 & 0.846 \\
\hline & $\begin{array}{l}\text { Knowledge of instructional } \\
\text { strategies }\end{array}$ & Q11-Q15 & 5 & 0.896 \\
\hline & $\begin{array}{l}\text { Knowledge of students' } \\
\text { learning }\end{array}$ & Q16-Q22 & 7 & 0.888 \\
\hline & Knowledge of subject matter & Q23-Q31 & 9 & 0.921 \\
\hline \multirow{2}{*}{$\begin{array}{l}\text { Beliefs of language testing } \\
\text { and assessment }\end{array}$} & Assessment for learning & Q32-Q38 & 7 & 0.906 \\
\hline & Assessment of learning & Q39-Q43 & 5 & 0.667 \\
\hline $\begin{array}{l}\text { Understanding of } \\
\text { assessment qualities }\end{array}$ & & Q44-Q49 & 6 & 0.869 \\
\hline \multirow{3}{*}{ Assessment for learning } & Planning assessment & Q50-Q55 & 6 & 0.897 \\
\hline & Conducting assessment & Q56-Q62 & 7 & 0.916 \\
\hline & Using assessment data & Q63-Q69 & 7 & 0.913 \\
\hline \multirow{2}{*}{ Assessment of learning } & Prepare for tests & Q70-Q71 & 2 & 0.573 \\
\hline & Interpret test results & Q72-Q76 & 5 & 0.900 \\
\hline \multirow[t]{2}{*}{ Ethical issues } & & Q77-Q82 & 6 & 0.904 \\
\hline & & TOTAL & 82 & \\
\hline
\end{tabular}

\subsubsection{Validity}

As stated earlier, validity in quantitative research is concerned with the accuracy of the research instrument in measuring what it is supposed to (Brown, 2000; R. B. Burns, 2000; Creswell, 2013; Mackey, 2005). For this phase, both content validity and construct validity were checked throughout the processes of developing and validating the questionnaire.

\section{$\checkmark$ Content validity}

Many experts (Brown, 2000; R. B. Burns, 2000; Creswell, 2013; Mackey, 2005) describe content validity as the degree to which the questionnaire content matches the theoretical content of whatever it tries to measure. Two approaches have been widely used to ensure content validity of a questionnaire: 1) the descriptive approach which shows that a questionnaire is developed based on the literature; and 2) the expert ratings approach, which involves the review of questionnaire items by those who have expertise in the area. 
For this questionnaire, both approaches were used to ensure the content validity of the questionnaire on pre-service EFL teachers' confidence levels in assessment literacy. First, the questionnaire was developed on the basis of a comprehensive review of previous literature on assessment literacy and teacher cognition. Second, the content of the questionnaire was reviewed after close consultation with Vietnamese teacher-trainers, and my supervisors who have expertise in testing and assessment. With their expertise and advice on the questionnaire development, any questionnaire items that were irrelevant to the purposes of the questionnaire were revised or discarded.

\section{$\checkmark$ Construct validity}

The construct validity of a questionnaire indicates if it can measure the construct it aims at (Brown, 2000; R. B. Burns, 2000; Creswell, 2013; Mackey, 2005). One way to check a questionnaire's construct validity is to use factor analysis. The purpose of factor analysis is to understand the structure of the variables and to reduce the number of the related variables in a questionnaire to a manageable size (Pallant, 2010). This helps produce a better version of a questionnaire which has fewer items but still can measure the original constructs (Field, 2013).

Moreover, the construct validity can be claimed if the convergent and discriminant validity of the construct are provided (Trochim \& Donnelly, 2008). Convergent validity can indicate if the variables under the same construct or the similar constructs, which are supposed to be related, are indeed related, whereas, discriminant validity shows that the constructs or variables which should be distinctive from each other, are indeed shown to be different (Trochim \& Donnelly, 2008). Convergent validity and discriminant validity can be examined by using correlation. High correlations among the variables/constructs can show convergent validity, whereas, low or not very high correlations can indicate discriminant validity.

In this current study, the construct validity of the questionnaire was established based on the careful processes of developing the questionnaire items, the review of the experts and factor analysis. The details of these processes are provided in Section 6.6.1 above. Moreover, the correlation among the similar and dissimilar sub- 
sections/sub-constructs was checked to ensure the convergent and discriminant validity of sub-sections/sub-constructs of the questionnaire. This is to confirm that the similar sub-sections/sub-constructs should be related and vice versa.

As stated earlier in Chapter 3, and Chapter 5, the development of pre-service EFL teachers' assessment literacy was based on previous literature. The questionnaire items were grouped into six sub-constructs including pedagogical content knowledge (PCK), beliefs of language testing and assessment, understanding of assessment qualities (UAQ), assessment for learning (AFL), assessment of learning (AOL) and ethical issues in testing and assessment (EI). In some sub-constructs, there are subsections. Pedagogical content knowledge (PCK) consists of four sub-sections: knowledge of teaching objectives and curriculum (TOC), knowledge of contextual issues (CI), knowledge of instructional strategies (IS), knowledge of students' learning (SL), and knowledge of subject-matter (SM). The sub-construct beliefs of language testing and assessment includes beliefs in assessment for learning (BAFL), and beliefs in assessment of learning (BAOL). In assessment for learning $(A F L)$, there are three sub-sections: planning assessment (PA), conducting assessment (CA), and using assessment data (UA). Assessment of learning (AOL) has two sub-sections: prepare for tests $(P T)$ and interpret test results (IT). Using SPSS version 18, the correlation between the sub-sections and the sub-construct was examined. For example, in the sub-construct pedagogical content knowledge (PCK), the convergent validity is good when each sub-section correlates highly with the sub-construct PCK (for example, .858 between TOC and PCK). For the dissimilar sub-sections under this sub-construct, the divergent validity among the sub-sections is also good as shown in the relatively low correlation among these subs-sections (for example, .690 between TOC and CI, .685 between TOC and SL). Similar patterns were found for other sub-constructs, for example, assessment for learning (AFL) and assessment of learning (AOL). For the two sub-constructs: understanding of assessment qualities (UAQ) and ethical issues (EI), the correlation among the items under each subconstruct was checked to ensure the convergent and discriminant validity. The summary of the results is presented in Tables 6-5 to 6-10. 
Table 6-5: Correlations among the sub-sections of PCK

\begin{tabular}{|l|l|l|l|l|l|l|}
\cline { 2 - 7 } \multicolumn{1}{c|}{} & TOC & CI & IS & SL & SM & PCK \\
\hline TOC & & .690 & .685 & .660 & .704 & .858 \\
CI & .690 & & .682 & .738 & .672 & .867 \\
IS & .685 & .682 & & .694 & .779 & .883 \\
SL & .660 & .738 & .694 & & .741 & .875 \\
SM & .704 & .672 & .779 & .741 & & .886 \\
\hline
\end{tabular}

Table 6-6: Correlations among the items of UAQ

\begin{tabular}{|l|l|l|l|l|l|l|l|}
\cline { 2 - 8 } \multicolumn{1}{c|}{} & Q44 & Q45 & Q46 & Q47 & Q48 & Q49 & UAQ \\
\hline Q44 & & .444 & .538 & .425 & .472 & .441 & .728 \\
Q45 & .444 & & .666 & .678 & .601 & .459 & .809 \\
Q46 & .538 & .666 & & .605 & .675 & .452 & .836 \\
Q47 & .425 & .678 & .605 & & .747 & .399 & .810 \\
Q48 & .472 & .601 & .675 & .747 & & .423 & .829 \\
Q49 & .441 & .459 & .452 & .399 & .423 & & .680 \\
\hline
\end{tabular}

Table 6-7: Correlations among the sub-sections of AFL

\begin{tabular}{|l|l|l|l|l|}
\cline { 2 - 5 } \multicolumn{1}{c|}{} & PA & CA & UA & AFL \\
\hline PA & & .755 & .733 & .843 \\
CA & .755 & & .802 & .868 \\
UA & .843 & .802 & & .988 \\
\hline
\end{tabular}

Table 6-8: Correlations among the items of EI

\begin{tabular}{|l|l|l|l|l|l|l|l|}
\cline { 3 - 8 } \multicolumn{1}{c|}{} & Q77 & Q78 & Q79 & Q80 & Q81 & Q82 & EI \\
\hline Q77 & & .774 & .633 & .559 & .622 & .558 & .893 \\
Q78 & .774 & & .592 & .547 & .586 & .511 & .804 \\
Q79 & .633 & .592 & & .583 & .672 & .601 & .823 \\
Q80 & .559 & .547 & .583 & & .652 & .613 & .807 \\
Q81 & .622 & .586 & .672 & .652 & & .682 & .854 \\
Q82 & .588 & .511 & .601 & .613 & .682 & & .814 \\
& & & & & & & \\
\hline
\end{tabular}

Table 6-9: Correlations among the sub-sections of AOL

\begin{tabular}{|l|l|l|l|}
\cline { 2 - 4 } \multicolumn{1}{c|}{} & PT & IT & AOL \\
\hline PA & & .638 & .918 \\
CA & .638 & & .891 \\
\hline
\end{tabular}


Table 6-10: Correlations among the sub-constructs

\begin{tabular}{|l|l|l|l|l|l|l|l|}
\cline { 2 - 8 } \multicolumn{1}{c|}{} & PCK & AFL & AOL & EI & UAQ & BAFL & BAOL \\
\hline PCK & & .829 & .713 & .670 & .697 & .713 & .446 \\
AFL & .829 & & .787 & .803 & .768 & .724 & .450 \\
AOL & .713 & .787 & & .758 & .670 & .527 & .517 \\
EI & .670 & .803 & .758 & & .671 & .535 & .461 \\
UAQ & .697 & .768 & .670 & .671 & & .717 & .588 \\
BAL & .713 & .724 & .527 & .535 & .717 & & .404 \\
BAAP & .446 & .450 & .517 & .461 & .588 & .404 & \\
\hline
\end{tabular}

\subsection{Limitations}

Despite the attempts to ensure the quality of this study, limitations are unavoidable. This phase acknowledges the following limitations:

$\checkmark$ Firstly, there might be a problem of bias in subject selection. Only the preservice EFL teachers at the four key teacher training universities in the three biggest cities in Vietnam were recruited. Therefore, the findings may only indicate the assessment confidence levels of the pre-service EFL teachers at these universities.

$\checkmark$ Secondly, this phase only included self-report data. The data could have been triangulated by observing pre-service EFL teachers' assessment practices and interviewing them.

$\checkmark$ Thirdly, due to the availability of the participants, I was unable to recruit a satisfactory number of participants for factor analysis in questionnaire validation as suggested by experts (Jung, 2013; Pallant, 2010).

$\checkmark$ Fourth, due to my inability to return to Vietnam on a number of occasions, I had to ask my colleagues and friends to collect the data. Therefore, I could not control all the biases and problems that might occur during this process.

\subsection{Summary}

This chapter describes the two stages of Phase 2 which looks at the assessment literacy confidence levels of the pre-service EFL teachers at the four key teacher training universities in Vietnam. All the details including the research questions and research procedures were carefully described. This chapter also discusses the validity and reliability of Phase 2 as well as presents its limitations. 
The following chapter (Chapter 7) will provide the findings and discussion of Phase 2. 


\section{Chapter 7:}

\section{PHASE 2 - PRE-SERVICE EFL TEACHERS' ASSESSMENT LITERACY CONFIDENCE LEVELS}

\section{Results and Discussion}

\subsection{Introduction}

As stated in Chapter 6, in Phase 2, the pre-service EFL teachers at the four teachertraining universities were asked to complete the questionnaire of pre-service EFL teachers' confidence levels in assessment literacy by marking their confidence levels on the scale from $0 \%$ to $100 \%$ for each questionnaire item. This chapter presents the findings of Phase 2 by first describing the overall assessment literacy confidence levels of the pre-service EFL teachers. Then it respectively looks at the relationship between gender, career choice, teaching experience, language testing and assessment training and pre-service EFL teachers' assessment literacy confidence levels. After that, it discusses the key findings in Phase 2. The chapter ends with a summary.

\subsection{Pre-service teachers' assessment literacy confidence levels}

The descriptive statistics of the questionnaires' results show relatively high levels of assessment literacy among these pre-service EFL teachers. In pedagogical content knowledge, the pre-service EFL teachers felt confident of their knowledge of teaching objectives $(M=75.7, S D=12.1)$, knowledge of contextual issues $(M=76.3, S D=$ 11.9), knowledge of instructional strategies $(M=72.8, S D=12.6)$, and knowledge of students' learning $(M=75.9, S D=11.5)$.

However, they scored the lowest confidence levels in their knowledge of subject matter $(M=66.0, S D=10.7)$. Their low confidence in their knowledge of subject matter might be explained by their lack of confidence in their English proficiency. In Vietnam, English proficiency of EFL teachers has been considered as an alarming issue for teacher preparation programmes and professional development of EFL teachers. A recent report in Tuoitre newspaper stated that most of the current Vietnamese EFL teachers were unable to pass the national English proficiency tests for EFL high school teachers ("Nâng chuẩn giáo viên tiếng Anh,” 2014). 
In regard to their beliefs in language testing assessment, the pre-service EFL teachers demonstrated stronger beliefs in assessment for learning $(M=77.7, S D=13.4)$ rather than assessment of learning $(M=67.1, S D=14.1)$. This is a good sign for testing and assessment reform in Vietnam. This is because it is likely that those who believe in the role of assessment for learning will use testing and assessment for enhancing teaching and learning quality, rather than only for accountability purposes. Moreover, the results indicate that the pre-service EFL teachers showed strong confidence in their understanding of assessment qualities $(M=73.9, S D=12.3)$. This means they were confident of their understanding of the six qualities of good testing and assessment including validity, reliability, practicality, interactiveness, authenticity, and impact as stated in the literature. Their high confidence in these issues might be because language testing and assessment courses paid more attention to test validation and psychometrics as reported by teacher-trainers in Phase 1.

Moreover, in assessment for learning, the pre-service EFL teachers were more confident in planning assessment $(M=76.0, S D=11.9)$, and using assessment data $(M=74.3, S D=11.6)$ than conducting assessment $(M=72.8, S D=12.9)$. In contrast, in assessment of learning, the pre-service EFL teachers scored higher confidence levels in interpreting test results $(M=72.9, S D=12.8)$ than in preparing for tests $(M$ $=69.5, S D=14.6)$. Their lower confidence in conducting assessment and preparing for tests might be explained by their lack of experience in testing and assessment in language classrooms. Therefore, it is important that teacher preparation programmes offer pre-service EFL teachers adequate practice in conducting assessment and preparing for tests.

Lastly, the pre-service EFL teachers were confident of their knowledge of the ethical issues in language testing and assessment $(M=71.4, S D=12.9)$. This result is aligned with what McGee and Colby (2014) found in their study that pre-service teachers scored high results in ethical issues, scoring and choosing assessment methods.

In general, the questionnaire's results indicate that pre-service EFL teachers felt confident in their assessment knowledge and skills. Table 7-1 below shows the summary of their confidence levels in testing and assessment. Graph 7-1 illustrates their confidence levels in different aspects of assessment literacy. 
Table 7-1: Overall pre-service EFL teachers' assessment literacy

\begin{tabular}{lllll}
\hline Section & Sub-section & N & Mean & SD \\
\hline \multirow{4}{*}{$\begin{array}{l}\text { Pedagogical content } \\
\text { knowledge }\end{array}$} & $\begin{array}{l}\text { Knowledge of teaching objectives } \\
\text { and curriculum }\end{array}$ & 365 & 75.7 & 12.1 \\
\cline { 2 - 5 } & Knowledge of contextual issues & 365 & 76.3 & 11.9 \\
\cline { 2 - 5 } & $\begin{array}{l}\text { Knowledge of instructional } \\
\text { strategies }\end{array}$ & 365 & 72.8 & 12.6 \\
\cline { 2 - 5 } & Knowledge of students 'learning & 365 & 75.9 & 11.5 \\
\cline { 2 - 5 } & Knowledge of subject matter & 365 & 66.0 & 10.7 \\
\hline $\begin{array}{l}\text { Beliefs of language testing and } \\
\text { assessment }\end{array}$ & Assessment for learning & 365 & 77.7 & 13.4 \\
\cline { 2 - 5 } $\begin{array}{l}\text { Understanding of assessment } \\
\text { qualities }\end{array}$ & Assessment of learning & 365 & 67.1 & 14.1 \\
\hline \multirow{3}{*}{$\begin{array}{l}\text { Assessment for learning } \\
\text { Assessment of learning }\end{array}$} & Planning assessment & 365 & 73.9 & 12.3 \\
\cline { 2 - 5 } & Conducting assessment & 365 & 76.0 & 11.9 \\
\cline { 2 - 5 } & Using assessment data & 365 & 74.3 & 11.6 \\
\hline $\begin{array}{l}\text { Ethical issues in language } \\
\text { testing and assessment } \\
\text { practices }\end{array}$ & Prepare for tests & 365 & 69.5 & 14.6 \\
\hline
\end{tabular}




\section{Graph 7-1: Overall pre-service EFL teachers' confidence levels in assessment literacy}

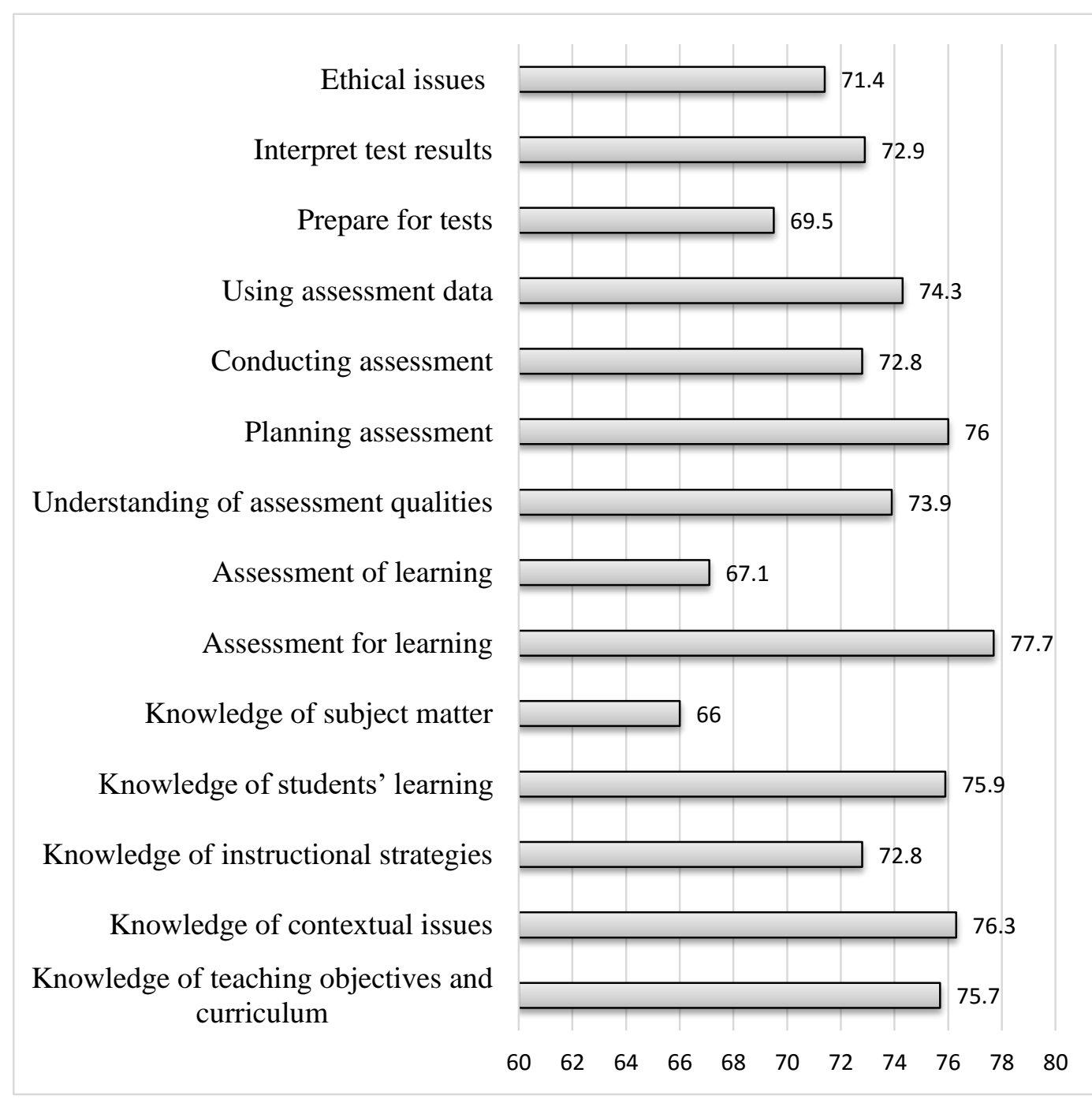

\subsection{Gender and pre-service teachers' assessment literacy confidence levels}

The dominance of female pre-service EFL teachers shows a significant trend of career choice in Vietnam where teaching is supposed to be a noble and suitable job for females. In this study, there were eleven times more female teachers $(\mathrm{N}=336)$ than male pre-service teachers $(\mathrm{N}=29)$. Therefore, it is important to know if gender could affect their assessment literacy confidence levels.

An independent samples t-test was conducted to compare the assessment literacy confidence levels between the male and female pre-service EFL teachers in this study. As can be seen from Table 7-2, the results of the independent samples t-test identified that the $\mathrm{p}$ value is above .05 which means that there is no statistically significant difference between the average scores of the pre-service EFL teachers' confidence 
levels in assessment literacy between the two groups. For example, in knowledge of contextual issues, there was no statistically significant difference in the scores for males $(M=78.51, S D=11.5)$ and females $(M=76.08, S D=11.97 ; t(363)=.885, p$ $=.39$, two-tailed). The magnitude of the differences in the means (mean difference $=$ $2.02,95 \% C I$ : -2.57 to 6.61$)$ was very small $(d=.016)$. The same pattern was found for other sub-constructs/ sub-sections of the questionnaire.

Based on these data, it can be concluded that gender had little effect on the pre-service EFL teachers' assessment literacy confidence levels. However, as can be seen in Graph 7-2, males did show a higher confidence levels in most aspects of assessment literacy than females. The overview of the findings is presented in Graph 7-2 and the details of the findings are summarised in Table 7-2.

\section{Graph 7-2: Gender and pre-service EFL teachers' assessment literacy confidence levels}

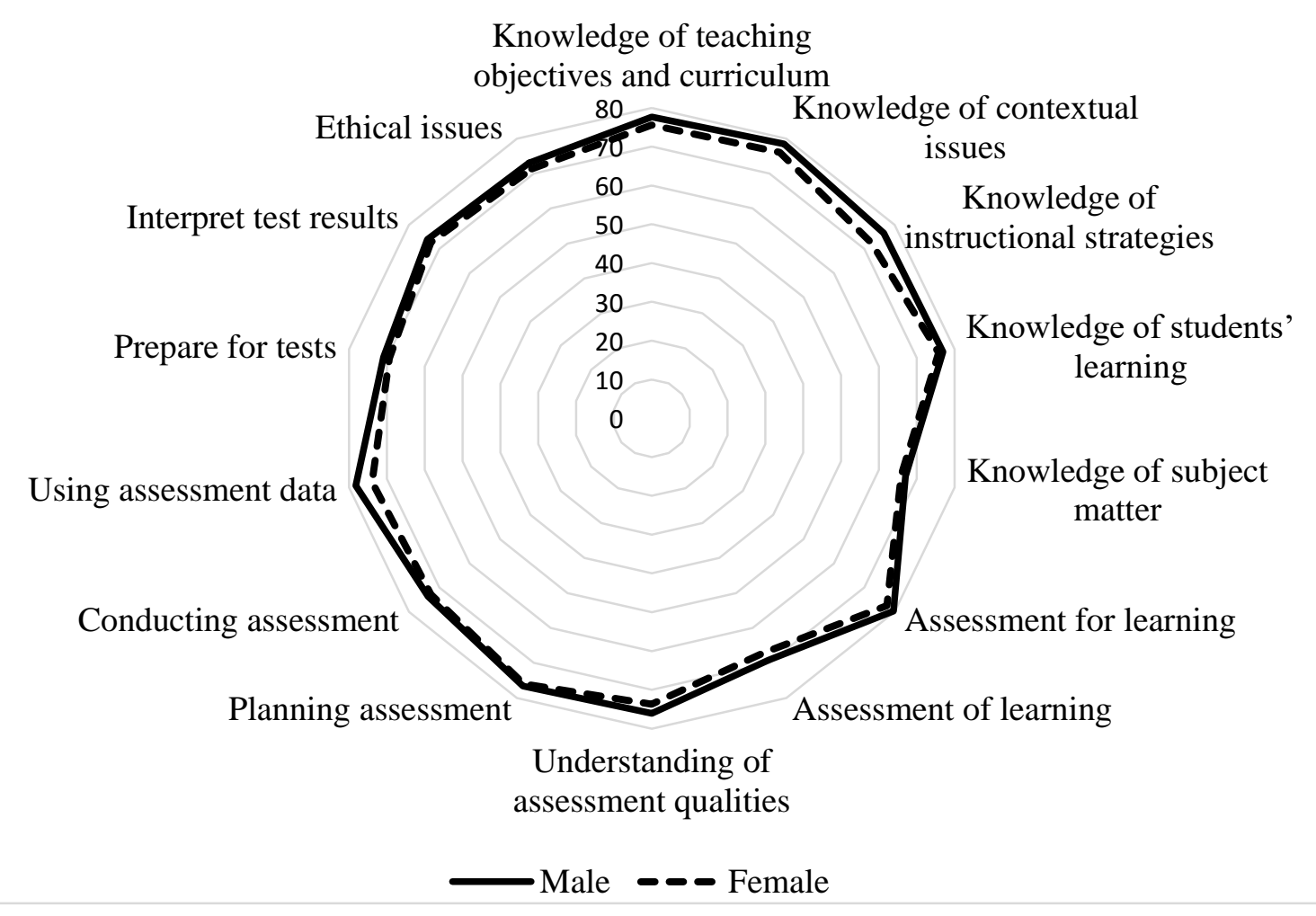


Table 7-2: Gender and pre-service EFL teachers' assessment literacy confidence levels

\begin{tabular}{|c|c|c|c|c|c|c|c|c|}
\hline \multirow[t]{2}{*}{ Section } & \multirow[t]{2}{*}{ Sub-section } & \multicolumn{2}{|c|}{$\begin{array}{c}\text { Male } \\
(\mathrm{N}=\mathbf{2 9})\end{array}$} & \multicolumn{2}{|c|}{$\begin{array}{l}\text { Female } \\
(\mathbf{N}=336)\end{array}$} & \multicolumn{3}{|c|}{ Independent samples t-test } \\
\hline & & Mean & SD & Mean & SD & t-value & $\mathbf{p}$ & Cohen's $d$ \\
\hline \multirow{5}{*}{ Pedagogical content knowledge } & $\begin{array}{l}\text { Knowledge of teaching objectives } \\
\text { and curriculum }\end{array}$ & 77.6 & 12.9 & 75.6 & 12.0 & 0.89 & 0.39 & 0.16 \\
\hline & Knowledge of contextual issues & 78.5 & 11.5 & 76.1 & 12.0 & 1.05 & 0.29 & 0.21 \\
\hline & Knowledge of instructional strategies & 76.5 & 15.0 & 72.4 & 12.4 & 1.66 & 0.98 & 0.29 \\
\hline & Knowledge of students' learning & 77.0 & 9.87 & 75.8 & 11.7 & 0.56 & 0.52 & 0.12 \\
\hline & Knowledge of subject matter & 67.1 & 12.0 & 65.9 & 10.5 & 0.59 & 0.58 & 0.11 \\
\hline \multirow{2}{*}{$\begin{array}{l}\text { Beliefs of language testing and } \\
\text { assessment }\end{array}$} & Assessment for learning & 79.7 & 11.6 & 77.5 & 13.5 & 0.84 & 0.35 & 0.17 \\
\hline & Assessment of learning & 69.2 & 13.0 & 67.0 & 14.2 & 0.81 & 0.39 & 0.16 \\
\hline $\begin{array}{l}\text { Understanding of assessment } \\
\text { qualities }\end{array}$ & & 76.1 & 12.6 & 73.7 & 12.3 & 1.00 & 0.34 & 0.19 \\
\hline \multirow{3}{*}{ Assessment for learning } & Planning assessment & 76.6 & 11.8 & 76.0 & 11.9 & 0.24 & 0.81 & 0.05 \\
\hline & Conducting assessment & 73.7 & 13.8 & 72.8 & 12.8 & 0.37 & 0.72 & 0.07 \\
\hline & Using assessment data & 78.2 & 11.0 & 73.9 & 11.6 & 1.90 & 0.08 & 0.38 \\
\hline \multirow{2}{*}{ Assessment of learning } & Prepare for tests & 70.9 & 14.5 & 69.4 & 14.6 & 0.53 & 0.60 & 0.10 \\
\hline & Interpret tests & 73.9 & 13.0 & 72.8 & 12.8 & 0.46 & 0.66 & 0.09 \\
\hline $\begin{array}{l}\text { Ethical issues in language } \\
\text { testing and assessment } \\
\text { practices }\end{array}$ & & 73.0 & 12.4 & 71.3 & 13.0 & 0.67 & 0.49 & 0.13 \\
\hline
\end{tabular}




\subsection{Career choice and pre-service EFL teachers' assessment literacy confidence levels}

In Vietnam, it is quite common that pre-service EFL teachers who choose to study at teacher training universities do not want to become teachers. As seen from the findings in Phase 1, the teacher-trainers reported that only the pre-service EFL teachers who were interested in becoming teachers would see the importance of the course and would have a good motivation for improving their assessment literacy. Therefore, whether pre-service EFL teachers' career choice would influence their assessment literacy confidence levels is an important issue that needs investigating. This problem is addressed in this phase when the relationship between career choice and pre-service EFL teachers' confidence levels in assessment literacy was examined.

To investigate whether career choice had an effect on the pre-service EFL teachers' assessment literacy confidence levels, an independent samples t-test was conducted to compare Group A $(\mathrm{N}=291)$ who wanted to become teachers after graduation and Group B $(\mathrm{N}=74)$ who did not want to choose a teaching career after graduation. The results as shown in Table 7-3 indicate no statistically significant difference in the average scores for all sub-constructs of the pre-service teachers' assessment literacy confidence levels between the two groups ( $\mathrm{p}>.05)$, except for beliefs of assessment of learning $(\mathrm{p}<.05)$.

For example, in knowledge of teaching objectives and curriculum, there was no statistically significant difference in the scores for Group A $(M=75.9, S D=11.5)$ and Group B $(M=75.2, S D=14.0 ; t(363)=.42, \mathrm{p}=.68$, two-tailed $)$. The magnitude of the differences in the means (mean difference $=.656,95 \%$ CI: -2.43 to 3.74 ) was very small $(d=0.05)$. Similarly, the same patterns of findings were found for other sub-constructs of assessment literacy confidence levels.

Based on these data, it can be concluded that career choice had little effect on most of the sub-constructs of the pre-service EFL teachers' assessment literacy confidence levels. This finding is contradictory to what teacher-trainers supposed that only those pre-service EFL teachers who were interested in becoming teachers after graduation would be motivated to learn about testing and assessment. Thus, further studies and 
data triangulation should be done to understand more about this problem in assessment training for pre-service EFL teachers in teacher preparation programmes. Moreover, it is interesting to find that pre-service EFL teachers' beliefs in testing and assessment were stable because this finding is aligned with previous studies which argued that pre-service teachers' beliefs are hard to change (Pajares, 1992). The overview of the findings is presented in Graph 7-3 and the details of the findings are summarised in Table 7-3.

\section{Graph 7-3: Career choice and pre-service EFL teachers' assessment literacy}

\section{confidence levels}

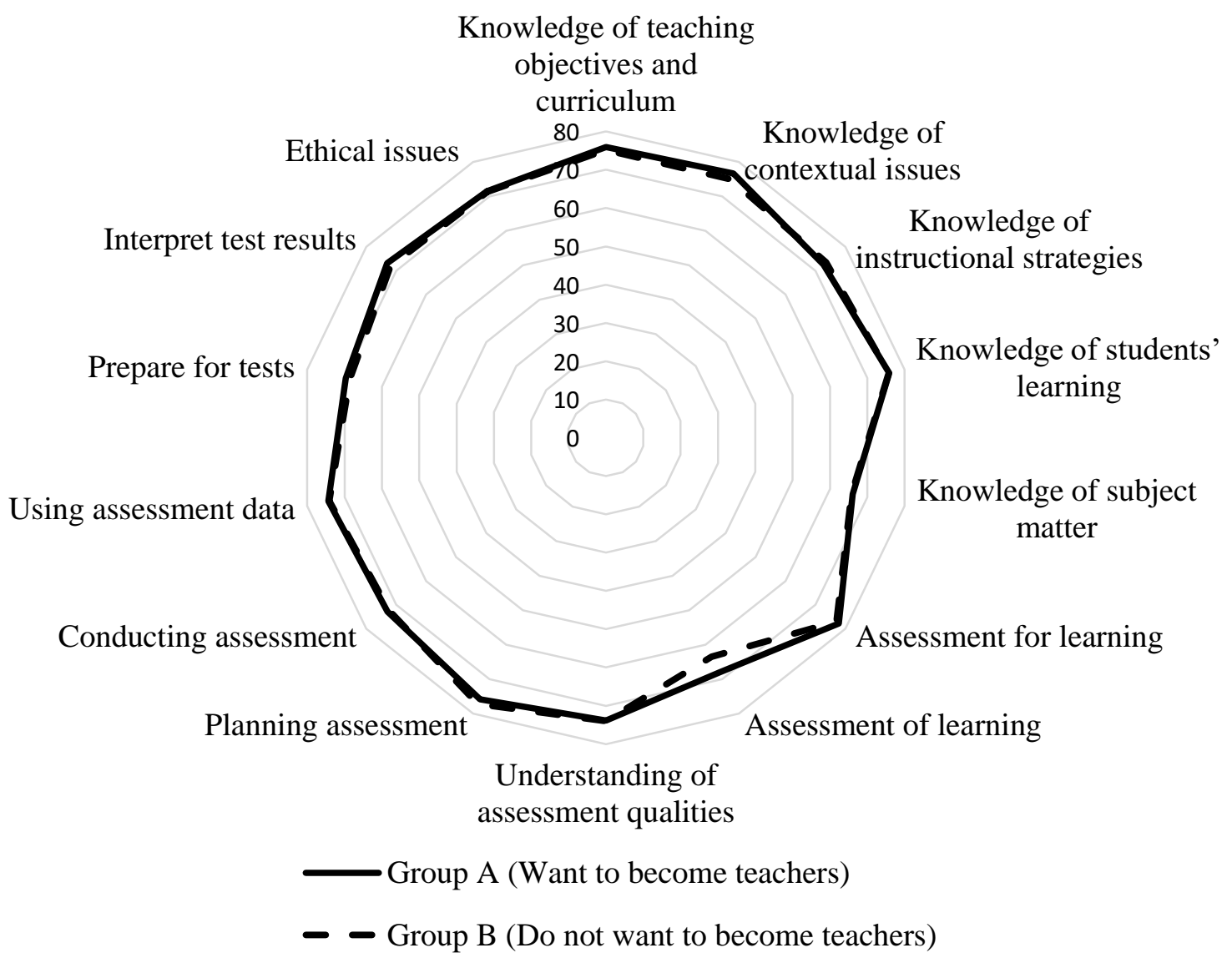


Table 7-3: Career choice and pre-service EFL teachers' assessment literacy

\begin{tabular}{|c|c|c|c|c|c|c|c|c|}
\hline & \multirow{2}{*}{ Sub-section } & \multicolumn{2}{|c|}{$\begin{array}{c}\text { Group A } \\
(\mathbf{n}=219)\end{array}$} & \multicolumn{2}{|c|}{$\begin{array}{c}\text { Group B } \\
(\mathrm{n}=74)\end{array}$} & \multicolumn{3}{|c|}{$\begin{array}{c}\text { Independent samples t- } \\
\text { test }\end{array}$} \\
\hline & & Mean & SD & Mean & SD & t-value & $\mathbf{p}$ & $\begin{array}{l}\text { Cohen's } \\
d\end{array}$ \\
\hline \multirow{5}{*}{ Pedagogical content knowledge } & $\begin{array}{l}\text { Knowledge of teaching objectives and } \\
\text { curriculum }\end{array}$ & 75.9 & 11.5 & 75.2 & 14.0 & 0.42 & 0.68 & 0.05 \\
\hline & Knowledge of contextual issues & 76.6 & 11.5 & 75.0 & 13.4 & 0.99 & 0.32 & 0.12 \\
\hline & Knowledge of instructional strategies & 72.6 & 12.5 & 73.5 & 13.2 & -0.58 & 0.57 & -0.07 \\
\hline & Knowledge of students' learning & 75.9 & 11.1 & 75.7 & 13.0 & 1.28 & 0.90 & 0.02 \\
\hline & Knowledge of subject matter & 66.1 & 10.2 & 65.8 & 12.5 & 1.66 & 0.87 & 0.02 \\
\hline \multirow{2}{*}{$\begin{array}{l}\text { Beliefs of language testing and } \\
\text { assessment }\end{array}$} & Assessment for learning & 77.8 & 13.2 & 77.0 & 14.2 & 0.44 & 0.66 & 0.06 \\
\hline & Assessment of learning & 68.1 & 13.5 & 63.5 & 15.8 & 2.48 & 0.01 & 0.31 \\
\hline Understanding of assessment qualities & & 73.9 & 12.0 & 74.0 & 13.4 & -0.06 & 0.95 & -0.01 \\
\hline \multirow{3}{*}{ Assessment for learning } & Planning assessment & 75.8 & 11.6 & 77.2 & 13.0 & -0.90 & 0.37 & -0.11 \\
\hline & Conducting assessment & 72.9 & 12.2 & 72.4 & 15.4 & 0.31 & 0.79 & 0.04 \\
\hline & Using assessment data & 74.3 & 11.0 & 74.1 & 13.8 & 0.87 & 0.99 & 0.02 \\
\hline \multirow{2}{*}{ Assessment of learning } & Prepare for tests & 69.7 & 14.3 & 68.6 & 15.8 & 0.60 & 0.55 & 0.08 \\
\hline & Interpret tests & 73.1 & 11.8 & 71.9 & 16.0 & 0.71 & 0.48 & 0.08 \\
\hline $\begin{array}{l}\text { Ethical issues in language testing and } \\
\text { assessment practices }\end{array}$ & & 71.5 & 12.3 & 71.3 & 15.5 & 0.13 & 0.90 & 0.02 \\
\hline
\end{tabular}




\subsection{Teaching experience and pre-service EFL teachers' assessment literacy confidence levels}

In Vietnam, pre-service EFL teachers do not usually have any formal teaching experience at school before a practicum. However, it is common that they work as teaching assistants or private tutors for language centres. Therefore, it is interesting to know if the teaching experience they got from their part-time jobs as teaching assistants and private tutors influenced their assessment literacy confidence levels.

In order to check whether the pre-service EFL teachers' teaching experience influenced their assessment literacy confidence levels, an independent samples t-test was conducted to examine the average score difference between Group C ( $N=293)$ who had teaching experience and Group D $(\mathrm{N}=72)$ who did not have any teaching experience. The results show a statistically significant difference in the average scores of these two groups in twelve out of fourteen sub-sections in the questionnaire $(\mathrm{p}<.05)$ except for their beliefs in assessment for learning and assessment of learning $(\mathrm{p}>.05)$

For instance, in knowledge of teaching objectives and curriculum, there was a statistically significant difference in the scores for Group C $(M=77.0, S D=12.0)$ and Group D $(M=70.4, S D=10.48 ; t(363)=4.26, \mathrm{p}=.000$, two-tailed $)$. The magnitude of the differences in the means (mean difference $=6.61,95 \%$ CI: 3.56 to 9.66) was moderate $(d=.58)$. Similarly, the same patterns of findings were found for knowledge of contextual issues, knowledge of instructional strategies, knowledge of students' learning, knowledge of subject matter, understanding of assessment qualities, planning assessment, conducting assessment, using assessment data and interpreting tests, and the ethical issues in language testing and assessment. However, there was no statistically significant difference in the scores between the two groups in their beliefs of testing and assessment ( $\mathrm{p}>.05)$.

To sum up, the results of the independent samples t-test indicate the effects of teaching experience on the pre-service EFL teachers' confidence levels in pedagogical content knowledge, understanding of assessment qualities, and assessment for learning, assessment for accountability purposes, and ethical issues 
in language testing and assessment. Also, those who had some teaching experience showed a higher level of confidence in assessment literacy. However, teaching experience did not influence the pre-service EFL teachers' testing and assessment beliefs. This finding can indicate that pre-service EFL teachers' beliefs in testing and assessment are unlikely to change.

The overview of the findings is presented in Graph 7-4 and the details of the findings are summarised in Table 7-4.

\section{Graph 7-4: Teaching experience and pre-service EFL teachers' assessment literacy} confidence levels

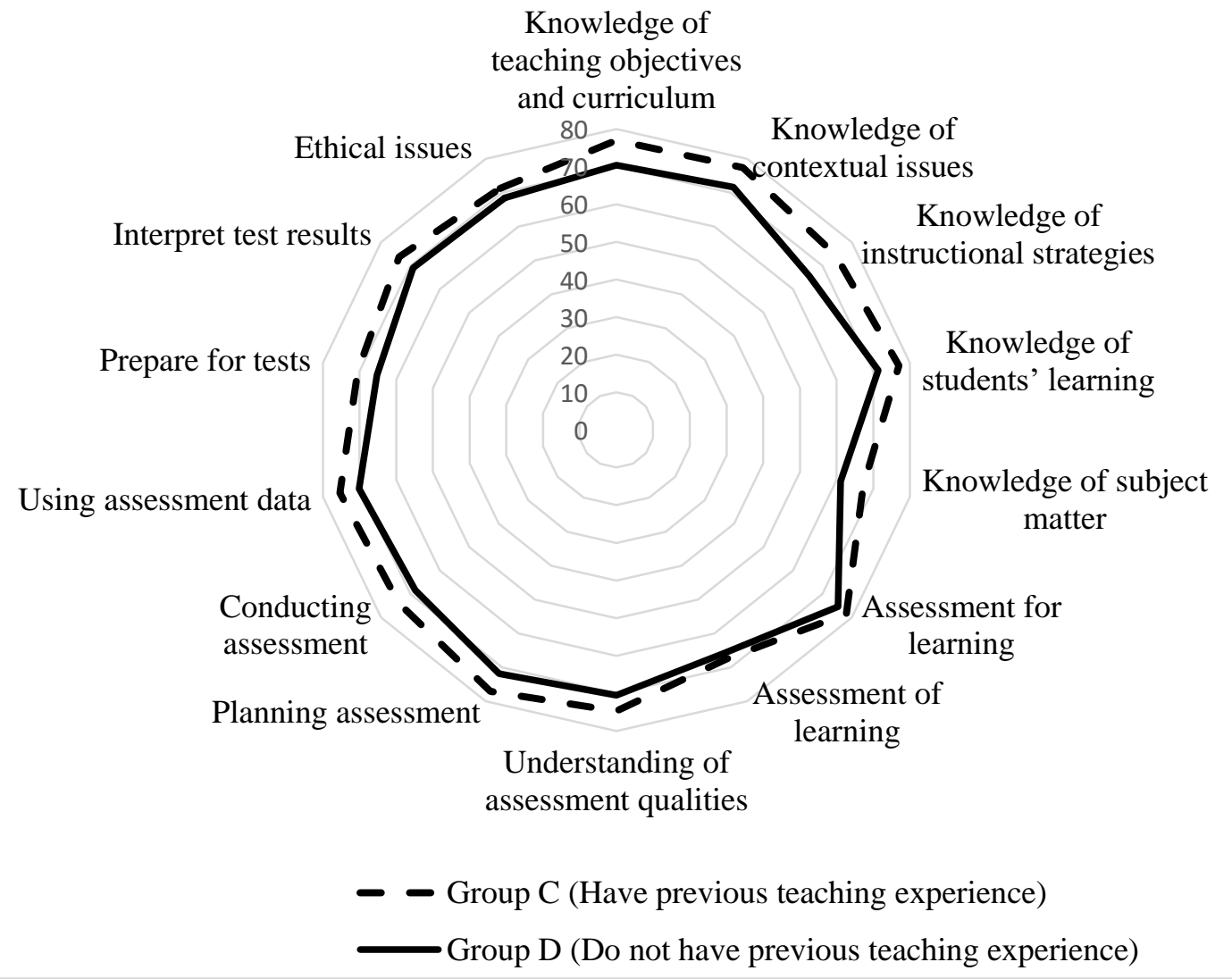


Table 7-4: Teaching experience and pre-service EFL teachers' assessment literacy confidence levels

\begin{tabular}{|c|c|c|c|c|c|c|c|c|}
\hline \multirow{2}{*}{ Section } & \multirow{2}{*}{ Sub-section } & \multicolumn{2}{|c|}{$\begin{array}{c}\text { Group C } \\
(\mathrm{N}=293) \\
\end{array}$} & \multicolumn{2}{|c|}{$\begin{array}{c}\text { Group D } \\
(\mathrm{N}=72) \\
\end{array}$} & \multicolumn{3}{|c|}{$\begin{array}{c}\text { Independent samples } \\
\text { t-test }\end{array}$} \\
\hline & & Mean & SD & Mean & SD & t-value & $\mathbf{p}$ & $\begin{array}{c}\text { Cohen } \\
{ }^{\prime} d\end{array}$ \\
\hline \multirow{5}{*}{ Pedagogical content knowledge } & $\begin{array}{l}\text { Knowledge of teaching objectives and } \\
\text { curriculum }\end{array}$ & 77.0 & 12.0 & 70.4 & 10.7 & 4.26 & 0.00 & 0.58 \\
\hline & Knowledge of contextual issues & 77.4 & 11.9 & 71.6 & 11.2 & 3.75 & 0.00 & 0.50 \\
\hline & Knowledge of instructional strategies & 74.5 & 12.2 & 65.6 & 11.9 & 5.55 & 0.00 & 0.74 \\
\hline & Knowledge of students' learning & 77.0 & 12.2 & 71.3 & 10.4 & 3.80 & 0.00 & 0.50 \\
\hline & Knowledge of subject matter & 67.2 & 10.6 & 61.1 & 9.5 & 4.51 & 0.00 & 0.61 \\
\hline \multirow{2}{*}{$\begin{array}{l}\text { Beliefs of language testing and } \\
\text { assessment }\end{array}$} & Assessment for learning & 78.2 & 13.6 & 75.3 & 12.2 & 1.70 & 0.09 & 0.23 \\
\hline & Assessment of learning & 67.5 & 14.6 & 65.9 & 12.0 & 0.97 & 0.33 & 0.12 \\
\hline Understanding of assessment qualities & & 74.7 & 12.6 & 70.5 & 10.5 & 2.65 & 0.01 & 0.37 \\
\hline \multirow{3}{*}{ Assessment for learning } & Planning assessment & 77.1 & 11.9 & 71.9 & 10.8 & 3.39 & 0.00 & 0.46 \\
\hline & Conducting assessment & 73.9 & 12.8 & 68.3 & 12.2 & 3.37 & 0.00 & 0.45 \\
\hline & Using assessment data & 75.3 & 11.7 & 70.1 & 10.6 & 3.47 & 0.00 & 0.47 \\
\hline \multirow{2}{*}{ Assessment of learning } & Prepare for tests & 70.5 & 14.5 & 65.3 & 14.1 & 2.77 & 0.01 & 0.37 \\
\hline & Interpret tests & 73.8 & 12.6 & 69.1 & 12.9 & 2.87 & 0.00 & 0.37 \\
\hline $\begin{array}{l}\text { Ethical issues in language testing and } \\
\text { assessment practices }\end{array}$ & & 71.2 & 13.0 & 68.4 & 12.2 & 2.27 & 0.02 & 0.22 \\
\hline
\end{tabular}

Group $C=$ Have previous teaching experience; Group $D=$ Do not have previous teaching experience 


\subsection{Language testing and assessment training and pre-service teachers' assessment literacy confidence levels}

Among the participants in this study, 88 participants had a separate course in testing and assessment while 277 did not. Therefore, it is important to know if training in testing and assessment influenced their assessment literacy confidence levels.

An independent samples t-test was conducted to check if language testing and assessment training influenced the pre-service EFL teachers' assessment literacy confidence levels between the two groups: Group $\mathrm{E}(\mathrm{N}=88)$ from the universities with a separate course in testing and assessment and Group $F(N=277)$ from the universities with no separate course in testing and assessment. Results as shown in Table 7.5 indicated a statistically significant difference between the average score for each sub-section of the pre-service teachers' assessment literacy confidence levels ( $p$ $<.05)$, except for their beliefs in assessment of learning ( $p>05)$.

For example, in knowledge of teaching objectives and curriculum, there was a statistically significant difference in the scores for Group E $(M=71.8, S D=12.1)$ and Group F $(M=77.0, S D=11.79 ; t(363)=-3.59, p=.000$, two-tailed $)$. The magnitude of the differences in the means (mean difference $=-5.224,95 \%$ CI: -8.08 to 2.36) was moderate $(d=0.44)$. Similarly, the same patterns of findings were found for other sub-sections of assessment literacy confidence levels.

Based on these results, it can be concluded that language testing and assessment training had an impact on the pre-service EFL teachers' assessment literacy confidence levels. This finding is similar to what McGee and Colby (2014) found about the influence of assessment training on teacher candidates' assessment literacy. However, in my study, it was surprising that those from the universities without a separate course in testing and assessment scored higher than those from the universities with a separate course in testing and assessment. Therefore, it is important that pre-service EFL teachers should be provided with more training in testing and assessment and opportunities for testing and assessment practices. This helps them assess their confidence levels in assessment literacy more accurately. 
The overview of the findings is presented in Graph 7-5 and the details of the findings are summarised in Table 7.5.

Graph 7-5: Language testing and assessment training and pre-service EFL teachers' assessment literacy confidence levels

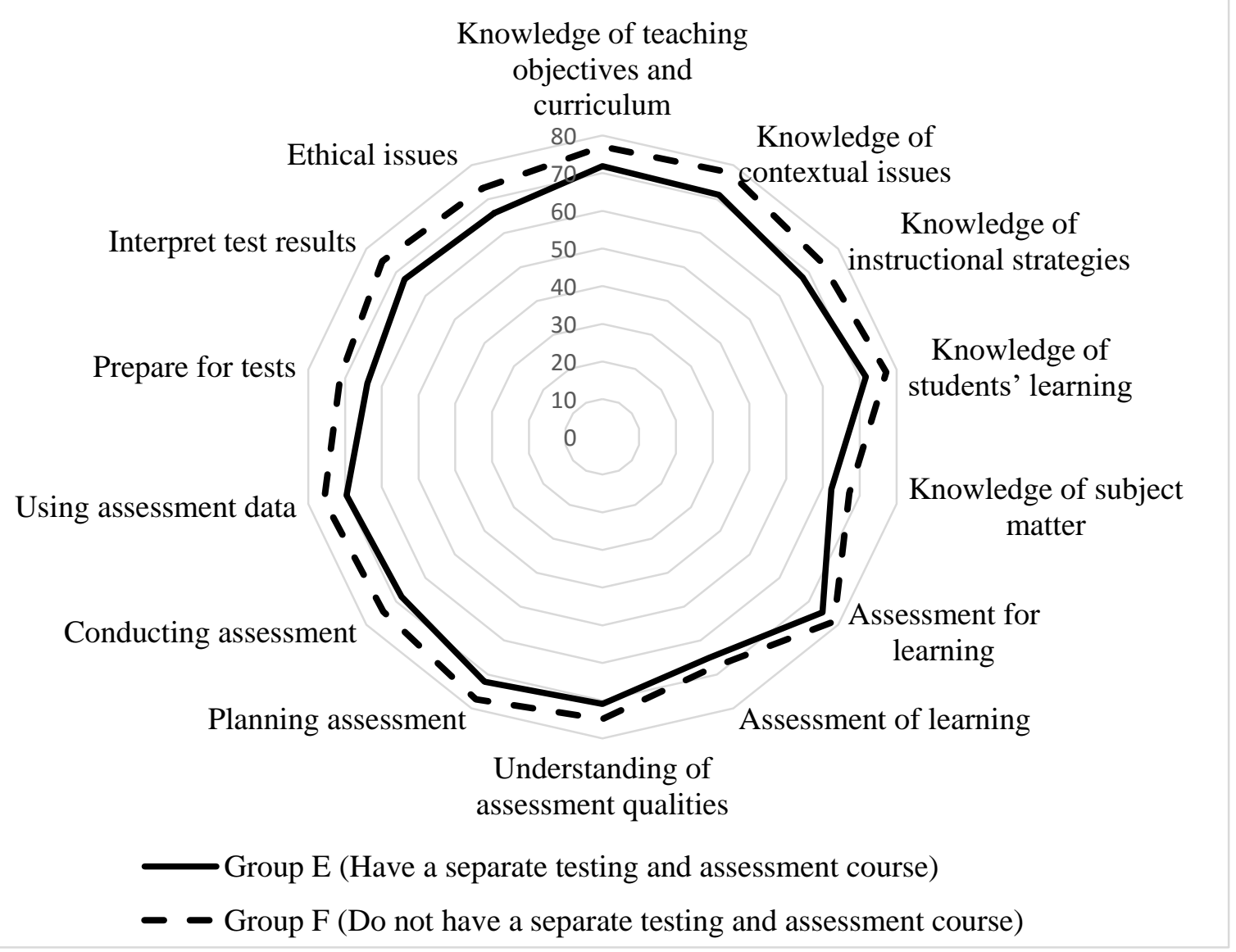


Table 7-5: Language testing and assessment training and pre-service EFL teachers' assessment literacy confidence levels

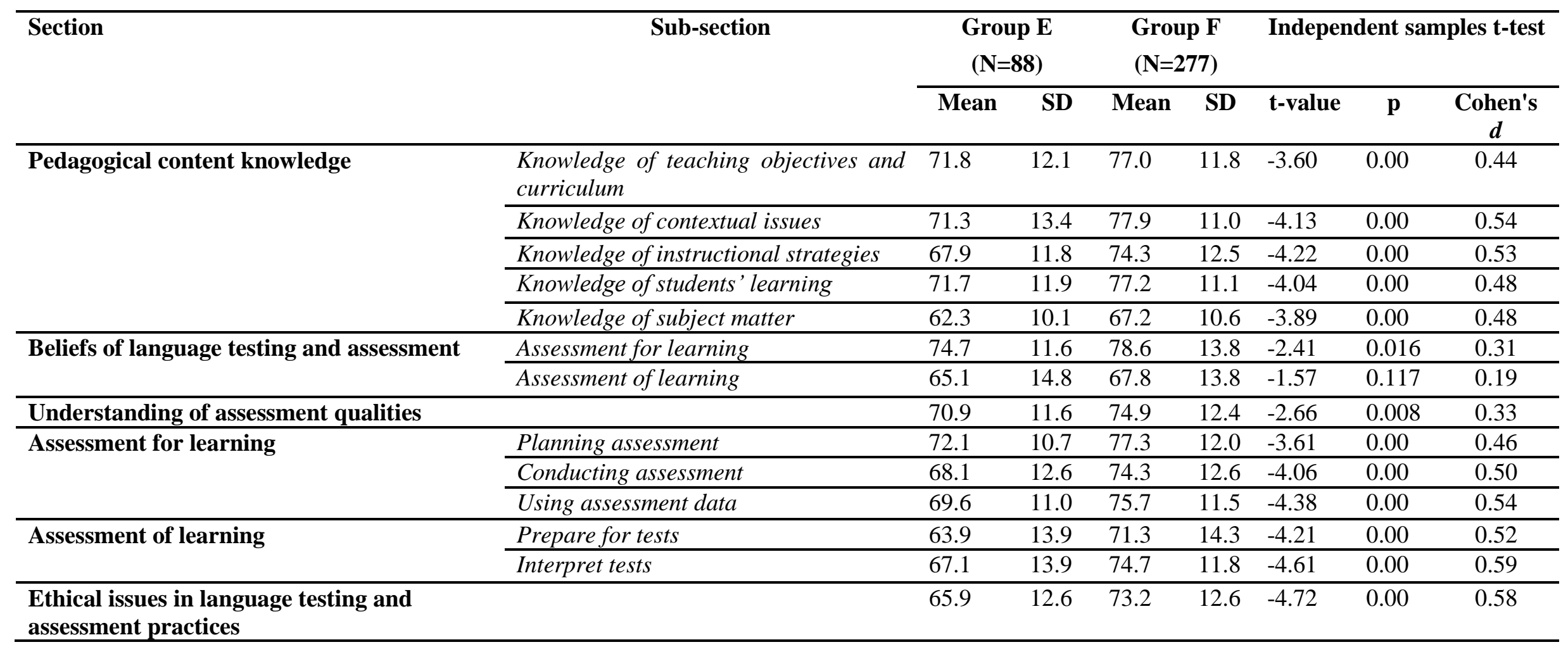

Group $E=$ Have a separate course in testing and assessment; Group $F=$ Do not have a separate course in testing and assessment 


\subsection{Discussion}

As a point of difference from the previous studies which tested pre-service EFL teachers' assessment literacy (Mertler, 2003; Volante \& Fazio, 2007), this study looks at the assessment literacy confidence levels of pre-service EFL teachers. 365 participants from four teacher training universities were asked to complete the questionnaire of pre-service EFL teachers' confidence levels in assessment literacy. The quantitative results suggest both pedagogical and methodological issues that should be taken into consideration.

\subsubsection{Pedagogical issues}

There are some important pedagogical issues that arise from the results of this study:

Firstly, in Phase 1, the teacher-trainers reported that only the pre-service EFL teachers who wanted to become teachers would be motivated to improve their assessment literacy. However, the findings from the questionnaire indicate little influence of preservice EFL teachers' career choice on their assessment literacy confidence levels. Therefore, it is inconclusive to claim pre-service EFL teachers' career choice as a barrier to their assessment literacy. It is more important that training in these areas should be relevant to pre-service EFL teachers' needs and be able to help them feel more interested in assessment training.

Secondly, it is surprising that those who had more training in assessment scored lower confidence levels. This raises the question of whether the training could assist the pre-service EFL teachers to become more aware of the complexities of testing and assessment, thus giving them a better understanding of their assessment literacy as well as their abilities in testing and assessment. Besides, the effect of training in testing and assessment on pre-service EFL teachers' assessment literacy emphasizes the importance of this training in teacher preparation programmes. Moreover, this finding also highlights that assessment literacy is a complex construct that cannot be judged only by examining pre-service EFL confidence levels in assessment literacy.

Thirdly, the pre-service EFL teachers' part-time teaching experience as teacher assistants and tutors had an effect on their assessment literacy confidence levels. Thus, it is important that teacher training programmes should create more teaching 
experience for their students. With adequate opportunities to practise testing and assessment, pre-service EFL teachers will be able to assess their confidence levels in assessment literacy more accurately. This would help them avoid being overconfident or underconfident about their knowledge and skills in testing and assessment.

Lastly, the findings indicate that pre-service EFL teachers' beliefs were hard to change. Moreover, gender, career choice, teaching experience and language testing and assessment had very little influence on pre-service EFL teachers' beliefs in testing and assessment. This finding is aligned with what has been reported in the literature that pre-service teachers' beliefs are reported to be hard to change (Kagan, 1992; F. A. J. Korthagen \& Kessels, 1999; Pajares, 1992). However, it is positive in this study that the pre-service EFL teachers believed more in the role of assessment for learning than assessment of learning. Therefore, these teacher training universities should encourage their pre-service EFL teachers to transform their beliefs into practice. This will create a new generation of EFL teachers in Vietnam who will change the way testing and assessment are currently used inside their classroom.

\subsubsection{Methodological issues}

So far in the literature, two research instruments have been widely used to investigate teachers' assessment literacy including: 1) surveys of attitudes, beliefs, and practices (O’Sullivan \& Johnson, 1993; Zhang \& Burry-Stock, 1997), and 2) tests of assessment knowledge (Impara et al., 1993; Mertler \& Campbell, 2005). However, as discussed in Chapter 6, these methods were not selected for my study partly due to the nature of pre-service EFL teachers and their lack of experience in testing and assessment, and partly due to the impracticality of the previous instruments.

Although the questionnaire I developed and validated in this study has a high reliability value and is very practical in collecting a large amount of data, this approach could limit the quality of the participants' answers. The questionnaire approach is unable to explain some problems with pre-service EFL teachers' assessment literacy. In this study, there are some issues that need further clarification from pre-service EFL teachers: for example, the difference in the mean scores of assessment literacy confidence levels between those who had a separate testing and 
assessment course and those who did not. Those who had more training were less confident in assessment literacy than those who did not. However, using only the questionnaire of pre-service EFL teachers' confidence levels hardly helps to uncover the reasons for their confidence levels in assessment literacy and whether the preservice EFL teachers' confidence levels in assessment literacy as they answered in the questionnaire could truly reflect their assessment literacy.

Moreover, pre-service EFL teachers' assessment literacy is a complex construct. Whether their confidence levels in assessment literacy as rated in the questionnaires can reflect their real abilities in testing and assessment should be ratified with other findings, for example, from the observation of their practices, stimulated recalls and interviews. In other words, only the data from the questionnaire of the participants' confidence levels in assessment literacy are inadequate to conclude about their assessment literacy.

\subsection{Summary}

This chapter presents the findings of Phase 2. The questionnaire results indicate relatively high confidence levels of the pre-service EFL teachers in assessment literacy. Moreover, gender and career choice did not affect their assessment literacy confidence levels. However, teaching experience and language testing and assessment training influenced their assessment literacy confidence levels. Those who had more training in testing and assessment were less confident. In addition, preservice EFL teachers' beliefs in testing and assessment were hard to be changed.

The findings of Phase 2 raise some pedagogical and methodological issues that should be taken into consideration. Teacher preparation programmes should pay more attention to link theory to practice in assessment training for pre-service EFL teachers. Moreover, assessment training is recommended to be compulsory in teacher training. In order to understand a complex construct like assessment literacy, it is necessary to investigate it from different perspectives. Only the data from the questionnaire are inadequate to claim pre-service EFL teachers' assessment literacy. Therefore, in Phase 3, I traced the development of the pre-service EFL teachers' 
assessment literacy during the practicum by employing different research instruments such as observations, stimulated recalls and interviews.

The following chapter (Chapter 8) will describe the research methodology of Phase 3 which looked at the development of pre-service EFL teachers' development in assessment literacy during a nine-week practicum. 


\section{Chapter 8:}

PHASE 3 - DEVELOPMENT OF PRE-SERVICE EFL TEACHERS'

\section{ASSESSMENT LITERACY DURING PRACTICUM}

Research Methodology

\subsection{Introduction}

Phase 3 consists of two parts (Part 1 and Part 2) and focuses on tracing assessment literacy development of four pre-service EFL teachers at Bach Dang University during their practicum. Chapter 8 describes the research methodology used in Phase 3. This chapter begins with an overview of Phase 3. It then presents each part of Phase 3 in terms of the research questions, the research participants, the research instruments and the research procedures. Next, it discusses the quality criteria, ethical issues, and the limitations of Phase 3. Finally, the summary of the chapter is provided.

\subsection{Overview of Phase 3}

Phase 3 consists of two parts (Part 1 and Part 2).

PART 1 consists of two stages:

- $\quad \underline{\text { Stage } 1}$ compares

1. the development of the pre-service EFL teachers' confidence levels in assessment literacy before and after their practicum.

2. the development of the pre-service EFL teachers' confidence levels in assessment literacy over three periods of time: before their language testing and assessment course, before their practicum, and after their practicum.

- $\quad$ Stage 2 aims to triangulate the findings in Stage 1.

PART 2 traces the development of four pre-service EFL teachers' assessment literacy during their practicum.

An overview of Phase 3 is provided in Figure 8-1: 
Figure 8-1: Overview of Phase 3

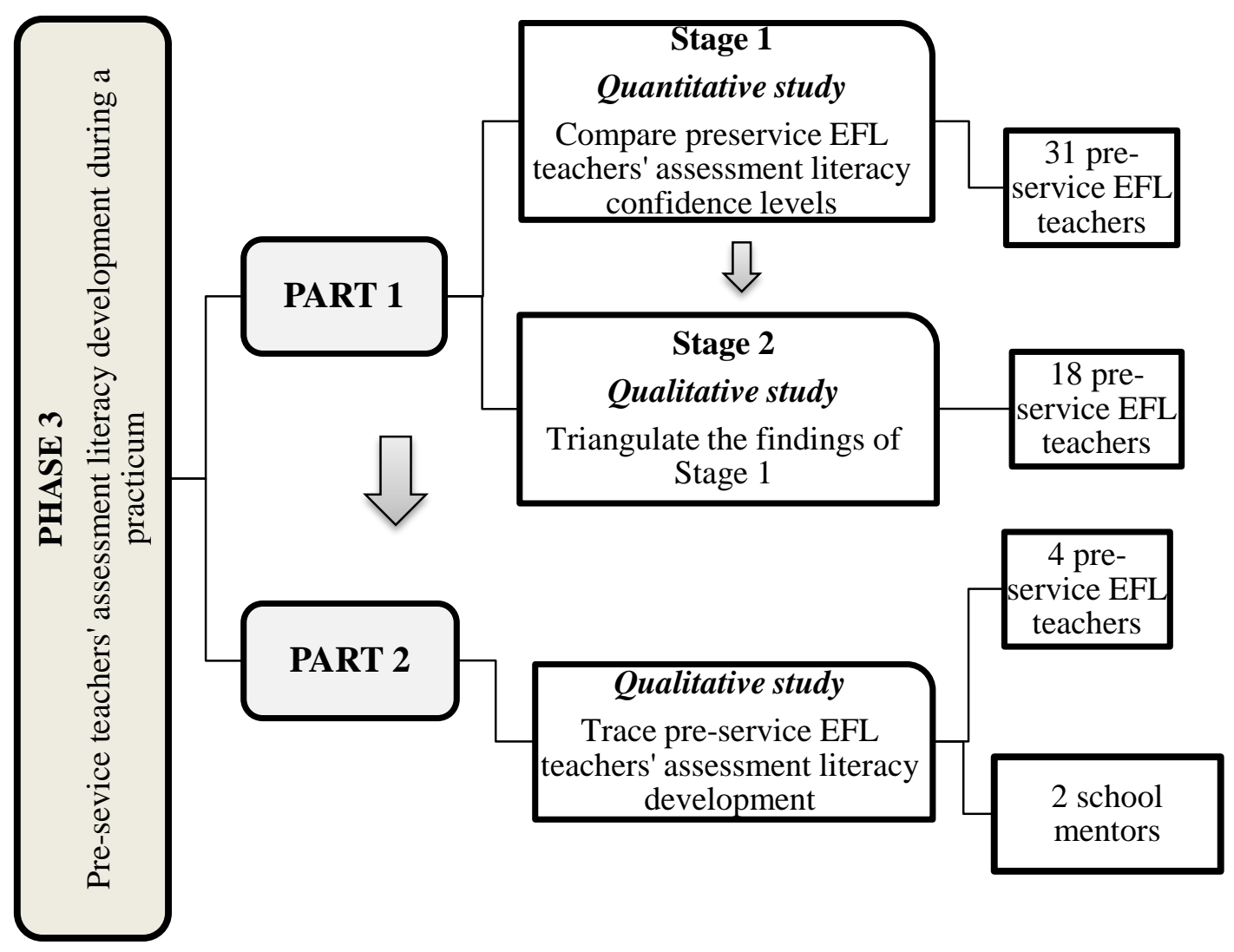

\subsection{PART 1: Development of pre-service EFL teachers' confidence levels in} assessment literacy during practicum

Part 1 consists of two stages. The details of each stage are presented below.

\subsubsection{STAGE 1}

\subsubsection{Research questions}

Stage 1 tried to answer the following research questions:

1. Is there a change in the pre-service EFL teachers' assessment literacy confidence levels before and after their practicum? 
2. Is there a change in the pre-service EFL teachers' assessment literacy confidence levels over three time periods: before their language testing and assessment course, before their practicum and after their practicum?

\subsubsection{Research participants}

The research participants were the final year students at Bach Dang University where I taught in Vietnam. This university was chosen for three main reasons. Firstly, it is among the key teacher training universities in Vietnam which offered a separate course in language testing and assessment for pre-service EFL teachers. Secondly, I had conducted my research at this university so it was easy for me to gain access to the participants. Lastly, the results from this stage are useful for my role as a teachertrainer at this university.

At this university, thirty-one final-year pre-service EFL teachers agreed to participate in this research. The response rate was $100 \%$. Among the participants, 30 were female, 2 did not want to become teachers after graduation and 5 had no teaching experience before their practicum.

\subsubsection{Research instruments}

In this stage, I used the validated questionnaire of pre-service EFL teachers' confidence levels in assessment literacy which was developed and validated in Phase 2 as the main research instrument.

\subsubsection{Research procedures}

\subsection{Data collection}

The questionnaires were administered three times: before the language testing and assessment course, before the practicum and after the practicum. Before the language testing and assessment course, I could not be present in Vietnam. Therefore, one of my colleagues helped me to collect data. I explained the data collection procedures and emailed her the consent form, the information sheet, and the questionnaire. She printed them out, and administered the questionnaire during the first week of the language testing and assessment course. I also asked her to strictly follow ethical requirements by: 
$\checkmark$ describing the purposes of my study clearly to all the participants.

$\checkmark$ providing all the participants with the information sheets, consent forms and allowing sufficient time for them to read and raise any concerns related to the study and their participation.

$\checkmark$ answering all the questions from the participants.

$\checkmark$ distributing the questionnaires only when the participants agreed to sign their consent forms.

After she finished her data collection, she sent all the questionnaires to me. After the course, I went back to Vietnam and directly worked with the pre-service EFL teachers. I administered the questionnaires twice: once in the first week of the practicum and once in the last week of their practicum. I also strictly followed the ethical guidelines by:

$\checkmark$ explaining the purposes of my study with the participants.

$\checkmark$ giving them the information sheets and consent forms.

$\checkmark$ answering their questions.

$\checkmark$ obtaining their signed consent forms before distributing the questionnaires.

\subsection{Data analysis}

I coded and imported the questionnaires into 18.0 SPSS software for analysis. I entered the questionnaire item-by-item for each participant. I then carried out data screening on SPSS to ensure the data input was correct. After that, in order to answer the first research question, I conducted a paired-samples t-test to compare the preservice EFL teachers' confidence levels in assessment literacy before and after their practicum. For the second research question, I used a one-way repeated measures ANOVA to investigate a change in the mean score of the pre-service EFL teachers' confidence levels over three periods of time: before their language testing and assessment course, before their practicum and after their practicum.

Before I performed these tests, as recommended by Pallant (2010), I checked the normality of the difference in the six sub-constructs of assessment literacy in the questionnaire including pedagogical content knowledge, assessment for learning, assessment of learning, beliefs in testing and assessment, understanding of 
assessment qualities and ethical issues in testing and assessment before and after the practicum. A Shapiro-Wilk's test $(\mathrm{p}>.05)$ and a visual inspection of their histograms, normal Q-Q plots and box plots showed that the assessment literacy confidence levels, as shown in the six sub-constructs, were normally distributed. In this step, I also calculated the effect size, Cohen's $d$, as an indication of the magnitude of the differences of the two groups (Pallant, 2010).

\subsubsection{STAGE 2}

\subsubsection{Research questions}

Stage 2 aimed to answer the following research question:

1. Did the pre-service EFL teachers' assessment literacy confidence levels as indicated in the questionnaire truly reflect their assessment literacy?

\subsubsection{Research participants}

Among the thirty one participants involved in Stage 1 of Phase 3, eighteen pre-service EFL teachers were chosen to participate in Stage 2 for two main reasons. Firstly, the pre-service EFL teachers involved in Stage 2 were those who participated in Stage 1 of Phase 3. This is important because the purpose of Stage 2 is to triangulate the findings in Stage 1. Secondly, because the thirty-one participants in Stage 1 of Phase 3 were assigned to different schools in different areas, I could only recruit these eighteen pre-service EFL teachers due to time and financial constraints. These preservice EFL teachers took their practicum at two local schools in City A.

\subsubsection{Research instruments}

Two semi-structured focus group interviews with these two groups of pre-service EFL teachers were selected for two reasons. First, semi-structured interviews allow flexibility of interview questions and more informative answers from participants (Patton, 2002). In the semi-structured focus group interviews, despite a set of prearranged questions to guide the focus and direction of my interviews, I could ask follow-up questions and probe the participants to get more insight into their assessment literacy confidence levels. Secondly, in a focus group interview, participants have an opportunity to listen to other participants and reflect on their own 
situations (Patton, 2002). Thus, this feature helped to provide me with more informative answers from the participants in my study.

\subsubsection{Research procedures}

I contacted the pre-service EFL teachers at the two local schools in City A to ask for their voluntary participation in my study. After receiving their consent, I arranged one focus group interview with each group at a time and venue of their convenience. One interview was conducted at the school site where they had their practicum and the other was done at Bach Dang University. At the interview, all the participants were clearly told about the study's purposes and their rights when participating in the study. The interviews were only conducted when all the participants had agreed to sign the consent forms. The interviews were conducted in Vietnamese and each interview lasted for thirty minutes.

\subsubsection{Data analysis}

Data analysis was conducted with the procedures adapted from Creswell (2013). First, the interviews were carefully transcribed and checked for accuracy. During this step, member check was done when the participants were contacted to review their answers. Second, open coding was done to identify any segments, or group of words that were related to the focus of the study. Third, these codes were grouped into categories. Fourth, all the categories were reviewed and grouped into themes to find an answer to the research question.

\subsection{PART 2: Development of pre-service EFL teachers' assessment literacy during practicum}

In order to get an insight into how the pre-service EFL teachers developed their assessment literacy during their practicum at Le Loi high school, the case study approach was selected for Part 2. This is because "case studies are the preferred strategy when 'how' and 'why' questions are being posed, when the investigator has little control over events, and when the focus is on a contemporary phenomenon within some real-life contexts" (R. K. Yin, 1994, p. 1). Although this approach can be criticised for its lack of generalizability from one case to another because of the different contexts (Creswell, 2013; Patton, 2002; Punch, 2009; R. K. Yin, 1994), it 
enabled me to zoom in the real-life context of a practicum to understand how the preservice EFL teachers could improve the way they test and assess their students.

\subsubsection{Research questions}

Part 2 asked the following research questions:

1. Is the pre-service EFL teachers' assessment literacy developed through the practicum?

2. What aspects of assessment literacy do the pre-service EFL teachers develop in the practicum? In what ways?

\subsubsection{Research participants}

Case selection and sampling are among the most important considerations in case study research (Duff, 2012). There are different strategies for choosing a case (Duff, 2012; Miles \& Huberman, 1994; Patton, 2002). Duff (2012) suggested to consider the entity and the phenomenon that researchers want to investigate when choosing a case. Following Duff's (2012) suggestions, I first identified the main focus of Part 2 which was to investigate how Vietnamese pre-service EFL teachers developed their assessment literacy during their practicum. For this purpose, I tried to choose typical cases which could help me understand this phenomenon.

Among the four universities involved in this $\mathrm{PhD}$ project, I decided to continue Part 2 of Phase 3 with the pre-service EFL teachers at Bach Dang University for two main reasons. Firstly, the pre-service EFL teachers at this university had learned about testing and assessment in a separate course of testing and assessment before the practicum. Therefore, it is interesting to examine how they applied what they had learned about this area into the practicum. Secondly, my eight years of working experience at this university enabled me to gain access to the research participants and understand the context of the study easily.

At the time of the study, there were seventy seven pre-service EFL teachers at this university who were assigned in ten different schools in two cities. Although all the pre-service EFL teachers at this university were willing to participate in my study, due to my time and financial limit, I could only manage to observe four pre-service 
EFL teachers and two school mentors at Le Loi high school in City A. This high school was selected for five reasons. First, as a former student at this school, I had known the school mentors and the school context before I conducted my study. Working with the school mentors whom I am familiar with enabled me to obtain access and informed consent more easily (Duff, 2012). Second, my familiarity with the school mentors and the pre-service EFL teachers also helped me get more useful data about the cases because it was easier for me to "observe or interact with familiar participants or sites for a more extended or intensive period" (Duff, 2012, p. 116). Third, with familiar sites, "there is likely to be a greater understanding of the context based on the prior knowledge" (Duff, 2012, p. 116). Fourth, this is the best school in the city whose teaching conditions were very supportive for the pre-service EFL teachers and my observation. Lastly, the pre-service EFL teachers at this school had completed a testing and assessment course before their practicum. It is interesting to investigate how they applied their learning into practice. In sum, the participants were chosen mainly based on what Stake (2000) recommended that the choice of cases should be to "offer opportunity to learn... that may mean taking the one most accessible, the one we can spend the most time with" (p.116).

\subsubsection{Research instruments}

Due to the complex nature of assessment literacy, different research instruments were employed to explore the development of pre-service EFL teachers' assessment literacy development during their practicum. Moreover, this study involved both the school mentors and the pre-service EFL teachers. Thus, different instruments were employed for each group of the participants.

The instruments used for each group of participants in this study are summarised in Table 8-1 and described in detail below. 
Table 8-1: Summary of research instruments in Part 2 of Phase 3

\begin{tabular}{ll}
\hline \multirow{3}{*}{ PRE-SERVICE TEACHERS } & Semi-structured individual interviews \\
\cline { 2 - 2 } & Semi-structured focus group interviews \\
\cline { 2 - 2 } & Non-participant observations \\
\cline { 2 - 2 } & Stimulated recalls \\
\hline Questionnaires \\
\cline { 2 - 2 } SCHOOL MENTORS & Lesson plans \\
\hline
\end{tabular}

\subsubsection{Pre-service EFL teachers}

\subsubsection{Semi-structured individual interviews}

The semi-structured individual interviews enabled me to get insights into the preservice EFL teachers' background, knowledge and beliefs in testing and assessment at the beginning of the practicum due to the flexibility of the interview questions (Patton, 2002).

\subsubsection{Semi-structured focus group interviews}

In this study, semi-structured focus group interviews were chosen for two reasons. Firstly, in focus group interviews, participants can listen to other participants and reflect on their own situation (Marshall \& Rossman, 2006). Therefore, this feature enabled me to gain insights when the participants reflected on their opinions and compared their opinions with other participants. Secondly, focus group interviews can reduce the tension within participants because they can have time to listen to other participants, to reflect on their own opinions and prepare for their answers (Marshall \& Rossman, 2006). Thanks to this, the participants in my study appeared able to discuss and share their opinions naturally and freely.

\subsubsection{Observation}

Non-participant observation was chosen as one of the data collection methods for this study for three main reasons: 
First, because this study is interested in the development of the pre-service EFL teachers' assessment literacy, it is necessary to focus on what they tested and assessed their students on inside their classroom, and how their assessment literacy was improved in practice. It would be difficult to capture these "live" instances of their development by other methods like interviews or surveys whereas observation proves its strong abilities in catching "live" data (Cohen, Manion, \& Morrison, 2000).

Second, non-participant observation, as S. Borg (2006) highlighted, has its advantages in teacher cognition research due to its ability to capture the natural process of teaching and learning without any interference and interruptions. In my study, as a non-participant observer, I did not give any advice, comment or evaluation on the mentoring processes during the practicum. This allowed me to record class teaching, as well as discussions between the mentors and the pre-service teachers naturally.

Third, data from non-participant observation helped me triangulate the findings of the pre-service EFL teachers' assessment literacy development. The observation, together with data from other methods, gives a better-rounded picture of how preservice EFL teachers developed their assessment literacy.

During the practicum, I observed and video-recorded all the teaching sessions of the four pre-service EFL teachers. I also audio-recorded all the pre-teaching and postteaching discussions between the school mentors and the pre-service teachers, as well as all the discussions between the pre-service EFL teachers and their peers.

\subsubsection{Stimulated recalls}

While the observation caught the live instances of what the four pre-service EFL teachers did inside the classroom, stimulated recall interviews were used as an effective way to uncover the reasoning and thinking processes behind their activities (S. Borg, 2006; Gass \& Mackey, 2000; Nunan, 1992; Yinger, 1986). In my study, stimulated recall interviews could provide me with different kinds of information such as why the pre-service EFL teachers designed and chose the kinds of assessment and the feedback they used. This gave me the evidence of their development in assessment literacy. 


\subsubsection{Lesson plans}

Lesson plans were collected to understand how the pre-service EFL teachers planned their lessons before each class and compared their preparation with their real classroom performance.

\subsubsection{Questionnaires}

The questionnaire of pre-service EFL teachers' confidence levels in assessment literacy was employed to check the development of the four pre-service EFL teachers' assessment literacy confidence levels.

\subsubsection{School mentors}

\subsubsection{Individual semi-structured interviews}

Individual semi-structured interviews were used to investigate participants' beliefs in teaching and learning, their mentoring approach, their expectations of the practicum and their evaluation of the practicum. This instrument was chosen because of its ability to allow for the flexibility of the interview questions (Patton, 2002) which could give me a better understanding of what the school-mentors did to help the preservice teachers improve their assessment literacy.

\subsubsection{Observation}

Thanks to its features of capturing "live" data (Cohen et al., 2000), non-participant observation was chosen because it did not interfere with the natural processes of teaching and mentoring of the school-mentors. This instrument was used to investigate what the school-mentors did to help the pre-service EFL teachers improve their assessment literacy during the practicum.

\subsection{Research procedures}

\subsubsection{Data collection}

Before the practicum, I contacted Le Loi high school, the school mentors and the preservice EFL teachers to ask for their consent to participate in my study. I also explained to the participants the purposes of my study, obtained their consent and discussed with them the detailed plan for my work with them during the practicum. 
The data collection for each group is summarized in Figure 8-2 below.

\section{Figure 8-2: Overview of Part 2's data collection}

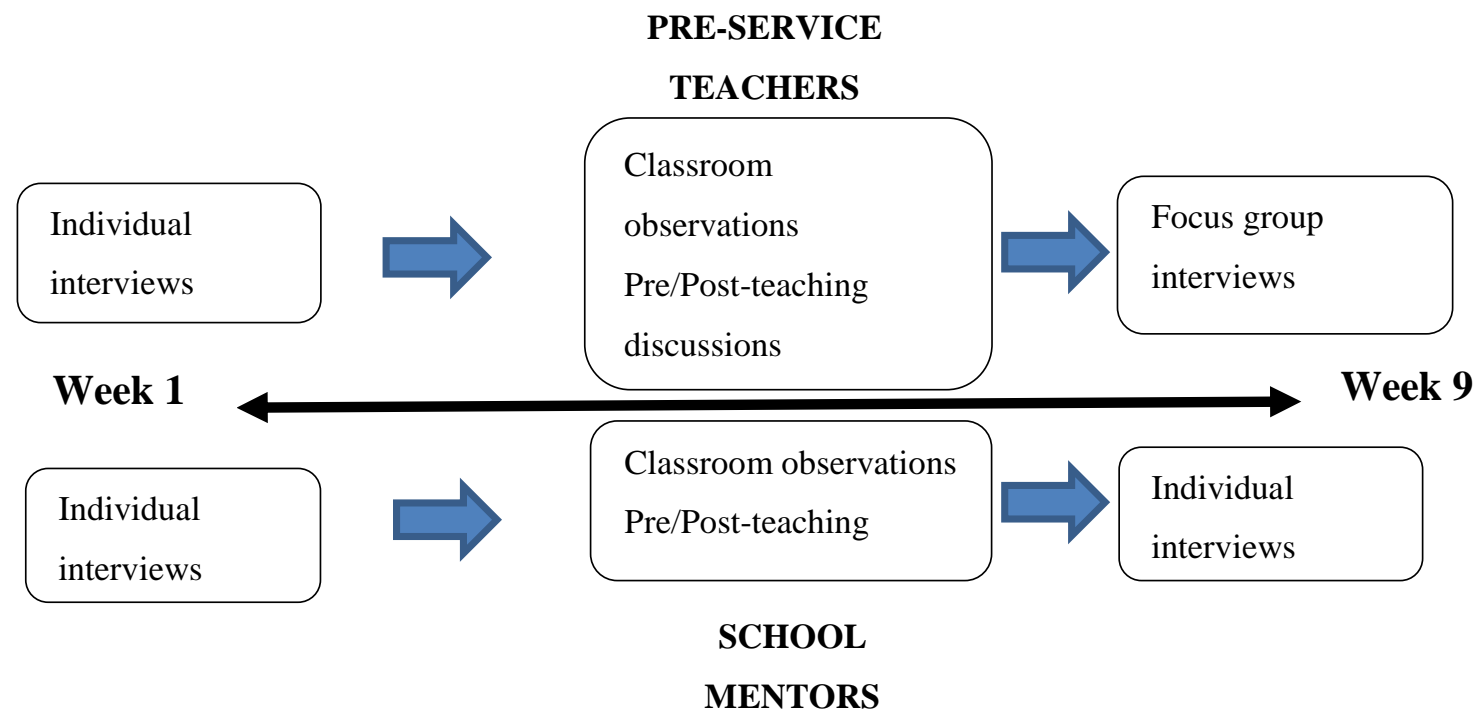

The details of the data collection procedures for each group are presented below.

\subsubsection{School mentors}

Before I collected the data, I contacted the school principal of Le Loi high school to obtain permission to collect data at this school. After I got the permission, I asked the school mentors for their voluntary participation in my research. All the four school mentors at this school were very supportive and willing to help me with data collection. However, after checking their class schedules in which many classes had the same time allocation, I could only manage to recruit two school mentors for my study. This is partly because these two school mentors did not have many classes which had the same schedule and partly because they taught two different grades, which could give me more insight into different classroom contexts.

One week before the practicum, I met and gave these two school mentors the information sheets, consent forms, described my research and responded to their questions and concerns. The data collection began in the first week of the practicum when I had obtained their consent. 
In the first week of the practicum, I conducted a semi-structured individual interview with each school mentor. These interviews were about their backgrounds, their beliefs in teaching English, testing and assessment as well as issues related to the practicum.

During the practicum, I managed to attend and record the pre-teaching and postteaching discussions between the school mentors and their mentees. Because the school mentors were very busy with their class schedules, they could only use their breaks of 15-20 minutes between their teaching shifts to help their mentees with lesson plans and teaching performance evaluation.

In the last week of the practicum, I conducted another individual semi-structured interview with each school mentor to understand about their overall evaluation of the practicum and their mentees' development in teaching and assessment literacy.

The data collection of the school-mentors are summarised in Figure 8-3:

Figure 8-3: Data collection from school mentors

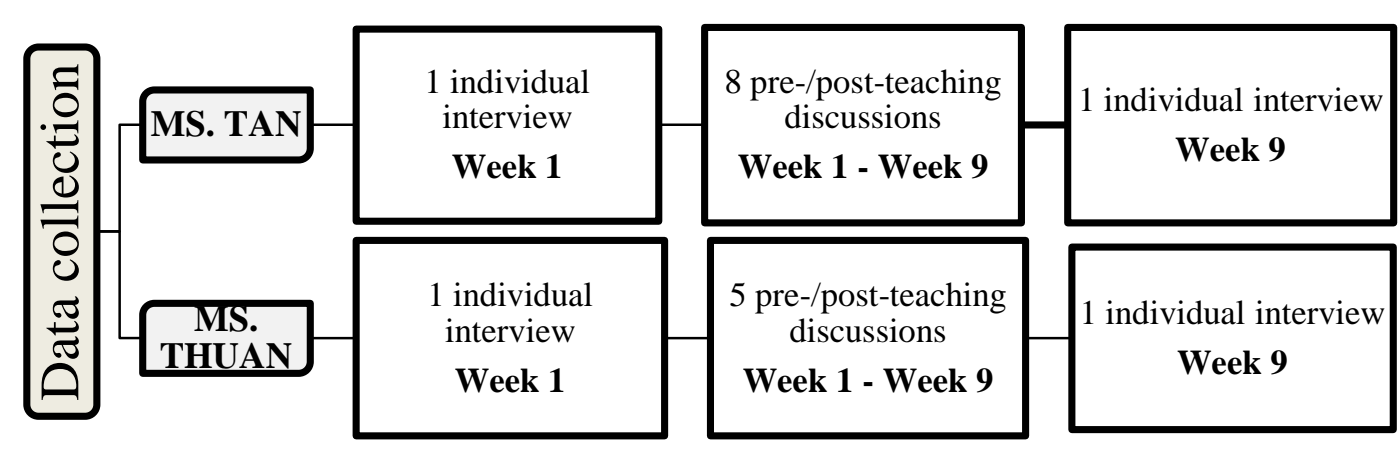

\subsubsection{Pre-service EFL teachers}

Before the practicum, I contacted Bach Dang University to get permission for conducting my research with the pre-service EFL teachers. After obtaining their permission, I worked directly with the four pre-service EFL teachers who were assigned to the two school mentors at Le Loi high school to ask for their voluntary participation in my research. After that, I gave all the participants the information sheets and consent forms. Also, all participants were given sufficient time to read the information sheets and consent forms carefully. All of their inquiries about the research and their participation were clearly explained before the data collection. Different instruments were employed to collect data during the practicum. 


\section{$\checkmark$ Questionnaires}

The questionnaires were administered twice: once in the first week of the practicum and once in the last week of the practicum.

\section{$\checkmark$ Observations}

In this study, all the class teaching of the pre-service EFL teachers was video-taped because I wanted to watch the class events more carefully later. However, the school mentors and pre-service EFL teachers found it inconvenient for them to be videorecorded during their pre-/post-teaching discussions so I only audio-recorded these discussions. Besides, I jotted down all the field notes while I observed the class teaching and discussions. I managed to observe most of the teaching sessions of these four pre-service EFL teachers and their discussions with the school mentors and among themselves. However, I had to miss some classes and some discussions due to the overlapping teaching schedules of the pre-service EFL teachers.

\section{$\checkmark$ Semi-structured focus group interviews}

I conducted two semi-structured focus group interviews: one in the first week of the practicum, and the other in the last week of the practicum.

\section{$\checkmark$ Stimulated recalls}

As stimulated recalls should be done as soon as possible to maximize what the participants can remember and avoid memory decay (Gass \& Mackey, 2000), I had to schedule the time for these sessions right after their teaching lessons. However, it was difficult to find a suitable time for these sessions due to the extensive work of the pre-service EFL teachers who, apart from teaching, had to participate in different school activities, such as classroom management and extra-curricular activities, as part of practicum requirements. Therefore, I could only conduct one to two stimulated recall sessions with each pre-service EFL teacher. In these sessions, I sometimes played the role of a facilitator as Woods (1996) suggested and asked the pre-service teachers to state aloud the thinking processes and reasoning behind their choice of assessment activities and feedback. They were also encouraged to comment on any issues related to their teaching while watching the videos. In some sessions, due to 
time constraints, I could only fast-forward the videos and stop at certain points to ask the pre-service EFL teachers to comment on issues that I was interested in. The data collected from each pre-service EFL teacher are summarised in Figure 8-4 below.

Figure 8-4: Data collection from pre-service EFL teachers

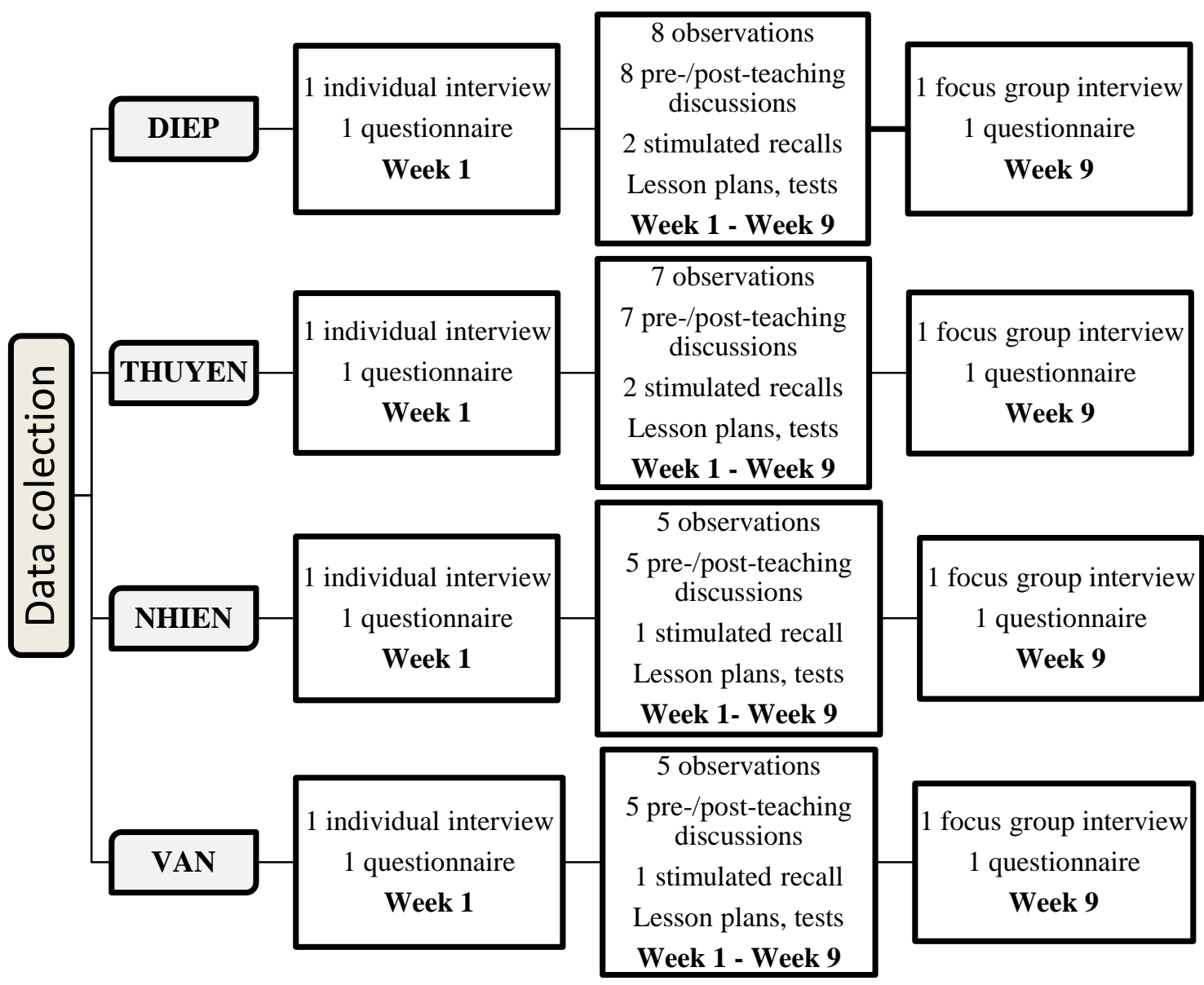

\subsubsection{Data analysis}

For quantitative data, the data from the questionnaires were collected, coded and entered into SPSS version 18.0 for analysis. The questionnaires were entered itemby-item for each participant. A paired-samples t-test was employed to compare the pre-service EFL teachers' assessment literacy confidence levels before and after their practicum and a one-way repeated measures ANOVA was used to compare their assessment literacy confidence levels at three points: before their language testing and assessment course, before their practicum and after their practicum. 
For qualitative data, all the videos and audios were transcribed carefully. The interviews were kept in Vietnamese for data analysis. The classroom teaching periods of pre-service EFL were conducted in English. However, some parts of the preservice EFL teachers' teaching periods were unclear for transcription due to the quality of the recorder and the classroom environment. For example, sometimes the students and the pre-service EFL teachers were so far away from the recorder that their voice could hardly be recorded. Moreover, there were occasions that noise from the construction sites outside the classroom and the airplanes prevented me from recognizing what the pre-service EFL teachers and their students said. Therefore, I had to ask the four pre-service EFL teachers to help me with their classroom performance's transcription. This could assist me to better transcribe what was happening in the videos. After that, they helped me review the transcripts to check if they needed to adjust anything. After receiving their agreement, I input all the data into NVivo 9. I organised the data from each pre-service EFL teacher and each school mentor into folders named by their pseudonyms. Then I categorized the data of each participant according to the research instruments. For example, in the folder named Diep (a pre-service EFL teacher), I sorted all the data from her classroom observation into one sub-folder named "Observation".

The data analysis was done simultaneously after I collected the data because this helped to guide the following steps of the data collection and enhanced the quality of the data analysis (Patton, 2002). For example, after I interviewed the pre-service teachers in the first week of the practicum, I tried to analyse the interview immediately to know about their beliefs, and their expectations. This information was used to guide my classroom observation as well as the follow-up interviews.

In data analysis, I analysed the data from each individual pre-service EFL teacher and then continued with data triangulation with the analysis of the school mentors' data and finally did a cross-case analysis to find the main themes of the pre-service EFL teachers' assessment literacy development during a practicum. 


\subsection{Problems with data analysis and interpretation}

In this study, I took a position of a non-participant observer. This means I did not interfere with the practicum and the natural mentoring processes. In the interview at the end of the practicum, I double-checked with the school mentors if my observation influenced their mentoring process. They both indicated that my observation did not change the way they supervised their pre-service EFL teachers. However, due to my presence in the classroom, the school mentors noticed that the students were more supportive of the pre-service EFL teachers by raising their hands to answer the questions more frequently.

Despite my attempts to take an "outsider's" perspective during data collection and data analysis, biases resulting from my familiarity with the context and the participants were unavoidable. In order to limit the possible biases, I took the following strategies suggested by Patton (2002):

$\checkmark \quad$ I tried to enhance trust with the participants to maximise the honesty of their answers.

$\checkmark \quad$ I consulted closely with my supervisors to avoid the influence of my feelings on my data analysis and interpretation.

$\checkmark$ I discussed the summary of the findings with the participants after I had collected the data.

$\checkmark \quad$ I thoroughly checked the accuracy of my translation of the transcripts.

$\checkmark$ In order to control the quality of the coding process, I also checked my analysis with my supervisors who gave me insight and advice about the data interpretation.

\section{7. $\quad$ Ethical issues}

Before I conducted Phase 3, I had obtained permission from the Ethics Committee of Victoria University of Wellington (See Appendix A). During the whole process of data collection and data analysis, I tried to follow the strict conduct of ethics by:

$\checkmark$ giving the participants the information sheets, and the right to withdraw from my study. 
$\checkmark$ explaining the purposes of my study clearly and responding to all the participants' questions and concerns.

$\checkmark$ obtaining their agreement before data collection.

$\checkmark$ keeping their identity confidential by using their pseudonyms in data analysis and data report.

\subsection{Quality criteria}

A quantitative study is judged by its reliability and validity while the transferability, dependability, credibility, and confirmability are the criteria to ensure the quality of a qualitative study (Lincoln \& Guba, 1986). Phase 3 includes both a quantitative and qualitative approach. For the quantitative study in this study, the reliability and validity was ensured by the carefully validated questionnaire of pre-service EFL teachers' assessment literacy confidence levels which was presented in Chapter 6. For the qualitative parts, the following strategies were taken to ensure trustworthiness.

\subsubsection{Credibility}

According to Lincoln and Guba (1986), credibility can be enhanced by prolonged engagement, persistent observation, peer debriefing, negative case analysis, member checking and triangulation. This study followed Lincoln and Guba's (1996) suggestions to enhance its credibility by:

\section{$\checkmark$ Member checking}

I sent all the transcripts and the summary of findings to the participants to ensure that they agreed with what they provided during the data collection.

\section{$\checkmark$ Data triangulation}

I examined different sources of data including observation, interviews, lesson plans, stimulated recalls, reflective journals to investigate the pre-service teachers' assessment literacy development.

\section{$\checkmark$ Peer debriefing}

During the whole process of data collection, and data analysis, I sought advice from my supervisors. I also received feedback and insight from experts and researchers in the same field when I presented my study at international conferences. 


\section{$\checkmark$ Prolonged engagement}

I used to be a student to Le Loi high school; therefore, I have known the school context and the school mentors for a long time. Moreover, as a teacher-trainer at tertiary level in Vietnam for eight years, I have had a long exposure to the context, and possess a wide knowledge of the context as well as the culture of the study. I also spent a whole nine-week-practicum with the school mentors and the pre-service EFL teachers to understand their development during this period.

\subsubsection{Transferability}

Marshall and Rossman (2006) stated that unlike quantitative research, qualitative studies would be difficult to replicate due to its nature. Instead, its transferability which means its ability to relate to the similar contexts, or participants, is considered. According to Lincoln and Guba (1986), the transferability of a qualitative study is enhanced when the researcher provides a rich, detailed description of the research so that readers can determine the extent of transferability into their own context and their study. Therefore, I provide a detailed description of the research procedure, the participants, and the data analysis which will assist readers to determine which part of my study is relevant for their context and their research.

\subsubsection{Dependability}

Dependability is the extent to which "the results make sense and are agreed on by all concerned" (R. B. Burns, 2000, p. 425). In order to enhance the dependability, different strategies should be taken, including triangulation (R. B. Burns, 2000; Davis, 1992), external audit (Lincoln \& Guba, 1986) and the report of any possible biases during data collection and analysis (R. B. Burns, 2000). This study, therefore, took the following steps to enhance its dependability:

$\checkmark$ Peer debriefing was done with my supervisors, the teacher-trainers and other $\mathrm{PhD}$ fellows to provide me with an opportunity to probe my biases, emotions and feelings that may have emerged during the study. Moreover, in this study, my supervisors were considered to serve as professionals to help me shape 
my study and provide continuous feedback about the findings and conclusions.

$\checkmark$ Triangulation was done when different research instruments were employed to trace the development of the pre-service teachers' assessment literacy during the practicum.

$\checkmark$ External audit was done when I kept track of my data analysis procedures. Moreover, the translation of the data was also checked by a teacher-trainer who is fluent in English and understands the context of the study.

$\checkmark$ Report of possible biases during the process of data analysis and interpretation is presented in Section 8.6 above.

\subsubsection{Confirmability}

Confirmability in qualitative research is related to objectivity in quantitative research (Lincoln \& Guba, 1986; Patton, 2002). However, Patton (2002) argued that it is difficult to enhance real objectivity, even in quantitative research, because human biases are unavoidable when the research instruments are designed and validated by researchers. Therefore, in qualitative research, he suggested that in order to enhance confirmability, a detailed description of the research method and procedures as well as the potential biases of data collection and data interpretation need to be provided. Following this suggestion, I carefully discussed all the potential biases in Section 8.6 above as well as carefully described the research participants' profiles, context and research procedures as above.

\subsection{Limitations}

This study has the following limitations:

$\checkmark$ Because of the size of the study, the findings cannot be generalised but can only describe the development of the pre-service teachers' assessment literacy during their practicum at Le Loi high school.

$\checkmark$ Moreover, within the time and financial limit, this study could not recruit more participants in order to understand more deeply about the assessment literacy development of different groups of pre-service EFL teachers. 
Because of the overlapping teaching schedules of the pre-service EFL teachers, I could not manage to observe all their teaching and their discussions to understand deeply about their development in assessment literacy.

\subsection{Summary}

This chapter presents all the issues of the research methodology in Phase 3. It describes the participants, explains the choice of the research instruments as well as details the research procedures. It also discusses the issues of ethics, the problems with data analysis and interpretation. Moreover, it addresses the quality criteria of the study. Finally, it outlines some limitations of the study that should be taken into consideration.

The results and discussion of Phase 3 are provided in the following chapter, Chapter 9. 


\title{
Chapter 9:
}

\section{PHASE 3 - DEVELOPMENT OF PRE-SERVICE EFL TEACHERS'}

\section{ASSESSMENT LITERACY DURING PRACTICUM}

\author{
Results and Discussion
}

\subsection{Introduction}

As noted in Chapter 8, Phase 3 consists of two parts (Part 1 and Part 2) which looks at how the pre-service EFL teachers developed their assessment literacy during the practicum. This chapter presents the findings of each part, followed by a discussion. The chapter ends with a summary of the key points.

\subsection{PART 1 - Development of pre-service EFL teachers' confidence levels in assessment literacy during practicum}

\subsubsection{STAGE 1}

In Stage 1, the pre-service EFL teachers were asked to complete a questionnaire of pre-service teachers' assessment literacy three times: before their language testing and assessment course, before their practicum, and after their practicum. The results of the findings are presented as below:

\subsubsection{Pre-service teachers' assessment literacy confidence levels before and after the practicum}

A paired-samples t-test was conducted to evaluate the impact of the practicum on the pre-service teachers' assessment literacy confidence levels in the six sub-constructs of assessment literacy. In general, there was a statistically significant increase in the confidence levels in all six sub-constructs of assessment literacy including pedagogical content knowledge, beliefs of testing and assessment, understanding assessment qualities, assessment for learning, assessment of learning, and ethical issues in testing and assessment.

In pedagogical content knowledge, there was a statistically significant increase in knowledge of teaching objectives and curriculum, knowledge of contextual issues, knowledge of instructional strategies, knowledge of students' learning, and 
knowledge of subject matter $(\mathrm{p}<.005)$ For example, in knowledge of teaching objectives and curriculum, the confidence levels increased between before the practicum $(M=74.35, S D=7.98)$ and after the practicum $(M=81.53, S D=10.71, t$ $(31)=-4.111, p<.005$ (two-tailed). The mean increase in PCK was -9.66 with a $95 \%$ confidence interval ranging from -10.74 to -3.61 . Cohen's $d$ is 0.76 which indicated a moderate effect size. Similar patterns of findings were found for the other subconstructs of assessment literacy. However, for these pre-service EFL teachers, they held stronger beliefs in assessment of learning than assessment for learning.

In summary, the findings indicated that the assessment literacy confidence levels of the pre-service EFL teachers statistically increased over the practicum. The overview of the findings is presented in Graph 9-1 and the details of the findings are summarised in Table 9-1.

Graph 9-1: Pre-service EFL teachers' confidence levels in assessment literacy before and after practicum

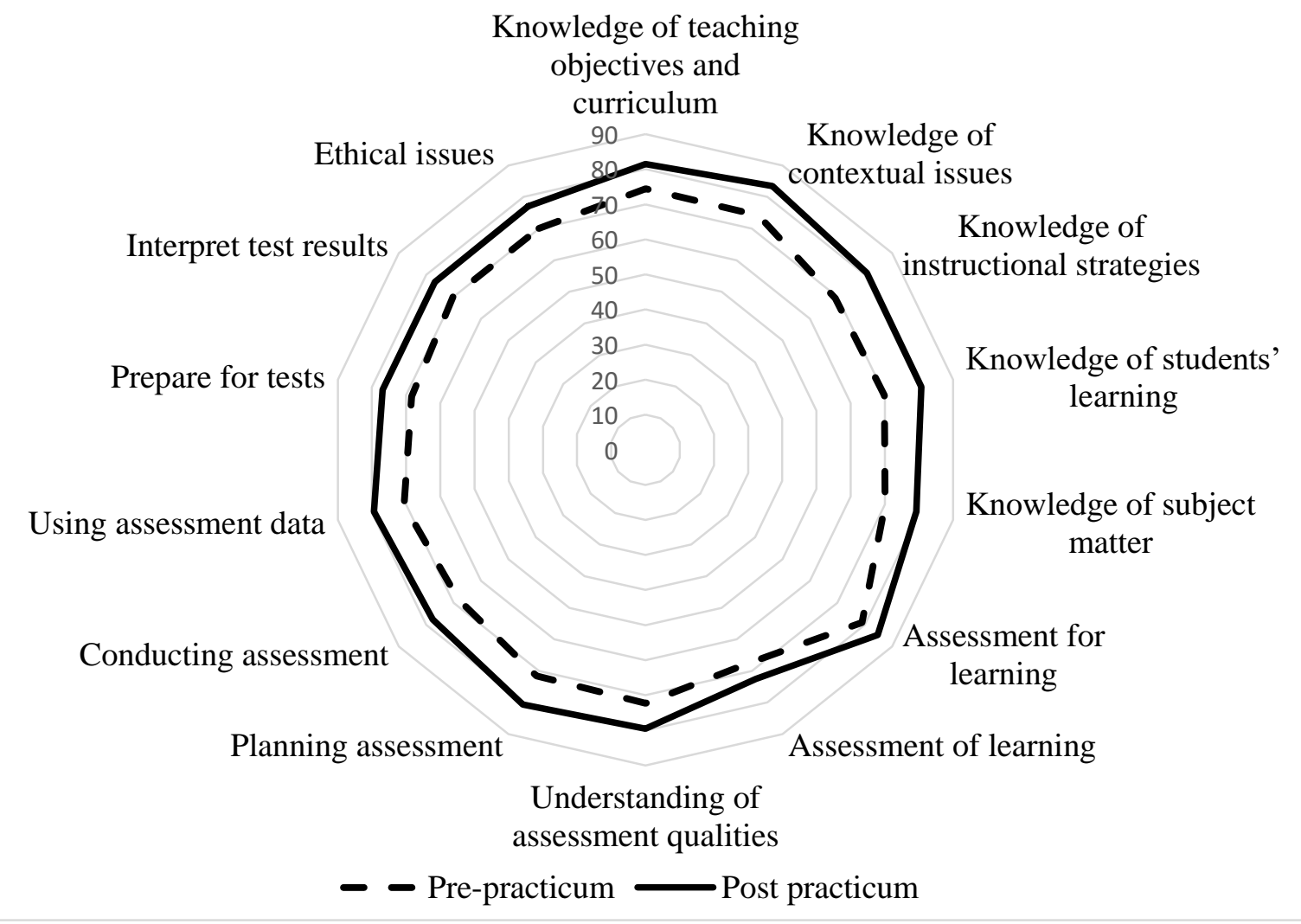


Table 9-1: Pre-service EFL teachers' assessment literacy confidence levels between before and after practicum

\begin{tabular}{|c|c|c|c|c|c|c|c|c|}
\hline \multirow[t]{2}{*}{ Section } & \multirow[t]{2}{*}{ Sub-section } & \multicolumn{2}{|c|}{$\begin{array}{l}\text { Pre-practicum } \\
\qquad(\mathrm{N}=31)\end{array}$} & \multicolumn{2}{|c|}{$\begin{array}{c}\text { Post-practicum } \\
(\mathbf{N}=31)\end{array}$} & \multicolumn{3}{|c|}{ Paired-samples t-test } \\
\hline & & Mean & SD & Mean & SD & t value & $\bar{p}$ & $\mathbf{d}$ \\
\hline \multirow{5}{*}{$\begin{array}{l}\text { Pedagogical content } \\
\text { knowledge }\end{array}$} & $\begin{array}{l}\text { Knowledge of teaching objectives and } \\
\text { curriculum }\end{array}$ & 74.4 & 8.0 & 81.5 & 10.7 & -4.111 & 0.000 & 0.76 \\
\hline & Knowledge of contextual issues & 74.2 & 7.4 & 83.5 & 9.7 & -5.102 & 0.000 & 1.08 \\
\hline & Knowledge of instructional strategies & 69.2 & 7.6 & 80.8 & 10.4 & -6.151 & 0.000 & 1.26 \\
\hline & Knowledge of students' learning & 69.9 & 9.0 & 80.7 & 11.5 & -5.825 & 0.000 & 1.05 \\
\hline & Knowledge of subject matter & 70.1 & 8.4 & 79.2 & 10.4 & -5.169 & 0.000 & 0.97 \\
\hline \multirow{2}{*}{$\begin{array}{l}\text { Beliefs of language testing } \\
\text { and assessment }\end{array}$} & Assessment for learning & 79.0 & 10.4 & 84.7 & 11.0 & -3.536 & 0.001 & 0.53 \\
\hline & Assessment of learning & 67.6 & 10.9 & 72.5 & 15.1 & -2.179 & 0.037 & 0.37 \\
\hline $\begin{array}{l}\text { Understanding of assessment } \\
\text { qualities }\end{array}$ & & 72.3 & 9.2 & 79.5 & 10.0 & -3.731 & 0.001 & 0.75 \\
\hline \multirow{3}{*}{ Assessment for learning } & Planning assessment & 71.6 & 8.5 & 80.6 & 11.8 & -4.736 & 0.000 & 0.88 \\
\hline & Conducting assessment & 68.3 & 11.2 & 77.6 & 11.8 & -5.323 & 0.000 & 0.81 \\
\hline & Using assessment data & 70.6 & 9.4 & 79.4 & 12.1 & -5.000 & 0.000 & 0.81 \\
\hline \multirow{2}{*}{ Assessment of learning } & Prepare for tests & 68.4 & 12.8 & 76.9 & 14.0 & -3.256 & 0.003 & 0.64 \\
\hline & Interpret tests & 70.1 & 10.1 & 76.8 & 14.0 & -3.187 & 0.003 & 0.54 \\
\hline $\begin{array}{l}\text { Ethical issues in language } \\
\text { testing and assessment } \\
\text { practices }\end{array}$ & & 70.1 & 9.44 & 77.04 & 13.03 & -2.914 & 0.007 & 0.47 \\
\hline
\end{tabular}




\subsubsection{Pre-service EFL teachers' confidence levels in assessment literacy over three time periods: before language testing and assessment course, before practicum, and after practicum}

A one-way repeated measures ANOVA was conducted to compare the pre-service EFL teachers' assessment literacy confidence levels in assessment literacy over three time periods: before language testing and assessment, before practicum and after practicum. The results show a significant effect for time in the development of the pre-service EFL teachers' confidence levels in assessment literacy. For example, in knowledge of teaching objectives and curriculum, there was an increase in the preservice teachers' assessment literacy confidence levels over the three time points: before the course $(M=69.27, S D=11.23)$, before the practicum $(M=74.35, S D=$ $7.98)$, after the practicum $(M=81.53, S D=10.71)$. There was a significant effect for time: Wilks' Lambda $=.000, \mathrm{~F}(2,29)=13.40, \mathrm{p}<.05$, multivariate partial eta squared $=.750$.

Similar patterns of findings were found for other sub-constructs. In summary, the assessment literacy confidence levels of the pre-service teachers increased over time. The overview of the findings is presented in Graph 9-2 and the details of the findings are summarised in Table 9-2. 
Graph 9-2: Pre-service EFL teachers' assessment literacy confidence levels over prelanguage testing and assessment course, pre-practicum and post-practicum

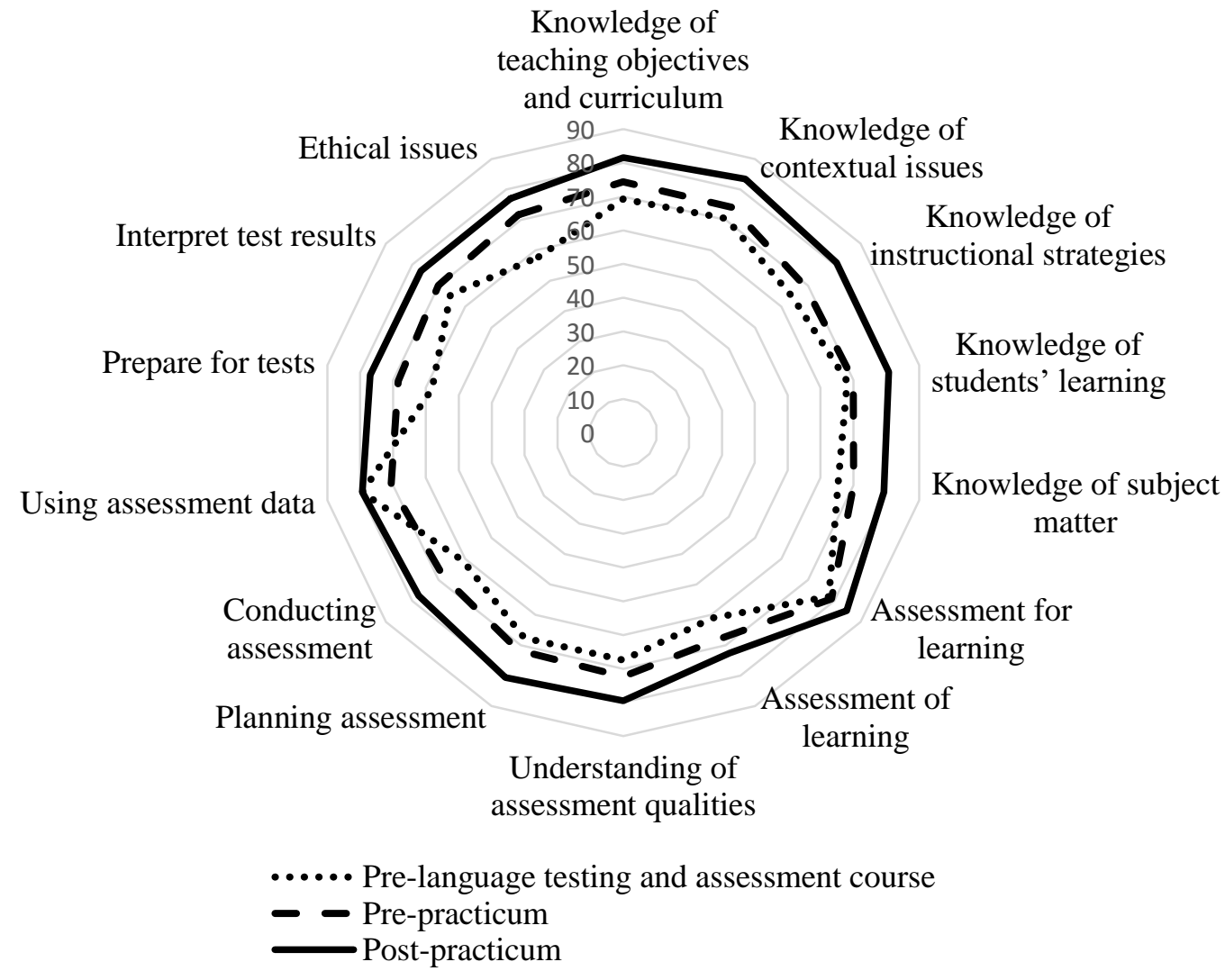


Table 9-2: Pre-service EFL teachers' assessment literacy confidence levels over pre-language testing and assessment course, pre-practicum and post-practicum

\begin{tabular}{|c|c|c|c|c|c|c|c|c|c|}
\hline & \multirow[t]{2}{*}{$\mathbf{N}=31$} & \multicolumn{2}{|c|}{$\begin{array}{l}\text { Pre-language } \\
\text { testing course }\end{array}$} & \multicolumn{2}{|c|}{$\begin{array}{l}\text { Pre- } \\
\text { practicum }\end{array}$} & \multicolumn{2}{|c|}{$\begin{array}{l}\text { Post- } \\
\text { practicum }\end{array}$} & \multirow{2}{*}{$\begin{array}{l}\text { Wilks' } \\
\text { Lambda } \\
\text { (p } \\
\text { value) } \\
\end{array}$} & \multirow[t]{2}{*}{$\begin{array}{l}\text { Partial } \\
\text { Eta- } \\
\text { squared }\end{array}$} \\
\hline & & $\mathbf{M}$ & SD & $\mathbf{M}$ & SD & $\mathbf{M}$ & SD & & \\
\hline \multirow{5}{*}{$\begin{array}{l}\text { Pedagogical content } \\
\text { knowledge }\end{array}$} & Knowledge of teaching objectives and curriculum & 69.3 & 11.2 & 74.4 & 8.0 & 81.5 & 10.7 & 0.000 & 0.750 \\
\hline & Knowledge of contextual issues & 70.4 & 9.5 & 74.2 & 7.4 & 83.5 & 9.7 & 0.000 & 0.609 \\
\hline & Knowledge of instructional strategies & 64.3 & 10.7 & 69.2 & 7.6 & 80.8 & 10.4 & 0.000 & 0.690 \\
\hline & Knowledge of students' learning & 68.1 & 10.4 & 69.9 & 9.0 & 80.7 & 11.5 & 0.000 & 0.606 \\
\hline & Knowledge of subject matter & 65.4 & 7.5 & 70.1 & 8.4 & 79.2 & 10.4 & 0.000 & 0.638 \\
\hline \multirow{2}{*}{$\begin{array}{l}\text { Beliefs of language } \\
\text { testing and } \\
\text { assessment }\end{array}$} & Assessment for learning & 77.9 & 10.0 & 79.0 & 10.4 & 84.7 & 11.0 & 0.003 & 0.325 \\
\hline & Assessment of learning & 61.0 & 12.1 & 67.6 & 10.9 & 72.5 & 15.1 & 0.008 & 0.284 \\
\hline $\begin{array}{l}\text { Understanding of } \\
\text { assessment qualities }\end{array}$ & & 67.4 & 10.6 & 72.3 & 9.2 & 79.5 & 10.0 & 0.000 & 0.481 \\
\hline \multirow{3}{*}{$\begin{array}{l}\text { Assessment for } \\
\text { learning }\end{array}$} & Planning assessment & 67.5 & 12.5 & 71.6 & 8.5 & 80.6 & 11.8 & 0.000 & 0.489 \\
\hline & Conducting assessment & 60.9 & 10.0 & 68.3 & 11.2 & 77.6 & 11.8 & 0.000 & 0.694 \\
\hline & Using assessment data & 79.4 & 12.1 & 70.6 & 9.4 & 79.4 & 12.1 & 0.000 & 0.455 \\
\hline \multirow{2}{*}{$\begin{array}{l}\text { Assessment of } \\
\text { learning }\end{array}$} & Prepare for tests & 58.2 & 15.7 & 68.4 & 12.8 & 76.9 & 14.0 & 0.000 & 0.596 \\
\hline & Interpret test results & 65.6 & 13.7 & 70.1 & 10.1 & 76.8 & 14.0 & 0.008 & 0.284 \\
\hline $\begin{array}{l}\text { Ethical issues in } \\
\text { language testing and } \\
\text { assessment practices }\end{array}$ & & 57.8 & 18.5 & 71.71 & 9.4 & 77.0 & 13.0 & 0.000 & 0.425 \\
\hline
\end{tabular}




\subsubsection{STAGE 2}

In order to triangulate the findings of Stage 1, two semi-structured group interviews were conducted with two groups of the pre-service EFL teachers at the two local schools in City A to get more insight into their assessment literacy confidence levels. The data analysis shows two main themes: (i) the importance of the language testing and assessment course; and (ii) the importance of the practicum in the pre-service EFL teachers' assessment literacy confidence levels development. The findings of Stage 2 are presented below.

\subsubsection{The importance of the language testing and assessment course}

Both groups that I interviewed agreed that their assessment literacy confidence levels increased because they took a course in language testing and assessment. The course made them feel better-prepared in testing and assessment. Thus, this helped them become more confident. For example, one pre-service EFL teacher mentioned: "Before the course, I did not know much about testing and assessment. After the course, I felt more confident because I learned some basic issues in testing and assessment" (Ngan).

However, there was one contradictory opinion about the development of their assessment literacy confidence levels. One pre-service EFL teacher reported that she scored lower confidence levels in testing and assessment after the language testing and assessment course due to her awareness of the complexities of testing and assessment: "I felt less confident after the course because before the course, what I imagined about testing and assessment was simple, but now I know that to test and assess students properly require a lot of knowledge and skills" (Tin).

From the interviews, it can be seen that the course influenced the development of the pre-service EFL teachers' assessment literacy confidence levels. It could help them better understand their assessment literacy confidence levels. This helps to explain why in Phase 2, those who had more training scored lower confidence levels because they might be aware of the complexities of testing and assessment tasks. 


\subsubsection{The importance of the practicum}

Before the practicum, the pre-service EFL teachers had not had any formal teaching experience at high schools. Moreover, within the time limit of the practicum, they reported their lack of opportunities to apply what they had learned about testing and assessment in practice. Therefore, they claimed that their rating of their assessment literacy confidence levels was generally based on the theoretical knowledge that they got from the training course. This is clearly evident in the following comment of a preservice EFL teacher:

After the course, we learned some basic knowledge of testing and assessment which made us more confident. However, in reality, we did not practise testing and assessment enough in the practicum. Therefore, when we completed the questionnaires, we only indicated our confidence levels based on our knowledge of the theoretical issues. If you asked me to apply this knowledge, I would not know how to assess students properly. (Duyen)

Further, the pre-service EFL teachers highlighted the mismatch between their assessment literacy confidence levels and their real abilities in testing and assessment. One pre-service EFL teacher expressed this concern:

I know that it is difficult to test and assess the students. When I rated my confidence levels in your questionnaire, I rated the high confidence levels in some skills. However, the more I practise testing and assessment, the less confident I am with these skills. (Ngan)

In summary, it can be seen that the experience the pre-service EFL teachers got from the practicum and the testing and assessment course helped them recognize the complexity of testing and assessment and understand their assessment literacy better. In other words, the results from the questionnaires are unable to provide adequate evidence to conclude about the pre-service teachers' assessment literacy. The preservice teachers could report high confidence levels of testing and assessment but still felt unsure if they could assess their students properly in practice. 


\subsubsection{Discussion}

From the findings of Part 1, there are both pedagogical and methodological issues that should be taken into consideration.

\subsubsection{Pedagogical issues}

Two important pedagogical implications in Part 1 include:

First, the findings emphasize the importance of training and experience in pre-service EFL teachers' assessment literacy. This study found that training and the experience during their training programmes helped the pre-service EFL teachers increase their assessment literacy confidence levels. This is aligned with previous studies (Campbell \& Evans, 2000; McGee \& Colby, 2014; Mertler, 2003) when training and experience in testing and assessment helped to develop teachers' assessment literacy. In these studies, those who had more training and experience scored higher in the test of assessment literacy. This finding can assist interested stakeholders to make more informed decisions about professional development and training programmes which offer more hands-on experience in testing and assessment for pre-service teachers and teachers. Moreover, teacher training universities should create more opportunities for their students to learn about testing and assessment during their teacher training programmes.

Second, whether pre-service EFL teachers' confidence levels are a good indicator for their assessment literacy or not needs to be considered. In Part 1, the pre-service EFL teachers reported their ratings of their confidence levels in assessment and testing knowledge and skills based on their theoretical knowledge of this field. However, due to their lack of experience in this area, they were afraid that they could not determine whether they could test and assess their students properly in practice. Therefore, teacher training programmes should offer their pre-service EFL teachers more opportunities to apply what they learn in their testing and assessment course in practice. By doing this, the pre-service EFL teachers can understand their assessment literacy better and can avoid being overconfident or under-confident about their testing and assessment knowledge and skills. 


\subsubsection{Methodological issues}

Part 1 identifies some important methodological issues. Although a questionnaire of pre-service EFL teachers' assessment literacy confidence levels was practical and effective in collecting data, this approach could not provide an insight into the preservice EFL teachers' assessment literacy. Because of their lack of experience in testing and assessment, the pre-service EFL teachers reported that their ratings of their confidence levels were based on their theoretical knowledge of the field.

Moreover, in order to conclude about pre-service EFL teachers' assessment literacy confidence levels, it is important to look at the issue from different angles. It is not persuasive to rely only on their ratings of their confidence levels in the questionnaire. Both the quantitative and qualitative results of this study indicate a strong need for the triangulation of data when measuring pre-service EFL teachers' assessment literacy. This is because data triangulation can provide a more-rounded picture of pre-service EFL teachers' assessment literacy.

\subsection{PART 2 - Development of pre-service EFL teachers' assessment literacy during practicum}

Stage 1 identifies a need for data triangulation to understand pre-service EFL teachers' assessment literacy development. Therefore, Part 2 zoomed into this aspect of the four pre-service EFL teachers' practicum at Le Loi high school. To find out the answers to the research questions, I followed four pre-service EFL teachers and the two school mentors who were assigned into two groups at Le Loi high school in City A. Group 1 (Diep and Thuyen) were supervised by Ms. Tan while Group 2 (Van and Nhien) worked with Ms. Thuan. All the names are pseudonyms for ethical reasons.

In this section, I first provide an overview of the practicum in terms of the environment, the school mentors' and the pre-service EFL teachers' backgrounds. After that, I respectively present the answers to the research questions. 


\subsubsection{Overview of the practicum}

\subsubsection{Environment}

At the time of the study, Le Loi high school was the top school for gifted students in City A. This school was well-equipped with modern facilities for teaching and learning. Also, the teaching environment at this school was very supportive for the pre-service EFL teachers. More importantly, the students at this school were willing to cooperate with the pre-service EFL teachers. This is clearly evident in the interview with Ms. Thuan in the first week of the practicum:

The pre-service EFL teachers will have no difficulties with the facilities and students at this school. Unlike some students at other schools, the students at this school are very nice and supportive. At other schools, the pre-service EFL teachers have to spend fifteen minutes every class to settle down the students. But at this school they will not need to do that.

Ms. Tan also emphasized the advantages of the teaching facilities at the school:

The pre-service EFL teachers at this school do not have to bring speakers, CD players to their classrooms because the classrooms at this school are well-equipped with modern facilities. At other schools, it is very inconvenient for the pre-service EFL teachers because they have to bring their own speakers and laptops to their class.

The practicum lasted for nine weeks. In the first two weeks, the pre-service EFL teachers were required to observe their school mentors and get familiar with the school and students. In the following weeks, the pre-service EFL teachers took turns to teach their school mentors' classes and spent their last week for evaluation and paperwork. Each pre-service EFL teacher was required to teach at least six periods during the practicum.

The class the pre-service EFL teachers taught had around thirty-six students who specialised in Physics, Mathematics and Chemistry. Although English was not their specialised subject, the students had a good motivation for learning English due to their desire to study overseas after high school. This is illustrated in Ms. Tan's interview in the first week of the practicum: "The students at this school are motivated to study English because they want to study overseas and win some scholarships". 
In sum, it can be said that the pre-service EFL teachers had a very supportive environment at this school which helped them to apply what they had studied at university into practice. The school mentors' and students' support as well as facilities were available for the pre-service EFL teachers. Moreover, as a researcher, I found no difficulty in getting support from the participants for my research.

\subsubsection{School mentors}

\subsection{Ms. Tan}

Group 1's school mentor was Ms. Tan. At the time of the study, she had had twelve years of teaching experience and had worked at Le Loi high school for five years. Moreover, she had been a school mentor for four years. She also got her Bachelor's degree and Master's degree from the same university as her two pre-service EFL teachers which gave her a better understanding of her mentees' training backgrounds.

Ms. Tan was a very caring, open-minded school mentor. She was also attentive to her mentees' difficulties and concerns. The two pre-service EFL teachers under her supervision highly appreciated her kindness and working style. At the end of the practicum, one of her mentees shared her opinion about Ms. Tan: "She is very professional and attentive. I really like her being critical when she evaluated our teaching performances" (Thuyen).

Like other teachers at her school, Ms. Tan had to learn how to test and assess her students from her own experience and that of her colleagues. She met some difficulties with testing and assessment in the early days of her teaching career due to the lack of practice in testing and assessment at university. Ms. Tan revealed this in her interview: "I did not have any training in testing and assessment at university. Therefore, I met difficulties in the early days of my teaching. Then I learned about testing and assessment from my colleagues and my teaching experience". About the current testing and assessment system, she highlighted the inconsistency in the way high school teachers evaluated students because there were no common marking criteria among the teachers and among the schools. She believed that it would be more beneficial for teaching and learning if teachers were guided how to test and assess their students. 


\subsection{Ms. Thuan}

Ms Thuan was the school mentor of the two pre-service EFL teachers in Group 2. At the time of the study, she had had fourteen years of teaching experience. She had worked at School A for nine years and had supervised four pre-service EFL teachers. Like Ms. Tan, she obtained her Bachelor's degree and Master's Degree at the same teacher training university as her mentees. Therefore, she could understand her mentees' training backgrounds.

Right from the beginning of the practicum, she displayed a positive attitude toward her mentees. She encouraged her pre-service EFL teachers to apply their knowledge into their teaching. Ms. Thuan said:

I am open-minded and happy if the pre-service EFL teachers can apply what they learned at university in the practicum. The pre-service EFL teachers have just learned about the theory and the new teaching approaches at university and they are young and creative in their teaching, which means that I can also learn from them.

According to her, good pre-service EFL teachers were those who were willing to learn, work hard, and know how to follow the mentor's advice. Her positive attitude was shown clearly during the practicum because she always listened to her mentees' concerns and difficulties. Thanks to her enthusiasm, she was highly respected and adored by her mentees.

Like Ms. Tan, Ms. Thuan expressed her concern for her lack of training in testing and assessment when she was at university. Like Ms. Tan, Ms. Thuan had to learn how to test and assess her students from her own experience and that of her colleagues. She recommended teacher training programmes at university to include the training in this area for the pre-service teachers.

Ms. Thuan also expressed her concern for the mismatch between teaching and testing at high schools. Although the communicative approach was encouraged in language teaching, the tests did not focus on students' communicative abilities and only tested grammar, vocabulary, and reading skills. With a lot of constraint of the current situation of testing and assessment, she strongly believed that only teachers' love for teaching and their enthusiasm could improve the current situation. Therefore, Ms. Thuan 
considered her students as her children who needed her constant help and guidance to improve their English. Moreover, she spent her unpaid hours to give them extra exercises, to check their assignments and to give them feedback after her lessons.

In short, the school mentors at Le Loi high school were supportive of the pre-service EFL teachers in their endeavor to apply what they had learned at university in their practicum. This is clearly evident in the interview at the end of the practicum when the four pre-service EFL teachers agreed that they had massive support from the school mentors and students during their practicum. Nhien said:

We were very lucky to spend our practicum at Le Loi school. We have learned a lot. We like our school mentors. The students were very nice and the facilities were very good. Our friends who were assigned at other schools had to struggle a lot during the practicum because their school mentors were not supportive or because they lacked the facilities for teaching. (Nhien)

\subsubsection{Pre-service EFL teachers}

All four pre-service EFL teachers were very enthusiastic and interested in teaching. Three of them reported that their career choice was influenced by their parents who believed that teaching was a noble and suitable job for women. Moreover, all four preservice EFL teachers felt that their interest and abilities matched their career choice. For example, Nhien said: "I chose a teacher-training university because my parents advised me to. Moreover, at school, I specialised in English and I was good at this subject. Also, teaching suits my abilities and interest".

These pre-service EFL teachers tried hard to study at university and they all got good grades. During their practicum, I could observe that they worked hard and always showed their eagerness to improve their knowledge and teaching skills. They always handed in their lesson plans on time and prepared carefully for their teaching. This is confirmed by their mentors when they commented about them during the practicum. Ms. Thuan said: "I think they worked hard and tried to improve their teaching skills during the practicum". Ms. Tan also had the same opinion: "I think these pre-service teachers worked hard during their practicum". 
Before this practicum, the pre-service EFL teachers had completed a language testing and assessment course. They held a strong belief in the role of testing and assessment to help improve teaching and learning. This is shown in their comments:

The purposes of testing and assessment are to know the understanding levels of the students, their capabilities so that teachers can evaluate their teaching quality, their teaching methods whether they are suitable or not, and whether the content of their teaching needs any adjustment. Moreover, testing and assessment serve as a measure for the education administrators and parents to know the levels of the students. (Diep)

Testing and assessment should be used to help learners and teachers to adjust their learning and teaching in a positive way. It should motivate learners. It provides evidence for interested stakeholders to make decision about awards, or educational reform. (Thuyen)

In my opinion, the purpose of testing and assessment is to know what students understand. From that, teachers and schools can adjust their teaching and curriculum to suit students' interest and levels of understanding, which helps increase the quality of teaching and learning. Moreover, testing and assessment are used to rank the students and give them admissions to schools which are suitable for their capacity. (Van)

In short, the four pre-service EFL teachers involved in Phase 3 were interested in teaching. In addition, they had a good motivation to improve their teaching skills and knowledge during the practicum. They also understood the important role of testing and assessment knowledge and skills for their future job. Therefore, it is interesting to know how they improved their assessment literacy during the practicum.

\subsubsection{Development of four EFL pre-service teachers' assessment literacy}

The data analysis shows that the pre-service EFL teachers improved their assessment literacy during the practicum. Their development was also confirmed by their school mentors who agreed that their mentees improved different testing and assessment skills during the practicum. For example, Ms. Thuan, in the interview at the end of the practicum, evaluated her mentees' development: “Although these pre-service teachers are not as good as my previous mentees, they developed their skills a lot since the beginning of the practicum. They are better at giving feedback, instructions, and 
designing a test". Ms. Tan also commented: "I asked them to design tests and helped them improve their tests. I think the pre-service teachers know how to design a test better than before". The data analysis identifies three main themes including:

1. the pre-service EFL teachers' assessment literacy development in six specific areas including (i) giving feedback, (ii) designing test items, (iii) administrating tests, (iv) observing students' learning, and adjusting teaching activities to suit students' interest, understanding and learning abilities, (v) giving instructions, and (vi) improving their content knowledge.

2. the individual differences in their assessment literacy development.

3. the incident-based learning of testing and assessment knowledge and skills during the practicum.

The details of the findings are presented as below.

\subsubsection{Pre-service EFL teachers' assessment literacy development in six specific areas}

During the practicum, the pre-service EFL teachers developed their assessment literacy basically from the observation of their school mentors' and their peers' teaching performances. They also knew how to improve their testing and assessment skills from the discussions with their school mentors and their peers. Moreover, they applied their previous experience with testing and assessment at high school and university as learners as well as what they had studied at university into the practicum.

The observation of their teaching performances, their pre-/post-teaching discussions and their stimulated recalls provide evidence of their development in: (i) giving feedback, (ii) designing test items, (iii) administering tests, (iv) observing students' learning, and adjusting teaching activities to suit students' interest, understanding and learning abilities, (v) giving instructions, (vi) questioning and (vii) improving their content knowledge. In support of these findings, when I gave the four pre-service EFL teachers the summary of the findings, they also confirmed their development in these areas. Examples to illustrate their development are shown as follows. 


\section{i. Giving feedback}

\section{THUYEN}

After Thuyen's teaching performance on $26^{\text {th }}$ February, 2014, Ms. Tan, in the post teaching discussion, pointed out some problems with the way Thuyen gave feedback. She said:

You did the correction rather fast. The purpose of Task 2 was to provide the students with an overview of the unit. So you had better ask students to read each passage and then show each passage on the screen and give feedback for each passage. When you showed all the answers on the screen, the students only concentrated on the answers and did not pay attention to your feedback so your feedback was not effective. Also, it would have been more effective if you had asked the students to highlight or underline some phrases and had asked them to use these phrases to write a new paragraph.

Moreover, Ms. Tan emphasized the importance of descriptive feedback. For example, she commented:

When the students' answers are different from your answers, you have to explain so that the students can understand the lesson thoroughly. Moreover, you have to doublecheck if they understand what you explain by asking them to do another sentence.

From this experience, in her subsequent teaching performances, Thuyen paid more attention to her explanation to help her students understand why their answer was incorrect and had follow-up activities to ensure that her students could apply what she taught. For example, in the subsequent teaching performance, she improved her feedback by not only giving the correct answer but also asked her student to explain the answer. Moreover, she gave her students a follow-up activity to practise what they had not done right as shown in the following episode.

T: Next part. The common mistake is spelling. Next part. Now tell me we should use the adjective or adverb. "Behaves" is a verb so we should use the adverb. Have you had the question? The question with part 4 . Any question?

T: Look at the screen. Become-became-become. You chose "became", It's not right. Now tell me the tense used. Which tense, Bang?

S: Simple past. 
T: So we should use past participle. "Become". Next, will, so we use the simple present tense. Now I see the common mistake here is subscriber. It means that a person. But why did you choose "subscribing", Bang? Why did you choose the answer "subscribing" here?

\section{Student cannot answer.}

T: But you have to focus on the phrase "take advantages of", get benefit. So who? Who get a benefit? A person not a thing. It's an action. Subscribing is an action. It cannot get benefit, cannot take advantages. So we should use the "subscriber" to mention a person. So the answer is subscriber. Ok. Now can you do the second one, Bang?

\section{Student answers.}

T: Ok. So we move to the next part. Bang, you can sit down.

In the above example, at first Bang could not answer Thuyen's question correctly. That was why she had to explain why his answer was wrong and guide him to the correct one. After that, she asked him to do another sentence to ensure that he could understand what she taught. This shows that Thuyen applied her mentor's advice into practice and developed the way she gave feedback to help students understand the lesson better.

\section{DIEP}

In the five-minute check-up of the previous lesson before teaching a new lesson on $20^{\text {th }}$ February, 2014, Diep did not know how to give feedback appropriately. She could only say "correct", "incorrect" or "yes", "no". Therefore, Ms. Tan instructed her to change the way she gave feedback. She advised Diep to state clearly what the students had done correctly and what they had to improve. Ms. Tan said: "You have to explain to your students what they had done correctly. Also, you need to show them how to correct their mistakes before you give them marks".

Thanks to this advice, Diep changed the way she gave feedback for her students. For example, in the check-up on $28^{\text {th }}$ March, 2014, she commented on her student's answers with clearer details of what he could do to improve.

T: Who can volunteer to go to the board? Xuan Huy, please! OK. I will check your vocabulary.

\section{Student goes to the board.}

T: Now I will check your vocabulary. Write down the words on the board.

T: An adjective to describe something that you not... 
T: Let yourself do something that you...

T: Can you tell me the main ideas of the reading passage?

S: The main idea of the reading passage is my hobbies.

T: Yes. How many hobbies were mentioned in the reading passage?

S: Playing guitar, keeping fish and collecting stamp.

T: Look at the screen. Now please talk about your hobbies and you can use some suggestions there within 2 minutes!

\section{S answers.}

\section{Teacher corrects the student's answer about vocabulary on the board.}

T: Xuan Huy, remember! To be attracted to. Not to be attracted with. Your content is good, your accuracy is ok. But please remember some grammatical points. For example, to be attracted to. Your fluency is not good.

The above example showed that Diep had corrected her student's mistakes and told her student to focus on his grammar. She also gave him a comment on his fluency. In the stimulated recall session after that lesson, I asked Diep why she gave feedback in that way, her reflection showed that she developed the way she gave feedback from the school mentor's advice. She said:

The purpose of the speaking lesson was to help students, with the information from the textbook, talk about their hobbies. Moreover, students can further practise speaking about their hobbies. Therefore, in the check-up, I asked the students to tell the meaning of the four new words they had learned in the previous lesson and to talk about their hobbies. After that, from what I had learned from Ms. Tan, I gave them more detailed feedback so that the students could know what they did correctly and what they had to improve.

\section{NHIEN}

In the pre-teaching discussion for Nhien's teaching on $11^{\text {th }}$ February, 2014, Ms. Thuan recognized that Nhien organised her feedback in an assessment activity inappropriately. Hence, Ms. Thuan advised her to change the order of her feedback. Ms. Thuan said:

When the students finish their work, you should not give them the answers before asking them to discuss their answers with each other. If you give feedback in that order, the students will not benefit from your correction. Instead, you should ask them to 
discuss their answers with each other, and after this discussion, you correct their answers.

Ms. Thuan further explained that students had to have time to discuss and learn from their peers before they had the feedback from the teacher. By doing that, the students would remember the lesson better and would concentrate on the teacher's feedback. Based on Ms. Thuan's advice, Nhien revised her lesson plan and applied what she had learned from Ms. Thuan into practice. This is clearly shown in Nhien's teaching for that lesson:

T: Ok, do this exercise.

\section{Students do their exercise.}

T: Finished? Now discuss your answers with your partners.

\section{Students discuss with their partners.}

T: Have you finished? So about the first question: What is the area of the rainforest in Cuc Phuong National Park? Who can answer? You please!

S: Two hundred square kilometres of rainforest.

T: Very good. Two hundred square kilometres. The next one, the next question, question number 2, who can help me? Anyone else? One and two, who can help me? You please!

S: Because the rainy season is over.

T: Yeah, right. Just the rainy season is over. So one minute, find this information. Which passage?

S: The second.

T: Yes, that's right. The next one, what can people learn in Nairobi National Park? Binh please!

S: They can learn how to recognise the different species of animals and plants and the habits of animals and how one species is dependent upon another for survival.

T: Yeah, right, thank you. Do you agree with him?

S: Yes

As can be seen in the above episode, Nhien revised the order of her feedback, and asked her students to discuss their answers with their partners before she asked some students to provide their answers. By doing that, she could check with the whole class whether they agreed with the answers that some students provided. Moreover, with this evidence, she could know whether her students understood her lesson. 
For her teaching on $22^{\text {nd }}$ February 2014, Van designed some Microsoft Power Point slides in which she showed all her answers after an exercise. In the pre-teaching discussion, Ms. Thuan advised her to hide the answers. According to Ms. Thuan, it was better to ask the students to answer first, and then give feedback for each answer. Ms. Thuan believed that giving the feedback like that could help the students remember the lesson well and could provide Van with evidence about whether her students could understand the lesson. Ms. Thuan commented:

You have to hide the answers on your slides. You should give feedback for each answer of the students. Because if you do like that, it is easier for the students to remember your feedback and for you to know if they can understand your lesson.

From this experience, Van improved the way she designed her feedback in the following teaching periods. For example, in her teaching performance on $8^{\text {th }}$ March, 2014, she asked her students to take turns to answer each question and she gave feedback for each answer.

T: Ok, have you finish do your task?

Ss: Yes

T: Ok, finish? Ok, so we will do exercise sentence by sentence. Ok, the first sentence, which word do you choose? You please.

S: Thưa Cô là communicate

T: Ok, so let's see. Communicates, that's right and the second word. You please!

S: Learn

T: Please repeat it!

Ss: Learn

T: Ok, that's learn, Ok, learn. She tell her doctor a fairy tale... Ok, and the next sentence. You please!

In summary, from the above examples, it can be seen that the four pre-service teachers improved the ways they gave their feedback. Moreover, they learned how to give feedback on time and in an order so that their students could improve their learning. In the next session, examples of how they learned to design test items are presented. 


\section{ii. Designing test items}

During the practicum, Ms. Tan asked Diep and Thuyen to design a one-hour test and a fifteen-minute test while Ms. Thuan only required Nhien and Van to design only a onehour test. Through this opportunity, the four pre-service EFL teachers could understand how to design a test properly which was shown in how they revised their tests.

\section{THUYEN}

In her first fifteen-minute test design, Thuyen struggled a lot. Her first version of the fifteen-minute test did not receive good feedback from Ms. Tan because it was too easy for the students. Thuyen shared this in her stimulated recall:

At university, I was only asked to do one or two assignments on test design. I only got results for these assignments but did not receive feedback on how to improve my tests. Therefore, I only understand some very basic things and do not understand much about test design. When I was asked to design a fifteen-minute test, I could not do it properly. Ms. Tan told me that the first version of the test I designed was too easy for the students.

With the guidance from Ms. Tan, Thuyen improved her test design skills. This is shown in the way she chose the test items for the last version of her test design. In the stimulated recall of her test design, she commented:

I designed the test based on the students' levels and Ms. Tan's advice. I followed Ms. Tan because she has been in charge of the class for a long time. In the first version, because I was worried about the time limit, I decided to use a multiple choice approach. However, Ms. Tan advised me to focus the test on how students can reproduce what they learned. I think 'productive' is better because students must think and understand the lessons well to complete the test. Using multiple choice test items cannot tell enough about students' understanding.

Thuyen was also clearer in her choice of the test items to suit her test purposes. She explained in the stimulated recall:

The first two sections, accounting for five marks, were designed for average students. However, the sentence rewrite section and the last section, I divided them into two main parts. I picked three questions from Unit 10 and increased their difficulty to test 
the students' understanding of this unit and the last two questions to test whether the students could master what I had taught in class. I also increased the test's difficulty.

With an opportunity to design a test during the practicum, Thuyen could understand the importance of understanding the targeted test takers when designing a test. She emphasized in the stimulated recall:

The most important lesson I have learned is that in order to design a reliable and valid test, I have to work closely with students and understand their levels. Within a limited time of the practicum, I must have the guidance from the school mentor. I was lucky when Ms. Tan helped me with test design. Without her guidance, I think I would have designed a worse test. All the students would have got 10 marks.

The episode from Thuyen's stimulated recall showed her improvement in test design. She realised that her first test was so easy that all the students could have the maximum ten marks. With the guidance from her school mentor, she targeted her questions for different groups of students. This helped her classify the levels of students and understand where to assist her students to improve their learning.

\section{DIEP}

Like Thuyen, Diep improved her test design skills when taking part in the discussion with Ms. Tan and Thuyen as well as the experience she got from Thuyen's test and Ms. Tan's test design. She said:

Ms. Tan's fifteen minute test focused more on students' reproduction. She asked the students to rewrite ten sentences while Thuyen used multiple choice approach. I can see that Ms. Tan's test was more difficult than Thuyen's. From that, I know that the test should suit the students' learning levels. It should not be too easy as Thuyen's first version of the test.

Moreover, Diep learned some experiences in test design from Ms. Tan. In the postteaching discussion for this test, Ms. Tan advised:

You did not give the instruction clearly for the test. For example, you wanted your students to rewrite the sentences using 'who' or 'which' but you did not tell them clearly. So the students wrote their own sentences. Now you cannot mark them right or wrong. Their sentences are right but they are not what you wanted to test your 
students. You wanted to know if they can use 'which' or 'who' to connect the sentences. Next time, if you want them to rewrite the sentences with 'which' or 'who', you have to state that clearly in the test instruction. For example, you can say something like rewrite the sentences using relative pronouns 'who' or 'which'.

Although Diep had no chance to apply Ms. Tan's advice due to the limited opportunities for test design practice during the practicum, Ms. Tan's advice helped Diep understand better about her problems and what she had to improve in her future test design. This was confirmed with Diep when I carried out member-check with her about the findings of the study.

\section{NHIEN}

Ms. Thuan asked Nhien and Van to design a test. However, she did not have enough time to guide them about test design. Moreover, she did not use their tests but only picked some items from their tests and made up a test on her own. That was why Van commented that she could not learn about test design during her practicum. However, Nhien shared that she could learn about test design by examining the test Ms. Thuan gave her students. Nhien commented:

When I designed the test, I based all the content on the textbook, even when I designed test items to test students' vocabulary. It means I copied the sentences from the textbooks and just left out some blanks for students to fill in. However, Ms. Thuan advised me not to copy everything like that. From her test, I then understand that I should not copy everything exactly like that. I should design a test that covers more knowledge and should design my own test items that can test knowledge like the ones in the textbook.

\section{iii. Administering tests}

None of the four pre-service teachers were confident when they first administered a test. However, with the guidance of their school mentors, they could manage to administer a test better. For example, in Thuyen's first test administration, she could not control her students and stop them from writing when the test finished. Therefore, her students cheated and checked their answers with each other. That was why Ms. Tan told her after the test: "You have to stop your students when the test is finished. And you have to give clear instructions right from the beginning. If you let them continue 
writing, they can copy each other's answers". From that experience, in the following test administration, Thuyen gave her students clear instructions and set the rules right from the beginning. By doing that, she could prevent her students' cheating.

Van, Diep and Nhien had similar difficulties during their first test administration as they had not had any test administration before the practicum. For Van and Nhien, they were instructed by Ms. Thuan to assign students who sat in the same row with different tests to avoid students' cheating and copying.

\section{iv. Observing students' learning}

During the practicum, the pre-service EFL teachers were guided how to observe their students and adjust teaching activities to improve teaching and learning quality. This resulted in their development in this area. Examples for each pre-service EFL teachers are presented below.

\section{NHIEN}

During some first teaching performances, Nhien only stood at the teacher's desk and hardly moved out of this position. She kept standing there and used her laptop to present the lesson to her students on the screen. Recognizing this problem, Ms. Thuan asked her to move around the class, and observe her students. Ms. Thuan said in one postteaching discussion:

You have to move and go around the class to observe your students. You should not stay at your desk all the time. You have to walk around the classroom to see if your students need to ask you something. You know, some students are shy to ask you questions in front of the class. But if you walk by their seats in class, they can stop you to ask for your explanation.

Since Ms. Thuan's comment, it was noticed that Nhien tried not to stand at her desk all the time and learned how to walk around the classroom to get her students involved in her lesson. 
On $17^{\text {th }}$ February, 2014, Van had a class on speaking skills. During this class, she kept calling certain students who raised their hands. Recognizing this problem, Ms. Thuan, in the post-teaching discussion, advised her:

You have to walk around the class to check your students' answers. If the question is easy, you should call some lower-level students to answer so that you can know the whole class' understanding. You have to ask them to answer so they will have an opportunity to think about the answer. If you do not call them, you will never know if they understand the lesson.

This helped Van to learn how to observe the students and get them involved in the lesson. During her teaching, Van walked around her class to check her students and to see if any students needed her support. Moreover, she avoided paying attention to only some active students in her class. She called different students in her class to answer her questions.

\section{DIEP}

In the class of $28^{\text {th }}$ February, Diep did not know how to be flexible in her teaching activities. Therefore, Ms. Tan helped her to know how to observe the students and know if they understood the lesson or not. Ms. Tan said:

When you teach, you have to observe your students to see if they are interested in your lesson. If you see any distraction from the students, you have to adapt your activity to draw their attention and this helps them understand the lesson. You see, in this teaching period, some students at the back of the class did not pay attention to what you taught. Why? It was because they were not interested and did not understand what you said.

Since then, Diep tried to improve her activities to attract students' attention to the lesson. She confirmed this development in her comment in the interview at the end of the practicum when she said: "I learned a lot of things in the practicum. I learned how to observe the students and adjust my activities to suit students' interest and understanding". 


\section{THUYEN}

In the pre-teaching discussion for the speaking lesson on $11^{\text {th }}$ March, 2014, Thuyen was advised by her school mentor to create more activities for students to practise their speaking skills. More importantly, Ms. Tan asked her to observe whether the students could understand the lessons by asking them to evaluate their friends' performances. By doing that, Thuyen could know whether the whole class understood the lesson. Ms. Tan said:

The most important thing in a speaking lesson is to allow students more time to practise their speaking skills and ask your students to practise. But remember to ask the students to listen to their friends' answers and give feedback. For example, those who can recognise the friends' mistakes will have a plus mark. Moreover, you can ask some questions related to the students' answers to check other students' understanding and attention. By doing that, you can observe whether the students pay attention to their friends' talking and can understand the lesson or not.

Then Thuyen paid more attention to observing whether her students were interested in and understood the lesson. For example, in her speaking lesson on $11^{\text {th }}$ March, 2014, she asked her students to evaluate their peers' performance or answer the questions related to their peers' answers to provide her with the evidence whether her students paid attention to the lesson or not.

T: Ok. Time is up. I need a pair to volunteer. Khoi and Huan, stand up and make the conversation. After they finish the conversation, I will ask you some information. If you do not give me the right answer, you know the punishment at the end of the lesson? Remember that!

\section{Khoi and Huan had a conversation.}

T: Ok, that's good. Now I will choose a person. Ok Ha, you have heard the conversation between Huan and Khoi? Tell me why?

S (Ha): I could not hear clearly.

T: Ok, Khoi and Huan because you speak lower, she can't catch your conversation. So next time you need to speak louder. Your conversation is good and creative. But your voice, you need to improve your voice. Yep, it is ok but as I say at the end of the lesson, you will receive a funny punishment. Remember that!

T: Now one more pair. Huyen and Tran, make a conversation. 


\section{Students had a conversation.}

T: Now, Quyen, stand up, tell me which Asian Games are mentioned in their conversation?

\section{Quyen could not answer. $T$ asked her to stand up and called another student.}

T: Tuan. Now the whole class, listen!

S (Tuan): The $2^{\text {nd }}$ Game.

T: Yes. Remember that if you cannot answer my questions, I will have a funny punishment for you.

\section{v. Giving instructions}

It can be argued that in order to assess their students properly, it is necessary that the pre-service EFL teachers had to develop other related-assessment skills. Giving instructions clearly is an important skill that pre-service EFL teachers need to develop. This is because that skill is also critical to their testing and assessment practices. If they cannot give clear instructions in testing and assessment, their students will be confused about what they have to do to fulfil assessment tasks.

Therefore, in this part, I also looked at pre-service EFL teachers' development in giving instructions. All the four pre-service EFL teachers had difficulty with giving instructions in their first few teaching performances. Most of their instructions were unclear and lengthy. This happened, as they reported, due to their lack of teaching experience, their fear and their worry when standing in front of many students and being evaluated by the school mentors. For example, Diep, in her first teaching performance, said that she could not control her feelings effectively. She explained why she kept smiling: "I was very nervous. I do not know why. I felt shy in front of the class".

This affected her instructions because she could not control her language well enough. For example, when she introduced an activity for her students, her instruction was very long and she did not explain the steps the students needed to do clearly:

T: Now, the whole class, before we start the lesson, I will have a small activity for you. And now I will divide the class into two teams: Team A and Team B. Each team will form a line, yeah, the sixteen of six members and the last member will be the leader, ok? The last member will look at the screen and watch a video...ahm...the task is you 
have to remember the information from the video and the other five members will turn back so that they cannot see the screen. Ok? You see? You have two minutes to watch the video and when the video finish, the leader whisper the information one by one, when the first person receive all the information, they will run to the board and write down the answer, do you understand?

To improve her instructions, Diep told me that she had to write down what she wanted to instruct her students carefully in her lesson plans and practise a lot before her class. Thanks to this, I could observe an improvement in giving instructions in Diep's teaching performances. In the following performances, although she sometimes gave lengthy instructions, Diep could show that she managed her teaching better by using clearer instructions. For example, on $7^{\text {th }}$ March, 2014, she introduced an activity for her students:

T: Now, the whole class. We will start a new lesson by a small activity. I will divide the class into two groups: Group A and Group B. Now we will look at the screen and when the letter occurs/ appears, Group A will run to the board, one member of Group A will run to the board and write down the country begins with this letter. And remember the name of the country is only Asia areas. And Group B will write down the name of the sports' name. Just sports name begins with this letter. Are you ready?

Nhien, Van and Thuyen went through similar stages while giving instructions. For example, one of Thuyen's instructions on $11^{\text {th }}$ March, 2014 confused her students:

T: Now, to start the lesson, I have a game for you. It is called "Pictionary". You know this game "Pictionary"? In Vietnamese, you can translate this game into Vietnamese. Pictionary, it means "Duoi hinh bat chu". You know? So I would like to divide class into 3 teams. You are team A, B and C. Each team will receive 8 key words from me. Now I will number. So 1, 2, 3, 4, 5, 6, 7, 8 . Who are the numbered 8 , raise your hand, $1,2,3,4,5,6,7,8$ now remember that you each member in each team comes to the board and take a key word from me, use the body or drawing, you know drawing? You draw on the board, ok? Do not use your voice to express the key words and other members will guess the key words, ok? Remember that each team will describe in 30 seconds. Now here we go, number 1 . 
In general, the four pre-service teachers' instructions were lengthy, repetitive and unclear. That was why Ms. Thuan advised them: "Keep your instructions short and simple. Also, you have to check if your students understand your instructions by asking them to repeat what they need to do or by demonstrating an example".

\section{vi. Improving content knowledge}

One of the most important things that non-native teachers who teach English must acquire is English proficiency. This is because content knowledge is considered as the "special component" which "consists of proficiency in and knowledge about the language and culture to be taught" (Lafayette, 1993). Moreover, English is "the medium of instruction" (Hlas \& Hildebrandt, 2010) for pre-service EFL teachers. Therefore, in this part, I also focus on how the four pre-service EFL teachers improved their content knowledge during the practicum.

Although the four pre-service EFL teachers in this study got good results at university for their English skills, their performance during the practicum showed that they had to improve their English proficiency more. This was because their English proficiency could affect the way they test and assess students. For example, due to their grammatical and pronunciation mistakes, it was sometimes difficult for their students to follow their feedback and instructions. Moreover, due to their limited English proficiency, they could not recognize their students' mistakes and how to correct their students' mistakes in some situations. Therefore, during the practicum, the four preservice EFL teachers were corrected by their school mentors many times about their pronunciation, language use, vocabulary and grammar. Thanks to this, they learned to improve their English proficiency and English grammar. In this section, I do not cite the examples to illustrate their problems with English proficiency due to ethical issues.

\subsubsection{Individual differences in the pre-service EFL teachers' assessment literacy development}

Although the four pre-service EFL teachers were assigned to the same school and each group of two pre-service EFL teachers worked with the same school-mentors, their assessment literacy development varied. This was shown in the results of the pre- 
service EFL teacher assessment literacy questionnaires as well as the data about their performance during the practicum. The results are presented below.

\subsection{Questionnaire results}

First, it can be seen that the four pre-service EFL teachers started their practicum with different levels of confidence in testing and assessment and their confidence also varied in different areas of assessment literacy. Moreover, after the practicum, although they tended to increase their confidence levels in many areas of testing and assessment (for example, knowledge of teaching objectives and curriculum, knowledge of students' learning), they scored lower in some areas (for example, assessment of learning, and ethical issues in language testing and assessment) and did not have the same levels of confidence in testing and assessment.

In general, their confidence levels were different both at the beginning and at the end of the practicum. For example, for knowledge of teaching objectives and curriculum, before the practicum, both Thuyen and Nhien had the same confidence levels (67.5\%). However, after the practicum, Thuyen (80.0\%) scored higher than Nhien $(75.0 \%)$. The summary of their assessment literacy confidence levels development before the practicum and after the practicum is illustrated in Graph 9-3, Graph 9-4 and Graph 9-5. 
Graph 9-3: Four pre-service EFL teachers' assessment literacy confidence levels before the practicum

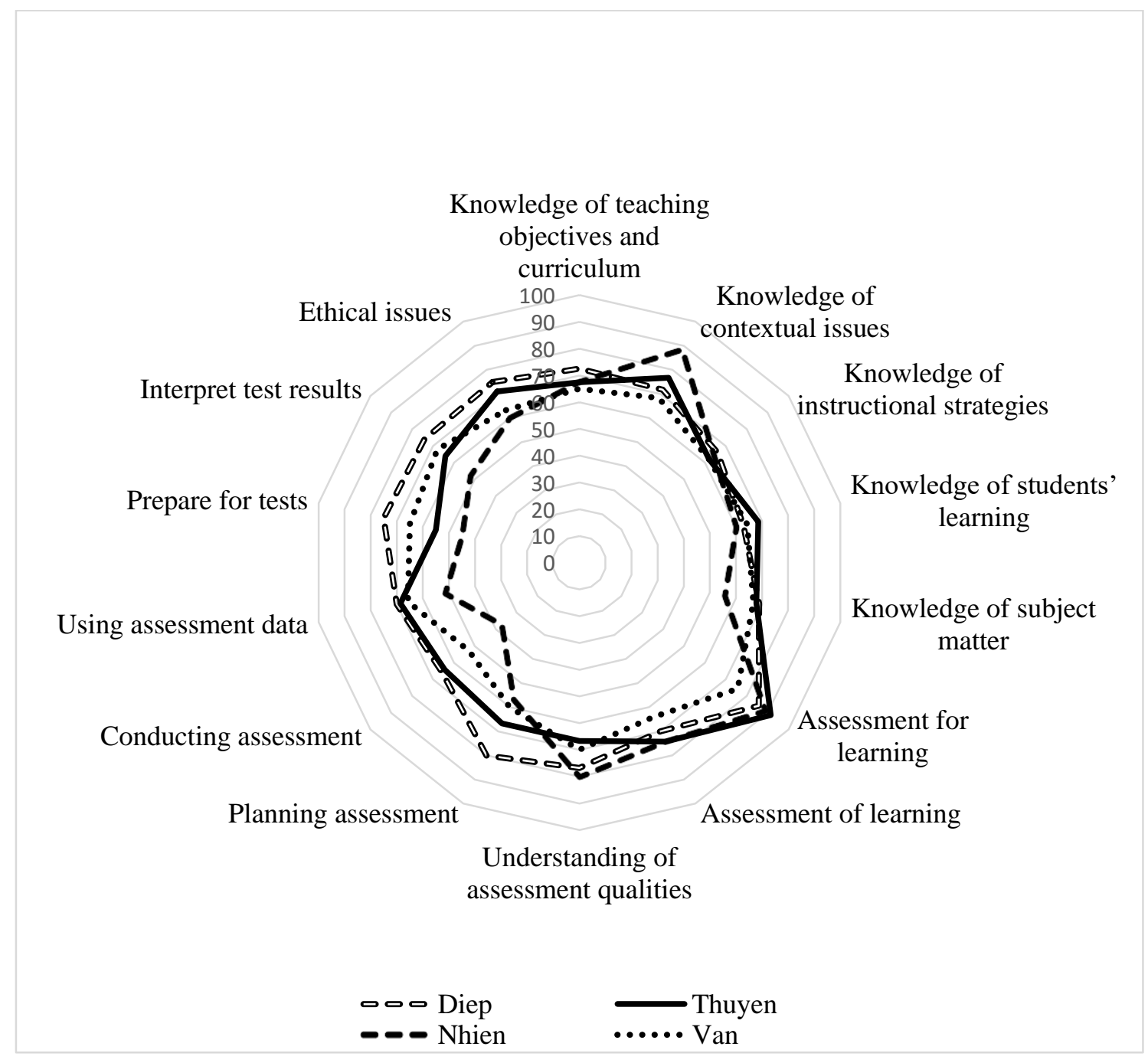


Graph 9-4: Four pre-service EFL teachers' assessment literacy confidence levels after the practicum

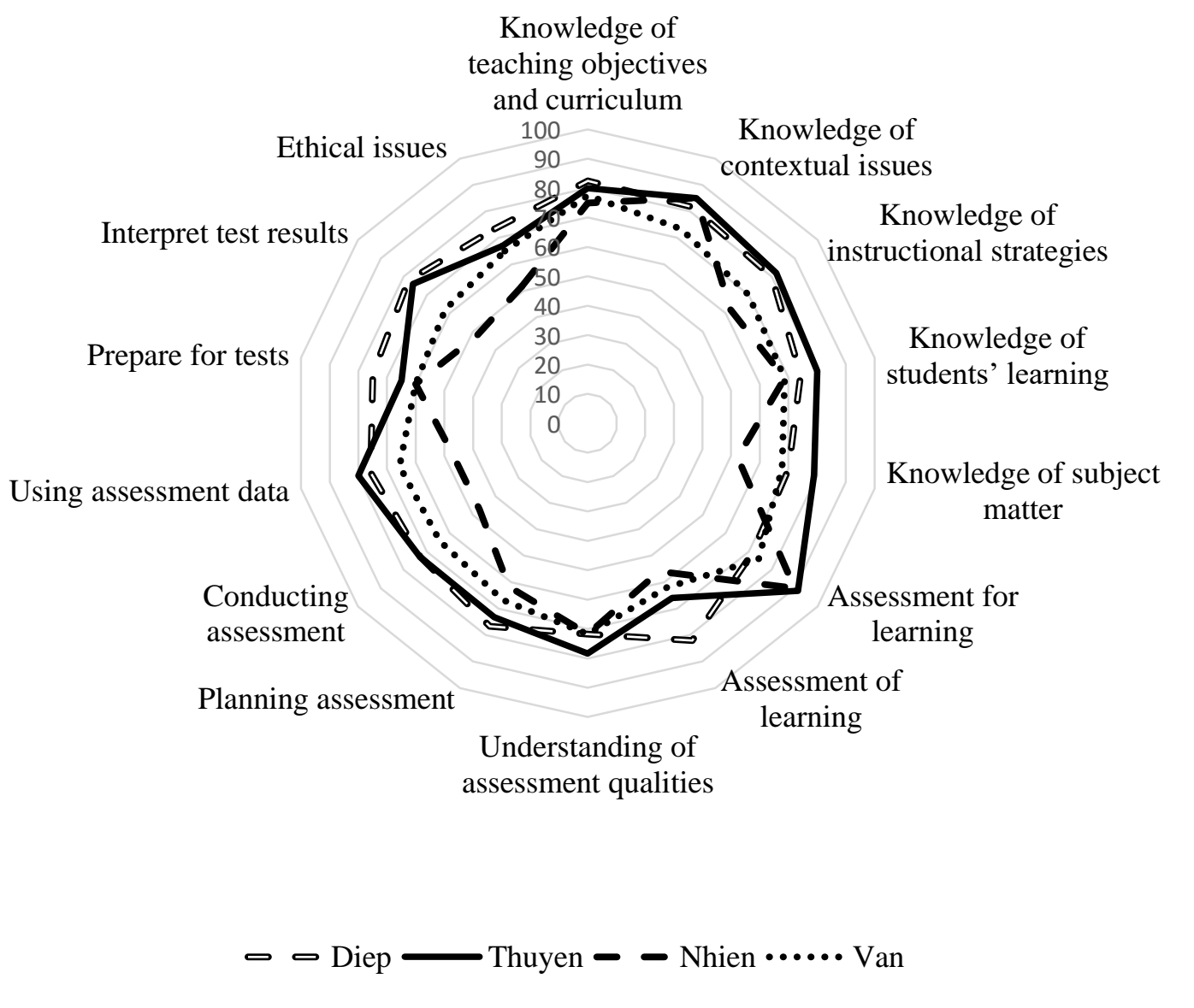


Table 9-3: Four pre-service EFL teachers' assessment literacy before and after the practicum

\begin{tabular}{|c|c|c|c|c|c|c|c|c|c|}
\hline \multirow[b]{2}{*}{ Section } & \multirow[b]{2}{*}{ Sub-section } & \multicolumn{2}{|c|}{ DIEP } & \multicolumn{2}{|c|}{ THUYEN } & \multicolumn{2}{|c|}{ NHIEN } & \multicolumn{2}{|c|}{ VAN } \\
\hline & & Before & After & Before & After & Before & After & Before & After \\
\hline \multirow{5}{*}{$\begin{array}{l}\text { Pedagogical content } \\
\text { knowledge }\end{array}$} & $\begin{array}{l}\text { Knowledge of teaching objectives and } \\
\text { curriculum }\end{array}$ & 72.5 & 82.5 & 67.5 & 80.0 & 67.5 & 75.0 & 65.0 & 77.5 \\
\hline & Knowledge of contextual issues & 71.7 & 81.7 & 76.7 & 85.0 & 88.3 & 85.0 & 68.3 & 73.3 \\
\hline & Knowledge of instructional strategies & 66.0 & 80.0 & 62.0 & 82.0 & 64.0 & 62.0 & 62.0 & 70.0 \\
\hline & Knowledge of students' learning & 62.9 & 74.3 & 68.6 & 80.0 & 60.0 & 68.6 & 64.3 & 68.6 \\
\hline & Knowledge of subject matter & 68.9 & 70.0 & 67.8 & 78.9 & 55.6 & 52.2 & 66.7 & 67.8 \\
\hline \multirow{2}{*}{$\begin{array}{l}\text { Beliefs of language } \\
\text { testing and assessment }\end{array}$} & Assessment for learning & 85.7 & 71.4 & 91.4 & 91.4 & 88.6 & 90.0 & 75.7 & 74.3 \\
\hline & Assessment of learning & 70.0 & 82.0 & 74.2 & 66.0 & 74.0 & 56.0 & 64.0 & 62.0 \\
\hline $\begin{array}{l}\text { Understanding of } \\
\text { assessment qualities }\end{array}$ & & 76.7 & 71.7 & 66.7 & 78.3 & 80.0 & 71.7 & 70.0 & 71.7 \\
\hline \multirow{3}{*}{$\begin{array}{l}\text { Assessment for } \\
\text { learning }\end{array}$} & Planning assessment & 80.0 & 76.7 & 66.7 & 73.3 & 56.7 & 61.7 & 60.0 & 66.7 \\
\hline & Conducting assessment & 65.7 & 72.9 & 64.3 & 72.9 & 37.1 & 47.1 & 52.8 & 64.3 \\
\hline & Using assessment data & 70.0 & 75.7 & 68.6 & 80.0 & 51.4 & 47.1 & 65.7 & 65.7 \\
\hline \multirow{2}{*}{ Assessment of learning } & Prepare for tests & 75.0 & 75.0 & 55.0 & 65.0 & 45.0 & 60.0 & 65.0 & 60.0 \\
\hline & Interpret test results & 74.0 & 78.0 & 64.0 & 76.0 & 52.0 & 48.0 & 68.0 & 62.0 \\
\hline $\begin{array}{l}\text { Ethical issues in } \\
\text { language testing and } \\
\text { assessment practices }\end{array}$ & & 75.0 & 73.3 & 71.0 & 67.0 & 60.0 & 51.7 & 63.3 & 65.0 \\
\hline
\end{tabular}


The details for each pre-service teachers are presented below.

\section{$>$ NHIEN}

As seen from Graph 9-5, among the four pre-service teachers, Nhien felt the least confident in most areas of assessment literacy. Moreover, at the beginning of the practicum, Nhien scored the highest in knowledge of contextual issues but the lowest in using assessment data. Also, she was the one who decreased her confidence levels in most testing and assessment related areas after the practicum including: knowledge of instructional strategies, knowledge of subject matter, beliefs in assessment for accountability purposes, understanding of assessment qualities, using assessment data and interpreting test results. Further, Nhien was the only one who increased her beliefs in assessment for learning after the practicum.

Graph 9-5 illustrates Nhien's development in assessment literacy confidence levels before and after the practicum. 


\section{Graph 9-5: Nhien's assessment literacy confidence levels before and after practicum}

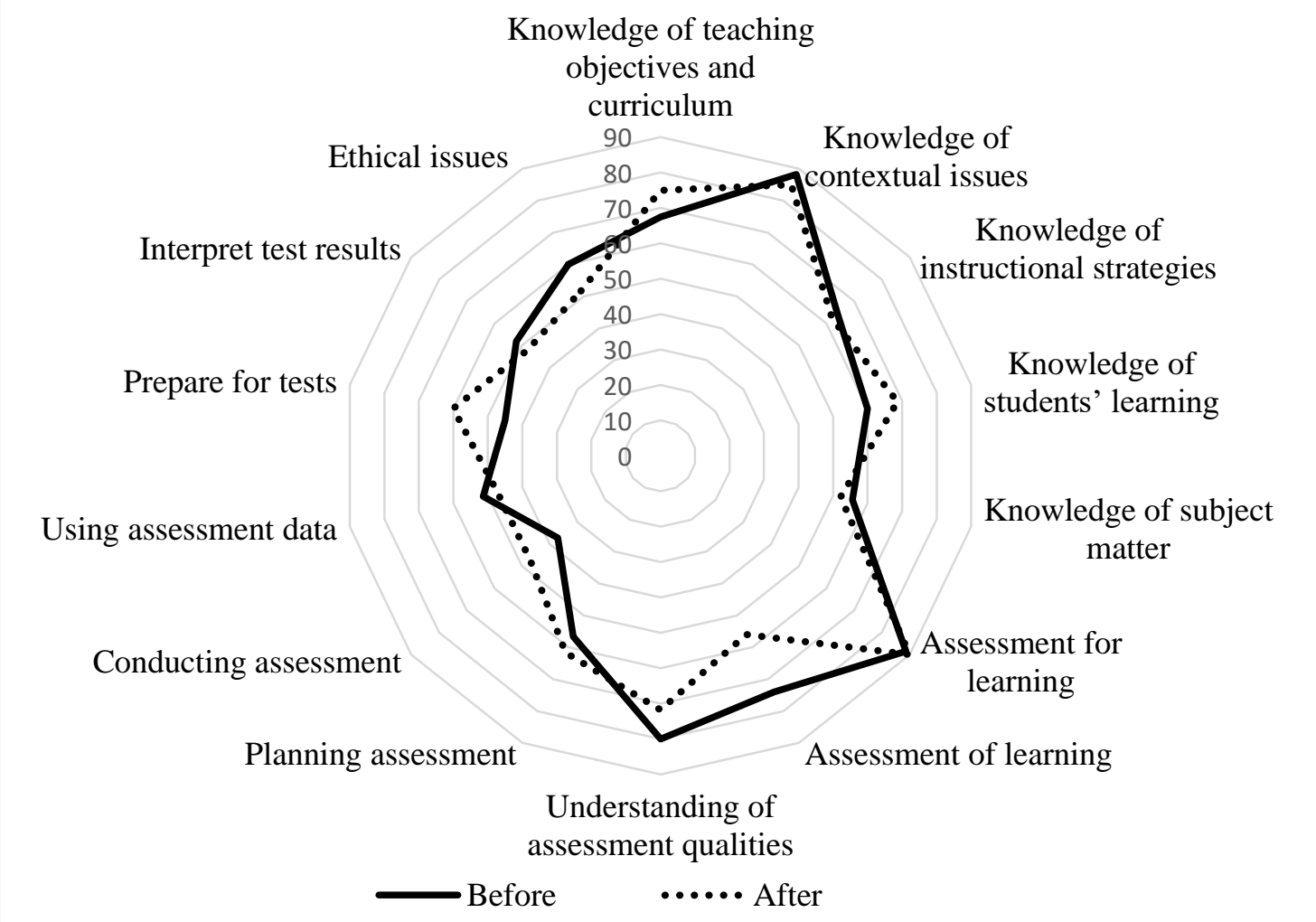

\section{DIEP}

As opposed to Nhien, Diep scored the highest in most areas of assessment literacy at the beginning of the practicum. However, after the practicum, she scored lower levels of confidence in beliefs in assessment for learning, understanding of assessment qualities, planning assessment, conducting assessment and ethical issues in testing and assessment practices. She was also the only one who increased her beliefs in assessment of learning after the practicum. Graph 9-6 gives an overview of Diep's assessment literacy confidence levels development during the practicum. 


\section{Graph 9-6: Diep's assessment literacy confidence levels before and after the practicum}

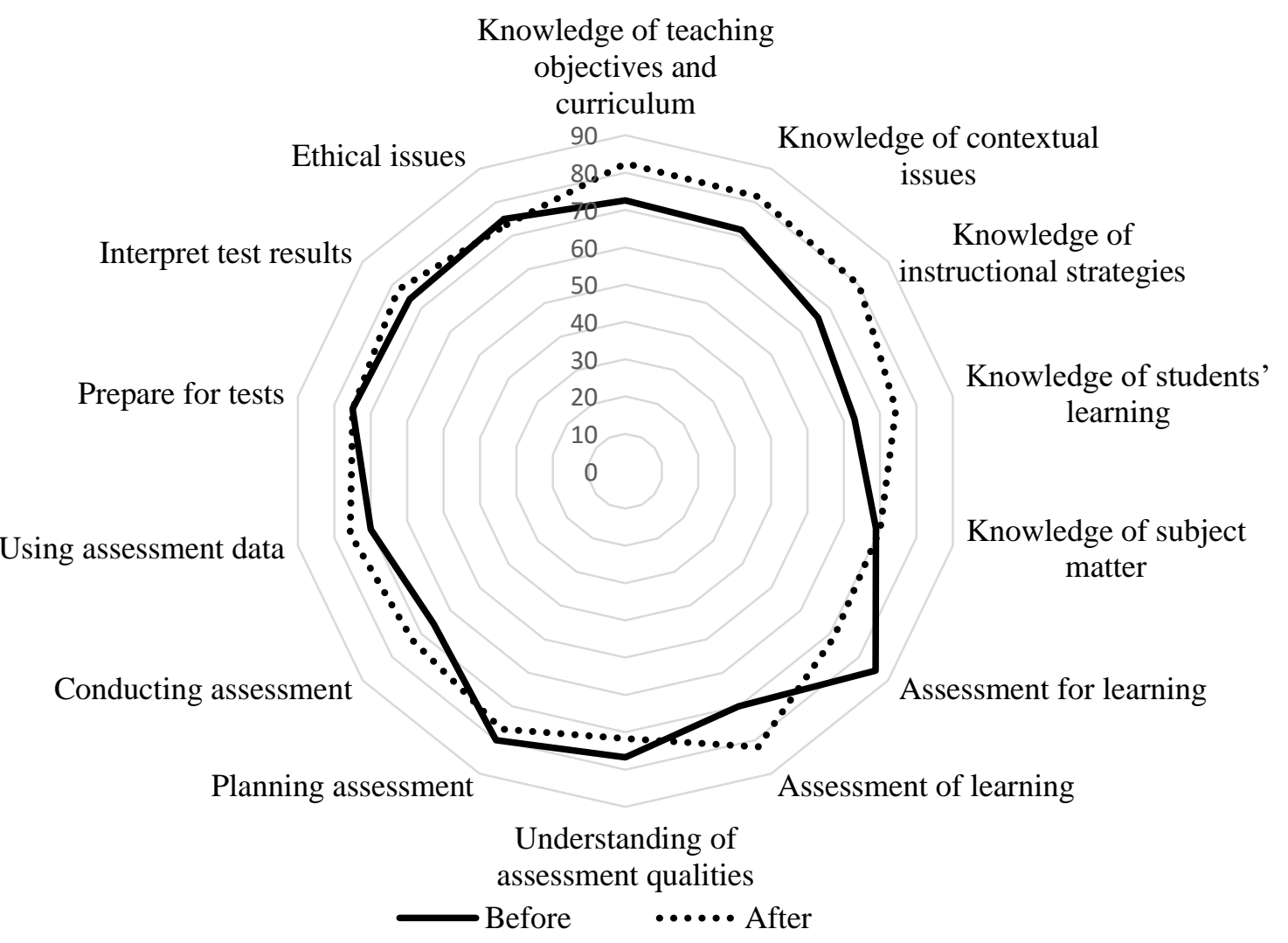

\section{THUYEN}

Among the four pre-service EFL teachers, Thuyen increased her confidence levels in assessment literacy the most during the practicum. She only decreased her confidence levels in her beliefs in assessment for accountability purposes and ethical issues in language testing and assessment practices. Also, she was the only one whose beliefs in assessment for learning remained constant during the practicum. Moreover, she held the strongest beliefs in assessment for learning among the four pre-service teachers. Graph 9-7 below presents her assessment literacy confidence levels' development during the practicum. 


\section{Graph 9-7: Thuyen's assessment literacy confidence levels before}

and after the practicum

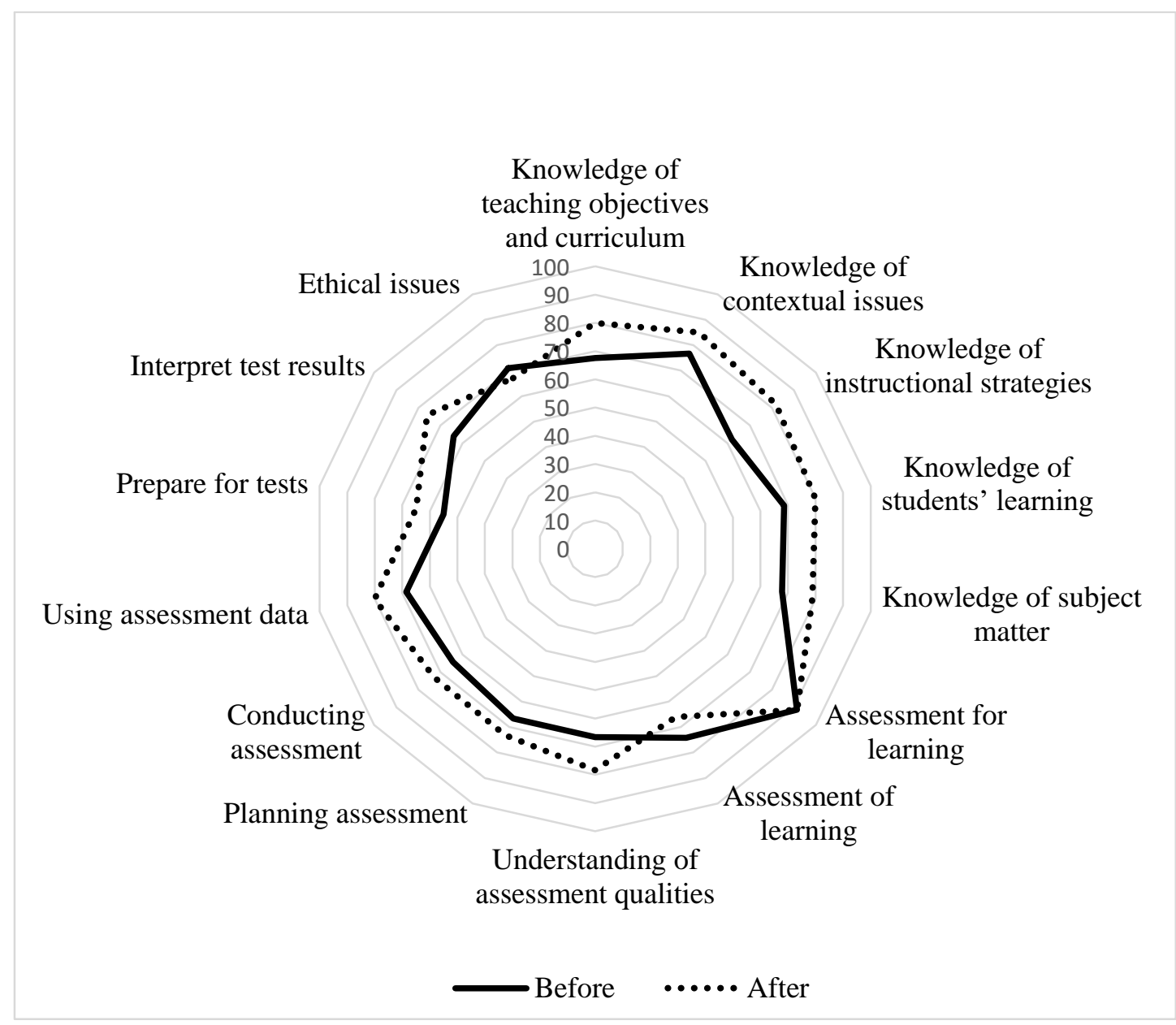

\section{VAN}

Like Thuyen, Van felt more confident in most areas of assessment literacy after the practicum. However, among the four pre-service EFL teachers, Van was the only one whose beliefs in both assessment for learning and assessment of learning decreased during the practicum. Moreover, she was the only one who scored higher in ethical issues in language testing and assessment practices and felt less confident in assessment of learning, particularly in test preparation after the practicum. This may be explained in her interview when she was the only one who reported that she did not improve this skill during the practicum. Graph 9-8 below gives an illustration of her assessment literacy confidence levels development. 


\section{Graph 9-8: Van's assessment literacy confidence levels before}

and after the practicum

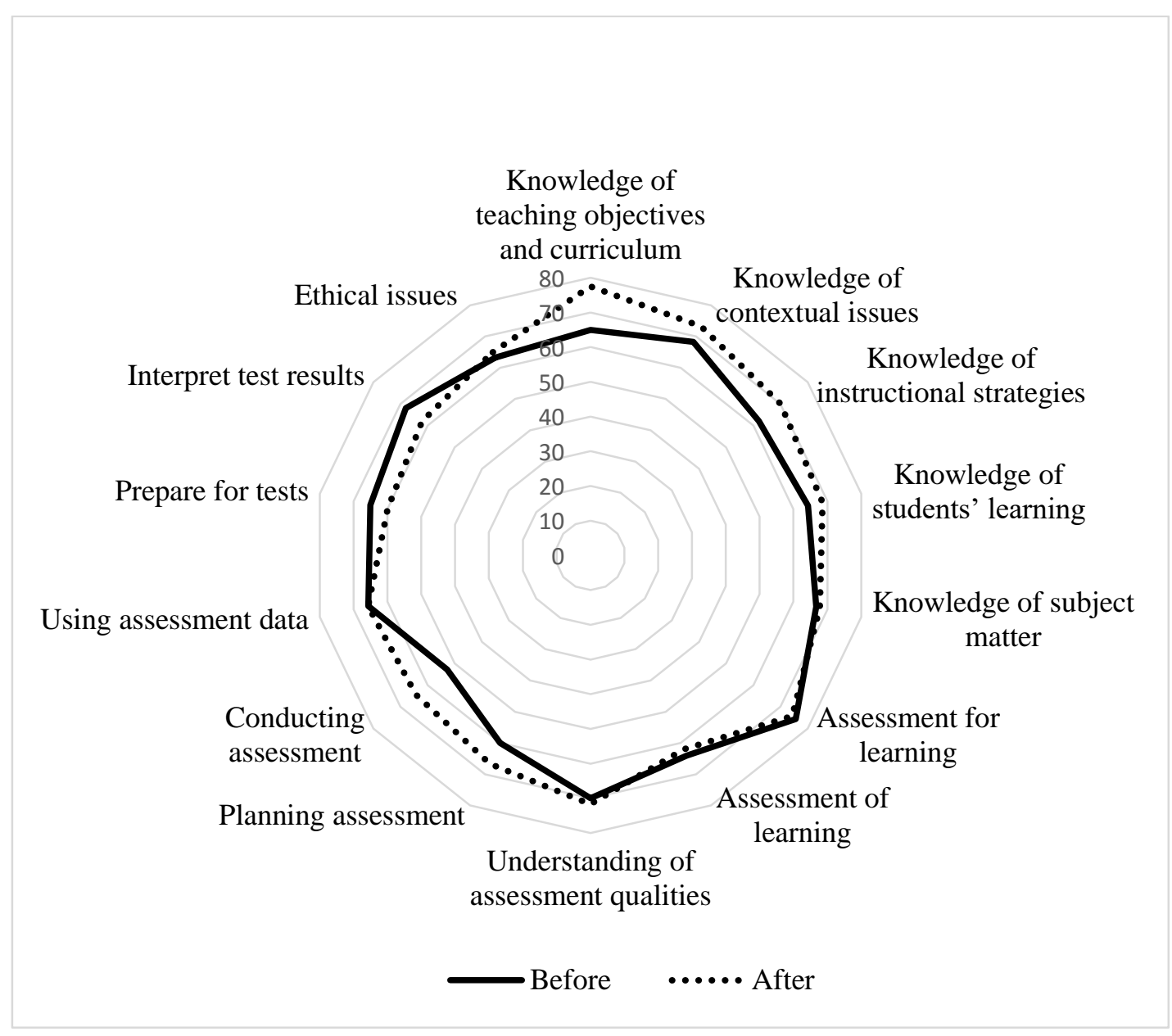

\subsection{Observation during the practicum}

At the end of the practicum, in the final focus group interview, the four pre-service EFL teachers confirmed their development in different areas of assessment literacy. However, it can be seen that their areas of development varied. Table 9-4 summarizes the areas of their assessment literacy development.

For Van, she reported her lack of knowledge in test design because the school mentor did not spend enough time on helping her with this. This is evident in Van's comment in the focus group interview at the end of the practicum: "My school mentor asked me to design one 45-minute test and one 15-minute test but she did not give me any feedback". 
Although Nhien was in the same group with Van, she shared her development in this area due to her observation of the school-mentor's test design. She said:

When I designed the test, I copied the content and all the questions in the test from the textbook, even some vocabulary questions. I mean I copied the exact sentences from the textbook. However, after the school mentor corrected my test, I learned how to design a test that can cover different knowledge and skills for students and I will not have to copy exactly the same questions from the textbook but will know how to design similar questions.

Moreover, even though the pre-service EFL teachers reported their development in the same areas of assessment literacy, the degree of their development was different. This is also evident in the comments of the school-mentors at the end of the practicum when they compared the development of their mentees with the previous mentees that they had worked with in the previous years, and within each group. In addition, each pre-service teacher got different results from their mentors for their performance during the practicum. Even the two pre-service teachers, who were in the same group with the same school-mentor, were given different grades for their teaching performance by their school mentors. The summary of their development is provided in Table 9-4.

Table 9-4: Overview of pre-service teachers' assessment literacy development during the practicum

$\begin{array}{lcccc} & \text { Diep } & \text { Thuyen } & \text { Nhien } & \text { Van } \\ \text { Giving feedback } & \sqrt{ } & \sqrt{ } & \sqrt{ } & \sqrt{ } \\ \text { Administrating tests } & \sqrt{ } & \sqrt{ } & \sqrt{ } & \sqrt{ } \\ \text { Designing test items } & \sqrt{ } & \sqrt{ } & \sqrt{ } & \varnothing \\ \text { Observing students' learning } & \sqrt{ } & \sqrt{ } & \sqrt{ } & \sqrt{ } \\ \text { Giving instructions } & \sqrt{ } & \sqrt{ } & \sqrt{ } & \sqrt{ } \\ \text { Developing content knowledge/ language abilities } & \sqrt{ } & \sqrt{ } & \sqrt{ } & \sqrt{ }\end{array}$

\subsubsection{Incident-based learning of assessment literacy}

During the practicum, the school-mentors did not receive specific guidelines for how to help the pre-service teachers with testing and assessment knowledge and skills. 
Therefore, the school mentors only instructed and advised what their mentees had to do when the problems arose during the pre-service EFL teachers' teaching performances. This led to the pre-service EFL teachers' incident-based learning of assessment literacy. In other words, the pre-service teachers only learned about testing and assessment from their own problems and their peers' ones.

In order to describe how the pre-service teachers incidentally developed their assessment literacy during the practicum, Diep was selected as the main case to illustrate this theme for three reasons. First, Diep was the pre-service teacher I observed the most during the practicum due to the practicality of her schedule. Second, Diep was a typical pre-service teacher who held a strong desire for teaching as a career. Last but not least, she completed a course in testing and assessment at university and achieved a good result.

The details of her development are presented as follows.

\section{CASE STUDY: DIEP}

\section{- Diep's background}

As a local student in city A, Diep had some advantages during the practicum because she could get both spiritual and financial support from her family. Therefore, before the practicum, she worked part-time as a teaching assistant at a popular language centre in City A. However, due to the heavy work load of the practicum, she decided to quit her job and devoted her time to the practicum.

At the time of the study, she had a great passion for teaching because she believed that this job suited her abilities and interest. Besides, her career choice was driven by her family who believed that teaching is a noble and highly suitable job for women.

Due to her determination to become an English teacher, Diep worked very hard and achieved a very good result at university. In her practicum, she endeavoured to improve her teaching skills to prepare herself for her future job as an English teacher. 


\section{- Diep's beliefs in testing and assessment}

Although Diep did not mention any technical terms in language testing and assessment in her answer, it can be seen that she categorised testing and assessment into two main purposes: assessment for learning, and assessment for accountability purposes. This is evident in her interview answer before the practicum:

The purposes of testing and assessment are to know the understanding levels of the students, their capabilities so that teachers can evaluate their teaching quality, their teaching methods (whether they are suitable or not?), and whether the content of their teaching needs any adjustment. Moreover, testing and assessment serve as a ruler for the education administrators and parents to know the levels of the students.

She also mentioned that to ideally test and assess students, it is necessary that: "Teachers determine the assessment purposes, have a plan for assessment, choose an appropriate kind of assessment, administer the tests, mark the tests, analyse the test results, and report the test results". The role of the teachers in testing and assessment was highlighted in her comment: "Teachers know the current situations and all the biases in testing and assessment, understand the test quality and their students' abilities, as well as the context to ensure the fairness and objectivity in testing and assessment”.

\section{- Diep's understanding of the current testing and assessment system}

Diep expressed her lack of knowledge about the current testing and assessment system at high schools in Vietnam. However, she noticed some problems with the system thanks to her part-time teaching experience as a private tutor and her own experience as a student. She said: "The current testing and assessment situation at high schools is still problematic and subjective. Some teachers cannot see the real importance of testing and assessment and some parts of their tests are too difficult or too easy".

Moreover, she mentioned the mismatch between the tests and students' abilities, especially when teachers recycled the same tests for different groups of students. Diep expressed her concern: "I know that some teachers used the same tests for many years and for different classes while the students' abilities of these classes are different". 
- Diep's training in testing and assessment

Like the other pre-service EFL teachers involved in this study, Diep finished a separate course in testing and assessment before the practicum. However, she expressed her concern about the lack of practice during the course. She believed that it would be more useful for pre-service EFL teachers if they were given more opportunities to apply what they learned into practice. She said:

I think the testing and assessment course should be longer and provide the students with opportunities to practise what they learned so that they can understand more deeply about the theories and can design a test or use evaluation in reality.

\section{- Diep's incident-based assessment literacy learning during the practicum}

I observed Diep the most during the practicum because her teaching schedule did not overlap with the other three pre-service EFL teachers. In total, I video-recorded eight teaching periods of Diep which helped me understand her development in testing and assessment. In the following section, Diep's incident-based assessment literacy learning during the practicum will be presented in chronological order. Table 9-5 summarises her teaching schedule.

Table 9-5: Summary of observations of Diep

\begin{tabular}{lll} 
& \multicolumn{1}{c}{ Date } & \multicolumn{1}{c}{ Lesson } \\
Observation 1 & $20^{\text {th }}$ February 2014 & Language Focus \\
Observation 2 & $28^{\text {th }}$ February 2014 & Test yourself \\
Observation 3 & $7^{\text {th }}$ March 2014 & Speaking \\
Observation 4 & $7^{\text {th }}$ March 2014 & Listening \\
Observation 5 & $12^{\text {th }}$ March 2014 & Test correction \\
Observation 6 & $14^{\text {th }}$ March 2014 & Writing \\
Observation 7 & $17^{\text {th }}$ March 2014 & Language Focus \\
Observation 8 & $28^{\text {th }}$ March 2014 & Listening
\end{tabular}

\section{Observation 1: 20 ${ }^{\text {th }}$ February, 2014}

The first lesson Diep taught was Language Focus, Unit 11. In the pre-teaching discussion, her school mentor was satisfied with her teaching content and activities. However, Diep was instructed to redesign her activities to allow more opportunities 
for her students to work with each other. The school mentor also asked her to correct her English mistakes in the lesson plan.

On the first day of her teaching, Diep was very nervous. However, she succeeded in following exactly what she outlined in her lesson plan. She also organised her lesson in a way that helped her students understand the lesson and practise what she taught. Moreover, she encouraged pair work and peer assessment when she asked her students to check their answers in pairs. At the end of her lesson, she also summarised the key points of her lesson to help her students remember what they had been taught. However, there are some issues with her assessment-related activities which can be identified in her first lesson.

Firstly, she did not know how to communicate the objectives of her lesson with her students. Although she stated clear objectives in her lesson plan as shown in the extract from her lesson plan (as shown below) she did not mention them when she taught her students:

At the end of the lesson, students will be able to:

- Distinguish the clusters $/ \mathrm{fr} /-/ \mathrm{spl} /-$ / spr/ and pronounce the words and dialogue containing these clusters correctly

- Use the relative clauses replaced by participles and to infinitives

- Present participle used to replace relatives clauses

- Past participle used to replace relative clauses

- To-infinitive used to replace relative clauses

Diep only introduced the lesson by saying: "Today we will learn about the three sounds / $\mathrm{r}$ / - -/spl/- / spr/".

Moreover, Diep still made some pronunciation and grammatical mistakes during her teaching. Because she taught English, these mistakes affected her teaching quality and confused her students. In addition, her instructions were not clear enough. Several times, she did not finish her instruction when explaining her requirement. For example, when she handed the assignments to the students, she gave an instruction: "Work in a group of four and". In this example, she stopped her instruction at "and" and did not tell exactly what her students had to do in this activity. This confused her 
students because they were unsure about what to do. They had to read the instructions on the hand-outs to finish their assignments.

In addition, when her students gave the answers, most of the time Diep only gave them evaluative feedback such as correct or incorrect, right or wrong, and yes or no. For example, in the following episode, Diep only corrected her students by saying yes or no.

T: OK, now the whole class, have you done the task one in your textbook? The first one, the hotel has special, who can? Quang Huy?

\section{S (Huy) answers.}

T: facilities, yes, thank you and the second one, Nguyet Anh.

S (Anh): Thưa cô aquatic.

T: Aquatic, yes, the next one, Ha Vy.

Only three times in this teaching period, Diep asked her students to explain why they chose the answer and gave them descriptive feedback. In the following episode, she tried to ask her students to give the evidence for their answers.

T: Now, the whole class, the first question. What is the purpose of the Asian Games? My Dung.

S (Dung): Thưa cô, the purpose of Asian Games is developing intercultural knowledge and friendship with Asia.

T: Within Asia, yes. Can you give me your evidence? In which paragraph?

S: In the first one.

T: Ok, as you can see the first paragraph. The Asian Games which take place every four years are held for the purpose of developing intercultural knowledge and friendship within Asia. OK, the second question? How many participants took part in the $14^{\text {th }}$ Asian Games? Minh Huy.

S (Huy): Thưa cô 9919 participants.

T: Give me the evidence, in which paragraph?

In the post-teaching discussion, Ms. Tan notified Diep of her problems from her teaching performances. She asked Diep to pay attention to her English skills, especially English pronunciation. Ms. Tan also advised her to practise giving better classroom instruction. More importantly, Ms. Tan told Diep not to focus on only the 
students who volunteered to answer the questions and advised her to ask different students in the class to check if they understood the lesson or not.

In summary, on the first day of teaching, three main things in testing and assessment based on Diep's teaching performance were highlighted including: how to observe students' learning, how to give instruction and her language skills. It was also observed that some of her problems with testing and assessment skills and knowledge were still not discussed by her mentor.

\section{- Observation 2: $28^{\text {th }}$ February, 2014}

The second lesson was Test Yourself, Unit 11. In the pre-teaching discussion, Ms. Tan asked Diep to develop some exercises apart from those in the textbook to help the students practise what they had learned in Unit 11 more carefully. She also pointed out some English mistakes in Diep's lesson plan. The objectives of this lesson were outlined in Diep's lesson plan:

At the end of the lesson, students will be able to:

- Improve listening skills for specific information and enhance the reading skill for comprehension

- Revise the grammatical point: use to-infinitive and participle to replace relative clauses

- Write a paragraph about the measures to protect the environment

- Learn some words and know more information related to water and environment conservation

However, like the previous teaching period, Diep did not communicate the success criteria and learning objectives clearly to her students. She only began her class by saying: "Ok, now, the whole class, keep silent! Now, the whole class, before we enter the new lesson, I will have a small activity for you".

And then she asked her students to play a game and came straight to the new lesson without introducing the targets that her students had to achieve after the lesson. Although Diep still could not successfully communicate the lesson objectives to her students, she paid more attention to her instructions. It was clearly shown in her 
lesson plan when she carefully wrote down her instructions and told me that she practised giving instruction in front of a mirror before her teaching.

Thanks to this, Diep's instruction was better than in the first teaching period. She also double-checked if her students understood her requirements by asking them the question "You catch it?" in her instruction. This can be seen in the following instruction from Diep:

Ok, now, I will divide the class into two teams, team A and team B. Team A will be given a white chalk and team $B$ will be given the yellow chalk. And the task is, because the topic of today is water, each member of team will come here, run to the board and write down the benefit of water in our life. Can you catch it? For example, and the second is solution to protect water, ok? So member of each group will run to the board and write down as much as ideas as possible. You catch it?

However, during her teaching, Diep still had problems with her instructions when she did not allow her students enough time to understand and follow her instruction. For example, she told her students: "and your members, members of your group can support you" but did not give time for her students to support each other.

Like the first teaching period, most of Diep's feedback was still evaluative. Only four times in her teaching, did she use descriptive feedback; for example, the following episode showed that she used descriptive feedback:

T: Yes, thank you. Sentence four, what would help people have to do to end or reduce pollution immediately? Who can? Huyen Khue?

S (Khue): Thưa cô là people would have to stop using many things that benefit them.

T: So give your evidence.

S (Khue): Pollution can be gradually reduced in several ways. Scientists and engineers can work to find ways to lessen the amount of pollution that such things as automobiles and factories causes.

T: Yes, it's true.

In the above example, Diep not only evaluated if her student's answer was correct or not but also asked this student to give evidence to support his answer. It was done to give her the information if this student could understand clearly about the answer. 
Diep still made language and pronunciation mistakes which confused her students. Therefore, in the post-teaching discussion, her school mentor advised her to practise her final sounds so that she could make them clearer for her students. Diep told me that she tried to practise very hard at home but her nervousness in the classroom prevented her from speaking English correctly. Also, Ms. Tan asked Diep to improve the way Diep corrected her students. Ms. Tan said:

You can give your students an A4 size paper for them to write their answers and ask your students to work in pair or individually and then you can correct their handouts. It will be more effective and time-saving. Moreover, I could see that the students still made mistake with matching exercises. If they made simple mistakes, it would be ok. However, if they made a wrong sentence, this meant they could not understand the lesson. For example, I could see that Nghia was incorrect. Next time, you will have to pay attention to that.

In summary, in the second teaching performance, Diep paid more attention to her instruction and language skills. However, she still had some problems which her school mentor pointed out in the post-teaching discussion including: pronunciation mistakes, how to correct students' answers effectively and how to observe if students could understand the lesson.

\section{- Observation 3: $7^{\text {th }}$ March, 2014}

The third teaching lesson was Speaking, Unit 12. In the pre-lesson planning discussion, Ms. Tan was concerned about Diep's instructions. She asked Diep to rework her instructions into simple language and be clear about what she wanted her students to do. Moreover, Ms. Tan advised Diep to have a guiding question to provide students with the objectives of the lesson.

Thanks to Ms. Tan's comments, Diep revised her lesson and tried to provide clear instructions while teaching. Also, she communicated the lesson's objectives to her students:

T: Now the whole class, look at the board! Who can tell me what these pictures are about? These pictures tell us about the Asian Games medal and result over a lot of 
years, some years. And now, before we start today, we practise speaking the Asian Game results and some sports event results.

In the post-teaching discussion, Ms. Tan pointed out some problems with Diep's teaching performance. First, Diep still pronounced some words incorrectly which might have confused her students. For example, because Diep was unsure about the pronunciation of the word "a bronze medal", although her students pronounced " $a$ bronze medal" correctly, Diep kept asking them to correct their pronunciation of this word.

Moreover, Ms. Tan asked Diep to provide more time for her students to practise the vocabulary before speaking. Because Diep followed the textbook exactly, Ms. Tan advised Diep to have more activities for students to practise their speaking skills. She said: "You have to create more activities for your students to practise speaking. Moreover, you did not spend enough time on teaching your students vocabulary". It can be seen that Ms. Tan saw the importance of follow-up assessment to check students' understanding when she asked Diep to have more activities for students to practise speaking and help them with their problems.

When Ms. Tan mentioned the lack of time spent on teaching vocabulary, Diep interrupted and explained that these words were simple and she thought the students had learned them. However, Ms. Tan disagreed: "No, you think your students could know these words but in reality they might not know them. You have to teach them and have to double-check if they knew these words". At this point, it can be seen that Ms. Tan advised Diep to check students' understanding before making any teaching decision. Ms. Tan further said:

You have to ask your students to practise speaking in pairs or in groups. When you call the students to present their answers, you have to ask the other students to listen. You can do it by asking students to pay attention to their friends' answers and give a plus mark for those who can pick up their friends' mistakes. Or you can ask other students some follow-up questions related to their friends' answers to ensure that they pay attention and understand the lesson.

In the above episode, Ms. Tan also encouraged Diep to use peer assessment in the language classroom. One more thing that Ms. Tan asked Diep to remember was to 
summarise the lesson using an activity which allowed students to connect all they had learned. Ms Tan said:

When I teach this lesson, I think the final activity is the most important. I usually have a sum-up activity which connect all the previous activities so that students can practise and make a long dialogue. For students at other school, you can ask such questions when and where, but for students at this school, these questions are too easy. You have to ask them to make a long dialogue.

In summary, in this period, the main things that Ms. Tan mentioned to help Diep improve her assessment literacy were: English language skills, observing students, using peer assessment, checking students' understanding before making any teaching decision and communicating the objectives of the lessons.

\section{- Observation 4: $7^{\text {th }}$ March, 2014}

On the same day, $7^{\text {th }}$ March, 2014, Diep had another lesson on listening skills. In this lesson, Ms. Tan was unsatisfied with Diep's grammatical mistakes. Moreover, she wanted Diep to have a check-up activity in the beginning of the lesson. This was to check if students understood the previous lesson and to give them some marks and feedback before teaching them a new lesson.

For Diep's teaching, Ms. Tan advised her to pay attention to some key words that Diep had to teach her students before listening. Without that, Ms. Tan claimed, it was difficult for her students to understand the listening lesson. Ms. Tan continued to instruct Diep to examine the transcript carefully and check if there were any words that might be difficult for her students and check if they could understand those words.

In addition, Ms. Tan praised Diep for her improvement in communicating the objectives of the lesson with the students. She also reminded Diep to double-check if the students really understood the lesson and could answer the questions on their own. This is because the students could look up the answers in the answer key in the textbook instead of listening and answering the questions on their own. This meant they could answer the questions but their answers did not reflect their listening skills. Ms. Tan said: 
The students usually look up the answers in the answer key to answer the questions and do not pay attention to listening. Therefore, for True or False questions, you have to ask them to give evidence. In this lesson, you had to check their evidence to ensure if they could listen and understand to answer the questions.

In the post-teaching discussion, Diep also asked for Ms. Tan's advice about whether it was a good idea to add more exercises to this lesson to check the students' understanding. Ms. Tan replied:

Are the exercises related to this lesson? In after-listening activities, you should have an activity to help students integrate other skills, for example, speaking, and writing. If you ask students to continue listening, they will be very tired. It is because they listen lot in a listening lesson. If you ask them to listen to a song, it may be ok. But of course, the song must be related to the lesson. If the song is not related to the lesson, you should not ask students to listen.

In summary, Diep was instructed to improve her language skills, understand the importance of check-up activities, observe and check students' understanding, as well as choose an appropriate task to evaluate students' understanding.

\section{- Observation 5: $12^{\text {th }}$ March, 2014}

The purpose of the lesson was to correct the one-period test that the students took before. In this period, Ms. Tan asked Diep to give the answers to the students and explained why their answers were right or wrong in their test. Moreover, she required Diep to design more exercises for the students to practise what they could not do well in the test.

In the pre-teaching discussion, Ms. Tan reviewed Diep's test design and advised Diep to give the instructions clearly in the test to avoid students' confusion. Due to her unclear instructions, Diep could not mark her students' work effectively because her students had a variety of answers. Although these answers were right, they were not what Diep expected to measure in her test design. From this experience, Diep learned about how to state clearly what she wanted to check her students' understanding. 
In this lesson, Diep managed to give feedback and explanation to help her students understand their levels. She picked out some sentences where many students went wrong to help them realise their problems. For example,

T: Mary was the first person to visit Kate's blog. Right or wrong? Right. The first person. But remember some students might be confused. Might be confused by using the structure "it takes somebody to do something". The second sentence "it was Mary that visited Kate's blog”. Some students might be confused. That's a past event. So we use past simple. And there is the superlative. The first person so we use to infinitive. And remember we will...If the sentence has the preposition we will change the preposition that goes before the relative pronouns. Do you understand? Avoid these mistakes?

Although Diep made some English mistakes in her explanation and her explanation was rather lengthy, she tried to explain the answer to the students to help them avoid these mistakes in the future. For this lesson, Ms. Tan did not give Diep any comments in the post-teaching discussion because she believed that this period was meant just for providing the answers to the test and for responding to any student questions. In summary, in this lesson, Diep learned about how to improve her test design, and how to give feedback to help students understand their mistakes.

\section{- Observation 6: $14^{\text {th }}$ March, 2014}

This lesson was about writing skills, Unit 12. In the pre-teaching discussion, Ms. Tan pointed out some of Diep's grammatical mistakes. Moreover, Ms. Tan emphasised the importance of the clarity and the purpose of each activity. She said: "Be clear in your instructions. Your instructions must state clearly what you require your students to do. Also, you have to clarify your purposes for each activity".

When Diep asked Ms. Tan about whether she could give her students a model essay at the beginning of the lesson to teach useful expressions, Ms. Tan did not support this idea. She said:

You should not give your students a model essay right at the beginning. Why? It is because they will copy the model essay and will not try to write creatively. If you want to check if they understand the useful expressions, you can show a short essay 
on the screen and ask them to find out the linking words. After that, you ask if they know any other linking words.

Then Diep asked Ms. Tan whether it was possible for her to give students the first sentence of the essay and ask students to write the rest instead of giving students a model essay right at the beginning. However, Ms. Tan did not support this idea because she believed students could not write correctly from the beginning when they had not learned anything about the lesson and that the activity would take a lot of time but could not provide evidence of students' understanding effectively.

In this lesson, Diep had a check-up activity at the beginning of the lesson to check whether her students could understand the previous lesson. She called one student to the blackboard to answer her questions. Moreover, after that student finished answering her questions, Diep asked other students to give feedback about their friend's answers. She shared in her stimulated recall that this was done to check if other students could follow their friend's answer and understand the previous lesson. The following episode shows how she did her check-up activity:

T: Who can volunteer to go to the board? I will test... check your vocabulary and after that you have to talk about an athlete that you like most. Right? So who volunteer? Diễm Quỳnh.

T: Now I will give you the meaning and you write the words on the board.

T: A person who perform gymnastics.

Student writes down on the board.

T: A room for people to perform gymnastics

Student writes down on the board.

T: A noun that people can join a game and they can play in any style they like.

\section{Student writes down on the board.}

T: They jump into the air and then they hit the ground so the verb is...

Student writes down on the board.

T: Please read loudly the vocabulary!

\section{Student reads the vocabulary}

T: Now please talk about an athlete that you like.

S: The athlete that I like most is Le Quang Liem. He is a... of Vietnam. In my opinion, he plays very well. In January 2012, FIDE rankings he is a twenty nine game player in the world and he ranks first in Vietnam and I think that he is very optimistic 
and ...he is very optimistic and (composing of) every game of chess. In a game, when I saw him play, he played ...when he competed with his Chinese competition. $\mathrm{He}$ must sit but he stand up while playing and I think that he over well the competition and he gain victory so I am very...I think that in every Vietnamese...

T: Now the whole class any comments. Minh Trung, do you have any comment on Quynh's talk?

S: I think she could talk fluently.

T: anyone else. Now, you could talk about an athlete that you like...you completed your task when you talked about the athlete Le Quang Liem, a famous chess player in Vietnam. So, let me check your vocabulary. Now the whole class, right or wrong the whole class?

S: Right.

T: This word, Quynh "j" or "g"? The second one a room that people perform gymnastics is a gymnasium. The word freestyle right or wrong the whole class?

S: Right.

T: Quynh, so you got 3 out of 4 words.

In this episode, despite her lack of detailed feedback for her student's answer, Diep improved the way she checked her students' understanding and attention by asking them to provide feedback about their friend's answer. Moreover, Diep paid attention to the check-up activity at the beginning of the lesson as advised by Ms. Tan.

In the post-teaching discussion, Ms. Tan pointed out Diep's problem with her correction in the check-up activity. Ms. Tan advised Diep to correct what the student wrote on the blackboard. She said:

Why did you ask Diem Quynh if she wrote letter " j" or letter "g"? If her word is wrong, you just say it is wrong. Do not double-check with your student like that. Your correction took you a lot of time because you kept asking the student many times if this letter was " $\mathrm{j}$ " or " $\mathrm{g}$ ". It is not necessary to do that. Just check if the words are right or wrong.

Moreover, Ms. Tan pointed out Diep's English mistakes and asked Diep to improve her English proficiency. Ms. Tan also mentioned about the quality of the feedback that Diep gave her students. Some of Diep's sample sentences were not good for 
students to improve their writing skills. Ms. Tan also suggested a more effective and efficient way to give feedback. She said:

Instead of asking your students to write on their own and then call some of them to present their answers on the blackboard, you can use posters and ask your student to write on them. After that, you ask your students to stick their writing on the board and then you correct them. It will save a lot of time for writing on the blackboard.

In summary, in this lesson, Diep was instructed to improve some of her English mistakes, and how to give feedback effectively.

\section{- Observation 7: $17^{\text {th }}$ March, 2014}

In this lesson, which was on language, Diep taught students about relative clauses. In the pre-teaching discussion, Ms. Tan did not give Diep any comments on the lesson plan. She also praised Diep for including interesting student activities in her design.

However, in the post-teaching discussion, Ms. Tan advised Diep not to ask if the students could understand the lesson many times while explaining the lesson to the students. She said:

Your explanation was so lengthy, and you kept interrupting your explanation to ask your students if they could understand what you said. You should not do something like that. I think just only a small group of students who could not understand. Therefore, you can take another opportunity to explain to them later.

Then Diep interrupted her school mentor and said: "I thought they could not understand. I saw that some students looked confused". When Diep explained this problem, Ms. Tan then explained that this had occurred because of Diep's lack of the review of the previous lesson which had made it hard for the students to understand the lesson. Ms. Tan then emphasized the role of reviewing and checking students' understanding before introducing any new lesson. She added:

Then next time, before any lesson, you have to think carefully about how to teach your lesson effectively. You have to guess what may be difficult for your student. I think this lesson was not difficult to the students, because they had learned about it before. In this lesson, you just taught them about the omission of relative pronouns. In this lesson. you had to review what is an object, what is a subject. Some students 
could be confused because you did not review this point. You should have done the review before you taught them a new language point. For example, you could ask them to review and ask them to do exercise number 1 before you moved to the next part.

Moreover, Ms. Tan advised Diep:

If students answer your questions, and you keep asking them if they understand, they will think that maybe what they say is wrong. They may think you want them to do something else. The students at this school are very good, you should not be too worried if they cannot understand.

After this, Ms. Tan carefully helped Diep to design an exercise to link different parts of the lesson to enhance students' understanding. She said:

You should not design multiple choice exercises only. You taught relative clauses and checked if they could use relative clauses. Therefore, multiple choice exercises cannot provide you with this evidence. This kind of exercise cannot help you check your students' understanding. Instead of using multiple choice exercises, you can ask your students to reproduce sentences using relative clauses.

Ms. Tan also commented on the way Diep gave marks to her students. In the checkup, Diep gave a maximum mark for their speaking. Diep believed that it was appropriate because that student volunteered to answer. However, Ms. Tan advised Diep not to give marks based on volunteering. She said:

You cannot give your student 10 mark for speaking. I do not think students can speak like a native speaker to get 10 mark. Moreover, you cannot give them maximum marks because they volunteer.

In summary, in this lesson, Diep was instructed four things: (1) how to review the previous lesson to enhance students' understanding, (2) how to check students' understanding properly, (3) how to give marks to students, (4) how to predict students' understanding. 


\section{- Observation 8: $28^{\text {th }}$ March, 2014}

During the practicum, all the pre-service EFL teachers had to teach one period for other teachers and pre-service EFL teachers at school had to observe. This could be considered as a show-case period where all the pre-service EFL teachers wanted to show what they had learned in the previous teaching performances. Diep chose this listening lesson to show her teaching abilities.

In the pre-teaching discussion, Ms. Tan did not comment about this lesson because she wanted to evaluate Diep's improvements. In this lesson, Diep demonstrated her improvement in assessment skills. In the check-up activity, she had a clearer instruction, and clearer criteria for checking students' performances than the previous teaching performances. She also showed her criteria for marking on the screen so that all the students could follow.

Moreover, Diep checked for evidence of students' understanding. An example of this can be seen in the conversation below:

T: The writer started his hobby when he was a little boy. Now listen again. So that's right. Now Blue team. Only 10 marks. Now red team. True or false.

S: False

T: So who can give me the evidences? Khanh Dat?

S: His parents.

T: That's right. Red team. 45 . Now blue team. Sent 4 . The writer didn't start with simple ABC books.

S: The writer started with simple ABC books.

T: Right. The writer started with simple ABC books. Blue team. 70

T: The next question. Sentence 5 true or false?

S: True.

T: True. Phuc why do you choose true?

S: Because in the listening, the author told that reading helps him to....he don't have to go out to learn about things.

T: Yes. I do not have to learn things in the very hard way.

Also, she designed more exercises to check students' understanding and avoid cheating. In the stimulated recall, she explained: "I designed some exercises and did 
not use the ones in the textbook. The students usually copied the answers in the textbook and did not pay attention to listening”.

In the post-teaching discussion, Ms. Tan praised Diep for her improvement in teaching skills and checking students' understanding. However, Ms. Tan was also concerned with Diep's pronunciation and advised Diep to focus more on this problem.

\section{- Summary of Diep's observation}

As can be seen from the description of Diep's teaching over the eight teaching periods, her assessment literacy development was generally based on the feedback of her school-mentor for her own problems. This led to an incident-based learning of assessment knowledge and skills. Due to the overlapping schedule of some of her teaching periods with the other pre-service teachers, I could not manage to observe Diep continuously and missed four of her teaching periods. Moreover, as Ms. Tan shared in the interview at the end of the practicum, she could not spend enough time on helping Diep with assessment knowledge and skills. Ms. Tan said:

I must say that I could not spend enough time to help my mentees with testing and assessment skills. I just sometimes gave them comments on what they did inappropriately. To be honest, I focused more on teaching skills, lesson planning, and other administrative tasks.

When I asked her if her mentees could perform well in testing and assessment after graduation, Ms. Tan shared: "I think they will be OK. They have learned some knowledge and skills in testing and assessment. When they become teachers, they will continue their learning. They will learn from their own problems and from their colleagues". Ms. Tan also expressed the need for detailed guidelines for areas in which to help pre-service EFL teachers as well as rubrics for evaluating pre-service EFL teachers' performances and development.

In summary, from the observations of Diep and the interview with Ms. Tan, it can be seen that testing and assessment were not considered as the central focus during the practicum. Ms. Tan only gave Diep advice about how to improve her assessment practices when there were problems with Diep's performance. This could cater for 
the differences in the way each pre-service EFL teacher developed their assessment literacy. However, this led to incident-based learning of assessment literacy and unsystematic learning of testing and assessment. It would have been more beneficial to Diep if Ms. Tan had known about what areas of testing and assessment Diep needed to improve on during the practicum, so that Ms. Tan could spend more time mentoring Diep in these areas within her nine-week practicum.

\subsubsection{Discussion}

Field experience or practicum has been recognised as an indispensable component to enhance pre-service teachers' teaching practices (Goodfellow \& Sumsion, 2000). In assessment training, the practicum is an opportunity for pre-service EFL teachers to practise testing and assessing their students and to improve their assessment literacy. Although previous studies have tracked pre-service EFL teacher cognition development during a practicum (e.g., Farrell, 2007; Gao \& Benson, 2012; Johnson, 1994; Macalister, 2012; Nguyen \& Hudson, 2010; Numrich, 1996), there has been a limited understanding of how pre-service EFL teachers improve their assessment literacy in a practicum. This study addresses this gap in the literature. It looks into how pre-service EFL teachers learn to do testing and assessment by tracing four preservice EFL teachers' development in assessment literacy during their nine-week practicum.

It is fortunate that the pre-service EFL teachers in this study did not experience some common problems during a practicum such as a power struggle (Doppen, 2007; Graham, 1997; Haigh \& Ward, 2004; Weaver \& Stanulis, 1996), school mentors' lack of efficacy (Hudson, 2005), or limited options of the preservice teachers to apply what they had learned (Ajayi \& Lee, 2005; Dunn et al., 2000) and technology in teaching (D. Brown \& Warschauer, 2006). The pre-service EFL teachers in this study enjoyed a supportive environment and good facilities for teaching and learning at Le Loi high school. However, they needed more support in terms of assessment training during the practicum. This study identified some pedagogical and methodological issues as follows. 


\subsubsection{Pedagogical issues}

First, the school mentors mentioned their lack of professional development in testing and assessment as well as mentoring skills. This limited the quality of their assessment training. They believed that to improve pre-service EFL teachers' assessment literacy, they had to be given more training in testing and assessment as well as mentoring skills. This is in line with what many experts (Davison, 2012; Stiggins, 1991b, 1995; Volante \& Fazio, 2007) recommended about adequate professional development in testing and assessment for those who work in these areas.

Second, as reported by the school mentors, testing and assessment received inadequate attention during the practicum. The school mentors only helped their preservice EFL teachers when they could identify some problems with the pre-service EFL teachers' assessment practices. This led to pre-service EFL teachers' incidentbased learning of assessment literacy during their practicum. Although this could cater for individual differences in the way the pre-service EFL teachers learned about testing and assessment, it might create an unsystematic learning of assessment. It would have been more beneficial for pre-service EFL teachers if the school mentors had been informed about what areas of testing and assessment pre-service EFL teachers needed to improve during their practicum.

Thirdly, the pre-service EFL teachers in this study showed variation in the development of assessment literacy during their practicum. Therefore, needs analysis should be done before assessment training to understand pre-service EFL teachers' needs in testing and assessment. This would help them to work on those areas where they felt less confident. To understand pre-service EFL teachers' needs in assessment training, the questionnaire of pre-service EFL teachers' confidence levels in assessment literacy which was developed in Phase 2 can be used for further research and assessment training for pre-service EFL teachers.

Fourth, the lack of communication between the school and the teacher training university as reported by the school mentors was a barrier to pre-service EFL teachers' development in testing and assessment. As the school mentors were not well-informed about practicum guidelines, it was difficult for them to provide 
appropriate assessment training during the practicum. Previous research has shown that the disconnect between school and university could lead to a gap between theory and practice (Dean, Lauer, \& Urquhart, 2005; P. Grossman, Martin, Place, \& Valencia, 2009; F. A. J. Korthagen \& Kessels, 1999; F. Korthagen, Loughran, \& Russell, 2006).

Fifth, the findings of this study have shown that the experience the pre-service EFL teachers got from the practicum helped them improve many aspects of assessment literacy such as giving feedback, giving instructions, and content knowledge. Therefore, teacher preparation programmes should offer more opportunities for preservice EFL teachers to practise doing testing and assessment during teacher preparation programmes. Moreover, different ways to help pre-service EFL teachers should be investigated to improve the quality of assessment training for them during their teacher preparation programmes. For example, in Taiwan, Fang (1996) and Wang et al. (2008) examined how to use a web-based model called "Practising, Reflecting and Revising with WATA system (P2R-WATA) Assessment Literacy model" to help pre-service biology teachers learn to do testing and assessment.

Sixth, although assessment training is important to pre-service EFL teachers' assessment literacy, assessment training in Vietnamese teacher training universities has received inadequate attention. The school mentors in this study reported their lack of focus on helping their mentees with testing and assessment practices. Thus, teacher preparation programmes should make assessment training during the practicum compulsory in order to enhance their graduates' assessment literacy.

\subsubsection{Methodological issues}

As indicated in Phase 2 and Part 1 of Phase 3, assessment literacy is a complex construct that can hardly be understood by just examining pre-service EFL teachers' confidence levels in their knowledge and skills of testing and assessment. Therefore, Part 2 of this study traced the development of four pre-service EFL teachers during their practicum using different research instruments such as stimulated recalls, observations, interviews, and questionnaires. Data triangulation is critical to the understanding of their development of assessment literacy. However, there are some methodological issues that should be taken into consideration: 
First, due to the tight teaching schedules of the school mentors and the preservice EFL teachers, it was impossible to attend all their teaching periods and discussions to examine the pre-service EFL teachers' development in assessment literacy. Therefore, it was difficult to keep track of the details of pre-service EFL teachers' development in assessment literacy during their practicum.

$\checkmark$ Second, it was important that data analysis was done as soon as possible to provide information for the next steps of the study. For example, after the observation, it was important to analyse the data to refine the questions for the stimulated recalls. However, due to time constraints, it was very difficult to perform data analysis right after the observation. Thus, it is important that further research into the development of pre-service EFL teachers takes this issue into consideration.

$\checkmark$ Third, as Vietnamese high school teachers are usually overloaded with their teaching schedules, part-time jobs, and administrative work, it is not easy to recruit participants for longitudinal research which involves a lot of the participants' work and time. Therefore, researchers need a lot of time and effort to build trust among the participants and need to be flexible with regard to the participants' working schedules.

\subsection{Summary}

Phase 3 looks at the development of the pre-service EFL teachers during a practicum. Part 1 of Phase 3 showed an increase in the pre-service EFL teachers' assessment literacy confidence levels when comparing levels before the course in testing and assessment, as well as before and after the practicum. However, the follow-up interview with two groups of the pre-service EFL teachers indicated a strong need for data triangulation to investigate the pre-service EFL teachers' assessment literacy development because their confidence levels in assessment literacy might not show their real abilities in practice. Therefore, Part 2 of Phase 3 traced a group of four preservice EFL teachers and two school mentors during their practicum to investigate the development of assessment literacy in pre-service EFL teachers. The findings identified three main themes in their development including: the pre-service teachers' assessment literacy development in some aspects (giving feedback, designing test 
items, administering tests, observing students' learning, adjusting teaching activities to suit students' interest, understanding and learning abilities, giving instructions, questioning and improving their content knowledge), the individual differences in their development and the incident-based learning of their assessment literacy.

The following chapter, Chapter 10, will provide an overall discussion of this present study. 


\section{Chapter 10:}

\section{DISCUSSION}

\subsection{Introduction}

This study looks at Vietnamese pre-service EFL teachers' assessment literacy from three perspectives: 1) language testing and assessment courses for pre-service EFL teachers, 2) pre-service EFL teachers' confidence levels in assessment literacy, and 3) pre-service EFL teachers' development in assessment literacy during their practicum. As stated earlier in Chapter 1, the development of pre-service EFL teachers' assessment literacy in this study is viewed through the lens of third generation Activity theory. This means that their development of assessment literacy is considered to be situated, and dynamic. It also requires interactions between preservice EFL teachers and other stakeholders involved in this process including school mentors, teacher-trainers, and their peers. In these activity systems, contradictions within and between activity systems are critical to changes and developments in the activity systems (Engeström, 1999; Lantolf, 2006). In order to help pre-service EFL teachers develop their assessment literacy, these contradictions need to be identified and solved.

In this chapter, the findings are discussed in the light of the contradictions of third generation Activity theory in: 1) language testing and assessment courses, 2) preservice EFL teachers' assessment literacy, and 3) development of pre-service EFL teachers' assessment literacy during practicum. This helps to identify the current problems of assessment literacy training for pre-service EFL teachers in Vietnam. Also, the discussion of the findings refers to previous studies in the areas of assessment literacy and teacher cognition to position this study in the big landscape of research in these areas. The chapter continues with an overall discussion and ends with a summary.

\subsection{Language testing and assessment courses}

Currently, there is a dearth of information in the literature about language testing and assessment training courses for pre-service EFL teachers. Brown and Bailey (2008) acknowledged that "all in all, there is still much we do not know about how language 
testing is being taught in language teacher training programs around the world, and how it should be taught" (p. 373). Moreover, the focus of previous studies varies from a wider international context of testing and assessment training as in the studies of Bailey and Brown (1996), and Brown and Bailey (2008) to a specific context as in Jin (2010) whose research described the role of this training in China, and Lam (2014) who examined testing and assessment training in Hong Kong. Therefore, Phase 1 contributes to the very limited literature on language testing and assessment courses by providing insight into the realities of these courses at the four key teacher training universities in Vietnam. Together with previous studies (Bailey \& Brown, 1996; Jin, 2010; Lam, 2014), this current research highlights the importance of language testing and assessment training in teacher education. It also shares the same findings with Bailey and Brown (1996), Jin (2010) and Lam (2014) that assessment training has received inadequate attention in teacher education.

Moreover, it is important to close the gap between theory and practice in these courses and consider the balance of knowledge about (content knowledge) and knowledge how (pedagogical content knowledge, practical knowledge) in teacher preparation programmes (A. Burns \& Richards, 2009). Besides that, teacher-trainers, within their limited time for assessment training, should be encouraged to find initiatives in their training approach to enhance their pre-service teachers' assessment literacy. For example, in Taiwan, the studies of Fan, Wang, and Wang (2011) and Wang, Wang, and Huang (2008) focused on how to use a web-based model to help pre-service teachers learn about test analysis and test revision. In Australia, Kleinsasser (2005) transformed an assessment course for second language teachers at postgraduate level by involving them in the process of learning and asking them to develop a portfolio to help them design, negotiate and document their own learning of testing and assessment.

To investigate language testing and assessment training in Vietnam, this phase listens to the voices of four Vietnamese teacher-trainers who were in charge of assessment training at four key teacher training universities. Four semi-structured interviews with these teacher-trainers help to identify five main contradictions that need to be solved in order to improve assessment education in teacher preparation programmes 
including: 1) contradiction within the subject (teacher-trainers), 2) contradiction between mediational tools and the object, 3) contradiction between the division of labour and the object, 4) contradiction between the rules and object, and 5) contradiction between object and object.

\section{- Contradiction within the subject (teacher-trainers)}

The first contradiction is identified within the four teacher-trainers in this study, between their current knowledge and expectations for developing their pre-service EFL teachers' assessment literacy. In order to maximize the quality of language testing and assessment training for pre-service EFL teachers, teacher-trainers are expected to update their knowledge in these areas. However, the four teacher-trainers involved in this study expressed their dissatisfaction with their knowledge and skills in testing and assessment. They also reported their lack of formal training in language testing and assessment. Moreover, they noted that the lack of professional development in testing and assessment limited the quality of their assessment training.

This finding is similar to Bachman's (2000) criticism in his discussion of the professionalization of language testing in the $21^{\text {st }}$ century that "the majority of practitioners who develop and use language tests, both in language classrooms and as part of applied linguistics research, still do so with little or no professional training". This is also a concern of Brookhart (2001b), Davison (2012), Fulcher (2012), and Stiggins (1991, 1995) who emphasized the importance of more formal training for those who work with testing and assessment. Therefore, more professional development in testing and assessment for teacher-trainers should be a priority to ensure testing and assessment training quality in teacher preparation programmes. Without professional development in these areas, it is obvious that teacher-trainers are under-prepared to assist their pre-service teachers to gain adequate assessment literacy. 
- Contradiction between the mediational tools and the object of developing preservice EFL teachers' assessment literacy

The second contradiction is between the mediational tools (teaching materials and references) and the object. In order to attain the goal of improving pre-service teachers' assessment literacy, teacher-trainers need to use mediational tools such as course materials and other reference resources. However, the teacher-trainers, in this study, reported having insufficient reference materials and training resources for the demands of their assessment training of pre-service EFL teachers. Further, one teacher-trainer noted that some parts of the materials she was using were not relevant and were too difficult for the students but she was unable to revise these due to the lack of reference resources at her university.

This finding indicates a strong need for more support from the top down to provide teacher-trainers with adequate resources for their training. Without that, it would be difficult for them to keep updated with the current trends in language testing and assessment. Also, it is essential that teacher-trainers be given more formal training in testing and assessment in order to maximise their usage of textbooks and reference materials because most available textbooks are "highly technical or too specialized for language educators seeking to understand basic principles and practice in assessment". Moreover, it is important that the materials used for assessment training should be expanded to include skills, knowledge and principles of testing and assessment (Davies, 2008).

\section{- Contradiction between the division of labour and the object}

The third contradiction identified is between the division of labour (length of assessment training) and the object. This is because the teacher-trainers reported that another reason which hindered their goal to improve their students' testing and assessment knowledge and skills was the limited length of language testing and assessment courses. Among the four participating universities, two universities did not have a separate course for language testing and assessment. This, the teachertrainers continued, meant they did not have enough time for helping their pre-service EFL teachers with different knowledge and skills in testing and assessment but could 
only provide their students with very basic knowledge. Also, they were unable to give their pre-service EFL teachers opportunities to practise what they had learned. For the two universities which could only offer five to ten periods for assessment training in their teaching methodology courses, it would be not easy for teacher-trainers to squeeze the necessary knowledge and skills of testing and assessment within such a limited time. This finding is similar to China and Hong Kong where Jin (2010) and Lam (2014) respectively also emphasized that language testing and assessment courses should be made compulsory and their length and course credits increased. Within a very limited period of time, it is impossible for teacher-trainers to offer all the necessary knowledge and skills in testing and assessment that pre-service EFL teachers need for their future jobs.

M. H. Nguyen (2013) investigated the curriculum of teacher training programmes for pre-service EFL teachers at a Vietnamese university and claimed that the curriculum of teacher training in Vietnam focused more on language skills and was inadequate for pre-service teachers to gain professional knowledge and skills in teaching. Therefore, it is important that teacher training universities in Vietnam pay more attention to their curriculum development. Also, needs analysis should be performed to understand where pre-service teachers need to improve during teacher training programmes.

As training in testing and assessment is unquestionably critical to their jobs as EFL teachers, language testing and assessment courses should be included in teacher preparation programmes. As S. Borg (2003) stated in his review that teacher education influenced pre-service teachers' cognition, Yin (2010) recognised that assessment training will definitely affect pre-service EFL teachers' testing and assessment practices. Without adequate assessment training, it is difficult for preservice EFL teachers to improve their assessment literacy.

\section{- Contradiction between the rules and the object}

The fourth contradiction is between the rules (including the influence of Confucianism, testing and assessment culture, and practicum rules) and the object of developing pre-service EFL teachers' assessment literacy. In this study, teacher- 
trainers reported that assessment training at the four universities focused more on the role of psychometrics and summative assessment than formative assessment. Stiggins (2002) was similarly concerned about the dominance of summative assessment over formative assessment in the education system. This is also in line with the previous studies of Bailey and Brown (1996) and Brown and Bailey (2008) and Jin (2010) which showed that language testing and assessment courses put more emphasis on measurement theory than on formative assessment.

In Vietnam, this can be explained by the persistent impact of testing and assessment culture on the current teacher training programmes in Vietnam. Like other examoriented societies where exam success is central to teaching and learning (Carless, 2011; Carless \& Lam, 2014), English language teaching and learning in Vietnam has experienced the same influence of this exam culture as EFL teachers value the importance of students' exam results rather than their students' communicative competence. In this study, the teacher-trainers reported their focus on summative assessment in the training course because they believed knowledge and skills of this is more important for pre-service teachers' future jobs. In addition, they noted that the culture of testing and assessment in Vietnam prioritises the role of summative assessment over formative assessment. The teacher-trainers mentioned that they spent more time on summative assessment because of its role in the real-life situations that pre-service teachers would face in their future jobs. This also influenced the content of the training programmes for pre-service EFL teachers at these four universities.

However, in this study, this choice of course content which prioritised the role of psychometrics and summative assessment might also be affected by the teachertrainers' limited exposure to the new approaches in testing and assessment in the world. According to (L. Taylor, 2009), to design a relevant language testing and assessment course, it is important that teacher-trainers acquire a thorough knowledge of testing and assessment. However, as reported in the interviews, the teacher-trainers were unsatisfied with their assessment literacy and they believed that they received inadequate formal training in testing and assessment. If the teacher-trainers had been given more opportunities to update their knowledge in testing and assessment, they 
would have made more informed decisions when selecting course content relevant to the future needs of their students. Also, it is obvious that if teacher-trainers' had greater knowledge of assessment literacy it would enable them to ensure the suitability of the materials for their students' understanding. Moreover, it is important to challenge teacher-trainers and pre-service EFL teachers to "become practical and theoretical assessment materials developer[s] within a developing, supportive, professional community" (Kleinsasser, 2005, p. 97).

In addition, the teacher-trainers expressed a concern about whether pre-service EFL teachers received training in testing and assessment in their practicum depended on their school-mentors. They also added that testing and assessment training might not be considered as the central focus in practicums. In other words, pre-service EFL teachers might not have opportunities to learn about testing and assessment in their practicums. This finding is similar to previous studies (e.g., Mertler, 2003; Plake, 1993; K. W. Vogt \& Tsagari, 2014) which highlighted the lack of pre-service teachers' exposure to language testing and assessment training in their training programmes. Moreover, this finding indicates that pre-service EFL teachers in Vietnam had few opportunities to practise what they learned and received little support and training in the practicums. This is a persistent problem in teacher education in Vietnam as noted by many Vietnamese experts (H. T. M. Nguyen, 2010; M. H. Nguyen, 2013; Pham, 2001) who commented about the lack of pre-service EFL teachers' exposure to real-life classrooms in the teacher preparation programmes.

To change this situation, it is important that policy-makers limit the influence of summative assessment on the way English is taught and learned in Vietnam. English tests and exams should match with teaching and learning requirements and value the role of English communicative competence. Moreover, assessment training needs to be made compulsory in teacher preparation programmes and teachers' professional development to equip EFL teachers in Vietnam with more testing and assessment methods. It is likely that EFL teachers with adequate assessment literacy will transform the way testing and assessment is currently implemented in English classrooms in Vietnam. 
- Contradiction between the object and the object

The fifth contradiction is between the teacher-trainers' object and the pre-service EFL teachers' object of developing assessment literacy in this study. This contradiction can be identified in the teacher-trainers' concern that some students in their training programmes found very little interest in improving their assessment literacy. Perhaps this is, as the teacher-trainers reported, because a number of students in their training programmes did not want to become teachers. Therefore, according to the teachertrainers, those students would not be interested in assessment training. The teachertrainers went on to explain that this attitude can jeopardise the object of improving pre-service teachers' assessment literacy. For example, Ms. Quy said: "Only those pre-service EFL teachers who are interested in becoming teachers will find this course useful and interesting". In other words, according to teacher-trainers, preservice teachers' desires to become teachers were related to their motivation to improve their assessment literacy.

To ensure that pre-service EFL teachers make an effort to improve their assessment literacy, appropriate policies about admission to teachers' training programmes as well as teacher training and teacher recruitment should be implemented to recruit only those who want to become teachers. Many enroll in teacher training programmes in Vietnam because the programmes do not incur tuition fees. For those pre-service EFL teachers, their commitment to the profession is important as is dedication to learning teaching strategies and assessment literacy. Therefore, related stakeholders, for example, policy makers, and university administrators should be more informed about pre-service teachers' interest and their commitment to a teaching career.

Moreover, more research to investigate the relationship between pre-service EFL teachers' commitment to teaching career and their motivation for developing their assessment literacy is necessary to inform policy-makers and teacher-trainers about how to effectively encourage assessment literacy training in teacher preparation programmes. That is why in Phase 2 of my study, I looked at the link between career choice and pre-service EFL teachers' confidence levels in assessment literacy. However, it is surprising that career choice did not have a statistically significant impact on their confidence levels in assessment literacy. Further research needs to be 
done to understand whether career choice is critical to pre-service EFL teachers' assessment literacy.

\section{- Summary}

Language testing and assessment courses in Vietnam still have some unsolved tensions. If this situation remains unchanged, Vietnamese pre-service EFL teachers will graduate without adequate training in testing and assessment. As teacher education can influence pre-service teachers' cognition (S. Borg, 2003), a lack of assessment training in teacher preparation programmes will affect their professional development in testing and assessment and how they apply testing and assessment in their future teaching. This is supported by previous studies which showed that inservice teachers reported their lack of testing and assessment training in the undergraduate teacher training programmes as a barrier to their assessment literacy (Plake, 1993). Hence, these contradictions can deprive Vietnamese pre-service EFL teachers of opportunities to learn and update their knowledge and skills of testing and assessment.

\subsection{Pre-service teachers' confidence levels in assessment literacy}

As stated earlier in the methodology chapter (Chapter 6), unlike the previous studies which employed an assessment literacy test (e.g., Mertler, 2003; Plake, 1993) or a survey of assessment practices (e.g., DeLuca \& Klinger, 2010; K. Vogt \& Tsagari, 2014; Volante \& Fazio, 2007; Zhang \& Burry-Stock, 1997), this study developed and validated a questionnaire of assessment literacy confidence levels for pre-service EFL teachers. This questionnaire was employed to examine the effects of gender, career choice, teaching experience, and training in testing and assessment on pre-service EFL teachers' confidence levels in assessment literacy.

In this study, the pre-service EFL teachers indicated high confidence levels of assessment literacy. Moreover, gender and career choice had no statistically significant effect on their confidence levels in assessment literacy while teaching experience and training in testing and assessment did. As teaching experience and training in testing and assessment can affect pre-service EFL teachers' assessment literacy, it is important that teacher preparation programmes provide them with more 
assessment training and more opportunities for practice in testing and assessment. In other words, the role of practicums is critical to pre-service EFL teachers' assessment literacy as it helps them connect received knowledge and experiential knowledge (Wallace, 1991) in testing and assessment.

Also, similar to what Pajares (1992) claimed about the stability of teachers' beliefs, this study found that the pre-service EFL teachers' beliefs in testing and assessment remained unchanged. However, due to practical constraints, this study was unable to triangulate the data to investigate pre-service EFL teachers' beliefs in testing and assessment. Besides, as Haney and McArthur (2002) and Phipps and Borg (2009) found that core beliefs are more consistent and powerful in both teachers' expression and their classroom practices while peripheral beliefs are stated but may not be observed in their classroom practices, different research methods should be employed to capture which self-report instruments are unable to understand pre-service EFL teachers' beliefs in testing and assessment.

The present study shows that pre-service EFL teachers' assessment literacy is a complex construct which is difficult to reveal by their confidence levels in assessment literacy. Moreover, the results from the questionnaires and follow-up semi-structured group interviews show the contradiction within pre-service EFL teachers when they reported their concern about whether their confidence levels could reflect their real abilities in assessment practices. This contradiction is discussed below.

- Contradiction within the subject (pre-service EFL teachers)

Although the results from the questionnaires indicated pre-service EFL teachers' high confidence levels in assessment literacy, it is surprising that the pre-service EFL teachers, in this study, who had more training in testing and assessment scored lower confidence levels in assessment literacy. Moreover, some pre-service EFL teachers in the follow-up semi-structured group interviews revealed that their ratings about their confidence levels in testing and assessment were based on their knowledge of the theoretical issues in testing and assessment. Due to their lack of experience in testing and assessment practices, they were concerned about whether their confidence 
levels in assessment literacy could indicate their real abilities in testing and assessment.

This contradiction raises the importance of more opportunities for pre-service EFL teachers to apply what they learn from language testing and assessment courses in practice. Without sufficient experience with testing and assessment practices, it is difficult for them to assess their assessment literacy appropriately and avoid being overconfident about their assessment literacy. This problem is also the concern of Moss (2013) who criticised university programmes which produce graduate teachers "who are over-confident and under-competent when it comes to summarizing achievement and using assessment information to promote student learning” (p. 252). She recommended that assessment training "go beyond counting the number of assessment courses in particular curriculum to examining what actually happens in those courses to develop assessment literacy and follow the graduates into the field to see if those courses impact actual assessment practices" (Moss, 2013, p. 252). Also, Davison (2004) identified that a lack of professional development in testing and assessment might be the reason for the individual variation in the way teachers in Hong Kong interpreted a written test and used criteria for their scoring. This can imply that the exposure to assessment training can influence the way pre-service EFL teachers understand their assessment literacy and ensure more accurate judgment of their assessment literacy confidence levels.

\section{- Summary}

As stated in the methodology chapter (Chapter 4) of this phase, due to the nature of Vietnamese pre-service EFL teachers, confidence levels of assessment literacy were chosen to examine pre-service EFL teachers' assessment literacy. However, from the findings of the follow-up semi-structured group interviews, it can be seen that assessment literacy is a complex construct when the pre-service EFL teachers expressed the contradiction within themselves about how they evaluated their confidence levels in assessment literacy and whether these confidence levels could communicate their real abilities in testing and assessment practices. Therefore, different research instruments should be employed to explore the complexity of pre- 
service EFL teachers' assessment literacy. Besides, data triangulation is necessary to uncover their assessment literacy.

Moreover, as Wallace (1991) clarified the difference between received knowledge and experiential knowledge. Pre-service EFL teachers can achieve received knowledge from their language testing and assessment courses. However, they can only develop their experiential knowledge from reflections of their testing and assessment practices in language classrooms. As pre-service EFL teachers' experiential knowledge is critical to their teaching practices (Wallace, 1991), it is necessary that teacher preparation programmes provide pre-service EFL teachers with opportunities to link theory to practice. This will help them evaluate their knowledge and skills in testing and assessment more accurately.

\subsection{Development of pre-service EFL teachers in assessment literacy during their practicum}

There has been considerable research into pre-service EFL teacher cognition during practicums (e.g., Macalister, 2012; Numrich, 1996; Peacock, 2001; Warford \& Reeves, 2003). However, none has looked at how pre-service EFL teachers develop their assessment literacy during practicums. This study attempts to fill this gap. The findings show that the pre-service EFL teachers, in this study, improved their assessment literacy. These findings are aligned with the previous studies (e.g., Farrell, 2007; Gao \& Benson, 2012; Johnson, 1994; Macalister, 2012; Nguyen \& Hudson, 2010; Numrich, 1996) which found that practicums have a significant impact on preservice teacher cognition.

Also, in this present study, there existed individual differences in the way pre-service EFL teachers developed their assessment knowledge and skills. In addition, the preservice EFL teachers learned about assessment literacy from their own assessment practices and feedback from school mentors. Based on the evidence of pre-service EFL teachers' incident-based learning of assessment literacy, a case study teaching approach should be used in assessment training in teacher preparation programmes. Although this approach has been widely used in law training (Gerber, 1989), it has received little attention in teacher education in general and assessment training in particular. It is beneficial for pre-service EFL teachers if they have opportunities to 
work on different solutions to different scenarios in language teaching and learning. For example, during language testing and assessment courses, pre-service EFL teachers can be asked to solve various scenarios of testing and assessment practices they may encounter in real-life contexts. This can help pre-service EFL teachers become better-prepared for their future jobs.

Moreover, previous research has shown that pre-service teachers can meet some problems during a practicum such as power struggles (Doppen, 2007; Graham, 1997; Weaver \& Stanulis, 1996), school mentors' lack of efficacy (Hudson, 2005), limited options to apply what they have learned (Ajayi \& Lee, 2005; Dunn et al., 2000) and technology in teaching (D. Brown \& Warschauer, 2006). The pre-service EFL teachers, in this study, enjoyed a supportive environment and good facilities for teaching and learning at Le Loi high school. However, in terms of their assessment literacy development, it can be seen that they needed more support during their practicum. The findings of this phase identify three main contradictions that might affect their development in assessment knowledge and skills: 1) contradiction within the subject, 2) contradiction between the rules and the object, and 3) contradiction between the division of labour and the object.

\section{- Contradiction within the subject (school mentors)}

The first contradiction can be identified within the school mentors. In order to help pre-service EFL teachers improve their assessment literacy, it is necessary for school mentors to update their testing and assessment knowledge and skills. However, in this study, the two school mentors reported their lack of professional development in this area. This might limit their supervision quality in testing and assessment knowledge and skills for their pre-service teachers. This finding is in line with Hudson's (2005) report that school mentors' lack of efficacy might be a barrier to pre-service teachers' development. Moreover, as Volante and Fazio (2007) pointed out, in order to develop pre-service teachers' assessment literacy, different stakeholders, including school mentors need to be involved and should improve their knowledge of assessment literacy. It is important that school mentors be given more opportunities for professional development in testing and assessment. Besides, they 
need training in mentoring skills to enhance the quality of their assessment training during a practicum.

\section{- Contradiction between the rules and the object}

The second contradiction is identified between the rules (guidelines for practicum, practicum culture) and the object of developing pre-service EFL teachers' assessment literacy. In the interviews, the school mentors reported that they were not given specific guidelines for what pre-service EFL teachers needed to learn during a practicum as well as rubrics for rating their mentees' performances. This might be the reason for pre-service EFL teachers' incident-based learning of assessment literacy during the practicum. Without detailed instructions about how to enhance pre-service EFL teachers' assessment literacy, the school mentors only gave the preservice EFL teachers advice when they found their pre-service EFL teachers' problems during the practicum. Although this mentoring approach could cater for individual differences in the development of pre-service EFL teachers' assessment literacy, it could bring about an unsystematic learning of testing and assessment skills during a practicum. Therefore, it is essential that school mentors be informed about the areas of assessment literacy in which pre-service EFL teachers need to improve during their practicums. In other words, school mentors need to be provided with specific guidelines about what to help pre-service EFL teachers with during their practicums.

In addition, this study showed a lack of communication between the school and the teacher training university highlighted by the fact that the school mentors were not well-informed about what they needed to help pre-service EFL teachers with. An associated concern reported in the literature was the lack of clarity and vagueness about the role of the school and the university in students' practicums (J. M. Allen \& Peach, 2007; Cherian, 2007) and the understanding of what is involved in practicums (Bullough \& Draper, 2004; Hayes, Capel, Katene, \& Cook, 2008). Also, the disconnect between the school and university could lead to a gap between theory and practice in practicums as stated in the previous research (e.g., Dean, Lauer, \& Urquhart, 2005; Grossman, Martin, Place, \& Valencia, 2009; F. A. J. Korthagen \& Kessels, 1999; F. Korthagen, Loughran, \& Russell, 2006). 
Further, research has shown that the relationship between schools and teacher training institutions can influence the quality of teacher education programmes (DarlingHammond, 2013; Louden \& Rohl, 2006). In addition, the split between theory and practice in teacher training programmes is considered as one of the biggest dangers that teacher training institutions face when they prepare teachers who only know about theory and know nothing about practice (Levine, 2006). Therefore, the school mentors, in this study, should have been informed about the training programmes for the pre-service teachers in order to link what the pre-service teachers had learned in their coursework at the university with the practicum. In other words, more connection between school mentors and teacher training universities should be encouraged to enhance pre-service teachers' assessment literacy development.

\section{- Contradiction between the division of labour and the object}

The third contradiction is between the division of labour (school mentors and preservice EFL teachers' workload) and the object. In this study, the two school mentors reported their lack of attention and time for helping pre-service EFL teachers with testing and assessment knowledge and skills due to their heavy workloads. In Vietnam, high school teachers' salaries are not high enough to cover the cost of living; therefore, they have to teach extra hours in after-school classes to supplement their earnings (Le, 2011). In this present study, the school mentors experienced the same difficulties as they struggled with their teaching schedules, and other administrative work at school. Therefore, within a nine-week practicum, it was difficult for them to closely work with and help pre-service EFL teachers to enhance their assessment literacy.

Moreover, during a practicum, apart from their teaching, pre-service EFL teachers are required to participate in different professional activities and undertake administrative work. The same situation happened to the pre-service EFL teachers in this study when they were expected to improve their skills in class management and administration. This might be the reason for their limited time spent for developing their assessment literacy. 
In other words, this contradiction is rooted in the heavy workloads of the school mentors who have limited time to arrange further assessment training for pre-service EFL teachers. Moreover, as a practicum is meant to provide pre-service EFL teachers with different knowledge and skills in teaching, assessment literacy was not considered as the central focus. To improve the current situation, it is important that teacher preparation programmes include assessment training in practicums and give clear guidelines for school mentors about the areas of assessment literacy where preservice EFL teachers need to improve. Moreover, during teacher preparation programmes, it is important that pre-service EFL teachers be given more opportunities for classroom observation to learn how teachers conduct testing and assessment in language classrooms.

\section{- Summary}

In this phase, the pre-service EFL teachers showed their development in assessment literacy. However, it can be seen that some contradictions in the current system limited the quality of assessment training during practicums. To enhance pre-service teachers' assessment literacy, the findings of this study suggest more communication between teacher training universities and schools to provide more support in assessment training for pre-service teachers. Moreover, it is important that school mentors have more opportunities for professional development in testing and assessment as well as mentoring skills. In addition, it is essential that school mentors and pre-service EFL teachers be informed about the areas of assessment literacy on which they need to work during their practicum. This will enable school mentors and pre-service EFL teachers to adjust their workload to cope with the demands of assessment training during practicum.

\subsection{Overall discussion}

This study has identified some contradictions in the current system of language assessment training in Vietnam. Through the lens of third generation Activity theory, pre-service EFL teachers' development in assessment literacy is considered to be situated, dynamic and involves the interaction between pre-service EFL teachers and different stakeholders. Therefore, to enhance pre-service EFL teachers' knowledge 
and skills of testing and assessment requires systematic collaboration among related stakeholders such as policy-makers, teacher-trainers, and school mentors.

To improve the current situation, systematic innovation should be initiated in policies from the top-down. Moreover, the reform of testing and assessment in Vietnam cannot be done unsystematically. It can be seen, from the findings, that even though the teacher trainers and school mentors in this study were aware of current problems, they were unable to improve the current situation due to the lack of support from the top-down. Therefore, in order to propose, develop and implement more appropriate policies for testing and assessment training in teacher preparation programmes, policy-makers also need to be assessment literate. Their assessment literacy will assist teacher-trainers, school mentors and related stakeholders to understand the importance of assessment literacy and assessment training in teacher training programmes. Besides, it will also help them to propose an appropriate solution to the current issues in language testing and assessment in Vietnam.

As Popham (2006) suggested, all the stakeholders involved in testing and assessment reforms need to acquire a comprehensive knowledge of these areas. He also supported the necessity for improving assessment literacy knowledge for policy-makers. In addition, he believed that assessment literacy should be promoted among other stakeholders such as students, and parents. Many experts (e.g., Arter, Stiggins, Duke, \& Sagor, 1993; Popham, 2006; Price, Rust, O’Donovan, Handley, \& Bryant, 2012; Schafer \& Lissitz, 1987; Stiggins, 2010) stressed the importance of assessment literacy training for principals and school administrators.

Moreover, in Vietnam, assessment training for pre-service EFL teachers can hardly avoid the influence of a testing and assessment culture in which exam success is central to teaching and learning. In order to minimise the negative effects of educational traditions on language teaching and learning, it is important that teacher training programmes make assessment training for pre-service EFL teachers compulsory and increase the length and credits of the course. This will give preservice EFL teachers more opportunities to gain adequate assessment literacy for their future jobs. With adequate assessment training, pre-service EFL teachers will be able to apply testing and assessment knowledge and skills in their teaching. It is likely that 
teachers' initiatives and innovation in their assessment practices gradually improve the current situation of language teaching and learning in which exam success is still the central focus. Moreover, this will limit the influence of testing and assessment on the way English is learned and taught in Vietnam.

As "teacher education has long been criticized as a weak intervention in the life of a teacher, barely able to make a dent in the ideas and behaviours teachers bring with them into the classroom from their own days as students" (Darling-Hammond, 2013), it is important that teacher training universities in Vietnam implement assessment training into their programmes for pre-service EFL teachers. Previous research in teacher cognition has identified the influence of 1) pre-service teachers' beliefs, 2) prior experience, 3 ) teacher education programmes, and 4) the practicum on how preservice teachers learn to teach. The same thing might happen to their development of assessment literacy. Therefore, assessment training should take these factors into great consideration. Moreover, Leighton, Gokiert, Cor, and Heffernan (2010) stressed the importance of training teachers in new forms of assessment apart from the traditional measurement theory and practices.

In conclusion, this study has shown some tensions in assessment literacy development of pre-service EFL teachers in Vietnam. In order to improve the current situation, different approaches should be initiated from both top-down and bottomup and from related stakeholders. In other words, to improve pre-service teachers' assessment literacy requires "an ultimately happy marriage between all vested parties that is required: government, faculties of education, school district leaders, administrators, and associate teachers. All are essential stakeholders for the appropriate training of assessment literate teacher candidates" (Volante \& Fazio, 2007, p. 764).

\subsection{Summary}

This chapter discusses the main findings of the present research. It presents the contradictions in language testing and assessment courses, pre-service EFL teachers' confidence levels in assessment literacy and their development of assessment literacy during their practicum. It also suggests possible solutions to solve the current problems in assessment training for pre-service EFL teachers in teacher preparation 
programmes in Vietnam. The discussion is also presented with reference to previous studies in the field of teacher cognition and assessment literacy.

The next chapter, Chapter 11, will summarise key findings of this research, acknowledge its limitations, and present theoretical and practical implications for assessment training in teacher education and for research. Chapter 11 also suggests further research in assessment literacy and ends with concluding remarks. 


\section{Chapter 11:}

\section{SUMMARY, IMPLICATIONS AND CONCLUSIONS}

\subsection{Introduction}

This chapter first presents a summary of the main findings, and their implications. It continues with a discussion of the limitations of this study, followed by suggestions for further research. The chapter ends with concluding remarks.

\subsection{Summary of findings}

This study was conducted in three phases to look at pre-service EFL teachers' assessment literacy in Vietnam from three angles: 1) the language testing and assessment courses for pre-service EFL teachers, 2) the pre-service EFL teachers' confidence levels in assessment literacy, and 3) the development of pre-service EFL teachers' assessment literacy during their practicum.

The summary of the findings for each phase are presented as follows:

\subsubsection{Phase $1-$ Language testing and assessment courses}

In Phase 1, four teacher-trainers at four key teacher training universities in Vietnam were interviewed to study language testing and assessment training for pre-service EFL teachers at these universities. The main findings of this phase are summarised as below.

- Teacher-trainers' background in testing and assessment:

$\checkmark$ Teacher trainers showed their dissatisfaction with their assessment knowledge and skills in testing and assessment.

$\checkmark$ Teacher trainers indicated a lack of their formal training in testing and assessment.

$\checkmark$ Teacher-trainers expressed their need for more professional development in testing and assessment in order to enhance the quality of their training. 
- Content of assessment training for pre-service EFL teachers:

$\checkmark$ The assessment training focused more on psychometrics and the role of summative assessment than formative assessment.

$\checkmark$ Teacher-trainers chose the content based on: 1) future jobs' requirements for pre-service EFL teachers, 2) course length, and 3) pre-service EFL teachers' current understanding levels.

$\checkmark$ Teacher-trainers did not feel satisfied with the content and the course materials they were using.

- Methods of instruction in assessment training for pre-service EFL teachers:

$\checkmark$ The two universities which had a separate course in testing and assessment chose a task-based teaching approach while the two universities which did not offer a separate course in testing and assessment used a lecture approach.

$\checkmark$ Teacher-trainers felt satisfied with the teaching approaches that they chose due to the advantages of these teaching approaches for their contexts.

- Support for assessment training for pre-service EFL teachers:

$\checkmark$ Teacher-trainers expressed their satisfaction with the current support they received for assessment training. This is because they were aware of the difficulties of their contexts.

- Assessment training during practicums:

$\checkmark$ Teacher-trainers were unsatisfied with the lack of focus on assessment training during practicums.

$\checkmark$ Teacher-trainers emphasised the important role of school-mentors in helping pre-service teachers improve their assessment practices during practicums. 
- Pre-service EFL teachers' perceptions of assessment training:

$\checkmark$ Pre-service EFL teachers understood the important role of testing and assessment training for their future jobs.

$\checkmark$ The pre-service EFL teachers who were determined to become teachers were more interested in language testing and assessment courses.

- The constraints of assessment training for pre-service EFL teachers:

$\checkmark$ The lack of systematic innovation in assessment training.

$\checkmark$ The lack of labour, facilities and time frames for assessment training.

\subsubsection{Phase 2 - Pre-service EFL teachers' assessment literacy confidence levels}

In Phase 2, a questionnaire was developed and validated to investigate 365 preservice EFL teachers' assessment literacy confidence levels. This phase also looked at the relationships between: 1) gender and pre-service teachers' assessment literacy confidence levels, 2) career choice and pre-service teachers' assessment literacy confidence levels, 3) teaching experience and pre-service teachers' assessment literacy confidence levels, and 4) training in testing and assessment and pre-service teachers' assessment literacy confidence levels. The findings are summarised below:

$\checkmark$ The pre-service EFL teachers indicated good confidence levels in assessment literacy.

$\checkmark$ Gender had no statistically significant effect on the pre-service EFL teachers' confidence levels in assessment literacy.

$\checkmark$ Career choice had no statistically significant effect on the pre-service EFL teachers' confidence levels in assessment literacy.

$\checkmark$ Teaching experience had a statistically significant effect on the pre-service EFL teachers' confidence levels in all sub-constructs of assessment literacy, except for their beliefs.

$\checkmark$ Training in testing and assessment had a statistically significant effect on the pre-service EFL teachers' confidence levels in all sub-constructs of assessment literacy, except for their beliefs.

$\checkmark$ Beliefs in testing and assessment were hard to change. 


\subsubsection{Phase 3 - Development of pre-service EFL teachers in assessment literacy during their practicum}

Phase 3 focused on the development of pre-service EFL teachers in assessment literacy. Phase 3 has two parts and the findings of each part are summarised as follows:

- Part 1 has two stages:

$\checkmark$ Stage 1 used the same questionnaire as in Phase 2 to look at the development of 31 pre-service teachers' confidence levels in assessment literacy at Bach Dang University over three periods of time: before the language testing and assessment course, before the practicum, and after the practicum. The results showed a statistically significant increase in the pre-service EFL teachers' confidence levels in assessment literacy over these periods of time.

$\checkmark$ In Stage 2, two semi-structured group interviews were conducted with 18 participants involved in Stage 1 to triangulate the findings of Stage 1. The results showed that assessment training in the language testing and assessment courses and the practicum helped the pre-service teachers improve their confidence levels in assessment literacy. However, their confidence did not truly reflect their real abilities in testing and assessment. The pre-service teachers explained that due to their lack of opportunities to practise testing and assessment, their ratings of their confidence levels were mainly based on their theoretical knowledge of testing and assessment.

- Part 2 focused on tracing the development of four pre-service EFL teachers at Le Loi High school. The results showed that:

The four pre-service teachers improved their assessment literacy in: (i) giving feedback, (ii) designing test items, (iii) administering tests, (iv) observing students' learning, and adjusting teaching activities to suit students' interest, understanding and learning abilities, (v) giving instructions, and (vi) improving their content knowledge. 
$\checkmark$ The four pre-service EFL teachers showed individual differences in assessment literacy development. Before and after the practicum, they had different levels of confidence in assessment literacy. Moreover, although they improved their confidence levels in assessment literacy, they varied in the levels and areas of development.

$\checkmark$ The pre-service teachers learned about testing and assessment based on their own performance and their problems. The case study of Diep showed how she improved her knowledge and skills of testing and assessment based on the feedback of her school mentors on her teaching.

\subsection{Implications}

This study looks at the development of pre-service EFL teachers during their teacher preparation programmes. The findings from this study have implications for 1) theory, 2) assessment training in teacher education and 3) research. The details are presented as follows.

\subsubsection{Implications for theory}

This study has identified the complex nature of assessment literacy. In order to become assessment-literate, pre-service teachers need to acquire different skills and knowledge such as PCK, ethical issues in testing and assessment, and different types of assessment. Therefore, a major implication of this study is to highlight a pressing need for a theoretical model which can help to operationalize the construct 'assessment literacy' in a more manageable way.

Moreover, although teachers' assessment literacy has received increasing attention in general education, research into language teachers' assessment literacy is still in its infancy. As assessment literacy for different fields may require teachers to have different sets of knowledge and skills, this study raises the importance of developing a conceptual framework for examining language teachers' assessment literacy, let alone pre-service EFL teachers' assessment literacy.

In addition, this research showed that career choice and gender did not influence preservice EFL teachers' confidence levels in assessment literacy while there was a relationship: 1) between training in testing and assessment and pre-service EFL 
teachers' assessment literacy development, and 2) between teaching experience and pre-service EFL teachers' assessment literacy development. In particular, the findings from Phase 2 and Phase 3 showed that pre-service EFL teachers improved their confidence levels in assessment literacy and developed their knowledge and skills in certain areas of assessment literacy during their practicum based on incidentbased learning.

However, it is also important to note that although teaching experience and training in testing and assessment could influence the pre-service EFL teachers' confidence levels in assessment literacy in this study, their beliefs in testing and assessment remained unchanged. This is in line with previous research which indicated that teachers' beliefs are difficult to change (da Silva, 2005; MacDonald, Badger, \& White, 2001; Pajares, 1992; Peacock, 2001).

Further, this study identified the incident-based learning of assessment literacy of Vietnamese pre-service EFL teachers and their variation in their assessment literacy development. This contributes to the literature about how pre-service teachers learn about testing and assessment during their practicum.

Last, the findings of this study provide a contextualised view of assessment training, and how pre-service EFL teachers develop their assessment literacy in the little explored context of Vietnam. This adds to the knowledge of assessment training for pre-service teachers in the societies where an exam-oriented culture can have a great influence on the role of testing and assessment in teaching and learning.

\subsubsection{Implications for assessment training in teacher education}

Ten implications for assessment training in teacher preparation programmes can be derived from this study:

First, it is necessary for teacher training universities in Vietnam to offer more assessment training for pre-service EFL teachers. This is because the findings showed that the pre-service EFL teachers, who were given an opportunity to learn about testing and assessment in their teacher preparation programmes, developed their assessment literacy. 
Second, despite the importance of assessment literacy, there has been a lack of focus on this area in teacher preparation programmes in Vietnam. Two teacher training universities involved in Phase 1 did not offer a separate course in testing and assessment. Therefore, teacher training universities, which have not paid enough attention to assessment training, need to re-design their curriculum to include this training for the sake of their pre-service teachers.

Third, assessment training for pre-service teachers needs to balance theory and practice. In other words, teacher training universities need to provide their pre-service teachers with more opportunities to practise testing and assessment tasks for two main reasons:

(1) This study showed that practice in testing and assessment could assist preservice teachers to assess their assessment literacy more properly. In the semistructured group interviews with 18 pre-service EFL teachers, they reported that their high confidence levels of assessment literacy did not truly reflect their assessment knowledge and skills in practice because they only based their ratings on their theoretical knowledge of testing and assessment.

(2) More importantly, the pre-service EFL teachers in this study displayed development in several areas of assessment literacy during their practicum.

Fourth, it is important to note that pre-service teachers' confidence levels in assessment literacy should not be used as the only indicator of their assessment literacy. Pre-service teachers' assessment literacy has to be examined from different angles. This is because the pre-service teachers in this study expressed their concern about whether or not their confidence levels in assessment literacy could indicate their abilities in testing and assessment practices. This happened because they had limited experience in testing and assessment practices and had to rely on their theoretical knowledge to indicate their confidence levels in assessment literacy.

Fifth, teacher preparation programmes need to pay more attention to how teaching experience and training in testing and assessment can influence the development of pre-service teachers' assessment literacy. In this study, gender and career choice did 
not affect pre-service teachers' confidence levels in assessment literacy while teaching experience and training in testing and assessment did.

Sixth, as teacher-trainers and school mentors play a critical role in pre-service EFL teachers' development in assessment literacy, they need to be updated with testing and assessment knowledge and skills. In this study, they reported their dissatisfaction with their received training in testing and assessment which they believed affected their training quality. There is a need for more professional development in testing and assessment for teacher-trainers, school mentors and all the related stakeholders.

Seventh, teacher training universities have to invest more in training resources and allocate more time for assessment training in teacher preparation programmes. In this study, teacher-trainers and school mentors reported these issues as barriers to assessment training quality.

Eighth, the individual differences of the pre-service teachers' development in assessment literacy in this study indicate the necessity of needs analysis for what knowledge and skills in testing and assessment pre-service teachers need during their teacher preparation programmes. The questionnaire of pre-service EFL teachers' confidence levels in assessment literacy developed in this study can be used as a tool to provide an overview of the areas in which pre-service EFL teachers feel less confident. This information is useful for curriculum development in teacher preparation programmes.

Ninth, this study indicated that incident-based learning of assessment literacy suggests the use of case studies in assessment training might be effective to prepare pre-service teachers for different real-world situations in language classrooms. Although case studies are popular in other fields such as business and law (Gerber, 1989), they have not been widely applied in teacher-training. Within the limited time for training, case studies are likely to provide pre-service teachers with different scenarios of testing and assessment practices in language classrooms. This will make them better-prepared for their future jobs.

Last, as many experts (e.g., Arter, Stiggins, Duke, \& Sagor, 1993; Popham, 2006; Price, Rust, O’Donovan, Handley, \& Bryant, 2012; Schafer \& Lissitz, 1987; Stiggins, 
2010) have stressed the importance of assessment for different groups of stakeholders such as teachers, parents, school principals and policy makers, assessment literacy for these groups are critical to assessment training in the context of Vietnam. In an examination-oriented country like Vietnam, assessment literacy for these groups is important to a systematic change in the testing and assessment system. Their assessment literacy will also help transform the current language testing and assessment model which focuses more on the role of summative assessment and the importance of grammar and vocabulary.

\subsubsection{Implications for research}

There are three main methodological implications from the findings of this study.

First, due to the dynamic, situated, complex and developmental nature of pre-service teachers' assessment literacy, it is important to look at this construct from different angles using data triangulation for two main reasons:

(1) The semi-structured group interviews in Phase 3 showed that using the questionnaire of pre-service teachers' confidence levels in assessment literacy was not persuasive enough to conclude about pre-service teachers' assessment literacy.

(2) The findings from Phase 3 highlighted the pre-service teachers' variation in their development and their areas of development during the practicum.

Second, in Phase 2, the questionnaire, which was developed and used to evaluate preservice teachers' confidence levels in assessment literacy in this study, can be used for further research into pre-service EFL teachers' assessment literacy.

Third, to trace pre-service EFL teachers' development in assessment literacy over a period of time using different research instruments requires different research skills. Also, I found that it is important to clarify research purposes and researchers' roles for participants in order to minimise researchers' impact on their practicum. For example, in stimulated recalls, it is important to make it clear from the beginning with pre-service teachers that they will not receive any comments or feedback on their 
performance from researchers. In my study, the pre-service teachers asked for my advice about their performance when I did my first stimulated recall.

Lastly, researchers need to be aware of the contextual factors in Vietnam where school mentors and pre-service teachers have tight teaching schedules. Also, school mentors and pre-service teachers might be afraid that their performances during a practicum might be evaluated if they participate in the study. This makes it difficult to recruit participants and follow them throughout their practicum. Therefore, personal relationship and trust are the keys to successful field research in Vietnam. In addition, it is crucial to clarify the purposes of the research and the ethics requirements to ensure that the rights of the participants are highly protected. This will ease participants' worries about facing a potential backlash due to their participation in research.

\subsection{Limitations of the study}

Despite the constant efforts to ensure the quality of this research, some limitations in terms of sample size and data collection were unavoidable due to practical constraints. The details of the limitations are presented as follows:

\section{- Sample size}

First, due to time and financial constraints, I could not recruit staff and teacher trainees from many different kinds of teacher training universities in Vietnam for this study. Only four key teacher training universities participated in this study. Therefore, the results of pre-service EFL teachers might be biased and might represent these four universities only.

Second, in Phase 3, I could only manage to follow four pre-service teachers during their practicum at Le Loi High School where the teaching environment, teaching facilities and school mentors were very supportive for the pre-service teachers. This could influence the ways the pre-service EFL teachers improved their assessment literacy in this study.

Third, the pre-service teachers involved in Phase 3 were all female, had good study results at university, and were determined to become teachers. Therefore, the findings 
of this study might be gender-biased and only represent those who share the same characteristics with these participants.

\section{- Data collection}

First, due to my inability to return Vietnam to directly collect data at certain points of the study, I had to ask for help from my friends and colleagues to recruit the participants and collect the data for me. Although I tried to explain the research procedures to them clearly, I could not manage all problems related to data collection which might have happened when I was not present in Vietnam.

Second, due to the tight and overlapping teaching schedules of the school-mentors and pre-service teachers, I was not able to observe all their teaching sessions and discussions. This limits my findings related to the pre-service EFL teachers' development in assessment literacy.

Third, my observation might have interfered with the natural process of the practicum and the way the pre-service teachers developed their assessment literacy.

Fourth, due to the technical capacity of the video camera that I used for classroom observation, it was impossible to capture the voice of the participants clearly if they were far away from the video camera or talked in a low or soft voice. In some parts of the videos, I was not able to figure out what the pre-service EFL teachers and students said. Other factors such as the noise of the games and sport matches that occurred outside of the classrooms sometimes affected the quality of the videos.

Last, the limited data collection might influence the findings of this study. In Phase 1, I could not observe any classes of language testing and assessment courses and only relied on semi-structured interviews with four teacher-trainers to investigate assessment training at the four key teacher training universities in Vietnam. Moreover, in Phase 2, only the questionnaire was used to examine pre-service teachers' confidence levels in assessment literacy. Data triangulation is necessary to confirm the influence of different factors such as career choice, and teaching experience on assessment literacy. Further, in Phase 3, I could not manage to observe 
all the teaching performances of the pre-service teachers due to their overlapping teaching schedules.

Despite these limitations, this research's original contribution lies in its focus on a gap in the literature of assessment literacy for EFL pre-service teachers and how they develop this literacy during their teacher preparation programmes. Moreover, this study provides the first insight into assessment training for pre-service EFL teachers in Vietnam, and how Vietnamese pre-service EFL teachers improve their assessment literacy during their teacher preparation programmes.

\subsection{Suggestions for further research}

Assessment literacy has received increasing attention recently. However, it still witnesses a lack of research into language teachers' assessment literacy and their cognition in this area. More research should be done to add to the knowledge of this complex and dynamic construct. The findings of this research and its limitations might suggest a research agenda on the area of assessment literacy and teacher cognition for EFL teachers and pre-service EFL teachers as follows:

This study, like some previous studies (e.g., Bailey \& Brown, 1996; Brown \& Bailey, 2008; Jin, 2010), only looks at assessment training for pre-service teachers from the perspective of course instructors. It is worth doing research into how trainee teachers view language testing and assessment courses.

$\checkmark$ The teacher-trainers in this study chose different methods of instruction for their language testing and assessment training. It would be worth investigating how these methods of instruction might influence pre-service EFL teachers' development of assessment literacy.

$\checkmark$ This study only used a questionnaire to examine pre-service EFL teachers' development in assessment literacy confidence levels before and after language testing and assessment courses. It would be interesting to use different research tools such as observations, stimulated recalls, and interviews to conduct a longitudinal study to trace the development of preservice EFL teachers' assessment literacy during their language testing and assessment courses as well as their teacher preparation programmes. 
$\checkmark$ In this study, a questionnaire of pre-service teachers' confidence levels in assessment literacy is designed specifically for pre-service EFL teachers. Although this questionnaire was validated with Vietnamese pre-service EFL teachers, more research should be done to examine the validity and reliability of this instrument for further uses in professional development and research.

$\checkmark$ This study only examines pre-service EFL teachers' assessment literacy in Vietnam. To check the generalizability of the findings, the study needs to be replicated in both similar and varied contexts.

$\checkmark$ Assessment literacy has been viewed to be important to teaching and learning quality. Therefore, it is interesting to examine the relationship between preservice EFL teachers' development in assessment literacy and their students' English proficiency improvement, as well as the relationship between EFL teachers' assessment literacy and their students' English proficiency improvement.

$\checkmark$ It is also recommended that research into the long-term effects of assessment training in teacher preparation programmes on teachers be conducted to understand the importance of this training to professional development.

$\checkmark$ There is also a need for research into assessment literacy of all the stakeholders involved in assessment training such as school/university administrators and policy makers, and how their assessment literacy might influence the quality of assessment training for pre-service EFL teachers.

\subsection{Concluding remarks}

\subsubsection{Contextual reflection}

One of the simple facts of life in the present time is that that English language skills of a good proportion of its citizenry are seen as vital if a country is to participate actively in the global economy and to have access to the information and knowledge that provide the basis for both social and economic development. Central to this enterprise are English teaching and English language teachers. There is consequently increasing demand worldwide for competent English teachers and for more effective approaches to their preparation and professional development.

(A. Burns \& Richards, 2009, p. 1) 
As assessment literacy is considered to be one of the essential literacies that preservice teachers need for their future jobs (L. Taylor, 2009; Volante \& Fazio, 2007), assessment training for them in teacher preparation programmes is indispensable. In exam-oriented countries where exam success has been viewed as a major purpose of teaching and learning (Carless, 2011; Carless \& Lam, 2014), assessment training and assessment literacy development for pre-service EFL teachers need to take these social and cultural issues into consideration. This study has shown the complex nature of assessment literacy. Thus, it is essential to raise the awareness of all the related stakeholders such as policy makers, teacher-trainers, school administrators, and parents about the importance of teachers' assessment literacy toward teaching and learning quality.

In addition, using the lens of third generation Activity theory, this study identifies the contradictions that need to be recognised and solved in order to help Vietnamese pre-service EFL teachers develop their assessment literacy. Moreover, it is important to note that to improve the current situation of assessment training for pre-service EFL teachers and EFL teachers in Vietnam "a happy marriage between all vested parties...is required: government, faculties of education, school district leaders, administrators, and associate teachers. All are essential stakeholders for the appropriate training of assessment literate teacher candidates" (Volante \& Fazio, 2007, p. 764).

\subsubsection{Personal reflection}

As stated in the introduction chapter, testing and assessment culture has had a tremendous impact on the way English is taught and learned in Vietnam. Although communicative competence is encouraged in English teaching and learning, testing and assessment do not match with these teaching goals and focus more on the role of grammar and vocabulary. This explains why Vietnamese students have been criticized for their inadequate English proficiency. Due to limited communicative competence in English, Vietnamese students have been deprived of opportunities for further education, jobs and chances to become "global citizens". Therefore, Vietnamese EFL teachers need to improve their assessment literacy in order to change the way they test and assess their students. 
As a teacher-trainer at one of the key teacher-training universities in Vietnam, I felt an urge to conduct research into Vietnamese pre-service EFL teachers' assessment literacy and the current assessment training for them in my own context. This study has helped me achieve my goals of having insight into these issues. My next steps will be to apply the findings of this research into practice, pursue further research in assessment literacy as well as to raise the awareness of the related stakeholders in assessment training about the importance of assessment training and assessment literacy for EFL teachers and pre-service EFL teachers.

In conclusion, assessment literacy for pre-service EFL teachers is important for their future jobs and for the sake of EFL students. As Popham (2009) says: "assessmentliterate teachers will typically make better decisions, and because we want students to be better taught, it should be obvious that today's teachers must acquire more assessment literacy" (p. 6). In other words, teachers' assessment literacy is indispensable to assessment reforms in language classrooms (Davison, 2004; Gu, 2014). 


\section{REFERENCES}

Abell, S. K., \& Siegel, M. A. (2011). Assessment literacy: What science teachers need to know and be able to do. In D. Corrigan, J. Dillon, \& R. Gunstone (Eds.), The professional knowledge base of science teaching (pp. 205-221). $\begin{array}{lll}\text { Springer } & \text { Netherlands. } & \text { Retrieved }\end{array}$ http://link.springer.com/chapter/10.1007/978-90-481-3927-9_12

Ajayi, L. J., \& Lee, S. K. (2005). Perceptual difference between intern teachers and university supervisors on the expectations and preferences for the fieldwork program. Education, 126(2), 259-274.

Allen, J. M., \& Peach, D. (2007). Exploring connections between the in-field and oncampus components of a preservice teacher education program: A student perspective. Asia-Pacific Journal of Cooperative Education, 8(1), 23-36.

Allen, L. Q. (2002). Teachers' pedagogical beliefs and the standards for foreign language learning. Foreign Language Annals, 35(5), 518-529. http://doi.org/10.1111/j.1944-9720.2002.tb02720.x

American Federation of Teachers, National Council on Measurement in Education, \& National Education Association. (1990). Standards for teacher competence in educational assessment of students. Educational Measurement: Issues and Practice, 9(4), 30-30. http://doi.org/10.1111/j.1745-3992.1990.tb00391.x

Andrade, H. L. (2010). Summing up and moving forward: Key challenges and future directions for research and development in formative assessment. In H. L. Andrade \& G. J. Cizek (Eds.), Handbook of formative assessment (pp. 344352). New York: Routledge. 
Andrews, S. (2001). The language awareness of the L2 teacher: Its impact upon pedagogical practice. Language Awareness, 10(2-3), 75-90. http://doi.org/10.1080/09658410108667027

Andrews, S. (2003a). "Just like instant noodles": L2 teachers and their beliefs about grammar pedagogy. Teachers and Teaching, 9(4), 351-375. http://doi.org/10.1080/1354060032000097253

Andrews, S. (2003b). Teacher language awareness and the professional knowledge base of the L2 teacher. Language Awareness, 12(2), 81-95. http://doi.org/10.1080/09658410308667068

Appleton, K. (2003). How do beginning primary school teachers cope with science? Toward an understanding of science teaching practice. Research in Science Education, 33(1), 1-25. http://doi.org/10.1023/A:1023666618800

Arce-Ferrer, A. J., Cab, V. P., \& Cisneros-Cohernour, E. J. (2001). Teachers' assessment competencies (p. 30). Paper presented at the Annual Meeting of the American Educational Research Association, Seattle, WA, USA.

Arter, J. A., Stiggins, R. J., Duke, D., \& Sagor, R. (1993). Promoting assessment literacy among principals. NASSP Bulletin, 77(556), 1-7. http://doi.org/10.1177/019263659307755602

Assessment Reform Group. (2002). Assessment for learning: 10 principles. University of Cambridge: Assessment Reform Group.

Association of Language Testers in Europe (Ed.). (1998). Multilingual glossary of language testing terms. Cambridge: Cambridge University Press. 
Bachman, L. F. (2000). Modern language testing at the turn of the century: Assuring that what we count counts. Language Testing, 17(1), 1-42. http://doi.org/10.1177/026553220001700101

Bachman, L. F. (2004a). Fundamental considerations in language testing. Oxford: Oxford University Press.

Bachman, L. F. (2004b). Statistical analyses for language assessment. Cambridge: Cambridge University Press.

Bachman, L. F., \& Palmer, A. S. (1996). Language testing in practice: Designing and developing useful language tests. Oxford.

Bailey, K. M., Bergthold, B., Jagodzinski Fleischman N., Holbrook, M. P., Tuman, J., Waissbluth, X., \& Zambo, L. J. (1996). The language learners' autobiography: Examining the "apprenticeship of observation." In D. Freeman \& J. C. Richards (Eds.), Teacher learning in language teaching (pp. 11-29). New York: Cambridge University Press.

Bailey, K. M., \& Brown, J. D. (1996). Language testing courses: What are they? In A. Cumming \& R. Berwick (Eds.), Validation in language testing (pp. 236256). Clevedon, UK: Multilingual Matters.

Bassey, M. (1981). Pedagogic research: On the relative merits of search for generalisation and study of single events. Oxford Review of Education, 7(1), 73-94.

Basturkmen, H., Loewen, S., \& Ellis, R. (2004). Teachers' stated beliefs about incidental focus on form and their classroom practices. Applied Linguistics, 25(2), 243-272. http://doi.org/10.1093/applin/25.2.243 
Bazeley, P., \& Jackson, K. (Eds.). (2013). Qualitative data analysis with NVivo (2nd ed.). London: SAGE Publications Ltd.

Beck, C., \& Kosnik, C. (2002). Professors and the practicum involvement of university faculty in preservice practicum supervision. Journal of Teacher Education, 53(1), 6-19. http://doi.org/10.1177/0022487102053001002

Bell, B., \& Cowie, B. (2001a). A model of formative assessment. In B. Bell \& B. Cowie (Eds.), Formative assessment and science education (pp. 80-94). Dordrecht: Kluwer Academic Publishers.

Bell, B., \& Cowie, B. (2001b). The characteristics of formative assessment in science education. Science $\quad$ Education, 55(5), 536-553. http://doi.org/10.1002/sce.1022

Bich, P. V. (1998). The Vietnamese family in change: The case of the Red River Delta (1st ed.). Richmond England: Routledge.

Black, P. (2013). Formative and summative aspects of assessment: Theoretical and research foundations in the context of pedagogy. In J. H. McMillan (Ed.), Sage handbook of research on classroom assessment (pp. 167-178). Thousand Oaks, CA: SAGE Publications.

Black, P., Harrison, C., Lee, C., Marshall, B., Wiliam, D., \& Press, O. U. (2003). Assessment for learning: Putting it into practice (1st ed.). Maidenhead: Open University Press.

Black, P., \& Wiliam, D. (1998). Assessment and classroom learning. Assessment in Education: Principles, Policy \& Practice, 5(1), 7-74. http://doi.org/10.1080/0969595980050102 
Black, P., \& Wiliam, D. (2006). Assessment for learning in the classroom. In J. Gardner (Ed.), Assessment and learning (pp. 9-25). London: UK.

Bloom, B. S., Hastings, J. T., \& Madaus, G. F. (1971). Handbook on formative and summative evaluation of student learning. New York: McGraw-Hill.

Bodur, Y. (2012). Impact of course and fieldwork on multicultural beliefs and attitudes. The Educational Forum, 76(1), 41-56. http://doi.org/10.1080/00131725.2011.627981

Borg, M. (2005). A case study of the development in pedagogic thinking of a preservice teacher. TESL-EJ, 9(2), 1-30.

Borg, S. (1994). Language awareness as methodology: Implications for teachers and teacher training. Language Awareness, 3(2), 61-71. http://doi.org/10.1080/09658416.1994.9959844

Borg, S. (2003). Teacher cognition in language teaching: A review of research on what language teachers think, know, believe, and do. Language Teaching, 36(2), 81-109. http://doi.org/10.1017/S0261444803001903

Borg, S. (2006). Teacher cognition and language education: Research and practice. London: Continuum.

Borg, S. (2012). Current approaches to language teacher cognition research: A methodological analysis. In R. Barnard \& A. Burns (Eds.), Researching language teacher cognition and practice: International case studies (pp. 1129). Multilingual Matters.

Borg, S. (n.d.). Resources. Retrieved from http://simon-borg.co.uk/resources/ 
Boud, D. (2000). Sustainable assessment: Rethinking assessment for the learning society. Studies in Continuing Education, 22(2), 151-167. http://doi.org/10.1080/713695728

Boyles, P. (2005). Assessment literacy. In M. H. Rosenbusch (Ed.), National assessment summit papers. Annes, IA: Iowa State. Retrieved from http://files.eric.ed.gov/fulltext/ED527580.pdf

Bradley, E. H., Curry, L. A., \& Devers, K. J. (2007). Qualitative data analysis for health services research: Developing taxonomy, themes, and theory. Health Services Research, 42(4), 1758-1772. http://doi.org/10.1111/j.14756773.2006.00684.x

Brandt, C. (2006). Allowing for practice: A critical issue in TESOL teacher preparation. ELT Journal, 60(4), 355-364. http://doi.org/10.1093/elt/cc1026

Braun, V., \& Clarke, V. (2006). Using thematic analysis in psychology. Qualitative Research in Psychology, $\quad 3(2), \quad 77-101$. http://doi.org/10.1191/1478088706qp063oa

Breen, M. P., Hird, B., Milton, M., Thwaite, A., \& Oliver, R. (2001). Making sense of language teaching: Teachers' principles and classroom practices. Applied Linguistics, 22(4), 470-501.

Brindley, G. (2001). Language assessment and professional development. In C. Elder, A. Brown, E. Grove, K. Hall, N. Iwashita, \& K. O’Loughlin (Eds.), Experimenting with uncertainty. Essays in honour of Alan Davies (pp. 126136). Cambridge: Cambridge University Press.

Broadfoot, P. (2007). An introduction to assessment. London: Bloomsbury Academic. 
Brookhart, S. M. (2001a). Successful students' formative and summative uses of assessment information. Assessment in Education: Principles, Policy \& Practice, 8(2), 153-169. http://doi.org/10.1080/09695940123775

Brookhart, S. M. (2001b). The "Standards" and classroom assessment research. (p. 15). Paper presented at the Annual Meeting of the American Association of Colleges for Teacher Education, USA.

Brookhart, S. M. (2007). Expanding views about formative classroom assessment: A review of the literature. In J. H. McMillan (Ed.), Formative assessment: Theory into practice (pp. 43-62). New York: Teachers College Press.

Brookhart, S. M. (2008). Grading (2nd ed.). New York: Pearson.

Brookhart, S. M. (2011). Educational assessment knowledge and skills for teachers. Educational Measurement: Issues and Practice, 30(1), 3-12. http://doi.org/10.1111/j.1745-3992.2010.00195.x

Brookhart, S. M. (2013). Grading. In J. H. McMillan (Ed.), Sage handbook of research on classroom assessment (pp. 257-271). USA: SAGE Publications, Inc.

Brookhart, S. M., \& Freeman, D. J. (1992). Characteristics of entering teacher candidates. Review of Educational Research, 62(1), 37-60. http://doi.org/10.3102/00346543062001037

Brown, A. (2012). Ethics in language testing and assessment. In C. Coombe, P. Davidson, B. O' Sullivan, \& S. Stoynoff (Eds.), The Cambridge guide to second language assessment (pp. 113-121). Cambridge: Cambridge University Press. 
Brown, D., \& Warschauer, M. (2006). From the university to the elementary classroom: Students' experiences in learning to integrate technology in instruction. Journal of Technology and Teacher Education, 14(3), 599-621.

Brown, G. T. L. (2004). Teachers' conceptions of assessment: Implications for policy and professional development. Assessment in Education: Principles, Policy \& Practice, 11(3), 301-318. http://doi.org/10.1080/0969594042000304609

Brown, G. T. L. (2008). Assessment literacy training and teachers' conceptions of assessment. Nova Science Publishers. Retrieved from https://researchspace.auckland.ac.nz/handle/2292/7489

Brown, G. T. L., Irving, E., \& Keegan, P. J. (2008). An introduction to educational assessment, measurement and evaluation (2nd ed.). North Shore, N.Z: Pearson Education.

Brown, H. D., \& Abeywickrama, P. (2010). Language assessment: Principles and classroom practices. White Plains, NY: Pearson Education.

Brown, J. D. (2000). Using surveys in language programs. New York: Cambridge University Press.

Brown, J. D., \& Bailey, K. M. (2008). Language testing courses: What are they in 2007? Language Testing, 25(3), 349-383. http://doi.org/10.1177/0265532208090157

Bryman, A. (2008). Social research methods. Oxford University Press, Incorporated. Bullough, R. V., \& Draper, R. J. (2004). Making sense of a failed triad mentors, university supervisors, and positioning theory. Journal of Teacher Education, 55(5), 407-420. http://doi.org/10.1177/0022487104269804 
Burns, A., \& Richards, J. C. (2009). Introduction. In A. Burns \& J. C. Richards (Eds.), The Cambridge guide to second language teacher education (pp. 1-8). Cambridge: Cambridge University Press.

Burns, R. B. (2000). Introduction to research methods (4th ed.). London: SAGE Publications Ltd.

Busch, D. (2010). Pre-service teacher beliefs about language learning: The second language acquisition course as an agent for change. Language Teaching Research, 14(3), 318-337. http://doi.org/10.1177/1362168810365239

Calderhead, J., \& Robson, M. (1991). Images of teaching: Student teachers' early conceptions of classroom practice. Teaching and Teacher Education, 7(1), 18. http://doi.org/10.1016/0742-051X(91)90053-R

Campbell, C. (1998). Preservice teachers' classroom assessment practices: An investigation into the factors that contribute to the discrepancy between measurement instruction and practical implementation (Ph.D.). Southern Illinois University at Carbondale, United States -- Illinois. Retrieved from http://search.proquest.com.helicon.vuw.ac.nz/pqdtft/docview/304453260/ab stract? accountid $=14782$

Campbell, C., \& Evans, J. A. (2000). Investigation of preservice teachers' classroom assessment practices during student teaching. The Journal of Educational Research, 93(6), pp. 350-355.

Carless, D. (2011). From testing to productive student learning: Implementing formative assessment in Confucian-heritage settings (1st ed.). New York: Routledge. 
Carless, D., \& Lam, R. (2014). Developing assessment for productive learning in Confucian-influenced settings. In C. Wyatt-Smith, V. Klenowski, \& P. Colbert (Eds.), Designing assessment for quality learning (pp. 167-182). Dordrecht: Springer Netherlands.

Chất lượng dạy và học Anh văn trong trường phổ thông: Đối phó với thi cử - Giáo dục [Teaching and learning English at school: Exam-orientedness] - Tuổi Trẻ Online. (2005). Retrieved May 2, 2014, from http://tuoitre.vn/Giaoduc/79691/chat-luong-day-va-hoc-anh-van-trong-truong-pho-thong-doi-phovoi-thi-cu.html

Cheng, M. M. H., Cheng, A. Y. N., \& Tang, S. Y. F. (2010). Closing the gap between the theory and practice of teaching: Implications for teacher education programmes in Hong Kong. Journal of Education for Teaching, 36(1), 91104. http://doi.org/10.1080/02607470903462222

Chen, P. P. (2005). Teacher candidates' literacy in assessment. Academic Exchange Quarterly, 9(3), 62+.

Cherian, F. (2007). Learning to teach: Teacher candidates reflect on the relational, conceptual, and contextual influences of responsive mentorship. Canadian Journal of Education, 30(1), 25-46.

Clarke, S. (2005). Formative assessment in action. London: Trans-Atlantic Publications, Inc.

Clark, M., \& Peterson, P. L. (1986). Teachers' thought process. In M. C. Wittrock (Ed.), Handbook of research on teaching (pp. 255-296). New York: MacMillan. 
Cochran, K. F., DeRuiter, J. A., \& King, R. A. (1993). Pedagogical content knowing: An integrative model for teacher preparation. Journal of Teacher Education, 44(4), 263-272. http://doi.org/10.1177/0022487193044004004

Cohen, L., Manion, L., \& Morrison, K. (2000). Research methods in education (5th ed.). New York: RoutledgeFalmer.

Coombe, C., Davidson, P., O’Sullivan, B., \& Stoynoff, S. (2012). The Cambridge guide to second language assessment. Cambridge: Cambridge University Press.

Coombe, C., Troudi, S., \& Al-Hamly, M. (2012). Foreign/second language asessment literacy. In C. Coombe, P. Davidson, B. O’ Sullivan, \& S. Stoynoff (Eds.), The Cambridge guide to second language assessment (pp. 20-29). Cambridge: Cambridge University Press.

Cowie, B., \& Bell, B. (1999). A model of formative assessment in science education. Assessment in Education, 6(1), 101-116.

Creswell, J. W. (2013). Qualitative, quantitative, and mixed methods approaches (4th ed.). Thousand Oaks: SAGE Publications, Inc.

Crooks, T. J. (1988). The impact of classroom evaluation practices on students. Review of Educational Research, 58(4), 438-481. http://doi.org/10.2307/1170281

Curtiss, P., \& Nistler, R. J. (1998). Pre-service teachers constructing knowledge about literacy instruction: A one-year self-study of an undergraduate literacy methods course. Educational Action Research, 6(1), 151-166. http://doi.org/10.1080/09650799800200048 
Daniel, L. G., \& King, D. A. (1998). Knowledge and use of testing and measurement literacy of elementary and secondary teachers. The Journal of Educational Research, 91(6), 331.

Darling-Hammond, L. (2000). Teacher quality and student achievement. Education Policy Analysis Archives, 8(0), 1. http://doi.org/10.14507/epaa.v8n1.2000

Darling-Hammond, L. (2013). Powerful teacher education: Lessons from exemplary programs (1st ed.). San Francisco, CA: Jossey-Bass.

da Silva, M. (2005). Constructing the teaching process from inside out: How preservice teachers make sense of their perceptions of the teaching of the four skills. TESL-EJ, 9(2).

Davies, A. (2008). Textbook trends in teaching language testing. Language Testing, 25(3), 327.

Davies, A., Brown, A., Elder, C., Hill, K., Lumley, T., \& McNamara, T. (1999). Dictionary of language testing. Cambridge: Cambridge University Press.

Davies, A., \& Hill, M. (2009). Making classroom assessment work. Wellington, N.Z.: NZCER Press.

Davis, K. A. (1992). Validity and reliability in qualitative research on second language acquisition and teaching. TESOL Quarterly, 26(3), 605-608. http://doi.org/10.2307/3587190

Davison, C. (2004). The contradictory culture of teacher-based assessment: ESL teacher assessment practices in Australian and Hong Kong secondary schools. Language $\quad$ Testing, 21(3), 305-334. http://doi.org/http://dx.doi.org.helicon.vuw.ac.nz/10.1191/0265532204lt286 oa 
Davison, C. (2007). Views from the chalkface: English language school-based assessment in Hong Kong. Language Assessment Quarterly, 4(1), 37-68. http://doi.org/10.1080/15434300701348359

Davison, C. (2012). Enhancing language and literacy assessment: Building assessment for learning communities. Paper presented at the CLESOL 2012, $\begin{array}{lll}\text { New } & \text { Zealand. } & \text { Retrieved }\end{array}$ http://clesol.nz/2012/Chris_Davison_Keynote.pdf

Dean, C., Lauer, P., \& Urquhart, V. (2005). Outstanding teacher education programs: What do they have that the others don't? The Phi Delta Kappan, 87(4), 284289.

Decision on the approval of the project entitled "Teaching and Learning Foreign Languages in the National Education System, Period 2008-2020.” (2008). Retrieved from $\quad$ http://jpf.org.vn/iwtcore/uploads/2012/08/13Decision_1400_QD-TTg-Eng.pdf

DeLuca, C., \& Klinger, D. (2010). Assessment literacy development: Identifying gaps in teacher candidates' learning. Assessment in Education: Principles, Policy \& $\quad$ Practice, $\quad$ 17(4), 419-438. http://doi.org/10.1080/0969594X.2010.516643

Điểm số "bóp méo" học trò. (2014). Retrieved November 13, 2014, from http://dantri.com.vn/giao-duc-khuyen-hoc/diem-so-bop-meo-hoc-tro881025.htm

Doppen, F. (2007). The influence of a teacher preparation program on preservice social studies teachers' beliefs: A case study. Journal of Social Studies Research, 31(1), 54-64. 
Dörnyei, Z. (2010). Questionnaires in second language research: Construction, administration, and processing (2nd ed.). New York; London: Routledge.

Dudley, P., \& Swaffield, S. (2002). Assessment literacy for wise decisions: A publication commissioned by the association of teachers and lecturers. London: Association of Teachers \& Lecturers.

Duff, P. (2012). Case study research in applied linguistics (1st ed.). Hoboken: Taylor and Francis.

Dunn, S. V., Ehrich, L., Mylonas, A., \& Hansford, B. C. (2000). Students' perceptions of field experience in professional development: A comparative study. Journal of Nursing Education, 39(9), 393-400.

Earl, L. M. (2003). Assessment as learning: Using classroom assessment to maximize student learning. Corwin Press.

Earl, L. M. (2012). Assessment as learning: Using classroom assessment to maximize student learning (2nd ed.). Thousand Oaks: Corwin.

Earl, L. M., Manitoba, \& School Programs Division. (2006). Rethinking classroom assessment with purpose in mind: Assessment for learning, assessment as learning, assessment of learning. Winnipeg: Manitoba Education, Citizenship and Youth.

Eckhout, T., Davis, S., Mickelson, K., \& Goodburn, A. (2005). A method for providing assessment training to in-service and pre-service teachers. Paper presented at the Annual Meeting of the Southwestern Educational Research Association, New Orleans, LA. 
Eisner, E. W. (2002). From episteme to phronesis to artistry in the study and improvement of teaching. Teaching and Teacher Education, 18(4), 375-385. http://doi.org/10.1016/S0742-051X(02)00004-5

Elbaz, F. (1983). Teacher thinking: A study of practical knowledge. London: Nichols Pub Co.

Engelsen, K. S., \& Smith, K. (2014). Assessment literacy. In C. Wyatt-Smith, V. Klenowski, \& P. Colbert (Eds.), Designing assessment for quality learning (pp. 91-108). Dordrecht: Springer Netherlands.

Engeström, Y. (1987). Learning by expanding: An activity-theoretical approach to developmental research. Retrieved November 4, 2014, from http://lchc.ucsd.edu/mca/Paper/Engestrom/Learning-by-Expanding.pdf

Engeström, Y. (1999). Activity theory and individual and social transformation. In Y. Engeström, Perspectives on Activity theory (pp. 19-38). Cambridge: Cambridge University Press.

Engeström, Y. (2001). Expansive learning at work: Toward an activity theoretical reconceptualization. Journal of Education and Work, 14(1), 133-156. http://doi.org/10.1080/13639080020028747

Engeström, Y. (2005). Developmental work research: Expanding Activity theory in practice. Lehmanns Media.

English teaching in Vietnam: Teacher "re-education." (2007). Retrieved from http://tuoitrenews.vn/education/8231/english-teaching-in-vietnam-teacherreeducation 
Ewell, P. (2004). Preservice teacher perceptions of intensive field experiences and classroom teacher mentoring: A case study. Retrospective Theses and Dissertations. Retrieved from http://lib.dr.iastate.edu/rtd/1157

Ewing, R. (2010). Curriculum and assessment: A narrative approach. South Melbourne: Oxford University Press.

Eyers, G. (2014). Preservice teachers' assessment learning: Change, development and growth (Thesis). ResearchSpace@Auckland. Retrieved from https://researchspace.auckland.ac.nz/handle/2292/23757

Fang, Z. (1996). A review of research on teacher beliefs and practices. Educational Research, 38(1), 47-65. http://doi.org/10.1080/0013188960380104

Fan, Y.-C., Wang, T.-H., \& Wang, K. H. (2011). A web-based model for developing assessment literacy of secondary in-service teachers. Computers \& Education, 57(2), 1727-1740. http://doi.org/10.1016/j.compedu.2011.03.006

Farrell, T. S. C. (1999). The reflective assignment: Unlocking pre-service English teachers' beliefs on grammar teaching. RELC Journal, 30(2), 1-17. http://doi.org/10.1177/003368829903000201

Farrell, T. S. C. (2001). English language teacher socialisation during the practicum. Prospect, 16(1), 49-62.

Farrell, T. S. C. (2007). Failing the practicum: Narrowing the gap between epectations and reality with reflective practice. TESOL Quarterly, 41(1), 193201. http://doi.org/10.2307/40264340

Farrell, T. S. C. (2008). 'Here's the book, go teach the class' ELT practicum support. RELC Journal, 39(2), 226-241. http://doi.org/10.1177/0033688208092186 
Feiman-Nemser, S. (2008). Teacher learning: How do teachers learn to teach? In M. Cochran-Smith, S. Feiman-Nemser, \& D. J. McIntyre (Eds.), Handbook of research on teacher education: Enduring questions in changing contexts (3rd ed., pp. 697-705). New York: Routledge.

Field, A. (2013). Discovering statistics using IBM SPSS statistics. SAGE.

Flick, U. (2009). An introduction to qualitative research (4th ed.). Los Angeles: SAGE Publications Ltd.

Fontana, A., \& Frey, J. H. (2005). The interview: From neutral stance to political involvement. In N. K. Denzin \& Y. S. Lincoln (Eds.), The Sage handbook of qualitative research (3rd ed., pp. 695-727). London; Thousand Oaks: SAGE Publications.

Foss, D. H., \& Kleinsasser, R. C. (2001). Contrasting research perspectives: What the evidence yields. Teachers and Teaching, 7(3), 271-295. http://doi.org/10.1080/13540600120078210

Freeman, D., \& Johnson, K. E. (1998). Reconceptualizing the knowledge base of language teacher education. TESOL Quarterly, 32(3), 397. http://doi.org/10.2307/3588114

Fulcher, G. (2012). Assessment literacy for the language classroom. Language Assessment Quarterly, $\quad$ 9(2), 113-132. http://doi.org/10.1080/15434303.2011.642041

Fulcher, G., \& Davidson, F. (2007). Language testing and assessment: An advanced resource book. New York: Routledge. 
Gao, X. (Andy), \& Benson, P. (2012). "Unruly pupils" in pre-service English language teachers' teaching practicum experiences. Journal of Education for Teaching, 38(2), 127-140. http://doi.org/10.1080/02607476.2012.656440

Gardner, J. N. (2006). Assessment and learning. London: SAGE.

Gass, S. M., \& Mackey, A. (2000). Stimulated recall methodology in second language research. London: Lawrence Erlbaum.

Gatbonton, E. (2000). Investigating experienced ESL teachers' pedagogical knowledge. Canadian Modern Language Review, 56(4), 585-616. http://doi.org/10.3138/cmlr.56.4.585

Gerber, R. J. (1989). Lawyers, courts, and professionalism: The agenda for reform. Greenwood Publishing Group.

Gess-Newsome, J., \& Lederman, N. G. (1999). Pedagogical content knowledge: An introduction and orientation. In J. Gess-Newsome \& N. G. Lederman (Eds.), Examining pedagogical content knowledge. Netherland: Kluwer Academic Publishers.

Gipps, C. V. (1994). Beyond testing: towards a theory of educational assessment. Washington, D.C: Falmer Press.

Gipps, C. V., \& Cumming, J. J. (2005). Assessing literacies. In N. Bascia, A. Cumming, A. Datnow, K. Leithwood, \& D. Livingstone (Eds.), International handbook of educational policy (Vol. 13, pp. 695-713). Dordrecht: Springer Netherlands. Retrieved from http://link.springer.com/10.1007/1-4020-3201$3 \_36$

Golombek, P. R. (1998). A study of language teachers' personal practical knowledge. TESOL Quarterly, 32(3), 447-464. http://doi.org/10.2307/3588117 
Goodfellow, J., \& Sumsion, J. (2000). Transformative pathways: Field-based teacher educators' perceptions. Journal of Education for Teaching, 26(3), 245-257. http://doi.org/10.1080/713676894

Gotch, C. M., \& French, B. F. (2014). A systematic review of assessment literacy measures. Educational Measurement: Issues and Practice, 33(2), 14-18. http://doi.org/10.1111/emip.12030

Graham, P. (1997). Tensions in the mentor teacher-student teacher relationship: Creating productive sites for learning within a high school English teacher education program. Teaching and Teacher Education, 13(5), 513-527. http://doi.org/10.1016/S0742-051X(96)00053-4

Graham, P. (2005). Classroom-based assessment: Changing knowledge and practice through preservice teacher education. Teaching and Teacher Education, 21(6), 607-621. http://doi.org/10.1016/j.tate.2005.05.001

Green, J., \& Thorogood, N. (2004). Qualitative methods for health research. London: SAGE Publications Ltd.

Grossman, P. L. (1990). The making of a teacher: Teacher knowledge and teacher education. New York: Teachers College Press, Teachers College, Columbia University.

Grossman, P., Martin, S. D., Place, N. A., \& Valencia, S. W. (2009). Complex interactions in student learning: Lost opportunities for learning. Journal of Teacher Education, 60(3).

Gudmundsdottir, S. (1990). Values in Pedagogical Content Knowledge. Journal of Teacher Education, 41(3), $44-52$. http://doi.org/10.1177/002248719004100306 
Gu, P. Y. (2012). Classroom assessment literacy for EFL teachers: Conceptualisation, elicitation and analysis. Paper presented at the Inaugural ALTAANZ Conference, The University of Sydney, Australia.

Gu, P. Y. (2014). The unbearable lightness of the curriculum: What drives the assessment practices of a teacher of English as a Foreign Language in a Chinese secondary school? Assessment in Education: Principles, Policy \& Practice, 21(3), 286-305. http://doi.org/10.1080/0969594X.2013.836076

Haigh, M., \& Ward, G. (2004). Problematising practicum relationships: Questioning the "taken for granted." Australian Journal of Education, 48(2), 134-148. http://doi.org/10.1177/000494410404800204

Halim, L., Meerah, T. S. M. M., Zakaria, E., \& Abdullah, S. I. S. S. (2012). An exploratory factor analysis in developing pedagogical content knowledge scale for teaching science. Research Journal of Applied Sciences, Engineering and Technology, 4(19), 3558-3564.

Hall, K., \& Burke, W. (2004). Making formative assessment work: Effective practice in the primary classroom. Maidenhead: Open University Press.

Hamp-Lyons, L. (2001). Ethics, fairness(es), and developments in language testing. In C. Elder, A. Brown, E. Grove, K. Hill, N. Iwashita, T. Lumley, \& K. O’Loughlin (Eds.), Experimenting with uncertainty. Essays in honour of Alan Davies (pp. 222-239). Cambridge: Cambridge University Press.

Haney, J. J., \& McArthur, J. (2002). Four case studies of prospective science teachers' beliefs concerning constructivist teaching practices. Science Education, 86(6), 783-802. http://doi.org/10.1002/sce.10038 
Harlen, W. (2005). Teachers' summative practices and assessment for learning tensions and synergies. The Curriculum Journal, 16(2), 207-223. http://doi.org/10.1080/09585170500136093

Harlen, W. (2006). On the relationship between assessment for formative and summative purposes. In J. Gardner (Ed.), Assessment and learning (pp. 103118). London: SAGE Publications Ltd.

Harlen, W. (2008). Trusting teachers' judgment. In S. Swaffield (Ed.), Unlocking assessment: Understanding for reflection and application (pp. 138-153). Abingdon, Oxon, UK: Routledge.

Harlen, W., \& James, M. (1997). Assessment and learning: Differences and relationships between formative and summative assessment. Assessment in Education, 4(3), 365-379.

Harris, D. N., \& Sass, T. R. (2011). Teacher training, teacher quality and student achievement. Journal of Public Economics, 95(7-8), 798-812. http://doi.org/10.1016/j.jpubeco.2010.11.009

Hattie, J., Biggs, J., \& Purdie, N. (1996). Effects of learning skills interventions on student learning: A meta-analysis. Review of Educational Research, 66(2), 99.

Hattie, J., \& Timperley, H. (2007). The power of feedback. Review of Educational Research, 77(1), 81-112. http://doi.org/10.3102/003465430298487

Hayes, S., Capel, S., Katene, W., \& Cook, P. (2008). An examination of knowledge prioritisation in secondary physical education teacher education courses. Teaching and Teacher Education, 24(2), 330-342. http://doi.org/10.1016/j.tate.2006.10.012 
Heritage, H. M. (Ed.). (2010). Formative assessment: Making it happen in the classroom (1st ed.). Thousand Oaks: Corwin.

Hill, K., \& McNamara, T. (2011). Developing a comprehensive, empirically based research framework for classroom-based assessment. Language Testing, 29(3), 395-420. http://doi.org/10.1177/0265532211428317

Hlas, A., \& Hildebrandt, S. (2010). Demonstrations of pedagogical content knowledge: Spanish liberal arts and Spanish education majors' writing. L2 $\begin{array}{lll}\text { Journal, } & \text { 2(1). } & \text { Retrieved }\end{array}$ http://escholarship.org/uc/item/9t09n5x9\#page-1

Holliday, A. (2007). Doing and writing qualitative research (2nd ed.). Thousand Oaks: SAGE Publications Ltd.

Ho, S. T. K. (2011). An investigation of intercultural teaching and learning in tertiary EFL classrooms in Vietnam. Retrieved from http://helicon.vuw.ac.nz/login?url=http://restrictedarchive.vuw.ac.nz/handle/ $123456789 / 6381$

Huai, N., Braden, J. P., White, J. L., \& Elliott, S. N. (2006). Effect of an Internetbased professional development program on teachers' assessment literacy for all students. Teacher Education and Special Education: The Journal of the Teacher Education Division of the Council for Exceptional Children, 29(4), 244-260. http://doi.org/10.1177/088840640602900405

Hudson, P. (2005). Mentors' personal attributes for enhancing their mentees' primary science teaching. Teaching Science, 51(2), 31-34. 
Impara, J. C., Plake, B. S., \& Fager, J. J. (1993). Educational administrators' and teachers' knowledge of classroom assessment. Journal of School Leadership, $3(5), 510-21$.

Inbar-Lourie, O. (2008). Constructing a language assessment knowledge base: A focus on language assessment courses. Language Testing, 25(3), 385-402. http://doi.org/10.1177/0265532208090158

Inbar-Lourie, O. (2012). Language assessment literacy. In The encyclopedia of applied linguistics. John Wiley \& Sons, Inc. Retrieved from http://onlinelibrary.wiley.com/doi/10.1002/9781405198431.wbeal0605/abstr act

Jacobs, L. C., \& Chase, C. I. (1992). Developing and using tests effectively: A guide for faculty (1st ed.). San Francisco: Jossey-Bass.

James, M., \& Pedder, D. (2006). Professional learning as a condition for assessment for learning. In J. Gardner (Ed.), Assessment and learning (pp. 27-41). London: SAGE.

Jamieson, N. L. (1995). Understanding Vietnam. Berkeley: University of California Press.

Jenkins, J. M., \& Veal, M. L. (2002). Preservice teachers' PCK development during peer coaching. Journal of Teaching in Physical Education, 22(1), 49-68.

Jin, Y. (2010). The place of language testing and assessment in the professional preparation of foreign language teachers in China. Language Testing. http://doi.org/10.1177/0265532209351431 
Johnson, K. E. (1994). The emerging beliefs and instructional practices of preservice English as a second language teachers. Teaching and Teacher Education, 10(4), 439-452. http://doi.org/10.1016/0742-051X(94)90024-8

Johnson, K. E. (1996). The vision versus the reality: The tensions of the TESOL practicum. In F. D, \& R. J. C. (Eds.), Teacher learning in language teaching (pp. 30-49). New York: Cambridge University Press.

Johnson, K. E. (2009). Second language teacher education: A sociocultural perspective (1st ed.). New York: Routledge.

Johnson, K. E., \& Golombek, P. R. (2011). A sociocultural theoretical perspective on teacher professional development. In K. E. Johnson \& P. R. Golombek (Eds.), Research on second language teacher education: A sociocultural perspective on professional development (pp. 2-12). New York: Routledge.

Jung, S. (2013). Exploratory factor analysis with small sample sizes: A comparison of three approaches. Behavioural Processes, 97, 90-95. http://doi.org/10.1016/j.beproc.2012.11.016

Kagan, D. M. (1992). Implication of research on teacher belief. Educational Psychologist, 27(1), 65-90. http://doi.org/10.1207/s15326985ep2701_6

Khadijeh, B., \& Amir, R. (2015). Importance of teachers' assessment literacy. International Journal of English Language Education, 3(1), 139. http://doi.org/10.5296/ijele.v3i1.6887

Kind, V. (2009). Pedagogical content knowledge in science education: Perspectives and potential for progress. Studies in Science Education, 45(2), 169-204. http://doi.org/10.1080/03057260903142285 
Kleinsasser, R. C. (2005). Transforming a postgraduate level assessment course: A second language teacher educator's narrative. Prospect, 20(3), 77-102.

Koh, K. H. (2011). Improving teachers' assessment literacy through professional development. Teaching Education, 22(3), 255-276. http://doi.org/10.1080/10476210.2011.593164

Koh, K. H., \& Velayutham, R. L. (2009). Improving teachers' assessment literacy in Singapore schools: An analysis of teachers' assessment tasks and student work. NIE Research Brief, 9(2), 1-4.

Korthagen, F. A. J., \& Kessels, J. P. A. M. (1999). Linking theory and practice: Changing the pedagogy of teacher education. Educational Researcher, 28(4), 4-17. http://doi.org/10.2307/1176444

Korthagen, F., Loughran, J., \& Russell, T. (2006). Developing fundamental principles for teacher education programs and practices. Teaching and Teacher $\quad$ Education, $\quad$ 22(8), 1020-1041. http://doi.org/10.1016/j.tate.2006.04.022

Krippendorff, K. (2011). Agreement and information in the reliability of coding. Communication Methods and Measures, 5(2), 93-112. http://doi.org/10.1080/19312458.2011.568376

Kubiszyn, T., \& Borich, G. (1996). Educational testing and measurement: Classroom application and practice (5th ed.). New York: HarperCollins.

Kunnan, A. J. (2000). Fairness and justice for all. In A.J Kunnan (Eds), Fairness and validation in language assessment (pp. 1-14). Cambridge: Cambridge University Press. 
Kunnan, A. J. (2004a). Regarding language assessment. Language Assessment Quarterly, 1(1), 1-4. http://doi.org/10.1207/s15434311laq0101_1

Kunnan, A. J. (2004b). Test fairness. In M. Milanovic \& C. Weir (Eds.), European language testing in a global context. Cambridge: Cambridge University Press.

Kunnan, A. J. (2006). Towards a model of test evaluation: Using the test fairness and wider context frameworks. In M. Milanovic \& C. Weir (Eds.), Selected papers from the association of language testers of Europe conference, Berlin, Germany. Washington, D.C: National Association for Foreign Students Affairs.

Lafayette. (1993). Subject-matter content: What every foreign language teacher needs to know. In G. Guntermann (Ed.), Developing Language Teachers for a Changing World (pp. 124-158). Lincolnwood, Ill., USA: Natl Textbook Co.

Lam, R. (2014). Language assessment training in Hong Kong: Implications for language assessment literacy. Language Testing, 0265532214554321. http://doi.org/10.1177/0265532214554321

Landis, J. R., \& Koch, G. G. (1977). The measurement of observer agreement for categorical data. Biometrics, 33(1), 159-174.

Lantolf, J. P. (2006). Sociocultural theory and the genesis of second language development. Oxford: Oxford University Press.

Lee, E., Brown, M. N., Luft, J. A., \& Roehrig, G. H. (2007). Assessing beginning secondary science teachers' PCK: Pilot year results. School Science and Mathematics, $\quad$ 107(2), $\quad$ 52-60. $\quad$ http://doi.org/10.1111/j.19498594.2007.tb17768.x 
Leighton, J. P., Gokiert, R. J., Cor, M. K., \& Heffernan, C. (2010). Teacher beliefs about the cognitive diagnostic information of classroom- versus large-scale tests: Implications for assessment literacy. Assessment in Education: Principles, Policy \& Practice, 17(1), 7-21.

Leung, C. (2004). Developing formative teacher assessment: Knowledge, practice, and change. Language Assessment Quarterly, 1(1), 19-41. http://doi.org/10.1207/s15434311laq0101_3

Le, V. C. (2000). Language and Vietnamese pedagogical contexts. In Partnership and interaction: Proceedings of the fourth international conference on language and development (pp. 73-80). Hanoi, Vietnam: Bangkok, Thailand: Asian Institute of Technology.

Le V. C. (2002). Sustainable professional development of EFL teachers in Vietnam (Phát triển nghiệp vụ bền vững cho giáo viên tiếng Anh của Việt Nam). Retrieved from http://localhost/xmlui/handle/123456789/2465

Le, V. C. (2011). Form-focused instruction: A case study of Vietnamese teachers' beliefs and practices (Thesis). University of Waikato. Retrieved from http://researchcommons.waikato.ac.nz/handle/10289/5253

Levin, B., \& He, Y. (2008). Investigating the content and sources of teacher candidates' personal practical theories (PPTs). Journal of Teacher Education, 59(1), 55-68. http://doi.org/10.1177/0022487107310749

Levine, A. (2006). Educating school teachers. Princeton: NJ: The Education Schools Projects.

Lian, L. H., Yew, W. T., \& Meng, C. C. (2014). Enhancing Malaysian teachers' assessment literacy. International Education Studies, 7(10), 74-81. 
Lincoln, Y. S., \& Guba, E. G. (1986). But is it rigorous? Trustworthiness and authenticity in naturalistic evaluation. New Directions for Program Evaluation, 1986(30), 73-84. http://doi.org/10.1002/ev.1427

Lomax, R. G. (1996). On becoming assessment literate: An initial look at preservice teachers' beliefs and practices. Teacher Educator, 31(4), 292-303.

Looney, J. W. (2011, April 8). Integrating formative and summative assessment: Progress toward a seamless System? OECD education working papers, No. 58. OECD Publishing. Retrieved from http://eric.ed.gov/?id=ED529586

Lortie, D. C. (1975). Schoolteacher: A Sociological study. University of Chicago Press.

Louden, W., \& Rohl, M. (2006). "Too many theories and not enough instruction": Perceptions of preservice teacher preparation for literacy teaching in Australian schools. Literacy, 40(2), 66-78. http://doi.org/10.1111/j.14679345.2006.00440.x

Loughran, J., Mulhall, P., \& Berry, A. (2004). In search of pedagogical content knowledge in science: Developing ways of articulating and documenting professional practice. Journal of Research in Science Teaching, 41(4), 370391. http://doi.org/10.1002/tea.20007

Macalister, J. (2012). Pre-service teacher cognition and vocabulary teaching. RELC Journal, 43(1), 99-111. http://doi.org/10.1177/0033688212439312

MacDonald, M., Badger, R., \& White, G. (2001). Changing values: What use are theories of language learning and teaching? Teaching and Teacher Education, 17(8), 949-963. http://doi.org/10.1016/S0742-051X(01)00042-7 
Mackey, A. (2005). Second language research: Methodology and design. Mahwah, NJ: Lawrence Erlbaum.

Magnusson, S., Krajcik, J., \& Borko, H. (1999). Secondary teachers' knowledge and beliefs about subject matter and their impact on instruction. In J. GessNewsome \& N. G. Lederman (Eds.), Examining pedagogical content knowledge (pp. 95-132). Dordrecht.

Malone, M. E. (2013). The essentials of assessment literacy: Contrasts between testers and users. Language Testing, 30(3), 329-344. http://doi.org/http://dx.doi.org.helicon.vuw.ac.nz/10.1177/02655322134801 29

Marshall, C., \& Rossman, G. B. (2006). Designing qualitative research. Sage Publications.

Marso, R. N., \& Pigge, F. L. (1992). A summary of published research: Classroom teachers' knowledge and skills related to the development and use of teacher$\begin{array}{lll}\text { made } & \text { tests. } & \text { Retrieved }\end{array}$ http://www.eric.ed.gov/ERICWebPortal/contentdelivery/servlet/ERICServle $\mathrm{t} ? \mathrm{accno}=\mathrm{ED} 346148$

Mauthner, N. S., \& Doucet, A. (2003). Reflexive accounts and accounts of reflexivity in qualitative data analysis. Sociology, 37(3), 413-431. http://doi.org/10.1177/00380385030373002

McGee, J., \& Colby, S. (2014). Impact of an assessment course on teacher candidates' assessment literacy. Action in Teacher Education, 36(5-6), 522-532. http://doi.org/10.1080/01626620.2014.977753 
McMillan, J. H. (2000). Fundamental assessment principles for teachers and school administrators. Practical Assessment, Research \& Evaluation, 7(8). Retrieved from http://pareonline.net/getvn.asp?v=7\&n=8

McNamara, T. F. 1949, \& Roever, C. (2006). Language testing: the social dimension. Malden, MA: Blackwell Pub.

Meijer, P. C., Verloop, N., \& Beijaard, D. (1999). Exploring language teachers' practical knowledge about teaching reading comprehension. Teaching and Teacher Education, 15(1), 59-84. http://doi.org/10.1016/S0742051X(98)00045-6

Mendoza, A. A. L., \& Arandia, R. B. (2009). Language testing in Colombia: A call for more teacher education and teacher training in language assessment. $\begin{array}{llll}\text { Retrieved } & \text { June } & 22, & \text { 2015, }\end{array}$ http://www.redalyc.org/articulo.oa?id=169216301005

Mertler, C. A. (2003). Preservice versus inservice teachers' assessment literacy: Does classroom experience make a difference? Paper presented at the Mid-Western Educational Research Association, Columbus, Columbus, USA. Retrieved from

http://wps.ablongman.com/wps/media/objects/1530/1567095/tchassesslit.pd f

Mertler, C. A. (2005). Secondary teachers' assessment literacy: Does classroom experience make a difference? American Secondary Education, 33(2), 76-92.

Mertler, C. A., \& Campbell, C. (2005). Measuring teachers' knowledge and application of classroom assessment concepts: Development of the 
“Assessment Literacy Inventory.” Paper presented at the Annual Meeting of the American Educational Research Association, Montreal, Quebec, Canada. Miles, M. B., \& Huberman, A. M. (1994). Qualitative data analysis: An expanded sourcebook. SAGE Publications.

Mitchell, K. J., Robinson, D. Z., Plake, B. S., \& Knowles, K. T. (Eds.). (2001). Testing teacher candidates: The role of licensure tests in improving teacher quality. Washington, D.C: National Academies Press.

Montee, M., Bach, A., Donovan, A., \& Thompson, L. (2013). LCTL teachers' assessment knowledge and practices: An exploratory study. JNCOLCTL, 13(Spring 2013), 1-31.

Moss, C. M. (2013). Research on classroom summative assessment. In J. H. McMillan (Ed.), Sage handbook of research on classroom assessment (pp. 235-255). Thousand Oaks, CA: SAGE Publications.

Mullock, B. (2006). The pedagogical knowledge base of four TESOL teachers. The Modern Language Journal, 90(1), 48-66. http://doi.org/10.1111/j.15404781.2006.00384.x

Nâng chuẩn giáo viên tiếng Anh: Thi là rớt [Improving English teachers' English proficiency: Low exam success rates]. (2014). Retrieved August 26, 2015, from http://tuoitre.vn/tin/giao-duc/20140724/nang-chuan-giao-vien-tienganh-thi-la-rot/625900.html

Nespor, J. (1987). The role of beliefs in the practice of teaching. Journal of $\begin{array}{lll}\text { Curriculum } & \text { Studies, } & \text { 317-328), }\end{array}$ http://doi.org/10.1080/0022027870190403 
Newfields, T. (2006). Teacher development and assessment literacy. In Authentic Communication: Proceedings of the 5th Annual JALT Pan-SIG Conference (pp. 48-73). Shizuoka, Japan: Tokai University College of Marine Science.

Newton, P. E. (2007). Clarifying the purposes of educational assessment. Assessment in Education: Principles, Policy \& Practice, 14(2), 149-170. http://doi.org/10.1080/09695940701478321

Nguyen, G. V. (2013). Orienting to pedagogical innovation: A case study of Vietnamese teachers' beliefs and practices regarding Task-based Language Teaching (Thesis). University of Waikato. Retrieved from http://researchcommons.waikato.ac.nz/handle/10289/7433

Nguyen, H. T. M. (2010). Peer mentoring: Practicum practices of pre-service EFL $\begin{array}{llll}\text { teachers } & \text { in } & \text { Vietnam. }\end{array}$ http://espace.library.uq.edu.au/view/UQ:219776

Nguyen, H. T. M. (2013). Peer mentoring: A way forward for supporting preservice EFL teachers psychosocially during the practicum. Australian Journal of Teacher Education, 38(7). http://doi.org/10.14221/ajte.2013v38n7.3

Nguyen, M. H. (2013). The curriculum for English language teacher education in Australian and Vietnamese universities. Australian Journal of Teacher Education, 38(11). http://doi.org/10.14221/ajte.2013v38n11.6

Nguyen, M. H. (2014). Preservice EAL teaching as emotional experiences: Practicum experience in an Australian secondary school. Australian Journal of Teacher Education, 39(8). http://doi.org/10.14221/ajte.2014v39n8.5 
Nguyen, T. C. L. (2009). Learner autonomy and EFL learning at the tertiary level in Vietnam (Phd thesis). Victoria University of Wellington, New Zealand. Retrieved from http://researcharchive.vuw.ac.nz/xmlui/handle/10063/1203.

Nguyen, T. M. H., \& Hudson, P. B. (2010). Preservice EFL teachers' beliefs about teaching writing and learning to teach writing before their practicum : A case study in Vietnam. Asian EFL Journal, 12(2), 43-67.

Nguyen, T. S. (2013, December 1). The relationship between Vietnamese EFL students' beliefs and learning preferences and native English-speaking teachers' beliefs and teaching practices (Thesis). University of Leicester. Retrieved from https://lra.le.ac.uk/handle/2381/28488

Noll, V. H. (1955). Requirements in educational measurements for prospective teachers. School and Society, 82, 88-90.

Numrich, C. (1996). On becoming a language teacher: Insights from diary studies. TESOL Quarterly, 30(1), 131-53.

Nunan, D. (1992). Research methods in language learning. Cambridge: Cambridge University Press.

Ogan-Bekiroglu, F. (2009). Assessing assessment: Examination of pre-service physics teachers' attitudes towards assessment and factors affecting their attitudes. International Journal of Science Education, 31(1), 1-39. http://doi.org/10.1080/09500690701630448

Ogan-Bekiroglu, F., \& Suzuk, E. (2014). Pre-service teachers' assessment literacy and its implementation into practice. The Curriculum Journal, 25(3), 344371. http://doi.org/10.1080/09585176.2014.899916 
O'Loughlin, K. (2009). Developing the assessment literacy of IELTS test users in higher education. Retrieved from http://www.ielts.org/pdf/vol13_report5.pdf Oosterhof, A. (1995). An extended observation of assessment procedures used by selected public school teachers. Paper presented at the Anual Meeting of the American Educational Research Association, San Francisco, CA, USA. Retrieved from http://files.eric.ed.gov/fulltext/ED390937.pdf

O’Sullivan, R. G., \& Johnson, R. L. (1993). Using performance assessments to measure teachers' competence in classroom assessment. Retrieved from http://eric.ed.gov/?id=ED358156

Pajares, M. F. (1992). Teachers' beliefs and educational research: Cleaning up a messy construct. Review of Educational Research, 62(3), 307-332. http://doi.org/10.3102/00346543062003307

Pallant, J. (2010). SPSS Survival Manual: A step by step guide to data analysis using SPSS (4 ed.). Maidenhead: Open University Press.

Patton, M. Q. (2002). Qualitative research and evaluation methods (3 ${ }^{\text {rd }}$ ed.). Thousand Oaks, Calif: Sage Publications.

Peacock, M. (2001). Pre-service ESL teachers' beliefs about second language learning: A longitudinal study. System, 29(2), 177-195. http://doi.org/10.1016/S0346-251X(01)00010-0

Petrić, B., \& Czárl, B. (2003). Validating a writing strategy questionnaire. System, 31(2), 187-215. http://doi.org/10.1016/S0346-251X(03)00020-4

Pham, H. H. (2001). Teacher development: A real need for English departments in Vietnam. English Teaching Forum, 39(4). Retrieved from http://americanenglish.state.gov/files/ae/resource_files/01-39-4-f.pdf 
Phipps, S., \& Borg, S. (2009). Exploring tensions between teachers' grammar teaching beliefs and practices. System, 37(3), 380-390. http://doi.org/10.1016/j.system.2009.03.002

Plake, B. S. (1993). Teacher assessment literacy: Teachers' competencies in the educational assessment of students. Mid-Western Educational Researcher, $6(1), 21-27$.

Popham, W. J. (2004). Curriculum, instruction, and assessment: Amiable allies or phony friends? Teachers College Record, 106(3), 417-428. http://doi.org/10.1111/j.1467-9620.2004.00345.x

Popham, W. J. (2006). Needed: A dose of assessment literacy. Educational Leadership, 63(6), 84-85.

Popham, W. J. (2009). Assessment literacy for teachers: Faddish or fundamental? Theory Into Practice, $\quad 48(1), \quad$ 4-11. http://doi.org/10.1080/00405840802577536

Popham, W. J. (2011). Assessment literacy overlooked: A teacher educator's confession. The Teacher Educator, 46(4), 265-273. http://doi.org/10.1080/08878730.2011.605048

Price, M., Rust, C., O’Donovan, B., Handley, K., \& Bryant, R. (2012). Assessment literacy: The foundation for improving student learning (1st ed.). Oxford: The Oxford Centre for Staff and Learning Development.

Punch, K. F. (2009). Introduction to research methods in education. SAGE.

Rea-Dickins, P. (2001). Mirror, mirror on the wall: Identifying processes of classroom assessment. Language Testing, 18(4), 429-462. 
http://doi.org/http://dx.doi.org.helicon.vuw.ac.nz/10.1191/02655320168243 0120

Richards, J. C. (1996). Teachers' maxims in language teaching. TESOL Quarterly, 30(2), 281-296. http://doi.org/10.2307/3588144

Richards, J. C., Ho, B., \& Giblin, K. (1996). Learning how to teach in the RSA Cert. In D. Freeman \& J. C. Richards (Eds.), Teaching learning in language teaching (pp. 242-259). Cambridge: Cambridge University Press.

Richardson, V. (1996). The role of attitudes and beliefs in learning to teach. In J. Sikula (Ed.), Handbook of research on teacher education (pp. 102-119). New York: Simon \& Schuster Macmillan.

Sadler, D. R. (1989). Formative assessment and the design of instructional systems. Instructional Science, 18(2), 119-144. http://doi.org/10.1007/BF00117714

Sadler, D. R. (1998). Formative assessment: Revisiting the territory. Assessment in Education: Principles, Policy \& Practice, 5(1), 77-84. http://doi.org/10.1080/0969595980050104

Scales, P. (1993). How teachers and education deans rate the quality of teacher preparation for the middle grades. Journal of Teacher Education, 44(5), 378383.

Scarino, A. (2013). Language assessment literacy as self-awareness: Understanding the role of interpretation in assessment and in teacher learning. Language Testing, 30(3), 309-327. http://doi.org/10.1177/0265532213480128

Schafer, W. D. (1993). Assessment literacy for teachers. Theory into Practice, 32(2), $118-126$. 
Schafer, W. D., \& Lissitz, R. W. (1987). Measurement training for school personnel recommendations and reality. Journal of Teacher Education, 38(3), 57-63. http://doi.org/10.1177/002248718703800312

Schön, D. A. (1987). Educating the reflective practitioner : toward a new design for teaching and learning in the professions (1st ed.). San Francisco: JosseyBass.

Schulz, R. (2005). The practicum: More than practice. Canadian Journal of Education / Revue Canadienne de L'éducation, 28(1/2), 147-167. http://doi.org/10.2307/1602158

Shepard, L. A. (2000). The role of assessment in a learning culture. Educational Researcher, 29(7), 4-14. http://doi.org/10.3102/0013189X029007004

Shepard, L. A. (2006). Classroom assessment. In R. L. Brennan (Ed.), Educational measurement (4th ed., pp. 623-646). Westport, CT: Praeger.

Shulman, L. S. (1986). Those who understand: Knowledge growth in teaching. Educational Researcher, $\quad$ 15(2), 4-14. http://doi.org/10.3102/0013189X015002004

Shulman, L. S. (1987). Knowledge and teaching: Foundations of the new reform. Harvard Educational Review, 57(1), 1-22.

Shute, V. J. (2008). Focus on formative feedback. Review of Educational Research, 78(1), 153-189.

Siegel, M. A., \& Wissehr, C. (2011). Preparing for the plunge: Preservice teachers' assessment literacy. Journal of Science Teacher Education, 22(4), 371-391. http://doi.org/http://dx.doi.org.helicon.vuw.ac.nz/10.1007/s10972-011-92316 
Sinh viên Việt Nam sử dụng tiếng Anh rất kém [Vietnamese students' low English proficiency] . (2008). Retrieved May 2, 2014, from http://dantri.com.vn/giaoduc-khuyen-hoc/sinh-vien-viet-nam-su-dung-tieng-anh-rat-kem-263403.htm

Stake, R. E. (2000). Case studies. In N. K. Denzin \& Y. S. Lincoln (Eds.), Handbook of qualitative research (pp. 435-545). Thousand Oaks, CA: SAGE Publications.

Stiggins, R. J. (1991a). Assessment literacy. The Phi Delta Kappan, 72(7), 534-539.

Stiggins, R. J. (1991b). Relevant classroom assessment training for teachers. Educational Measurement: Issues and Practice, 10(1), 7-12.

Stiggins, R. J. (1995). Assessment literacy for the 21st century. The Phi Delta Kappan, 77(3), 238-245.

Stiggins, R. J. (1999a). Assessment, student confidence, and school success. The Phi Delta Kappan, 81(3), 191-198.

Stiggins, R. J. (1999b). Evaluating classroom assessment training in teacher education programs. Educational Measurement: Issues and Practice, 18(1), 23-27. http://doi.org/10.1111/j.1745-3992.1999.tb00004.x

Stiggins, R. J. (2002). Assessment crisis: The absence of assessment for learning. Phi Delta Kappan, 83(10), 758-765.

Stiggins, R. J. (2005). From formative assessment to assessment for learning: A path to success in standards-based schools. Phi Delta Kappan, 87(4), 324-328. http://doi.org/10.1177/003172170508700414

Stiggins, R. J. (2007a). Assessment through the student's eyes. Educational Leadership, 64(8), 22. 
Stiggins, R. J. (2007b). Conquering the formative assessment frontier. In J. H. McMillan (Ed.), Formative assessment: Theory into practice. New York: Teachers College Press.

Stiggins, R. J. (2010). Essential formative assessment competencies for teachers and school leaders. In H. L. Andrade \& G. J. Cizek (Eds.), Handbook offormative assessment (pp. 233-250). Routledge.

Stiggins, R. J., \& Chappuis, J. (2005). Using student-involved classroom assessment to close achievement gaps. Theory into Practice, 44(1), 11-18. http://doi.org/10.2307/3496986

Stiggins, R. J., \& Conklin, N. F. (1988). Teacher training in assessment. Portland, Oreg: Northwest regional educational lab.

Stiggins, R. J., \& Conklin, N. F. (1992). In teachers' hands: Investigating the practices of classroom assessment. Albany: State University of New York Press.

Stronge, J. H., Ward, T. J., Tucker, P. D., \& Hindman, J. L. (2007). What is the relationship between teacher quality and student achievement? An exploratory study. Journal of Personnel Evaluation in Education, 20(3-4), 165-184. http://doi.org/http://dx.doi.org.helicon.vuw.ac.nz/10.1007/s11092008-9053-Z

Sướng và khổ của sinh viên Việt Nam [Happiness and sadness of Vietnamese $\begin{array}{llll}\text { students]. (2014). } & \text { Vietnam. } & \text { Retrieved }\end{array}$ http://vnexpress.net/interactive/2014/hoc-sinh-viet-nam-1/mobile.html 
Swaffield, S. (2011). Getting to the heart of authentic assessment for learning. Assessment in Education: Principles, Policy \& Practice, 18(4), 433-449. http://doi.org/10.1080/0969594X.2011.582838

Tamir, P. (1988). Subject matter and related pedagogical knowledge in teacher education. Teaching and Teacher Education, 4(2), 99-110. http://doi.org/10.1016/0742-051X(88)90011-X

Tatoo, M. T., \& Coupland, D. B. (2003). Teacher education and teachers' beliefs: Theoretical and measurement concerns. In J. Raths \& A. C. McAninch (Eds.), Teacher beliefs and classroom performance: The impact of teacher education: Advances in teacher education (pp. 123-182). Greenwich, CN, USA: Information Age Publishing.

Taylor, K. W. (1998). Surface orientations in Vietnam: Beyond histories of nation and region. The Journal of Asian Studies, 57(4), 949-978. http://doi.org/10.2307/2659300

Taylor, L. (2009). Developing assessment literacy. Annual Review of Applied Linguistics, 29 $21-36$. http://doi.org/http://dx.doi.org/10.1017/S0267190509090035

Taylor, L. (2013). Communicating the theory, practice and principles of language testing to test stakeholders: Some reflections. Language Testing, 30(3), 403412.

http://doi.org/http://dx.doi.org.helicon.vuw.ac.nz/10.1177/02655322134803 38 
Thí sinh ít chọn môn sử, ngoại ngữ [Low number of English, History exam takers]. (2014). Retrieved November 5, 2014, from http://news.zing.vn/zingnewspost405792.html

Thừa thầy, thiếu thợ, vì đâu? [Too many masters, very few technical workers: Why?] (2013). Retrieved December 15, 2014, from http://www.tienphong.vn/xa-hoichuyen-hom-nay/thua-thay-thieu-tho-vi-dau-648004.tpo

Tìm đến cội nguồn vấn nạn “dạy thêm - học thêm” tràn lan [Investigating the reasons for taking after-hour classes]. (2014). Retrieved September 10, 2015, from http://www.tinmoi.vn/tim-den-coi-nguon-van-nan-day-them-hoc-them-tranlan-01639204.html

Timperley, H., \& Parr, J. (2010). Evidence, inquiry and standards. In H. Timperley \& J. Parr (Eds.), Weaving evidence, inquiry and standards to build better schools (pp. 9-23). Wellington, NZ: NZCER.

Tổng số thí sinh rớt đại học năm nay [Number of entrance exam fallers this year] . (2013). Retrieved November 5, 2014, from http://kenhtuyensinh.vn/gan400000-thi-sinh-rot-dai-hoc

Torrance, H., \& Pryor, J. (1998). Investigating formative assessment: teaching, learning and assessment in the classroom. Open University Press.

Trochim, W. M. K., \& Donnelly, J. P. (2008). Research methods knowledge base (3 ${ }^{\text {rd }}$ ed.). Mason, Ohio: Cengage Learning.

Truong, D. T. (2013). Confucian values and school leadership in Vietnam. Victoria University of Wellington, New Zealand. Retrieved from http://researcharchive.vuw.ac.nz/handle/10063/2774 
Tsuboi, Y. (2007). Twentry years after the adoption of the Doi Moi policy. Retrieved from

https://dspace.wul.waseda.ac.jp/dspace/bitstream/2065/12801/1/43_070321Tsuboi-e.pdf

Urmston, A. (2003). Learning to teach English in Hong Kong: The opinions of teachers in training. Language and Education, 17(2), 112-137. http://doi.org/10.1080/09500780308666843

van Driel, J. H., \& Berry, A. (2012). Teacher professional development focusing on pedagogical content knowledge. Educational Researcher, 41(1), 26-28. http://doi.org/10.3102/0013189X11431010

Verloop, N., Van Driel, J., \& Meijer, P. (2001). Teacher knowledge and the knowledge base of teaching. International Journal of Educational Research, 35(5), 441-461. http://doi.org/10.1016/S0883-0355(02)00003-4

Vietnam's inservice English teacher competency framework: Guidelines for professional practice. (2014). NFL2020forum. Retrieved from file://C:/Users/nguyent6/Downloads/implications\%20for\%20trainers.pdf

Vì sao dạy và học tiếng Anh mãi "giậm chân tại chỗ”? [Why English teaching and learning in Vietnam remain unchanged?] (2014). Retrieved December 31, 2014, from http://dantri.com.vn/su-kien/vi-sao-day-va-hoc-tieng-anh-maigiam-chan-tai-cho-1013931.htm

Vogt, K., \& Tsagari, D. (2014). Assessment literacy of foreign language teachers: Findings of a European study. Language Assessment Quarterly, 11(4), 374402. http://doi.org/10.1080/15434303.2014.960046 
Vogt, W. P. (2014). Selecting the right analyses for your data: Quantitative, qualitative, and mixed methods. New York: The Guilford Press.

Volante, L., \& Fazio, X. (2007). Exploring teacher candidates' assessment literacy: Implications for teacher education reform and professional development. Canadian Journal of Education, 30(3), 749-770.

Vygotsky, L. S., \& Cole, M. (1978). Mind in society: The development of higher psychological processes. Cambridge: Harvard University Press.

Wallace, M. J. (1991). Training foreign language teachers: A reflective approach. Cambridge: Cambridge University Press.

Walters, F. S. (2010). Cultivating assessment literacy: Standards evaluation through language-test specification reverse engineering. Language Assessment Quarterly, 7(4), 317-342. http://doi.org/10.1080/15434303.2010.516042

Wang, T. H., Wang, K. H., \& Huang, S. C. (2008). Designing a web-based assessment environment for improving pre-service teacher assessment literacy. Computers \& Education, 51(1), 448-462. http://doi.org/doi: DOI: 10.1016/j.compedu.2007.06.010

Warford, M., \& Reeves, J. (2003). Falling into It: Novice TESOL teacher thinking. Faculty Publications: Department of Teaching, Learning and Teacher Education. Retrieved from http://digitalcommons.unl.edu/teachlearnfacpub/117

Weaver, D., \& Stanulis, R. N. (1996). Negotiating preparation and practice: Student teaching in the Middle. Journal of Teacher Education, 47(1), 27-36. http://doi.org/10.1177/0022487196047001006 
Webb, N. L. (2002). Assessment literacy in a standards-based urban education system. Paper presented at the AERA annual meeting, New Orleans, LA. Retrieved

from http://facstaff.wcer.wisc.edu/normw/AERA\%202002/Assessment\%20literac y\%20NLW\%20Final\%2032602.pdf

Wells, G. (1999). The zone of proximal development and its implications for learning and teaching. In Dialogic Inquiry. Cambridge University Press. Retrieved from http://dx.doi.org/10.1017/CBO9780511605895.012

White, C. S., Sturtevant, E. G., \& Dunlap, K. L. (2002). Preservice and beginning teachers' perceptions of the influence of high stakes tests on their literacyrelated instructional beliefs and decisions. Reading Research and Instruction, 42(2), 39-62. http://doi.org/10.1080/19388070309558385

White, P. (2009). Developing research questions: A guide for social scientists. Basingstoke [England]; New York: Palgrave Macmillan.

Wiliam, D. (2011). What is assessment for learning? Studies in Educational Evaluation, 37(1), 3-14. http://doi.org/10.1016/j.stueduc.2011.03.001

Wiliam, D., \& Thompson, M. (2008). Intergrating assessment with learning: What will it take to make it work? In C. A. Dwyer (Ed.), The future of assessment: Shaping teaching and learning (pp. 53-84). United States -- New York: Taylor \& Francis.

Willis, J. E. (2011). Towards learner autonomy: An assessment for learning approach (Thesis). Queensland University of Technology. Retrieved from http://eprints.qut.edu.au/45498/ 
Wilson, S. M., Floden, R. E., \& Ferrini-Mundy, J. (2001). Teacher preparation research: Current knowledge, gaps, and recommendations. Washington, DC: University of Washington, Center for the Study of Teaching and Policy.

Woods, D. (1996). Teacher cognition in language teaching: Beliefs, decision-making and classroom practice. Cambridge England: Cambridge University Press.

Wright, T. (2010). Second language teacher education: Review of recent research on practice. Language Teaching, 43(03), 259-296. http://doi.org/10.1017/S0261444810000030

Yinger, R. J. (1986). Examining thought in action: A theoretical and methodological critique of research on interactive teaching. Teaching and Teacher Education, 2(3), 263-282. http://doi.org/10.1016/S0742-051X(86)80007-5

Yin, M. (2010). Understanding classroom language assessment through teacher thinking research. Language Assessment Quarterly, 7(2), 175-194. http://doi.org/10.1080/15434300903447736

Yin, R. K. (1994). Case study research: Design and methods (2nd ed.). Thousand Oaks: Sage Publications.

Zeidler, D. L. (2002). Dancing with Maggots and Saints: Visions for subject matter knowledge, pedagogical knowledge, and pedagogical content knowledge in science teacher education reform. Journal of Science Teacher Education, 13(1), 27-42. http://doi.org/10.1023/A:1015129825891

Zhang, Z., \& Burry-Stock, J. (1997). Assessment practices inventory: A multivariate analysis of teachers' perceived assessment competency. Retrieved from http://eric.ed.gov/?id=ED408333 
Zheng, H. (2009). A review of research on EFL pre-service teachers' beliefs and practices. Journal of Cambridge Studies, 4(1), 73-81. 
Appendix A: Ethics approval

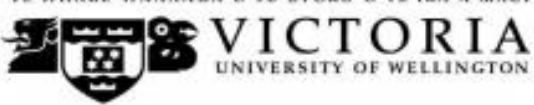

MEMORANDUM

Phone $0-4-4635676$

Fax $\quad 0-4-4635209$

Email Allisonkirkmanmuwe.ne.nz

\begin{tabular}{l|l}
\hline TO & Thi Huynh Loc Nguyen \\
\hline COPY TO & $\begin{array}{l}\text { Peter Gu } \\
\text { Jean Parkinson }\end{array}$ \\
\hline FROM & Dr Kathy Nelson, Acting Convener, Human Ethics Committee \\
\hline DATE & 4 April 2013 \\
\hline PAGES & 1 \\
\hline \multicolumn{2}{|l}{} \\
\hline SUBJECT & $\begin{array}{l}\text { Ethics Approval: } 19698 \\
\text { Development of assessment literacy among Vietnamese } \\
\text { preservice EFL teachers }\end{array}$ \\
\hline
\end{tabular}

Thank you for your application for ethical approval, which has now been considered by the Standing Committee of the Human Ethics Committee.

Your application has been approved from the above date and this approval continues until 30 April 2015. If your data collection is not completed by this date you should apply to the Human Ethics Committee for an extension to this approval.

Best wishes with the research.

Kathy Nelson

Human Ethics Committee 


\section{MEMORANDUM}

\begin{tabular}{l|l}
\hline TO & Thi Huynh Loc Nguyen \\
\hline COPY TO & Peter Gu \\
\hline FROM & Dr Allison Kirkman, Convener, Human Ethics Committee \\
\hline DATE & 4 November 2013 \\
\hline PAGES & 1 \\
\hline \multicolumn{2}{|l}{} \\
\hline SUBJECT & $\begin{array}{l}\text { Ethics Approval: 20374 } \\
\text { Development of Assessment Literacy among Vietnamese } \\
\text { Preservice EFL Teachers }\end{array}$ \\
\hline
\end{tabular}

Thank you for your application for ethical approval, which has now been considered by the Standing Committee of the Human Ethics Committee.

Your application has been approved from the above date and this approval continues until 30 December 2015. If your data collection is not completed by this date you should apply to the Human Ethics Committee for an extension to this approval.

Best wishes with the research.

Allison Kirkman

Human Ethics Committee

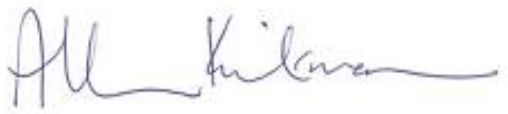




\section{PHASE 1: LANGUAGE TESTING AND ASSESSMENT COURSES}

Appendix B: Phase 1 - Language testing and assessment courses

- Information sheet.

- Consent form.

- Interview guidelines. 


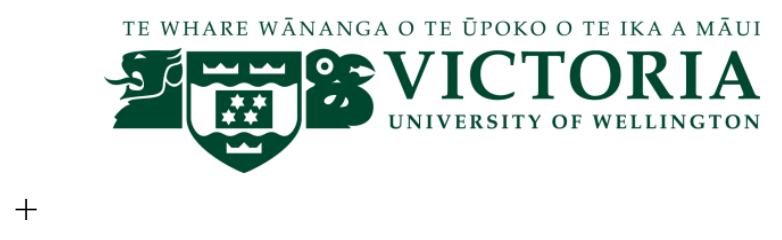

INFORMATION SHEET

Teacher trainer's version

This project is being conducted by Thi Huynh Loc Nguyen, PhD candidate, School of Linguistics and Applied Language Studies, Victoria University of Wellington. It has been given ethical approval by the University's Human Ethics Committee.

The aim of the project is to investigate assessment literacy of pre-service EFL language teachers at teachers training universities in Vietnam and how they develop their assessment knowledge and practice in testing and assessment courses, and practicum. This project is beneficial for not only Vietnamese pre-service EFL teachers but also language teacher educators, government policy makers and curriculum designers to understand the professional needs of pre-service EFL teachers and better prepare them for their future teaching.

I would like to invite you to participate in this study. If you agree, you will be interviewed in Vietnamese for about 45 minutes about the current status of language testing and assessment training at your university. The interview will be conducted at your convenient time and venue.

Your participation in this study is voluntary and you are free to decline without giving any reason. You may also withdraw from the research at any time during data collection without explanation. The collected data will be destroyed after your withdrawal. Within one month after the interview, you will be contacted to review the transcripts of the interview and correct errors of transcription. The data from the interview will be kept confidential. No participant will be identified personally. Data can be accessed by the researcher and her supervisors only. These data will be destroyed within two years after the completion of the project. 
The thesis will be submitted to the School of Linguistics and Applied Language Studies, and deposited at the Library of Victoria University of Wellington. The results of the research may be presented at academic conferences or published in academic journals.

Should you require any further information or clarification, please do not hesitate to contact me at ThiHuynhLoc.Nguyen@vuw.ac.nz or my supervisors, Dr. Peter Gu at peter.gu@ vuw.ac.nz and Dr. Jean Parkinson at jean.parkinson@ vuw.ac.nz, School of Linguistics and Applied Language Studies, Victoria University of Wellington, New Zealand. 
CONSENT FORM

DEVELOPMENT OF ASSESSMENT LITERACY AMONG VIETNAMESE PRESERVICE EFL TEACHERS

CONSENT TO PARTICIPATE IN RESEARCH

NAME (please print clearly):

I understand the procedure of this research as set out in the INFORMATION SHEET.

I have had an opportunity to ask questions and have had them answered to my satisfaction.

I understand that the data I provide will be stored in the School of Linguistics and Applied Language Studies at Victoria University of Wellington.

I also understand that my data will remain confidential, and that no personal information that may be used to identify me uniquely will be stored with the data.

I understand that within a period of six months from today I may withdraw myself or any data or information I have provided from this project, without having to give reasons.

I understand that, if I so request, details of the purpose of the research will be discussed with me once I have completed my participation, and that I may ask for a summary of results from the study to be sent to me at a later date.

I agree to take part in this research.

Signed:

Date:

Please tick here if you wish to receive a copy of a short summary of the study, and give below an address to which this summary can be sent:

Address to which report can be sent: 


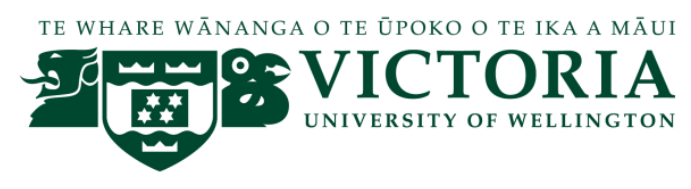

\section{TEACHER TRAINERS' INTERVIEW GUIDELINES}

\section{Introduction}

Thank you for agreeing to participate in my study. The purpose of the interview is to get some information about the current status of language testing and assessment courses at your university.

\section{Interview questions}

\section{$\checkmark$ Background and position}

1. Is there a course at your university covering language testing and assessment?

2. If yes, what is the title of the course? If no, is language testing and assessment covered in other courses?

3. How long has the language testing and assessment course (or the course with a module focusing on testing and assessment) been offered at your university?

4. What is your involvement in course development? (Designing materials, tests, etc.)

5. Have lecturers of these courses had any official training in language testing and assessment before teaching the courses? If Yes, what are they? If No, what difficulties do you think lecturers meet when preparing for teaching language testing and assessment due to the lack of training in language testing and assessment?

\section{$\checkmark$ Current status of the language testing and assessment course}

6. How important is language testing and assessment in the curriculum of your university?

7. What is the main teaching content in the language testing and assessment course (or the course with a module focusing on testing and assessment)?

8. Who is in charge of designing the content of language testing and assessment course at your university?

9. Why do you think such content is chosen to be taught in the course? If you could change the content, what would you change and why? 
10. What is the main teaching method of the language testing and assessment course (or the course with a module focusing on testing and assessment)?

11. Why do you think this teaching method is chosen? If you could change the method of teaching, what would you change and why?

12. Do you think the time frame and facilities allocated for language testing and assessment in your university are appropriate or not?

\section{Students' attitudes and perceptions of the language testing and assessment} course

13. How do your students perceive the importance of the course?

14. Are the students interested in language testing and assessment? What are their main difficulties when taking this course?

15. Do you think the course is necessary and useful for their future teaching? If Yes, in what ways? If No, why do you think so?

\section{Wrap up}

16. Is there anything else you would like to share with me so that I can fully understand the issues related to the language testing and assessment course at your university?

\section{Thank you very much!}


Appendix C: Phase 2 - Pre-service EFL teachers' assessment literacy confidence levels

- Information sheet.

- Consent form.

- Questionnaire. 


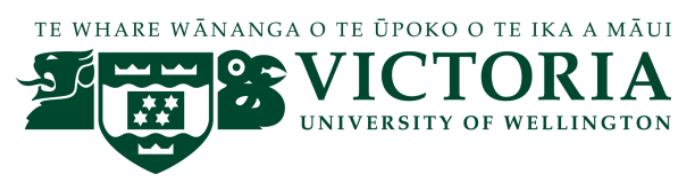

\section{INFORMATION SHEET}

Student's version

INFORMATION SHEET

This project is being conducted by Thi Huynh Loc Nguyen, PhD candidate, School of Linguistics and Applied Language Studies, Victoria University of Wellington. It has been given ethical approval by the University's Human Ethics Committee.

The aim of the project is to investigate assessment literacy of pre-service EFL language teachers at teachers training universities in Vietnam and how they develop their assessment knowledge and practice in the testing and assessment courses, and the practicum. This project is beneficial for not only Vietnamese pre-service EFL teachers but also language teacher educators, government policy makers and curriculum designers to understand the professional needs of pre-service EFL teachers and better prepare them for their future teaching.

I would like to invite you to participate in this study. If you agree, you will be asked to fill in Assessment Literacy Questionnaire. The questionnaire will take you about 35 minutes. The Assessment Literacy Questionnaire will ask you about your confidence levels of testing and assessment knowledge and skills.

The data from the questionnaire will be kept confidential. No participant will be identified personally. Data can be accessed by the researcher and her supervisors only. These data will be destroyed within two years after the completion of the project.

The thesis will be submitted to the School of Linguistics and Applied Language Studies, and deposited at the Library of Victoria University of Wellington. The results of the research may be presented at academic conferences or published in academic journals. 
Your participation in this study is voluntary and you are free to decline without giving any reason. You may also withdraw from the research at any time during data collection without explanation. The collected data will be destroyed after your withdrawal.

Should you require any further information or clarification, please do not hesitate to contact me at ThiHuynhLoc.Nguyen@vuw.ac.nz or my supervisors Dr. Peter Gu at peter.gu@ vuw.ac.nz and Dr. Jean Parkinson at jean.parkinson@vuw.ac.nz, School of Linguistics and Applied Language Studies, Victoria University of Wellington, New Zealand. 


\title{
CONSENT FORM
}

\section{DEVELOPMENT OF ASSESSMENT LITERACY AMONG VIETNAMESE PRESERVICE EFL TEACHERS}

\author{
CONSENT TO PARTICIPATE IN RESEARCH
}

NAME (please print clearly):

I understand the procedure of this research as set out in the INFORMATION SHEET.

I have had an opportunity to ask questions and have had them answered to my satisfaction.

I understand that the data I provide will be stored in the School of Linguistics and Applied Language Studies at Victoria University of Wellington.

I also understand that my data will remain confidential, and that no personal information that may be used to identify me uniquely will be stored with the data.

I understand that I may withdraw myself or any data or information I have provided from this project during data collection without having to give reasons.

I understand that, if I so request, details of the purpose of the research will be discussed with me once I have completed my participation, and that I may ask for a summary of results from the study to be sent to me at a later date.

I agree to take part in this research.

Signed:

Date:

Please tick here if you wish to receive a copy of a short summary of the study, and give below an address to which this summary can be sent:

Address to which report can be sent: 


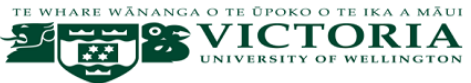

\section{ASSESSMENT LITERACY QUESTIONAIRE}

Instructions: This questionnaire is a part of a $\mathrm{PhD}$ research project on developing preservice EFL teachers' assessment literacy in Vietnam. It aims at investigating the confidence levels of the Vietnamese preservice EFL teachers' knowledge and skills of testing and assessment. As there is no right or wrong answer, please answer ALL the questions as honestly as you can. The data you provide in this questionnaire will be analyzed on an anonymous basis and will not affect any result of your study. Please follow the instructions of each question carefully before answering.

\section{SECTION I - Personal information}

Please tick $\checkmark$ the appropriate box $\square$.

1. Sex Male $\square \quad$ Female $\square$

2. Do you want to become a teacher after graduation?

3. Do you have any previous experience of teaching before the practicum?

Yes $\square \quad$ No $\square$

4. Does your university have a separate course of language testing and assessment?

\section{$\underline{\text { SECTION II -Assessment literacy }}$}

A. Pedagogical content knowledge: Think about your level of confidence in your ability to perform each task listed. Indicate the degree of your confidence in your ability to successfully perform the task by circling the number in the following scale:

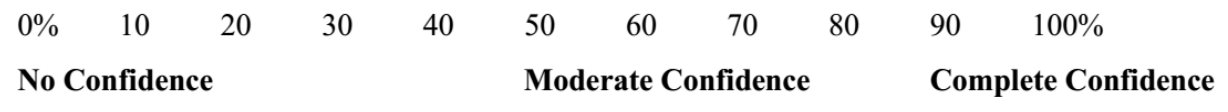

\section{Knowledge of teaching objectives and curriculum}

1. I know what $\mathrm{I}$ am required to teach according to the curriculum.
No Confidence
$0 \% \quad 10 \quad 20 \quad 30$
$40 \quad 50$
$\begin{array}{llll}70 & 80 & 90 & 100 \%\end{array}$
Complete Confidence

2. I can help my students understand what they are required to learn according to the curriculum.

$\begin{array}{lllllllllllll}\text { No Confidence } & 0 \% & 10 & 20 & 30 & 40 & 50 & 60 & 70 & 80 & 90 & 100 \% & \text { Complete Confidence }\end{array}$

3. I can plan my teaching to meet curriculum requirements.

$\begin{array}{lllllllllllll}\text { No Confidence } & 0 \% & 10 & 20 & 30 & 40 & 50 & 60 & 70 & 80 & 90 & 100 \% & \text { Complete Confidence }\end{array}$

4. I can evaluate if my teaching has achieved what the curriculum requires.

$\begin{array}{lllllllllllll}\text { No Confidence } & 0 \% & 10 & 20 & 30 & 40 & 50 & 60 & 70 & 80 & 90 & 100 \% & \text { Complete Confidence }\end{array}$

\section{Knowledge of contextual issues}

5. When planning my lessons, I consider the availability of various facilities for teaching English (for example, computers, and cassette players).
No Confidence
$0 \% \quad 10 \quad 20 \quad 30 \quad 40$
$40 \quad 50$
$\begin{array}{lllll}60 & 70 & 80 & 90 & 100 \%\end{array}$
Complete Confidence

6. During an English lesson, I can adapt my teaching to the availability of facilities.
No Confidence
$\begin{array}{lllll}0 \% & 10 & 20 & 30 & 40\end{array}$
$40 \quad 50$ 
7. I can make use of the available facilities for teaching English to achieve the targets of my teaching.

$\begin{array}{lllllllllllll}\text { No Confidence } & 0 \% & 10 & 20 & 30 & 40 & 50 & 60 & 70 & 80 & 90 & 100 \% & \text { Complete Confidence }\end{array}$

8. I know how high school teachers teach English at the school where I teach.

$\begin{array}{lllllllllllll}\text { No Confidence } & 0 \% & 10 & 20 & 30 & 40 & 50 & 60 & 70 & 80 & 90 & 100 \% & \text { Complete Confidence }\end{array}$

9. I know if my teaching will be supported by my school.

$\begin{array}{lllllllllllll}\text { No Confidence } & 0 \% & 10 & 20 & 30 & 40 & 50 & 60 & 70 & 80 & 90 & 100 \% & \text { Complete Confidence }\end{array}$ 10. When I plan my teaching, I consider the support I can get from the school where I teach.

$\begin{array}{lllllllllllll}\text { No Confidence } & 0 \% & 10 & 20 & 30 & 40 & 50 & 60 & 70 & 80 & 90 & 100 \% & \text { Complete Confidence }\end{array}$

\section{Knowledge of instructional strategies}

11. I am familiar with communicative language teaching.

$\begin{array}{lllllllllllll}\text { No Confidence } & 0 \% & 10 & 20 & 30 & 40 & 50 & 60 & 70 & 80 & 90 & 100 \% & \text { Complete Confidence }\end{array}$

12. I focus my teaching on helping my students to communicate in English.

$\begin{array}{lllllllllllll}\text { No Confidence } & 0 \% & 10 & 20 & 30 & 40 & 50 & 60 & 70 & 80 & 90 & 100 \% & \text { Complete Confidence }\end{array}$

13. I can create language use opportunities for my students in addition to what's in the textbooks.

$\begin{array}{lllllllllllll}\text { No Confidence } & 0 \% & 10 & 20 & 30 & 40 & 50 & 60 & 70 & 80 & 90 & 100 \% & \text { Complete Confidence }\end{array}$

14. I have good lesson presentation skills.

$\begin{array}{lllllllllllll}\text { No Confidence } & 0 \% & 10 & 20 & 30 & 40 & 50 & 60 & 70 & 80 & 90 & 100 \% & \text { Complete Confidence }\end{array}$

15. I can help my students practice English.

$\begin{array}{lllllllllllll}\text { No Confidence } & 0 \% & 10 & 20 & 30 & 40 & 50 & 60 & 70 & 80 & 90 & 100 \% & \text { Complete Confidence }\end{array}$

\section{$\underline{\text { Knowledge of students' learning }}$}

16. I consider my students' learning when planning my instruction.

$\begin{array}{lllllllllllll}\text { No Confidence } & 0 \% & 10 & 20 & 30 & 40 & 50 & 60 & 70 & 80 & 90 & 100 \% & \text { Complete Confidence }\end{array}$

17. I know whether my students have learnt what I taught them.

$\begin{array}{lllllllllllll}\text { No Confidence } & 0 \% & 10 & 20 & 30 & 40 & 50 & 60 & 70 & 80 & 90 & 100 \% & \text { Complete Confidence }\end{array}$

18. I know my students' strengths in learning English.

$\begin{array}{lllllllllllll}\text { No Confidence } & 0 \% & 10 & 20 & 30 & 40 & 50 & 60 & 70 & 80 & 90 & 100 \% & \text { Complete Confidence }\end{array}$

19. I know my students' weaknesses in learning English.

$\begin{array}{lllllllllllll}\text { No Confidence } & 0 \% & 10 & 20 & 30 & 40 & 50 & 60 & 70 & 80 & 90 & 100 \% & \text { Complete Confidence }\end{array}$

20. I know the activities that my students are interested in.

$\begin{array}{lllllllllllll}\text { No Confidence } & 0 \% & 10 & 20 & 30 & 40 & 50 & 60 & 70 & 80 & 90 & 100 \% & \text { Complete Confidence }\end{array}$

21. I can tell whether my students feel bored with the lessons.

$\begin{array}{lllllllllllll}\text { No Confidence } & 0 \% & 10 & 20 & 30 & 40 & 50 & 60 & 70 & 80 & 90 & 100 \% & \text { Complete Confidence }\end{array}$

22. I can avoid embarrassing my students when they cannot give the correct answers.

$\begin{array}{lllllllllllll}\text { No Confidence } & 0 \% & 10 & 20 & 30 & 40 & 50 & 60 & 70 & 80 & 90 & 100 \% & \text { Complete Confidence }\end{array}$ 


\section{Knowledge of subject matter}

23. I understand what communicative competence means in language teaching.

$\begin{array}{lllllllllllll}\text { No Confidence } & 0 \% & 10 & 20 & 30 & 40 & 50 & 60 & 70 & 80 & 90 & 100 \% & \text { Complete Confidence }\end{array}$ 24. When planning my lessons, I consider how to help my students improve their communication skills.

No Confidence $\quad \begin{array}{lllllllllllll} & \% & 10 & 20 & 30 & 40 & 50 & 60 & 70 & 80 & 90 & 100 \% & \text { Complete Confidence }\end{array}$

25. I focus my teaching on helping my students improve their communication in English.

$\begin{array}{lllllllllllll}\text { No Confidence } & 0 \% & 10 & 20 & 30 & 40 & 50 & 60 & 70 & 80 & 90 & 100 \% & \text { Complete Confidence }\end{array}$

26. I know how to teach grammar to high school students.

$\begin{array}{lllllllllllll}\text { No Confidence } & 0 \% & 10 & 20 & 30 & 40 & 50 & 60 & 70 & 80 & 90 & 100 \% & \text { Complete Confidence }\end{array}$

27. I know how to teach English skills to high school students.

No Confidence $\quad \begin{array}{lllllllllllll} & 0 & 10 & 20 & 30 & 40 & 50 & 60 & 70 & 80 & 90 & 100 \% & \text { Complete Confidence }\end{array}$

28. I can use grammatical and appropriate English when I teach.

$\begin{array}{lllllllllllll}\text { No Confidence } & 0 \% & 10 & 20 & 30 & 40 & 50 & 60 & 70 & 80 & 90 & 100 \% & \text { Complete Confidence }\end{array}$

29. I can easily catch my students' grammatical mistakes.

$\begin{array}{lllllllllllll}\text { No Confidence } & 0 \% & 10 & 20 & 30 & 40 & 50 & 60 & 70 & 80 & 90 & 100 \% & \text { Complete Confidence }\end{array}$

30. I know what English ability means.

No Confidence $\quad 0 \% \begin{array}{llllllllllll} & 10 & 20 & 30 & 40 & 50 & 60 & 70 & 80 & 90 & 100 \% & \text { Complete Confidence }\end{array}$

31. I know how to help my students reach their target English ability.

$\begin{array}{lllllllllllll}\text { No Confidence } & 0 \% & 10 & 20 & 30 & 40 & 50 & 60 & 70 & 80 & 90 & 100 \% & \text { Complete Confidence }\end{array}$

B. Beliefs of language testing and assessment: Think about your agreement with the following statements. Indicate the degree of agreement you have with the statements by circling the number in the following scale:

$\begin{array}{lllllllllll}0 \% & 10 & 20 & 30 & 40 & 50 & 60 & 70 & 80 & 90 & 100 \%\end{array}$

Completely disagree Completely agree

\section{Assessment for learning}

32. Assessment should be used for the improvement of student learning.

$\begin{array}{lllllllllllll}\text { Completely disagree } & 0 \% & 10 & 20 & 30 & 40 & 50 & 60 & 70 & 80 & 90 & 100 \% & \text { Completely agree }\end{array}$

33. Assessment should be used for the improvement of teaching.

$\begin{array}{lllllllllllll}\text { Completely disagree } & 0 \% & 10 & 20 & 30 & 40 & 50 & 60 & 70 & 80 & 90 & 100 \% & \text { Completely agree }\end{array}$

34. Assessment results should produce concrete information to give students feedback.

$\begin{array}{lllllllllllll}\text { Completely disagree } & 0 \% & 10 & 20 & 30 & 40 & 50 & 60 & 70 & 80 & 90 & 100 \% & \text { Completely agree }\end{array}$

35. Assessment should help diagnose students' learning problems.

$\begin{array}{lllllllllllll}\text { Completely disagree } & 0 \% & 10 & 20 & 30 & 40 & 50 & 60 & 70 & 80 & 90 & 100 \% & \text { Completely agree }\end{array}$

36. Assessment should be designed by the teachers who teach that group of students.

$\begin{array}{lllllllllllll}\text { Completely disagree } & 0 \% & 10 & 20 & 30 & 40 & 50 & 60 & 70 & 80 & 90 & 100 \% & \text { Completely agree }\end{array}$ 
37. Students should be assessed by different methods of assessment.

$\begin{array}{lllllllllllll}\text { Completely disagree } & 0 \% & 10 & 20 & 30 & 40 & 50 & 60 & 70 & 80 & 90 & 100 \% & \text { Completely agree }\end{array}$

38. There should be on-going assessments during the students' study.

$\begin{array}{lllllllllllll}\text { Completely disagree } & 0 \% & 10 & 20 & 30 & 40 & 50 & 60 & 70 & 80 & 90 & 100 \% & \text { Completely agree }\end{array}$

\section{Assessment of learning}

39. Assessment should be used for school evaluation and administration.

$\begin{array}{lllllllllllll}\text { Completely disagree } & 0 \% & 10 & 20 & 30 & 40 & 50 & 60 & 70 & 80 & 90 & 100 \% & \text { Completely agree }\end{array}$

40. Assessment should help people rank the students.

$\begin{array}{lllllllllllll}\text { Completely disagree } & 0 \% & 10 & 20 & 30 & 40 & 50 & 60 & 70 & 80 & 90 & 100 \% & \text { Completely agree }\end{array}$

41. Assessment results should assure parents and all interested people that students are making progress in school.

$\begin{array}{llllllllllll}\text { Completely disagree } & 0 \% & 10 & 20 & 30 & 40 & 50 & 60 & 70 & 80 & 90 & 100 \%\end{array} \quad$ Completely agree

42. Assessment should be designed by the local education department or school authorities.

$\begin{array}{lllllllllllll}\text { Completely disagree } & 0 \% & 10 & 20 & 30 & 40 & 50 & 60 & 70 & 80 & 90 & 100 \% & \text { Completely agree }\end{array}$

43. Students should be assessed only at the end of their study.

$\begin{array}{lllllllllllll}\text { Completely disagree } & 0 \% & 10 & 20 & 30 & 40 & 50 & 60 & 70 & 80 & 90 & 100 \% & \text { Completely agree }\end{array}$

C. Understanding of assessment qualities: Think about your level of confidence in your ability to perform each task listed. Indicate the degree of your confidence in your ability to successfully perform the task by circling the number in the following scale:

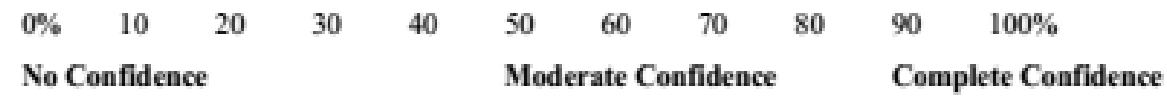

44. I know if an assessment can produce the same information of my students' level of knowledge under the same conditions on all oceasions.

$\begin{array}{llllllllllll}\text { No Confidence } & 0 \% & 10 & 20 & 30 & 40 & 50 & 60 & 70 & 80 & 90 & 100 \%\end{array} \quad$ Complete Confidence

45. I consider how an assessment can affect my students' leaming.

$\begin{array}{lllllllllllll}\text { No Confidence } & 0 \% & 10 & 20 & 30 & 40 & 50 & 60 & 70 & 80 & 90 & 100 \% & \text { Complete Confidence }\end{array}$

46. I consider whether I have appropriate support (for example, enough time, and facilities) for doing an assessment.

$\begin{array}{lllllllllllll}\text { No Confidence } & 0 \% & 10 & 20 & 30 & 40 & 50 & 60 & 70 & 80 & 90 & 100 \% & \text { Complete Confidence }\end{array}$

47. I consider what skills my students need to complete my assessment tasks suecessfully.

$\begin{array}{lllllllllllll}\text { No Confidence } & 0 \% & 10 & 20 & 30 & 40 & 50 & 60 & 70 & 80 & 90 & 100 \% & \text { Complete Confidence }\end{array}$

48. I consider what knowledge my students need to complete my assessment tasks successfully.

$\begin{array}{lllllllllllll}\text { No Confidence } & 0 \% & 10 & 20 & 30 & 40 & 50 & 60 & 70 & 80 & 90 & 100 \% & \text { Complete Confidence }\end{array}$ 
49. I know if an assessment can reflect my students' real abilities in using English.

$\begin{array}{lllllllllllll}\text { No Confidence } & 0 \% & 10 & 20 & 30 & 40 & 50 & 60 & 70 & 80 & 90 & 100 \% & \text { Complete Confidence }\end{array}$

D. Assessment for learning: Think about your level of confidence in your ability to perform each task listed. Indicate the degree of your confidence in your ability to successfully perform the task by circling the number in the following scale:

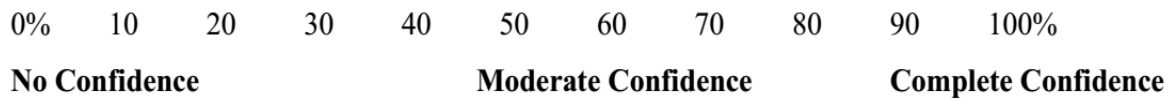

\section{Planning assessment}

50. I know clearly what I want my students to learn.

$\begin{array}{lllllllllllll}\text { No Confidence } & 0 \% & 10 & 20 & 30 & 40 & 50 & 60 & 70 & 80 & 90 & 100 \% & \text { Complete Confidence }\end{array}$

51. I can make flexible judgments of student learning based on what's happening inside the classroom.

$\begin{array}{lllllllllllll}\text { No Confidence } & 0 \% & 10 & 20 & 30 & 40 & 50 & 60 & 70 & 80 & 90 & 100 \% & \text { Complete Confidence }\end{array}$

52. I can give clear criteria for what my students need to do to successfully achieve what they are required to learn.

$\begin{array}{lllllllllllll}\text { No Confidence } & 0 \% & 10 & 20 & 30 & 40 & 50 & 60 & 70 & 80 & 90 & 100 \% & \text { Complete Confidence }\end{array}$

53. I know the purposes of the available assessment methods.

$\begin{array}{lllllllllllll}\text { No Confidence } & 0 \% & 10 & 20 & 30 & 40 & 50 & 60 & 70 & 80 & 90 & 100 \% & \text { Complete Confidence }\end{array}$

54. I can choose the assessment methods that are appropriate for what I want to assess.

$\begin{array}{lllllllllllll}\text { No Confidence } & 0 \% & 10 & 20 & 30 & 40 & 50 & 60 & 70 & 80 & 90 & 100 \% & \text { Complete Confidence }\end{array}$

55. I can evaluate if an assessment has helped me achieve a particular curriculum target.

$\begin{array}{lllllllllllll}\text { No Confidence } & 0 \% & 10 & 20 & 30 & 40 & 50 & 60 & 70 & 80 & 90 & 100 \% & \text { Complete Confidence }\end{array}$

\section{Conducting assessment}

56. I know if a classroom question I ask will be able to elicit different levels of student ability.

$\begin{array}{lllllllllllll}\text { No Confidence } & 0 \% & 10 & 20 & 30 & 40 & 50 & 60 & 70 & 80 & 90 & 100 \% & \text { Complete Confidence }\end{array}$

57. I know which classroom questions I should ask to check my students' different levels of learning.

$\begin{array}{lllllllllllll}\text { No Confidence } & 0 \% & 10 & 20 & 30 & 40 & 50 & 60 & 70 & 80 & 90 & 100 \% & \text { Complete Confidence }\end{array}$

58. I know what tasks to use in a test to check my students' levels of learning.

$\begin{array}{lllllllllllll}\text { No Confidence } & 0 \% & 10 & 20 & 30 & 40 & 50 & 60 & 70 & 80 & 90 & 100 \% & \text { Complete Confidence }\end{array}$

59. I know which assessment methods I should use to check my students' levels of learning.

$\begin{array}{lllllllllllll}\text { No Confidence } & 0 \% & 10 & 20 & 30 & 40 & 50 & 60 & 70 & 80 & 90 & 100 \% & \text { Complete Confidence }\end{array}$

60. I can help my students know how to self-assess their learning.

$\begin{array}{lllllllllllll}\text { No Confidence } & 0 \% & 10 & 20 & 30 & 40 & 50 & 60 & 70 & 80 & 90 & 100 \% & \text { Complete Confidence }\end{array}$

61. I can help my students know how to carry out peer assessment.

$\begin{array}{lllllllllllll}\text { No Confidence } & 0 \% & 10 & 20 & 30 & 40 & 50 & 60 & 70 & 80 & 90 & 100 \% & \text { Complete Confidence }\end{array}$ 
62. I can adapt my assessment methods flexibly according to classroom situations that arise.

$\begin{array}{lllllllllllll}\text { No Confidence } & 0 \% & 10 & 20 & 30 & 40 & 50 & 60 & 70 & 80 & 90 & 100 \% & \text { Complete Confidence }\end{array}$

\section{Using assessment data}

63. I can use assessment results to judge my student's performance level.

$\begin{array}{lllllllllllll}\text { No Confidence } & 0 \% & 10 & 20 & 30 & 40 & 50 & 60 & 70 & 80 & 90 & 100 \% & \text { Complete Confidence }\end{array}$

64. I can use assessment results to provide feedback that helps my students improve their work.

$\begin{array}{lllllllllllll}\text { No Confidence } & 0 \% & 10 & 20 & 30 & 40 & 50 & 60 & 70 & 80 & 90 & 100 \% & \text { Complete Confidence }\end{array}$

65. I can help my students to use assessment results to meaningfully track their own learning.

$\begin{array}{lllllllllllll}\text { No Confidence } & 0 \% & 10 & 20 & 30 & 40 & 50 & 60 & 70 & 80 & 90 & 100 \% & \text { Complete Confidence }\end{array}$

66. I can help my students use assessment results to plan next steps in their own learning (what/how to study/practice, etc.).

$\begin{array}{lllllllllllll}\text { No Confidence } & 0 \% & 10 & 20 & 30 & 40 & 50 & 60 & 70 & 80 & 90 & 100 \% & \text { Complete Confidence }\end{array}$

67. I can use assessment results to diagnose problems with my students' learning.

$\begin{array}{lllllllllllll}\text { No Confidence } & 0 \% & 10 & 20 & 30 & 40 & 50 & 60 & 70 & 80 & 90 & 100 \% & \text { Complete Confidence }\end{array}$

68. I use assessment results to plan my instruction.

$\begin{array}{lllllllllllll}\text { No Confidence } & 0 \% & 10 & 20 & 30 & 40 & 50 & 60 & 70 & 80 & 90 & 100 \% & \text { Complete Confidence }\end{array}$

69. I can use assessment results to adjust my teaching.

$\begin{array}{lllllllllllll}\text { No Confidence } & 0 \% & 10 & 20 & 30 & 40 & 50 & 60 & 70 & 80 & 90 & 100 \% & \text { Complete Confidence }\end{array}$

E. Assessment of learning: Think about your level of confidence in your ability to perform each task listed. Indicate the degree of your confidence in your ability to successfully perform the task by circling the number in the following scale:

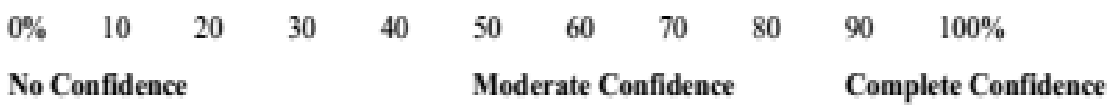

\section{Prenare for tests}

70. I know how to prepare my students for large-scale tests such as end-of-term tests, and university entrance exam.

$\begin{array}{llllllllllll}\text { No Confidence } & 0 \% & 10 & 20 & 30 & 40 & 50 & 60 & 70 & 80 & 90 & 100 \%\end{array} \quad$ Complete Confidence

71. I avoid teaching to the tests.

$\begin{array}{lllllllllllll}\text { No Confidence } & 0 \% & 10 & 20 & 30 & 40 & 50 & 60 & 70 & 80 & 90 & 100 \% & \text { Complete Confidence }\end{array}$

\section{Internret test results}

72. I can explain test results to interested people such as parents, principals, schools and districts.

$\begin{array}{lllllllllllll}\text { No Confidence } & 0 \% & 10 & 20 & 30 & 40 & 50 & 60 & 70 & 80 & 90 & 100 \% & \text { Complete Confidence }\end{array}$ 
73. I can help my students interpret their test results.

$\begin{array}{lllllllllllll}\text { No Confidence } & 0 \% & 10 & 20 & 30 & 40 & 50 & 60 & 70 & 80 & 90 & 100 \% & \text { Complete Confidence }\end{array}$ 74. I can help students understand what they need to do to improve their test results.

$\begin{array}{lllllllllllll}\text { No Confidence } & 0 \% & 10 & 20 & 30 & 40 & 50 & 60 & 70 & 80 & 90 & 100 \% & \text { Complete Confidence }\end{array}$

75. I can explain how student learning can be improved based on the test results.

$\begin{array}{lllllllllllll}\text { No Confidence } & 0 \% & 10 & 20 & 30 & 40 & 50 & 60 & 70 & 80 & 90 & 100 \% & \text { Complete Confidence }\end{array}$

76. I can tell how the school can improve their teaching based on the test results.

$\begin{array}{lllllllllllll}\text { No Confidence } & 0 \% & 10 & 20 & 30 & 40 & 50 & 60 & 70 & 80 & 90 & 100 \% & \text { Complete Confidence }\end{array}$

F. Ethical issues in language testing and assessment practices: Think about your level of confidence in your ability to perform each task listed. Indicate the degree of your confidence in your ability to successfully perform the task by circling the number in the following scale:

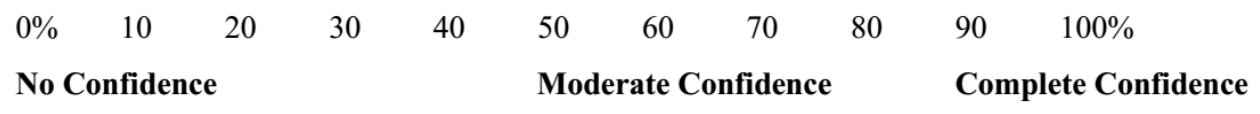

77. I know what should not be done in testing and assessment.

$\begin{array}{lllllllllllll}\text { No Confidence } & 0 \% & 10 & 20 & 30 & 40 & 50 & 60 & 70 & 80 & 90 & 100 \% & \text { Complete Confidence }\end{array}$

78. I can avoid what should not be done in testing and assessment.

$\begin{array}{lllllllllllll}\text { No Confidence } & 0 \% & 10 & 20 & 30 & 40 & 50 & 60 & 70 & 80 & 90 & 100 \% & \text { Complete Confidence }\end{array}$

79. I can recognize if the assessment information is used in a harmful way for my students.

$\begin{array}{lllllllllllll}\text { No Confidence } & 0 \% & 10 & 20 & 30 & 40 & 50 & 60 & 70 & 80 & 90 & 100 \% & \text { Complete Confidence }\end{array}$

80. I can report to the interested people such as principals, colleagues, and parents the inappropriate use of assessment results.

$\begin{array}{lllllllllllll}\text { No Confidence } & 0 \% & 10 & 20 & 30 & 40 & 50 & 60 & 70 & 80 & 90 & 100 \% & \text { Complete Confidence }\end{array}$

81. I can recognize if the chosen assessment methods are not fair to all the students.

$\begin{array}{lllllllllllll}\text { No Confidence } & 0 \% & 10 & 20 & 30 & 40 & 50 & 60 & 70 & 80 & 90 & 100 \% & \text { Complete Confidence }\end{array}$

82. I can catch the inappropriate use of assessment methods.

$\begin{array}{lllllllllllll}\text { No Confidence } & 0 \% & 10 & 20 & 30 & 40 & 50 & 60 & 70 & 80 & 90 & 100 \% & \text { Complete Confidence }\end{array}$

\section{THE END}

Thank you very much! 
Appendix D: Phase 3 - Development of pre-service EFL teachers' assessment literacy during practicum

- Information sheet.

- Consent form.

- Interview guidelines 


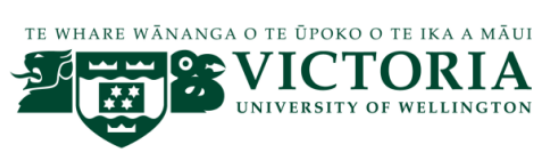

\section{INFORMATION SHEET}

\section{DEVELOPMENT OF VIETNAMESE PRE-SERVICE EFL TEACHERS' ASSESSMENT LITERACY}

\section{Student teacher's version}

This project is being conducted by Thi Huynh Loc Nguyen, PhD candidate, School of Linguistics and Applied Language Studies, Victoria University of Wellington. It has been given ethical approval by the University's Human Ethics Committee.

The aim of the project is to investigate assessment literacy of pre-service EFL language teachers in Vietnam and how they develop their assessment knowledge and practice in the testing and assessment courses, and the practicum. This project is beneficial for not only Vietnamese pre-service EFL teachers but also language teacher educators, government policy-makers and curriculum designers to understand the professional needs of pre-service EFL teachers and better prepare them for their future teaching.

I would like to invite you to participate in this study. If you agree, you will be involved in the following steps. Firstly, you will be asked to complete a questionnaire: once before and once after the language testing and assessment course, once before and once after the practicum. Secondly, you will be interviewed in Vietnamese twice: one individual 45-minute-semi-structured interview before the practicum about your background, your learning/ teaching history, your experience with language testing and assessment, your feelings about the practicum, and a 45-minute-semi-structured group interview after the practicum about your evaluation of your development and the practicum. The interview will be conducted at your convenient time and venue. Thirdly, you will be observed during your class teaching during the practicum. After some classes, you will participate in stimulated recalls. Lastly, your lesson plans and teaching journals will be collected. 
Your participation in this study is voluntary and you are free to decline without giving any reasons. You may also withdraw from the research at any time during data collection without explanation. The collected data will be destroyed after your withdrawal. Within one month after the interview, you will be contacted to review the transcripts of the interview and correct errors of transcription. The data from the interview will be kept confidential. No participant will be identified personally. Data can be accessed by the researcher and her research supervisors only. These data will be destroyed within two years after the completion of the project.

The thesis will be submitted to the School of Linguistics and Applied Language Studies, and deposited at the Library of Victoria University of Wellington. The results of the research may be presented at academic conferences or published in academic journals.

Should you require any further information or clarification, please do not hesitate to contact me at ThiHuynhLoc.Nguyen@vuw.ac.nz or my supervisors Dr. Peter Gu at peter.gu@ vuw.ac.nz and Dr. Jean Parkinson at jean.parkinson@ vuw.ac.nz, School of Linguistics and Applied Language Studies, Victoria University of Wellington, New Zealand. 


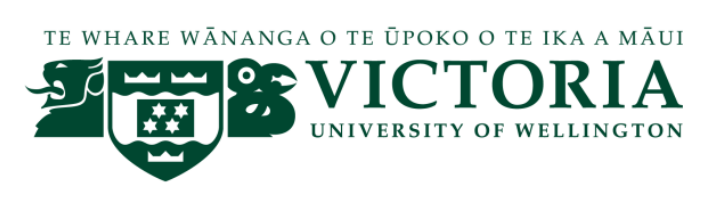

\section{INFORMATION SHEET \\ DEVELOPMENT OF VIETNAMESE PRE-SERVICE EFL TEACHERS' ASSESSMENT LITERACY}

\section{School mentor's version}

This project is being conducted by Thi Huynh Loc Nguyen, PhD candidate, School of Linguistics and Applied Language Studies, Victoria University of Wellington. It has been given ethical approval by the University's Human Ethics Committee.

The aim of the project is to investigate assessment literacy of pre-service EFL language teachers at five representative teachers training colleges in Vietnam and how they develop their assessment knowledge and practice in the testing and assessment courses, and the practicum. This project is beneficial for not only Vietnamese pre-service EFL teachers but also language teacher educators, government policy makers and curriculum designers to understand the professional needs of pre-service EFL teachers and better prepare them for their future teaching.

I would like to invite you to participate in this study. If you agree, you will be involved in interviews and observations. You will be interviewed in Vietnamese twice: one 45-minute-semi-structured interview before the practicum about your background, your learning/ teaching history, your experience with language testing and assessment, your job as an English teacher and as a mentor, and the current status of language testing and assessment at your school, and another 45-minutesemistructured-interview after the practicum about your evaluation of your student teachers' development and the practicum. The interview will be conducted at your convenient time and venue. Moreover, you will be observed during your model class teaching and discussions with your student teachers. 
Your participation in this study is voluntary and you are free to decline without giving any reasons. You may also withdraw from the research at any time during data collection without explanation. The collected data will be destroyed after your withdrawal. Within one month after the interview, you will be contacted to review the transcripts of the interview and correct errors of transcription. The data from the interview will be kept confidential. No participant will be identified personally. Data can be accessed by the researcher and her research supervisors only. These data will be destroyed within two years after the completion of the project.

The thesis will be submitted to the School of Linguistics and Applied Language Studies, and deposited at the Library of Victoria University of Wellington. The results of the research may be presented at academic conferences or published in academic journals.

Should you require any further information or clarification, please do not hesitate to contact me at ThiHuynhLoc.Nguyen@vuw.ac.nz or my supervisors Dr. Peter Gu at peter.gu@ vuw.ac.nz and Dr. Jean Parkinson at jean.parkinson@vuw.ac.nz, School of Linguistics and Applied Language Studies, Victoria University of Wellington, New Zealand. 


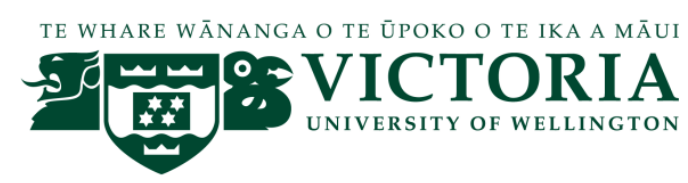

\section{CONSENT FORM}

DEVELOPMENT OF ASSESSMENT LITERACY AMONG VIETNAMESE PRESERVICE EFL TEACHERS

\author{
CONSENT TO PARTICIPATE IN RESEARCH
}

NAME (please print clearly):

I understand the procedure of this research as set out in the INFORMATION SHEET.

I have had an opportunity to ask questions and have had them answered to my satisfaction.

I understand that the data I provide will be stored in the School of Linguistics and Applied Language Studies at Victoria University of Wellington.

I also understand that my data will remain confidential, and that no personal information that may be used to identify me uniquely will be stored with the data.

I understand that I may withdraw myself or any data or information I have provided from this project during data collection without having to give reasons.

I understand that, if I so request, details of the purpose of the research will be discussed with me once I have completed my participation, and that I may ask for a summary of results from the study to be sent to me at a later date.

I agree to take part in this research.

Signed:

Date:

Please tick here if you wish to receive a copy of a short summary of the study, and give below an address to which this summary can be sent:

Address to which report can be sent: 


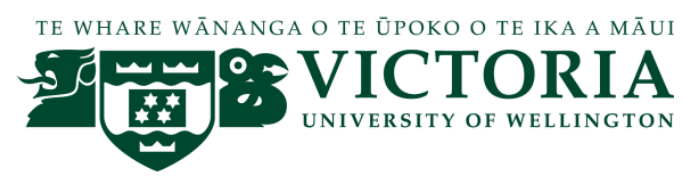

\section{INTERVIEW QUESTIONS}

\section{Student teacher's version}

\section{BEFORE THE PRACTICUM}

Thank you very much for your participation in my research. This semi-structured interview will last 45 minutes. It will be about your background, your learning/ teaching history, your experience with language testing and assessment, your feelings about the practicum.

\section{Background information}

Name:

Sex Male $\square$ Female $\square$

Age

Education:

Teaching experience:

\section{Learning/Teaching history/Self-image/Future career}

1. Describe your experiences as an English language learner.

2. Why did you choose to major in English language education? Describe your experiences as a student of English language education.

3. How would you describe yourself as a teacher?

4. Do you want to become an English teacher in the future? Why and why not?

5. How did you learn about language testing and assessment?

6. Describe how you understand and how you feel about language testing and assessment.

7. Describe your future plans after graduation.

\section{Learning/teaching English in Vietnam/classroom}

1. What do you think about the current state of language testing and assessment in Vietnam? (policy, constraints, positive points, negative points, etc.) 
2. What do you think is the purpose of language testing and assessment?

3. Describe your typical language testing and assessment in your class/ school.

4. What do you think are the positive and negative aspects of the current language testing and assessment at your school?

5. Describe an ideal language testing and assessment system.

6. What do you think an ideal language testing and assessment system?

7. What do you think about the role of language teachers in language testing and assessment renovation?

8. Do you think the training at college prepares you enough for the future job in terms of language testing and assessment?

\section{Practicum}

1. How would you describe yourself as a student teacher?

2. Describe three things that you have learned about English teaching in your coursework at the university. How do you think these have influenced your teaching?

3. Describe the classes you took at your university prior to the practicum.

4. In terms of your own professional development, what do you want to get out of the practicum?

5. What do you think your mentor teachers want you to learn from the practicum?

6. Describe an ideal practicum, an ideal mentor and an ideal student teacher.

\section{AFTER THE PRACTICUM}

Thank you very much for your participation in my research. This interview will last 45 minutes. It will be about your evaluation of your development and the practicum.

1. What have you learnt from observing your mentor teachers' classroom teaching sessions?

2. What have you learnt from a model class taught by a representative mentor teacher and then from the post-observation conference?

3. What do you think you have learnt from classroom teaching and the post-observation conferences?

4. What do you think your pupil's needs are for your English class? What do you think they have gained from you as a student teacher? What kind of classroom environment do you want to create for your pupils?

5. Describe what you think is ideal university coursework for preparing student teachers for the practicum and their future teaching experiences. 
6. What impact do you think language testing and assessment have on your student teaching?

7. What impact do you think language testing and assessment have on your pupil learning?

8. What do you consider to be the barriers to implementation of language testing and assessment in the classroom?

9. Reflect on three episodes that occurred during the practicum that you learned the most from, you struggled with or you were successful with.

10. What impact do you think your mentor teacher's mentoring has had on your teaching?

11. What aspects of the practicum do you think have been the most or the least helpful for you?

12. What did you enjoy the most or the least in your practicum?

13. What do you think about your relationship with your mentor teacher, peer student teachers and pupils? How do you think this has influenced your practicum experience?

14. Do you feel you have experienced any changes in your beliefs about teaching and/or your instructional practices as a result of the practicum?

15. Have you experienced any changes in your desire to become an English teacher as a result of the practicum?

16. What strengths and weaknesses do you think the current practicum has?

17. What suggestions do you have for pre-service teacher education programs?

18. How have you implemented what you learned about language testing and assessment in your class? 


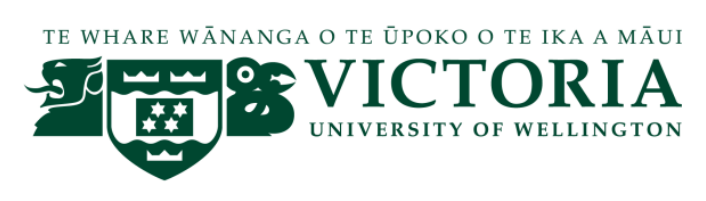

\section{INTERVIEW QUESTIONS}

\section{School mentor's version}

\section{BEFORE THE PRACTICUM}

Thank you very much for your participation in my research. This interview will last for 45 minutes. It will be about your background, your learning/ teaching history, your experience with language testing and assessment, your job as an English teacher and as a mentor, and the current status of language testing and assessment at your school.

\section{Background information}

Sex Male $\square$ Female $\square$

Age

Education:

Teaching experience:

Mentoring experience:

Training in testing and assessment: Yes $\square$ No $\square$

Learning/Teaching history/self-image/teacher learning/experience with language testing and assessment

1. Describe your experiences as an English language learner. Did you enjoy your English language learning? Why and why not?

2. Why did you choose to major in English language teaching? Describe your experiences as a student in English language teaching when you were at university. Did your education at university prepare you well for your current job? Why and why not?

3. Why did you choose to become an English teacher? Describe your experience as an English teacher.

4. How would you describe yourself as an English teacher? (What are your duties/ responsibilities?) 
5. Describe your experiences with language testing and assessment when you were still a student. Were you happy with language testing and assessment? Why and why not?

6. Have you changed the way you test and assess your students due to your previous experience with language testing and assessment?

7. Did you get any training in language testing and assessment? If yes, where? What do you think about language testing and training for pre-service teachers?

8. Do you think you are confident with the way you test and assess your students? Why and why not?

9. Describe your experiences with language testing and assessment when you become a teacher? Are you happy with language testing and assessment at your school? Why and why not?

\section{Language testing and assessment in Vietnam/ Classroom}

9. What do you think about the current state of language testing and assessment in Vietnam? (policy, constraints, positive points, negative points, etc.)

10. What do you think is the purpose of language testing and assessment?

11. Describe your typical language testing and assessment in your class/ school.

12. What do you think are the positive and negative aspects of the current language testing and assessment at your school?

13. Describe an ideal language testing and assessment system.

14. What do you think about the role of language teachers in language testing and assessment renovation?

\section{Practicum}

1. Describe your role as a mentor teacher during the practicum.

2. Describe an ideal practicum, an ideal mentor, an ideal student teacher, and an ideal environment for mentoring.

3. Describe the ways in which you have tried to meet the needs of your student teachers.

\section{AFTER THE PRACTICUM}

Thank you very much for your participation in my research. This interview will last for 45 minutes about your evaluation of your student teachers' development and the practicum. 
1. What do you think your student teachers have been learning from their classroom teaching sessions, class observations, and the post-observation conferences?

2. What do you think your student teachers learned from the model class taught by a model teacher and then the post-observation conference?

3. Describe what you have done for your student teachers to help them implement what they have learned at university into their classroom teaching.

4. What difficulties do you think your student teachers have been experiencing in implementing what they have learned?

5. Describe what you have done for your student teachers to help them implement language testing and assessment into their classroom.

6. What difficulties do you think your student teachers have been experiencing in implementing what they have learned about language testing and assessment into the classroom's reality?

7. What impact do you think the training have had on your student teachers' teaching?

8. What do you consider to be the barriers for your student teachers to implement what they have learned in classrooms?

9. What do you think your student teachers have gotten out of the practicum experience?

10. What support did you get from the university mentors and school during your duty as a school mentor?

11. Are you happy with what you have offered student teachers during the practicum? Why and why not?

12. Which aspects of the practicum do you think have been the most or the least helpful for your student teachers?

13. What strengths and weaknesses do you think the current practicum has?

14. What suggestions do you have for pre-service teacher education programs? 